AIRBORNE LASER SCANNING

FOR FORESTED LANDSLIDES INVESTIGATION

IN TEMPERATE AND TROPICAL ENVIRONMENTS

Khamarrul Azahari Razak 


\section{Leden promotiecommisie}

Prof. Dr. Jean Poesen

Prof. Dr. Thomas Glade

Prof. Dr. Norbert Pfeifer

Prof. Dr. Veldkamp

Dr. Theo van Asch

Prof. Dr. Hans Middelkoop
KU Leuven University, Belgium University of Vienna, Austria Vienna University of Technology, Austria University of Twente, The Netherlands Utrecht University, The Netherlands Utrecht University, The Netherlands

\section{$(1$ university of twente.}

D-

ITC dissertation number 244

ITC, P.O. Box 217, 7500 EA Enschede, The Netherlands

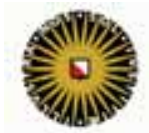

University of Utrecht

ISBN 978-90-365-3625-7

DOI $10.3990 / 1.9789036536257$

Cover designed by Rami Abuganaya's Design $®$ Singapore

Printed by ITC Printing Department

Copyright (C) 2014 by Khamarrul Azahari Razak, UTM Malaysia

All rights reserved. No part of this publication may be reproduced in any form, by print or photo print, microfilm or any other means, without written permission by the publishers. 


\title{
AIRBORNE LASER SCANNING FOR FORESTED LANDSLIDES INVESTIGATION IN TEMPERATE AND TROPICAL ENVIRONMENTS
}

\section{LASERALTIMETRIE VOOR ONDERZOEK VAN BEBOSTE AARDVERSCHUIVINGEN IN GEMATIGDE EN TROPISCHE MILIEUS}

(met een samenvatting in het Nederlands)

\begin{abstract}
Proefschrift
ter verkrijging van de graad van doctor aan de Universiteit Utrecht op gezag van de rector magnificus, prof.dr. G.J. van der Zwaan, ingevolge het besluit van het college voor promoties in het openbaar te verdedigen op maandag 3 maart 2014 des middags te 12:45 uur
\end{abstract}

Khamarrul Azahari Razak

geboren op 7 november 1980

te Terengganu, Malaysia 


$\begin{array}{ll}\text { Promotoren: } & \begin{array}{l}\text { Prof.dr. S.M. de Jong } \\ \text { Prof.dr. V. Jetten }\end{array} \\ & \\ \text { Co-promotoren: } & \begin{array}{l}\text { Dr. C.J. van Westen } \\ \text { Dr. M.W. Straatsma }\end{array}\end{array}$

This thesis was (partly) accomplished with financial support from the Ministry of Higher Education Malaysia and Universiti Teknologi Malaysia, and the Faculty of Geo-Information Science and Earth Observation of the University of Twente, The Netherlands. 


\section{Acknowledgements}

My journey comes to the end. Thanks to Allah almighty. This thesis would never been completed without the great support, encouragement, time, and cooperation of many inspired people. Their roles and contributions over the period of my $\mathrm{PhD}$ research are highly appreciated. This special column is dedicated to all of them.

First and foremost, I owe many thanks to Cees van Westen, my supervisor who created the path and provided opportunities to conduct this research under his supervision and team at ITC. Also, I would like to express my utmost gratitude to Cees van Westen and his family during my difficult time in the Netherlands.

A special mention and thanks to Menno Straatsma, my supervisor. Without his constructive criticism and technical advice this thesis would not have been possible. He directed my research in a very exciting way and I have learned a lot under his supervision. His thoughtful comments and remarks were very useful and helpful in shaping this thesis in its present form.

My very special thanks to Steven de Jong, my promoter for his contributions, amazing inputs, and his always available when needed the right solution. He always inspires my research work and views the problems from different angles. Personally, I am proud to be one of your students. Thanks also to Victor Jetten, my promotor for his support and interest in this research. Jasamu tetap ku kenang.

I am also very grateful to all the people at ITC - past and present; all the management team, especially Paul van Dijk, Loes Colenbrander, Theresa van den Boogaard, Bettine geerdink, Marie Chantal Metz, Marion Pierik, Job Duim, Benno Masselink, hotel management and also to all ESA staff for fruitful discussions and positive feedback gained especially during the $\mathrm{PhD}$ lunch. $\mathrm{A}$ big thank to Loes Colenbrander for her patience, assistance and tireless in making this thesis ready for printing and all the arrangement that were made to it. You always there at the right time with your solutions, started from my first day at ITC till the end.

My Malaysian friends in Enschede, Frederick, Fauzi, Hakim and their family wish you all the best for your PhD and thanks for making me feel at home from time to time. My colleagues in the Department of Earth System Analysis (most of them are graduated) are always become a great source of technical advice and discussions with them provided a lot of insight into my research. Some people I would like to mention in particular, Byron, Tolga, Xuanmei, 
Sekhar, Sharon, Anandita, Fekerte, Andre, Sumbal Saba, Thea, Sanaz, and Nasrullah. I wish all of you a very good luck in your research and career.

I wholeheartedly thank Jean Philippe Malet for his great support in providing accessibility to the Bois Noir area, and contacts, sharing the existing geospatial data. Also the ALS data acquisition has been provided through the funding from the French Project ANR Risk-Nat SISCA 'Systeme Integre de Surveillance de Glissements de Terrain Argileux' (2009-2021), from the Restauration des Terrains de Montagne (RTM, Division of Barcelonnette), and UNU-ITC School on Geoinformation for Disaster Risk Management. Thanks also to Michiel Damen and Robert Voskuil who conducted a special course for landslide interpretation and mapping, and subsequently contributed their expert knowledge in landslide assessment in this thesis.

To Yousif Hussin and his family, thanks for your efforts and time that you have made, reminding me the right path. Syams, Ameya, Vinod and Fatemah, I thankfully remember your support and assistance in collecting field reference data in Bois Noir catchment, France. A special mention to Alexander Bucksch for his skeletonization solution, amazing ideas and lively discussions we had. I am truly grateful to my co-authors and contributors, Michele Santangelo, Jasmi Abd Talib, Noor Bakri Endut and Hakan Nefeslioglu who have been providing data, given inspiring comments to my papers and technical chapters. I also thank to Biswajeet Pradhan for sharing the existing landslide inventory map in the Cameron Highlands, Malaysia.

My wife, Rabieahtul Abu Bakar I have no words to express my gratitude. This thesis is purely dedicated to you and our children, Ibrahim Adham, Muhammad Hud, Abu Bakar and my little princess, Fathimah Az-Zahra. Her contributions to this thesis were immense and without your support this PhD would not have come to the end. To my lovely parents, my mom (Rubiah Binti Ibrahim) and my dad (Razak Bin Mat), to my deepest heart, thanks for everything that you gave me, and nothing possible to pay back all of your sacrifice. I pray you have a long life with all the benefit, in this world and hereafter. 
Dedicated to my wife, Rabieahtul Abu Bakar my sons, Ibrahim Adham, Muhammad Hud, Abu Bakar and my daughter, Fathimah Az-Zahra 


\section{Table of Contents}

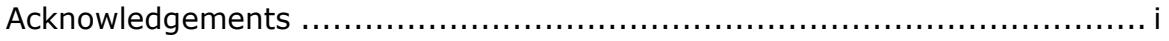

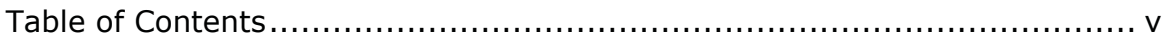

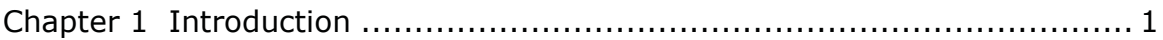

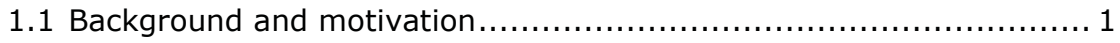

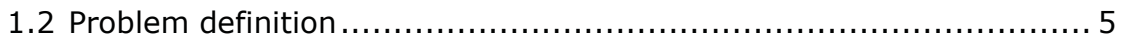

1.2.1 Landslide inventory mapping ........................................ 5

1.2.2 ALS terrain model quality associated to forested landslides...... 7

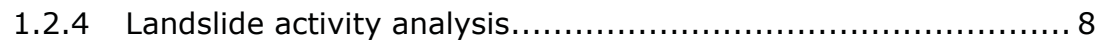

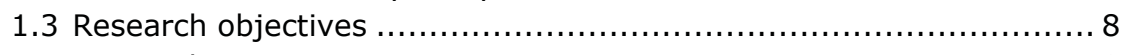

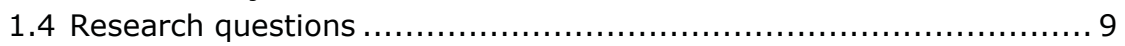

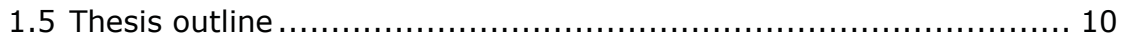

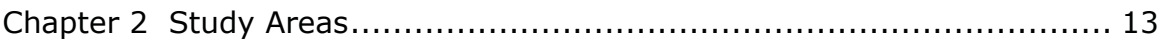

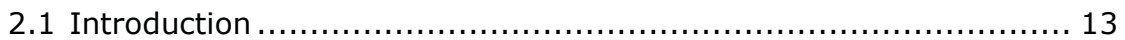

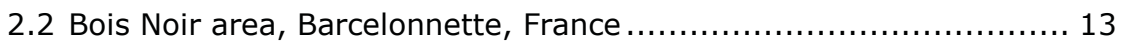

2.3 Cameron Highlands, Pahang, Malaysia................................ 17

Chapter 3 Airborne laser scanning of forested landslides characterization:

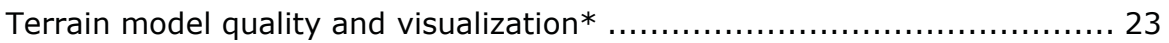

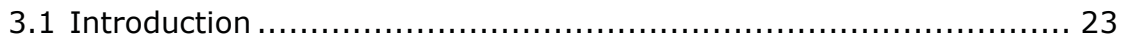

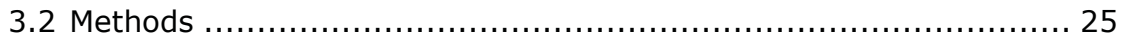

3.2.1 Data collection ................................................... 25

3.2.2 Quantitative assessment of landslide DTM accuracy ............ 26

3.2.3 Qualitative assessment of DTM interpretability ............... 30

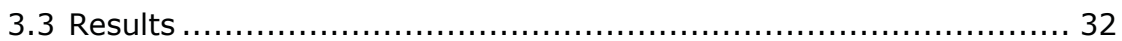

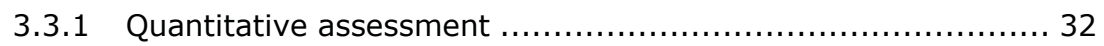

3.3.2 Qualitative assessment of ALS-derived DTMs .................... 36

3.3.3 Expert interpretations of DTMs ................................ 36

3.3.4 Visualization methods ............................................ 41

3.3.5 Effect of ALS point density on landslide recognition............ 42

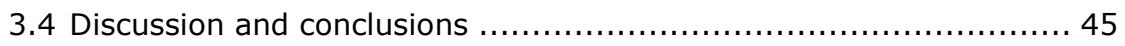

Chapter 4 Generating an optimal DTM from airborne laser scanning data for landslide mapping in a tropical forest environment ......................... 49

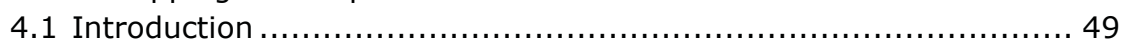

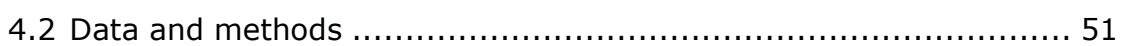

4.2.1 Airborne laser scanning measurement........................ 51

4.2.2 Field validation terrain height data......................... 51

4.2.3 ALS filtering and its parameterization.......................... 52

4.2.4 Surface interpolation methods to create gridded DTMs .......... 53

4.2.5 Quantitative assessment of ALS-derived DTMs ................ 56 
4.2.6 Landslide interpretability of ALS-derived DTMs ................ 56

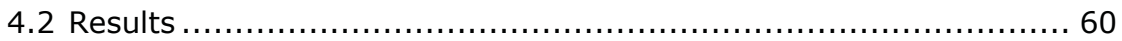

4.3.1 Quantitative assessment of the ALS-filtered data............... 60

4.3.2 Landslide interpretability of ALS-derived images................ 61

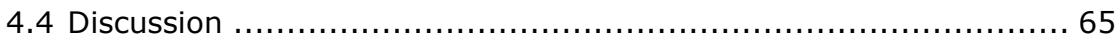

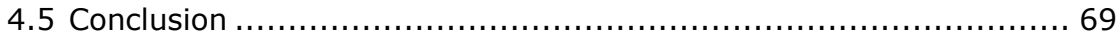

Chapter 5 Airborne laser scanning derived landslide inventory in the tropics:

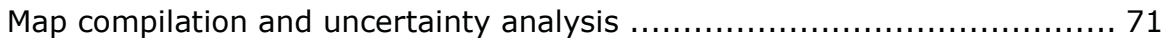

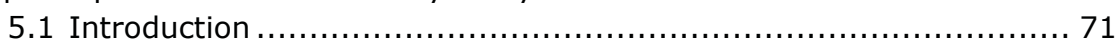

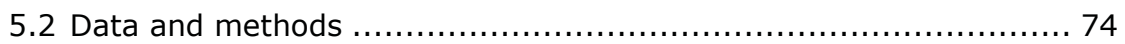

5.2.1 Airborne laser scanning data and DTM generation............... 74

5.2.2 ALS-derived landslide inventories and reference maps ........... 74

5.2 .3 Existing landslide inventory map ............................ 75

5.2.4 Quantitative assessment of tropical landslide inventories....... 76

5.2 .5 Comparison of size-frequency distributions ..................... 77

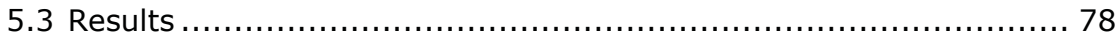

5.3.2 Error assessment of landslide inventory maps .................. 84

5.3.3 Frequency-size distributions of landslide inventories ........... 87

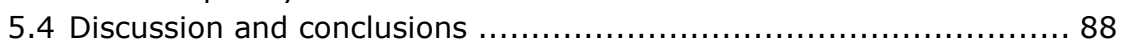

Chapter 6 Landslide susceptibility assessment using laser scanning-derived

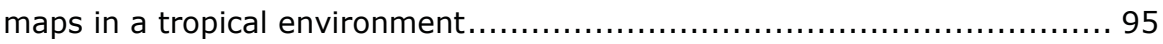

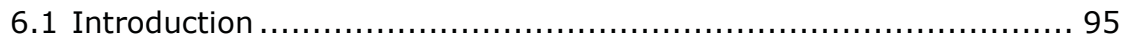

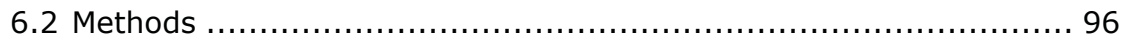

6.2.1 Airborne laser scanning campaign and data ................... 96

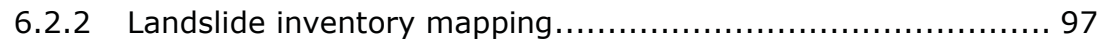

6.2.3 Landslide conditioning factors ................................ 98

6.2.4 Landslide susceptibility analysis................................. 102

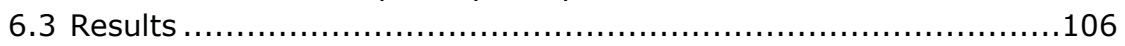

6.3.1 Landslide inventory mapping ..................................... 106

6.3.2 Generation of landslide conditioning factor maps ...............106

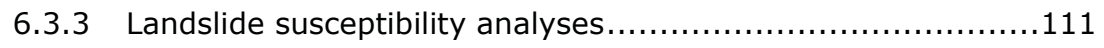

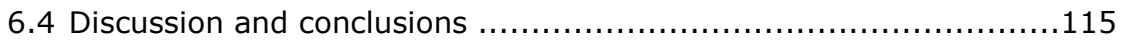

Chapter 7 Tree growth anomalies induced by landslides: Insight from high-

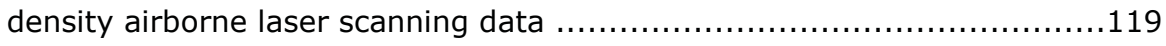

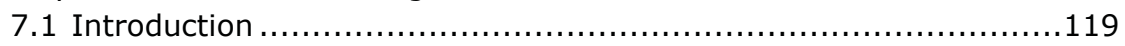

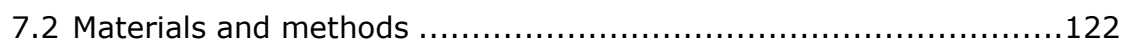

7.2.1 Airborne laser scanning measurement........................ 123

7.2.2 Landslide DTM and inventory mapping .......................... 123

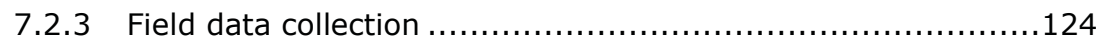

7.2.4 Extraction of tree height and gap fraction from ALS data .......126

7.2.5 Tree inclination and orientation from skeletonization ............129 


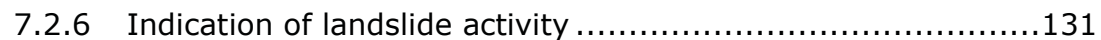

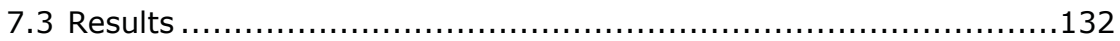

7.3.1 Morphological characterization of landslide zones ...............132

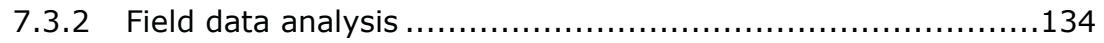

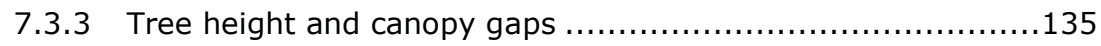

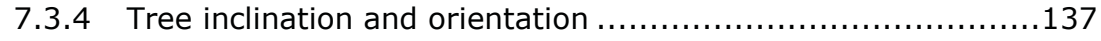

7.3.5 Disrupted trees and landslide activity ........................ 137

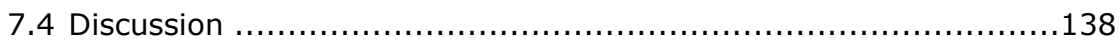

Chapter 8 Synthesis and conclusion....................................... 143

8.1 Landslide DTM quality and interpretability ............................ 143

8.2 Uncertainty in ALS-based landslide inventory maps ................. 145

8.3 Landslide susceptibility mapping based on ALS data ................. 147

8.4 Vegetation as bio-indicators of landslides.............................. 149

8.5 Research challenges and future research direction ................... 150

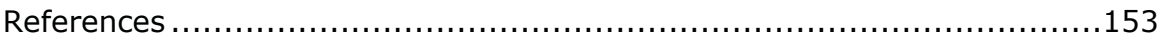

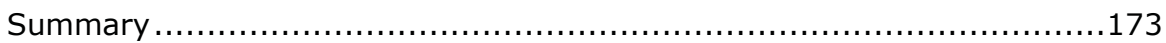

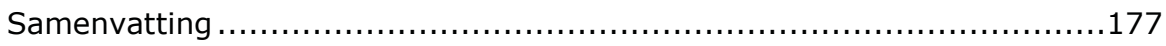

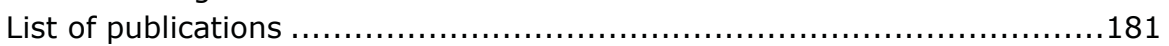

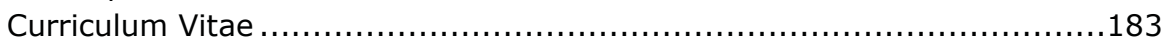

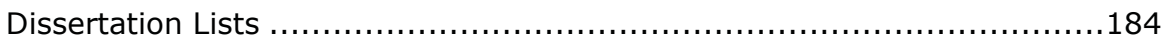




\section{Chapter 1}

\section{Introduction}

\subsection{Background and motivation}

Mass movement is the downslope movement of rock, soil, or regolith, largely under the force of gravity (Cruden, 1991). Landslides are a specific type of mass movement that is characterized by a sliding of the upper layer, and they may occur over a wide variety of spatial and temporal scales. The main societal significance of landslide analyses lies in the hazard that landslide events pose to people and property. According to the United Nations International Strategy for Disaster Reduction (UNISDR) and the database of the Centre for Research on the Epidemiology of Disasters (CRED; EM-DAT, 2011), landslides are ranked $3^{\text {rd }}$ in terms of number of fatalities among the top ten natural disasters. Landslides have killed more than 80000 people around the world in the last 10 years (Petley, 2011). The data in such catalogues are only an indication of the general trends, and should be interpreted as a minimum given the incompleteness of the database. Despite remarkable efforts of compiling and updating landslide maps at regional, national or global scale, the number of landslide events is often underestimated, especially in populated mountainous regions (Petley et al., 2005; Petley et al., 2010).

In the monsoon-dominated regions in Southeast Asia (e.g. Malaysia), landslides frequently occur in areas characterized by steep hillslopes, high rainfall intensities, seasonally dry periods, and unstable soils (Douglas, 1999; Sidle and Ochiai, 2006). In South and Southeast Asia, deforestation resulted losses of original forestland of about $28000 \mathrm{~km}^{2}$ per annum (UN-ESCAP, 2008). The growing population required a more dense transportation network across the rural areas. The development of new transport infrastructure often seriously affected the slope stability (Petley at al., 2007), increasing the hazard for the society. Based on a comprehensive survey in the tropics, rate of landslide disturbance is increased from 5 to 8 times in a 170 m wide swath along road corridors (Larsen and Parks, 1997). Other studies reported an 25 to 350 times increase in landslides in forests with small roads compared to pristine forests (Gray and Megahan, 1981; Amaranthus et al., 1985). Documenting landslides provides fundamental information on the landslideprocesses, which is very useful for reducing landslide hazards and risk (Corominas and Moya, 2008). 
Landslides are also significant from other perspectives. In geomorphology, landslides have been recognized as effective agents responsible for the longterm evolution of hillslopes. They shape mountainous landscapes, either by large episodic or small frequent events. In the ecology and physiology of forest ecosystems, landslides are responsible for the disruption of forests ecosystems across a wide range of scales in space and time (Frolking et al., 2009; Thomas, 1994; Clark, 1990). They disrupt forest homogeneity by creating forest gaps due to larger and fast landslides, but also affect the size and shape of the trees on slow moving landslides.

This research primarily focused on landslide mapping in areas partially or completely covered by dense woody vegetation, to which we will refer to as forested landslides. Woody vegetation affects landslides in multiple ways. Vegetation roots increase soil shear strength, which increases slope stability (Greenway, 1987; McIntosh et al., 2009). Forests also increase evaporation rates, and prevent pore pressure from exceeding the critical threshold for triggering landslides. On the other hand, trees increase the weight of the top layer, adding to the downslope force, and Crozier (2010) emphasized the infiltration capacity in forested slopes was higher than in areas partially covered by vegetation. Hence the ability to gain water offsets any effect from enhanced root cohesion resulting in a reduction in slope stability. These effects make that forested landslides are not uncommon (e.g. Jones, 1973; De Ploey and Cruz, 1979; Thomas, 1983). Especially prolonged and intense rainfall will lead to an increase in landslide activity. So (1971) reported the occurrence of 702 landslides as a result of a rainfall total of over $400 \mathrm{~mm}$ in a day in Hong Kong. About $35 \%$ of these landslides were located in a sloping forested area with tree height over $2.5 \mathrm{~m}$.

\section{Landslide mapping: New tools for an old problem}

Landslide inventory maps are fundamental for assessing landslide susceptibility, hazard, and risk. The landslide inventory gives the locations of landslides, their topology and geometrical characteristics, the possible failure mechanism, the state of activity and frequency of occurrences, the possible causal factors, and the historical damage (Van Westen et al., 2008). Different landslide mapping techniques have been applied depending on purpose of the inventory, the extent of the study area, the scale and resolution of the source maps, and the skills and experience of the investigators (Guzzetti et al., 2000; Van Westen et al., 2006). An extensive review on landslide mapping techniques on the detection, fast characterization, rapid mapping and longterm monitoring is given in SafeLand Deliverable 4.1 (2010). Landslide inventory mapping is routinely carried out based on one of following approaches:- 
- Geomorphological field mapping is often applied in identifying single landslides or small groups of landslides triggered by a specific event in a certain period (e.g. Cardinalli et al., 2006; Santangelo et al., 2010), or in validating an inventory compiled by aerial-photo interpretation (Guzzetti et al., 2000; Cardinalli et al., 2001).

- Visual interpretation of aerial photos (black and white, color-infrared) remains the most common method to map landslides. Particularly stereoscopic aerial photos are often used for a detailed morphological analysis (e.g. Cardinalli et al., 2000; Brardinoni et al., 2003; Van Westen and Lulie Getahun, 2003; Prokesova et al., 2010; Fiorucci et al., 2011).

- Visual interpretation of mono- and stereoscopic satellite images using a various visualisations based on different band combinations of multispectral imagery that may be pan-sharpened (e.g. Hovius et al., 1997; Nichol et al., 2006; Marcelino et al., 2009; Fiorucci et al., 2011).

- Analysis of satellite- and airborne-based synthetic aperture radar (SAR), e.g. Singhroy and Molch (2004), Rott (2009), Lauknes et al. (2010). Examples of analyses include Differential Synthetic Aperture Radar Interferometry and Persistent Scatters.

- (Semi)-automated classification of multispectral satellite images based on spectral and topographic characteristics (Nichol et al., 2006; Tarolli et al., 2010; Mondini et al., 2011). For example, an automated classification scheme has been carried out using an object-oriented knowledge-based method (Martha et al., 2010, 2011, 2012; Stumpf and Kerle, 2011).

- Analysis of topographic morphology based on very high resolution airborne laser scanning-derived images (McKean and Roering, 2004; Sekiguchi and Sato, 2004; Van Den Eeckhaut et al., 2005, 2007; Glenn et al., 2006; Schulz, 2007; Kasai et al., 2009; Bell et al. 2011; Razak et al., 2011). Examples of developed methods are surface roughness, slope and fractal dimension.

The objective of the image analyses is to create an inventory map that is as complete as possible and that can be carried out in a reasonable amount of time (Ibsen and Brunsden, 1996; Glade, 2001). New mapping techniques based on airborne remote sensing data are promising tools to facilitate the production of reliable landslide inventory maps. In this thesis, the focus is on airborne laser scanning as these data provide a wealth of data on both the vegetation and the underlying terrain.

\section{Airborne laser scanning for forested landslides characterization}

According to Petrie and Toth (2008), airborne laser scanning (ALS) is the most important geospatial data acquisition technology that has been introduced in mainstream topographic mapping in the last two decennia. ALS has revolutionized the acquisition of terrain data and physical presence of the objects because it can collect explicit 3D data in large volumes at an 
unprecedented accuracy within a relatively short time. ALS is based on an airborne platform that carries three instruments: (1) a dGPS for positioning, (2) an inertial navigation system that determines the pitch, heading, and roll of the aircraft, and (3) an airborne laser scanner: a laser rangefinder unit includes the actual laser, the transmitting and receiving optics, and the receiver with its detector, time counter, digitizing unit and including its optical scanning mechanism. After synchronization and integration of these data streams, a georeferenced point cloud results. With its ability to penetrate the space in the forest foliage and reach the ground, in addition to its independence of solar incidence, ALS is superior over passive optical (e.g. aerial-photograph, optical satellite images) and active radar sensors (e.g. interferometric synthetic aperture) for generating a high resolution digital terrain model in a mountainous forested terrain (Kraus and Pfeifer, 1998; Hodgson et al., 2003; Kraus, 2007). Typical raster-based products of ALS point clouds are Digital Terrain Model (DTM) of the bare earth, a Digital Canopy Model (DCM) of the top of the vegetation, and a normalized Digital Canopy Model (nDCM), the difference between DCM and DTM, which represents the canopy height.

Landslide inventory mapping has made significant steps forward due to the availability of ALS data. In the first place, the use of monoscopic- and stereoscopic-derived images created from a ALS-derived DTMs allowed for a much better recognition of diagnostic features for landslide interpretation (Sekiguchi and Sato, 2004; Van Den Eeckhaut et al., 2005; Van Den Eeckhaut et al., 2007; Schulz, 2007; Kasai et al., 2009). ALS-derived stereoscopic images are superior to stereo-radargrammetry, stereo-aerial photos, and stereo-optical imagery, to interpret the landslide morphology. Secondly, ALS data has been used to characterize vegetation and single trees (Razak et al. 2011). Patterns in vegetation and possible disruptions may be used in the inventory as well. The disadvantages of ALS data are that the data collection is still relatively expensive, even though prices have dropped over the last decade and therefore the data is not available for many areas.

ALS data provides a synoptic view, even in large inaccessible areas, which makes it useful to accurately map landslide-morphological features in a tropical environment with a relatively low point density. The data is a promising technique to produce multi-sources spatial data for landslide susceptibility mapping tools, notably the topographic and vegetation characteristics in a populated mountainous region with poor triggering data. Moreover, past landslide events and conditioning factor maps derived solely from ALS data can be alternative input for statistical landslide modeling. In addition, high density ALS (HDALS) is state-of-the-art for geometrically retrieving disrupted trees in temperate and tropical environments. Tree growth anomalies disturbed by different landslide processes can be 
parameterized purely based on HDALS data and its vegetation characteristics may provide clues to landslide activity. With the advancement of ALS system and point cloud processing routine, it is capable of producing and updating landslide maps, as more rapid recovery take places for landslide terrain in the tropics than in temperate forests (Douglas et al., 1999) and becoming a rapid mapping tool for emergency response and disaster management.

\subsection{Problem definition}

\subsubsection{Landslide inventory mapping}

Despite the importance of landslide inventory maps for mitigation and planning, they are rarely created (Brabb and Harrod, 1989; Nadem et al., 2006; Guzzetti et al., 2012). The compilation of landslide inventory maps is a tedious procedure due to the fact that each individual landslide has to be mapped and described together with their characteristics (Van Westen et al., 2006). Paucity of reliable information on landslides, therefore, hampers the possibility of assessing landslide susceptibility, hazard and risk at the regional, national and continental scales (e.g. Brabb et al., 2000).

The different approaches for landslide inventory mapping listed in section 1.1 all have drawbacks. Field mapping yields a high accuracy if aided by GPS and sophisticated instrumentation such as a laser rangefinder binocular (Santangelo et al., 2010), but it is very time consuming and expensive, and therefore only applied in limited areas (Haneberg et al., 2009; Santangelo et al., 2010). Monoscopic and stereoscopic images derived from a topographical map have significant limitations to a landslide inventory map (Will, 2002), because the altitudes on topographic maps are usually extracted from aerial photographs. Therefore the resulting DTM generally has a low accuracy. DTMs in densely forested and built-up areas that are based on photogrammetry depend on the sun light, flying height, camera types, and a relevant ground point should be visible from at least two imaging positions (Kraus, 2007). Therefore the ground surface is not well represented in photogrammetric DTMs of forested terrain, which leads to incomplete and unreliable landslide inventories. Brardinoni et al. (2003) reported that not visible or undetectable landslides from aerial photographs can represent up to $85 \%$ of the total number of failures and significant volume (up to $30 \%$ ) of debris to the amount mobilized.

Visual analysis based on very high resolution satellite remote sensing images proved to be effective to map fresh landslides in a large forested terrain, where the landslides have left clear signs of their occurrences (Guzzetti et al., 2012). Semi-automatic detection of landslides based on optical satellite sensors, particularly the use of multispectral information was most efficient 
for recent or reactivated slope failures, with clearly distinct radiometric signatures in a forested terrain (e.g. Mondini et al. 2011). These methods also work for fresh landslides in subtropical environments (e.g. Borghuis et al., 2007; Tsai et al., 2010; Yang and Chen, 2010). However, old and dormant landslides under forest are difficult to map and characterize. The resulting map poorly represents landslides in such landscapes (Fookes et al., 1991; Wills and McCrink, 2002; Brardinoni et al., 2003).

Satellite- and airborne interferometric SAR have advantage optical methods with respect to the dependency on clear skies during data collection. However, application of SAR data for landslide inventory mapping is limited due to atmosphere propagation effects, foreshortening, layover effects and vegetation decorrelation in forested terrain (Rott, 2009).

In equatorial forests, landslide inventory mapping is further hampered by rapid revegetation of the slides. Vegetation growth causes the signature of small and shallow landslides to be obscure within months or seasons. Hence, soon after their occurrence, the evidences of landslides cannot be recognized easily on the images (Fig. 1.1).

Airborne laser scanning has already been successfully used to map forested dormant landslides in the Flemish Ardennes, Belgium (Van den Eeckhout et al. 2007). However, it has not yet been applied to forested landslide complexes in the temperate regions, or to tropical forests. No studies have reported on mapping and classifying complex landslides, and estimating their activity beneath dense vegetation.
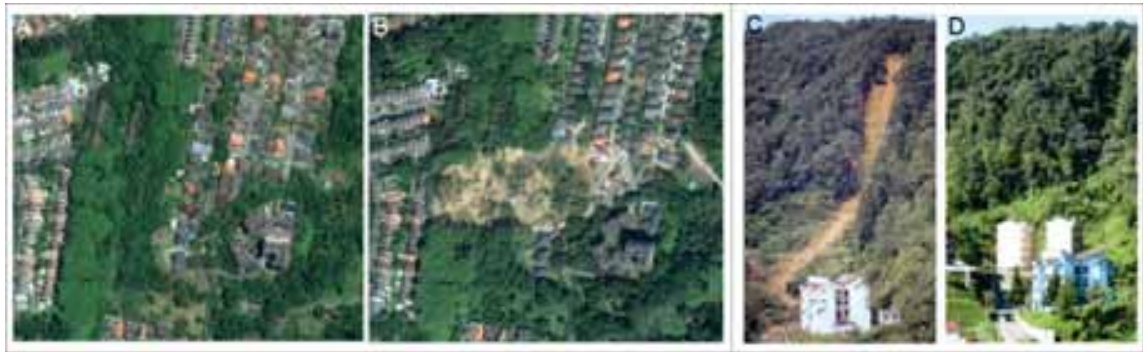

Fig. 1.1: Landslides in a tropical environment. A) High resolution satellite image captured four months before the catastrophic at Bukit Antarabangsa, Kuala Lumpur, Malaysia. B) Fatal landslides that caused significant economic and human losses in December 2008. C) A debris flow occurred in October 1996 in the Cameron Highlands, Pahang, Malaysia. D) The same area as in C), where the landslide area is re-vegetated. Note that the eight floor apartments were constructed at the landslide deposition zone. 


\subsubsection{ALS terrain model quality associated to forested landslides}

Manual interpretation of terrain features lies at the basis of landslide inventory mapping. Hence the quality of the landslide DTM is crucial for an accurate interpretation. The essential step in DTM generation is the classification of ground points and non-ground points, which is also known as DTM filtering, or bare earth extraction. Despite the automated methods for DTM filtering (Kobler et al., 2007), complex situations still require additional attention, or fine-tuning of filter settings. Complexity may be due to dense forests, and undergrowth, steep slopes, terrain discontinuities, large terrain variability, (Huising and Gomez Pereira, 1998; Sithole and Vosselman, 2004). All of these cases occur on forested landslides.

A number of studies have reported on terrain model quality (Hodgson and Bresnahan, 2004; Pfeifer and Mandlburger, 2009). Despite a general consensus on the usefulness of ALS for landslide mapping, a few knowledge gaps remains: (1) no studies specifically assessed the DTM quality of forested landslides, (2) there are no guidelines for tuning DTM filters to derive an optimal DTM in quantitative terms of vertical error and in qualitative terms of image interpretability, (3) the minimum required point density of ALS data is unknown, which is relevant to minimize survey costs for landslides in forested regions. Therefore, a careful assessment is needed of DTM filtering for detailed landslide mapping in tropical and temperate regions.

\subsubsection{Landslide susceptibility mapping}

Landslide susceptibility is mathematically defined as the probability of spatial occurrence of known slope failures, given a set of geo-environmental factors (Guzzetti et al., 2005). A susceptibility map portrays the areas prone to landslides, which is useful to take into account in short and long term landuse planning. In many forested tropical regions that are under population pressure, predicting landslide susceptibility is crucial as many land use changes occur due to newly established roads, agricultural areas, and builtup areas.

Several studies have assessed and predicted the landslide occurrences in the Malaysian mountainous landscape (e.g. Pradhan, 2010; Pradhan et al., 2010; Pradhan and Lee, 2010a). However, the training data of these susceptibility studies are based on historic inventories of landslide occurrences. The historic data are limited by the duration of the inventory, and they are likely biased towards landslides along transportation routes, and inhabited areas. ALS can be used to deliver create landslide inventory maps that is unbiased towards roads, or populated area. At the same time, ALS can be used to deliver the geo-environmental factor maps that are used to predict the landslide 
probability. These factor maps represent topographic, hydrological, anthropogenic, and geological information. Based on the highly detailed information that can be derived from ALS data improvements in susceptibility mapping is expected, but no studies have reported on the use of ALS-derived conditioning factor maps.

\subsubsection{Landslide activity analysis}

Landslide activity analysis is a crucial aspect of landslide inventory mapping and it is even more challenging in a forested rugged terrain. Assessment of landslide activity is based on the observation of the past activity and from the analysis and interpretation of geomorphic features which can be associated to the degree of activity of the landslide. Landsliding may damage trees and produce silent witnesses, sensu Corominas and Moya (2008). Trees as silent witnesses may be displaced, tilted, partially buried, bended, or limited in growth by landslides. Several attempts have been made to use tree irregularities as indicator to landslide activity. Van Den Eeckhaut et al. (2009) used dendrogeomorphology to link tree rings to landslide activity. However, dendromorphology is costly and requires an intensive field investigation and subsequent laboratory analysis, resulting in a relatively low number of samples, and limitation in terrain coverage and tree species. Mackey and Roering (2011) successfully used multitemporal images to track individual trees over time. Tree tracking only works with slow moving landslides, and requires a sequence of images.

The importance of disrupted trees as bio-indicator to local surface deformation has been recognized (Parise, 2003), but studies into this relation were always hampered by difficulties in spatially retrieving these indicators. ALS has been used extensively to delineate single trees and analyse their vertical trees (e.g. Reitberger et al. 2009). However, the extraction of tree irregularities due to landslides from ALS data has not been studied so far, mainly because of the high density data required for a detailed analysis (Bucksch et al. 2010). Although TLS provides some practical solutions of the tree extraction (e.g., Eysn et al. 2013), no methods exist to spatially map tilted and bended trees from airborne laser scanning data, and the degree to which vegetation is affected by landsliding still remains unexplored.

\subsection{Research objectives}

This study investigates the suitability of airborne laser scanning for mapping and classifying landslides under forests in temperate and tropical environments. The specific objectives of this research are:

- to quantitatively and qualitatively evaluate optimal ALS-derived DTMs for landslide inventory mapping.

- $\quad$ to evaluate the uncertainty in ALS-derived landslide interpretations. 
- to evaluate the suitability of airborne laser scanning for producing landslide susceptibility maps.

- to analyse ALS-derived vegetation indicators that are indicative for landslide activity.

\subsection{Research questions}

From the research objectives, the following major and minor research questions were formulated:

1. Is it possible to generate an optimal digital terrain model for mapping and classification of landslides in a temperate forest (Chapter 3 ) and a tropical rainforest (Chapter 4) using airborne laser scanning (ALS) data?

a. What is the ALS derived DTM accuracy in a temperate forest and in a tropical rainforest environment?

b. What is the best ALS derived DTM that offers maximum interpretability with respect to landslide indicators?

c. What are the minimum and optimal required point densities of ALS data for mapping landslides?

2. What is the uncertainty of ALS-derived landslide inventories (Chapter 5)?

a. How to quantitatively compare landslide inventories compiled at different scales and source data (ALS, aerial-photo/satellite images)?

b. What is the positional mismatch and completeness of landslide inventory maps produced by means of multi-scale visual analysis of stereoscopic ALS images?

c. How to compare ALS derived landslide inventories that contain landslides generated under different conditions over a long period of time, with historical landslide inventories that cover a short period of time?

3. What are the requirements of ALS derived factors maps that are used in statistical landslide susceptibility assessment (Chapter 6 )?

a. Which of these factors maps can be derived using semi-automated techniques, and what is their accuracy?

b. How much additional data is required apart from ALS derived factor data?

c. What is the influence of the temporal aspects of both the landslide inventories and factors maps (land cover) on the landslide susceptibility prediction results?

4. How accurately can ALS data represent disrupted vegetation by landslides (Chapter 7)?

a. Which vegetation indicators can be used for characterizing slope instability based on field data? 
b. Which of these vegetation indicators for slope instability can be derived from ALS point clouds?

c. What are the minimum and optimal required point densities of ALS data for vegetation indicators landslides?

To answer these questions, two studies areas were selected. One study area was located in the Cameron Highlands, a tropical region in peninsular Malaysia with different land cover types. The other study area was situated in Southern French Alps, with a temperate climate.

\subsection{Thesis outline}

Chapter 1 provides the research background and the key challenges, and then specifies research objectives in the form of research questions and outlines the structure of the dissertation.

Chapter 2 describes the study areas in different environments: i) Bois Noir area in a temperate climate, ii) Cameron Highlands in the Malaysian tropical environment.

Chapter 3 illustrates the suitability of high density ALS data for bare earth extraction used for landslide identification and characterization in a temperate landscape. The quantitative and qualitative assessment of ALSderived DTMs was carried out to evaluate the preservation of landslide morphological features. An appropriate point density is presented for a detailed analysis of landslide morphological characterization.

Chapter 4 highlights the potential of ALS data with a low point density for generating an optimal DTM for landslide mapping in the tropics. Field measurements were used for an error assessment of the DTM, while landslide interpretation of different DTMs was used to determine the required data for optimal landslide recognition.

Chapter 5 demonstrates the quantification of uncertainty of ALS-derived landslide inventory maps in the tropics. The landslide maps, generated independently by four expert interpreters, were evaluated in terms of correctness and completeness. Uncertainty issues related to landslide inventory mapping in the anthropogenic region are critically discussed, with respect to consistency, compilation time, funding, local knowledge and experience.

Chapter 6 describes the investigation of the potential use of airborne laser scanning data for generating landslide susceptibility maps in a tropical populated region with poor information on the landslide triggers. Two 
reference landslide inventory maps were used in a multivariate logistic regression analysis. The existing historic inventory map was used as well as the new inventory map based on the ALS data. Several geo-environmental factor maps were derived from the ALS data. These factor maps were used as independent variables.

Chapter 7 addresses vegetation analysis as a bio-indicator for landslides. Based on raster-based and point-based analyses of ALS data, it quantifies forest canopy gaps, tree height dissimilarities, and single tree inclination and orientation. The statistical tests showed significant differences between the extracted parameters in landslide and non-landslide zones.

Chapter 8 highlights the research contributions discovered in Chapters 3-7, provides answers to the research questions, and lists the (near) future research works especially in the context of tropical environments. 


\section{Chapter 2}

\section{Study Areas}

\subsection{Introduction}

Two different study areas (Fig. 2.1) were selected in order to pursue the objectives of this research covering the temperate and tropical environments. In France, the Bois Noir area was selected, which is close to Barcelonnette basin; in Malaysia, the Cameron Highlands was studied. In this chapter, the geology, geomorphology, and vegetation is described. In addition the ALS data and field reference data are given to limit iterations in other chapters.
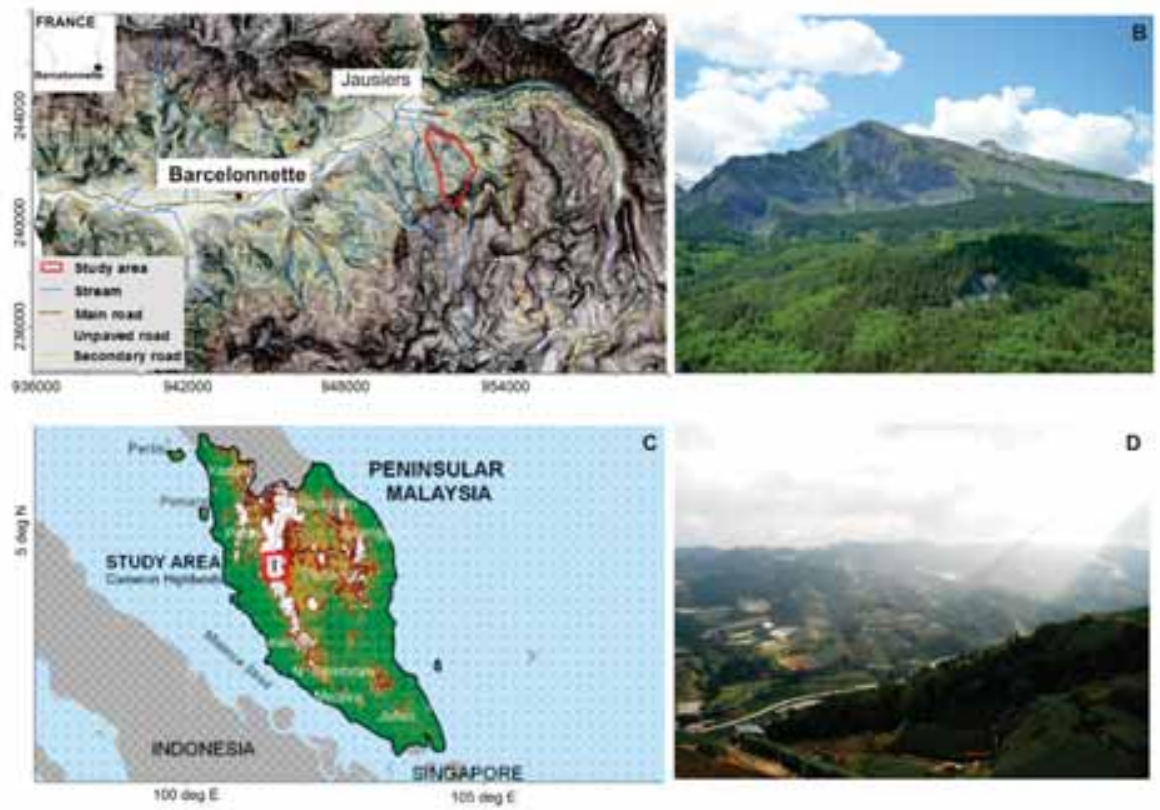

Fig. 2.1: Study areas. A) Bois Noir, Barcelonnette, France C) Cameron Highlands, Malaysia and associated field photos in $B$ and $D$, respectively.

\subsection{Bois Noir area, Barcelonnette, France}

The Bois Noir catchment is located on the north-facing slope of the Barcelonnette basin (Figs, 2.1A; 2.2A) in the southern French Alps, $2.5 \mathrm{~km}$ to the south-east of Jausiers (Alpes-de-Haute-Provence, France). The Barcelonette basin is drained by the Ubaye river, while Bois Noir is situated 
between two small streams, the Torrent de la Frache and the Riou Versant. The altitude of the study area ranges between 1400 and $2100 \mathrm{~m}$ above mean sea level, and the area is characterized by irregular topography with slope gradients between 10 and $70^{\circ}$ (Thiery et al., 2007). This forested catchment is situated in the dry intra-Alpine zone, and is characterized by strong interannual rainfall variability. The HISTALP meteorological dataset (Efthymiadis et al., 2006) contains a measurement station at $2 \mathrm{~km}$ from Bois Noir $\left(44^{\circ} 25^{\prime}\right.$ $\mathrm{N}, 6^{\circ} 45^{\prime} \mathrm{E}$ ). The average rainfall is $1015 \pm 179 \mathrm{~mm}$ year ${ }^{-1}$ for the period 1800-2004. Rainfall intensity can exceed $50 \mathrm{~mm} \mathrm{~h}^{-1}$ especially during summer storms (Flageollet et al., 1999). Maquaire et al. (2003) reported that the mean annual temperature is $7.5^{\circ} \mathrm{C}$ with 130 frost days per annum.

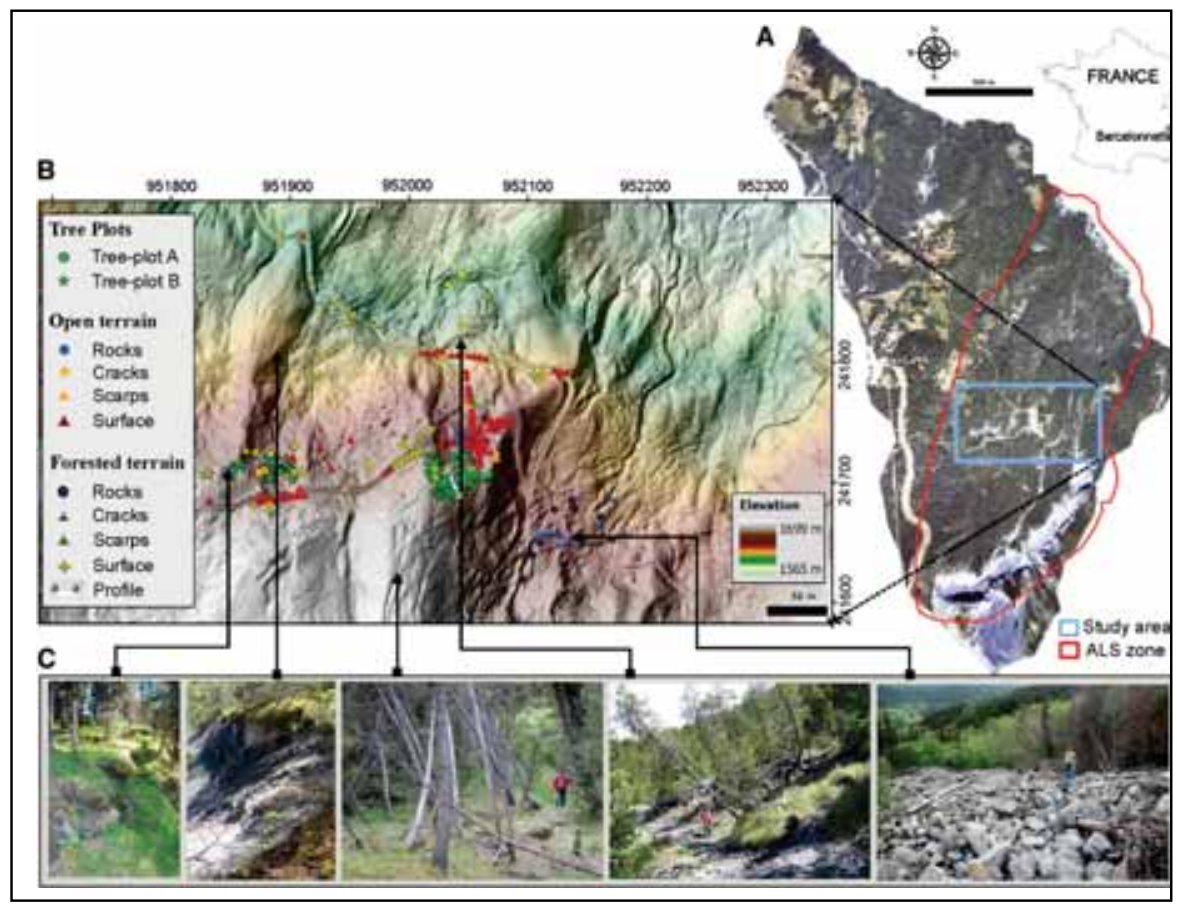

Fig. 2.2: Location of the study area at the Bois Noir landslide in the Barcelonnette Basin (South French Alps). A) Orthophoto of the study area and the ALS zone in 2009. B) Map showing validation points measured in different geomorphological features and trees over forested and open terrain. C) Photographs of representative landslides features.

Geologically, the northern part of Bois Noir is characterized by morainic colluvium and autochthonous Callovo-Oxfordian unstable black marls, overlaid by deposits of reworked glacial till. The area is highly affected by landslides (Flageollet et al., 1999; Maquaire et al., 2003). The southern part 
of Bois Noir is characterized by outcrops of limestone in the summit crest and features steep slopes of up to $70^{\circ}$, with extensive scree slopes. The hummocky topography is inherited from the different phases of the Quaternary glaciation (Hippolyte and Dumont, 2002).

Flageollet et al. (1999) stated that the slope instability is controlled by the climatic conditions. Instability is likely to occur after heavy rainfall following a relatively dry period. A hydrological discontinuity created by the contact of marine deposits and black marls plays a role in landslide susceptibility. According to Thiery et al. (2007), these predisposing geomorphic and climatic factors explain the development of rotational or translational shallow landslides, which usually affect the uppermost two to six meters. They also reported that this area has been identified as highly susceptible to landslides although most of the area is covered by vegetation. Thiery et al. (2007) created a landslide inventory map of $1: 10,000$ scale, based on aerial-photo interpretation, field surveys and historical records. Tilted and deformed trees, as well as recent scarps and open cracks clearly indicated that there is scope and reason to believe that the Bois Noir landslide has been subjected to multiple reactivations in the recent past (Lopez Saez et al., 2011).

The forest in the Ubaye Valley was seriously affected by the population pressure and soil erosion in the $15^{\text {th }}$ and $16^{\text {th }}$ centuries (Weber, 1994). However, in the $19^{\text {th }}$ century reforestation was started over the Ubaye valley through the enforcement of local laws (Arnaud, 1906). A land use map derived from a 2004 Landsat ETM+ fused with a 1994 SPOT-P image exemplified that most of area is covered by forests, i.e. coniferous, deciduous and broadleave forests (Thiery et al., 2007). The forest is mainly comprised of Pinus uncinata Mill. Ex Mirb (mountain pine), Pinus sylvestris (Scotch Pine), Larix deciduas (Larch), Picea abies (Spruce), and Pinus Nigra (Austrian pine). The study area was largely covered by unthinned $P$. uncinata plantations of about a century old resulting in very small crowns and high stem densities. The areas characterized by larger crowns and lower stem densities are due to irregular thinning of the P. uncinata plantations. On scree slopes, the pioneering P. uncinata trees occur with larger crowns. These areas have a lower tree density, and the trees can occur as multi-stemmed shrubs.

Historical forestry records

The forestry archives of the French National Forest Office (ONF) were analyzed for the Bois Noir area (ONF, 2011). The archives covered a 115 year period between 1895 and 2010, and contained information on tree status, soil, roots, tree diseases, landscape and surface hydrology. The archived data also reported damage to trees in the Bois Noir area from either landslides, hailstorm or disease. The earliest record of trees affected by 
landslides dated back to 1897. In 1925, 1947 and 1993, about 240 trees were reported affected by landsliding (Fig. 2.3). No causal factors were given for the 1925 and 1947 events. Unfortunately, no detailed spatial information was available for these events. Mudflow and debris flow events in 1960 resulted in more than 50 trees inclined. A road construction in 1993 resulted in many landslides in the subsequent years (Thiery et al., 2004). Disrupted trees were also observed in the years following the landslide events.

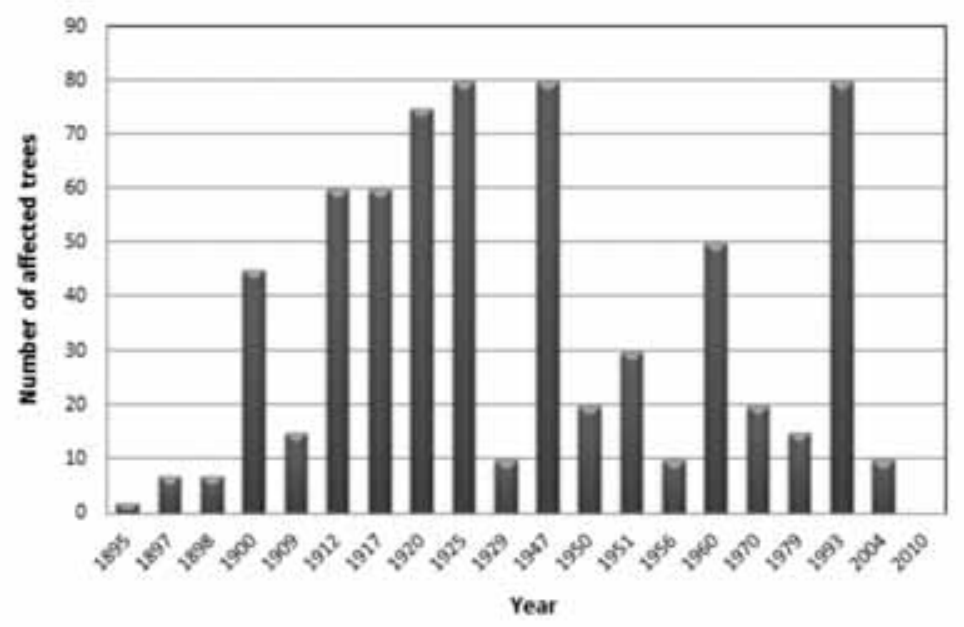

Fig. 2.3: Number of disrupted trees caused by landsliding reported in the historical forestry reports for Bois Noir, Barcelonnette, France.

The historical inventory also reported on a fairly large number of trees in the Bois Noir area that were affected by three diseases: Rhizosphaera kalkhoffii, Lophodermium seditiosium, and Sphaeropsis sapinea. Sphaeropsis sapinea was reported first in the Bois Noir area. It is caused by a fungus (Diplodia pinea, and can infect younger trees. Especially pine trees that are growing under stressful conditions are easily attacked. The historical report suggests that landslides were the main factor contributing to the disruption of vegetation, whereas tree diseases play a role after the events took place. For instance, after the landslide events in 1993, about 200 trees were seriously affected by diseases.

\section{Areal extent of chapters 3 and 7}

The Bois Noir study area was used in two chapters, chapters 3 and 7. Chapter 3 focused on a small and active part of 24 ha, which is indicated in the blue rectangle in Fig. 2.2B. This spatial subset was used to limit data volumes and to optimize the scale of visualization. The locations of the field data for chapter 3 are indicated in Fig. 2.2B as well. These reference points indicate the terrain height measurements. Chapter 7 deals with vegetation analysis in the whole area, and is indicated by the red polygon in Fig. 2.2B, 
and the total extent of Fig. 2.4. The points in Fig. 2.4 represent the field reference data for vegetation analysis collected in June 2009, June 2010, and September 2011. In total, biometric data of 560 individual trees were collected.

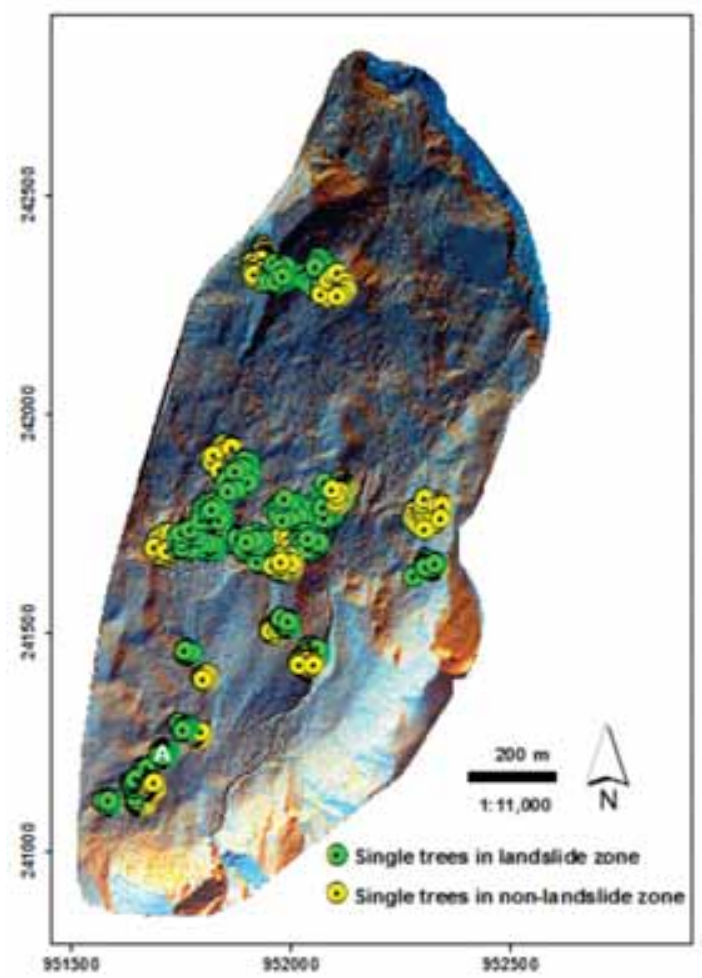

Fig 2.4: Field tree reference data collected in Bois Noir (Barcelonnette, France) showing on a $25 \mathrm{~cm}$ color composite image derived from ALS-derived DTM. Location of drunken trees is shown in a tree plot A.

\subsection{Cameron Highlands, Pahang, Malaysia}

The Cameron Highlands area is located in the Indo-Malaysian tropical rainforest zone and on an undulating plateau in the central part of the main range of Peninsular Malaysia (Fig. 2.5). The study area covers $100 \mathrm{~km}^{2}$ stretching from Kampung Raja to Ringlet, up to $5 \mathrm{~km}$ to the east from the major road of the Cameron Highlands. The height ranges between 820 and $2000 \mathrm{~m}$ above mean sea level, with an annual rainfall between 2500 and $3000 \mathrm{~mm}$ per year, and a daily maximum rainfall of approximately $100 \mathrm{~mm}$. Given its relatively high altitude, the temperatures are lower than in the rest of Peninsular Malaysia, with an average daily temperature of $23^{\circ} \mathrm{C}$ and 
night-time average of $10^{\circ} \mathrm{C}$ (MMD, 2011). This relatively cool temperature makes the Cameron Highlands a popular tourist attraction.

Geologically, Peninsular Malaysia is subdivided in a N-S direction by the Saub-Bentong suture, dividing the East Malaya terrane derived from Gondwanaland in the Devonian, from the Sibumasu terrane derived from Gondwanaland in the Permian (Metcalfe, 2000). Two important compressional events affected the Peninsula, one in Late Permian times and the other in the mid- to late Cretaceous.

The Late Palaeozoic compressional event was a major orogenic mountain building phase with associated emplacement of major Permo-Triassic granite plutons that form the eastern and main ranges (Harbury et al., 1990). The current tectonic situation is related to the subduction of the Australian plate under the Sunda plate (with movement of about $34 \mathrm{~mm} / \mathrm{year}$ ), producing large earthquakes along the Sumatran subduction zone and the Sumatran transform fault (Vigny et al., 2005; Yan et al., 2006). Also the divergent boundary effect of the Sagaing and Sumatra right-slip faults poses an explicit implication on the seismic situation in Malaysia. Peninsular Malaysia is in a relative low seismic hazard zone, without any recorded earthquakes of a magnitude of more than 5. The estimated horizontal Peak Ground Acceleration in rock of $6-8 \% \mathrm{~g}$ with a $10 \%$ probability of occurrence within 50 years (Petersen et al., 2004).

The study area is underlain by megacrystic biotite granites (Krahenbuhl, 1991) with some scattered outcrops of meta-sediments, which are composed of schists, phyllite, slate, and limestones (Chow and Zakaria, 2003). Across the schist area, the thickness of the residual soil is less than $6 \mathrm{~m}$, overlain by weathered rock (hard to weak layers (Bujang et al., 2008), and often located at the higher elevation areas (Husaini et al., 2005). 

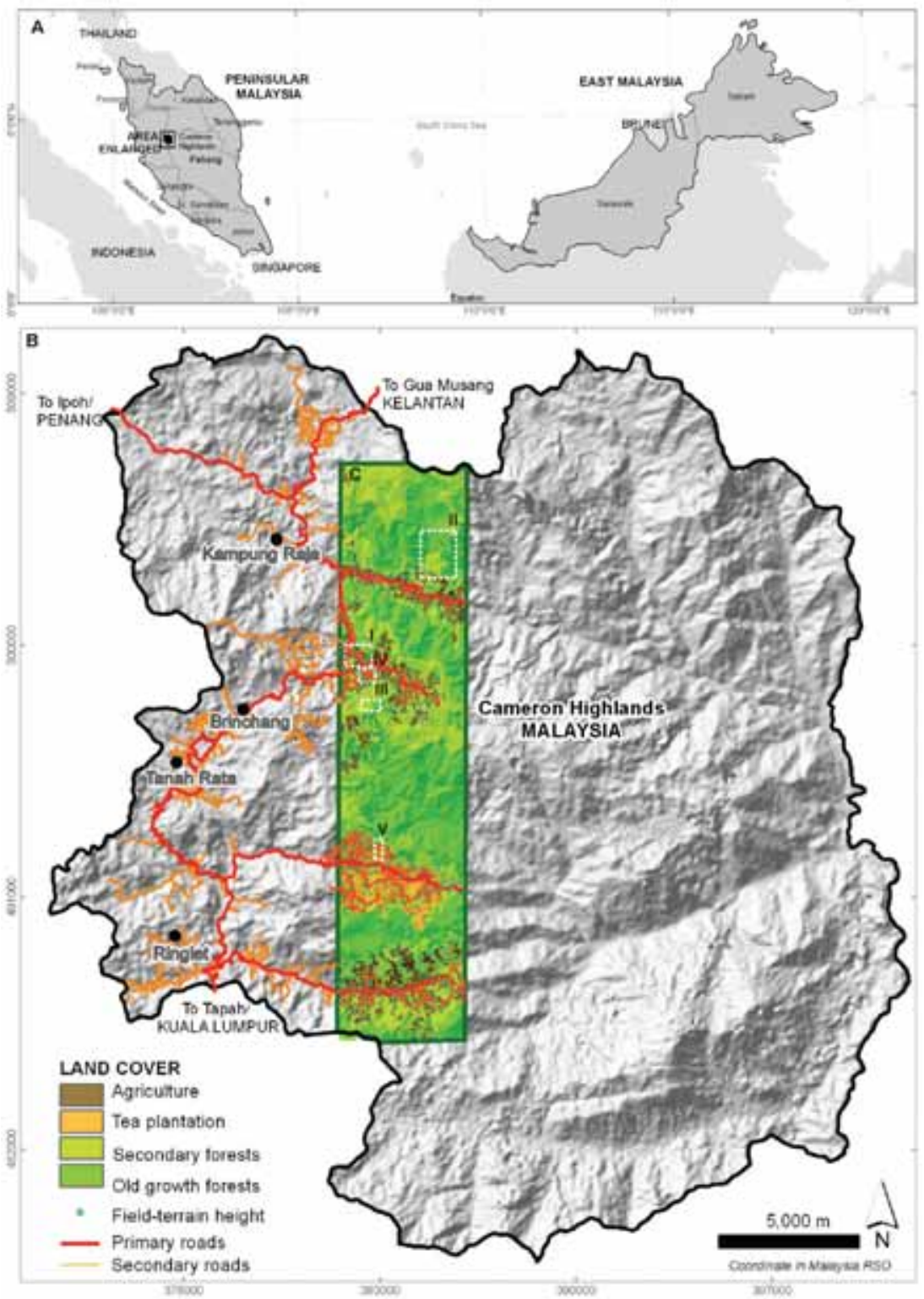

Fig. 2.5: The study area. A) Location of the study area in the Cameron Highlands, Peninsular Malaysia. B) The district of the Cameron Highlands shown with a shaded relief map derived from a $30 \mathrm{~m}$ ASTER GDEM. The rectangular area represents the actual study area $\left(100 \mathrm{~km}^{2}\right)$ with indication of land-cover types and field terrain heights. The dotted white boxes I to $\mathrm{V}$ indicate the detail locations presented in Chapter 4. 
Weathering profiles in the granites can be very thick, and roadcuts in these weathered materials present many problems related to slope instability (Durgin, 1977; Brand, 1989; Thomas, 1994). Weathering classifications (e.g. Dearman, 1978; Hencher and Martin, 1982) for profiles of granite in Malaysia show a depth of 30 meters. The completely weathered zone (Weathering Grade 6 ) is up to $10 \mathrm{~m}$ thick and indistinctly preserves the textures, but not structures, of the original bedrock. The weathered zone (Grades 5, 4 and 3) is up to $25 \mathrm{~m}$ thick and consists of in situ, moderately to highly weathered bedrock materials that indistinctly to distinctly preserve the minerals, the texture and the structure of the original bedrock (Raj, 1985).

The forest types consist of lowland evergreen rainforest (hill dipterocarp forest and upper dipterocarp forest), lower montane forest (montane oak forest), and upper montane forest (montane ericaceous forest) (Wyatt-Smith, 1995). The undergrowth consists largely of woody plants - seedlings and sapling trees, shrubs and young woody climbers. The stemmed palms (e.g. Arenga westerhoutti), stemless palms (e.g. Licuala spp) and rattans (e.g. Calamus castaneus) are the dominant undergrowth in the study area. The tropical climate and nutrient-rich granitic soil provide a favourable environment for agricultural activities (e.g. vegetables, floriculture, and tea plantation). The increasing population pressure has led to the clearing of the original forest for the construction of housing estates, roads and new agricultural areas.

Landslides are an increasing problem in the Cameron Highlands, as a result of human interactions such as deforestation, and terrain modification for roads and agriculture (Douglas, 1999; Chow and Zakaria, 2003; Pradhan and Lee, 2010). One of current practices is to excavate the top of ridges and to create artificial platforms for agriculture terraces and housing. The excavated materials are dumped along the sides of the plateaus, leading to severe erosion and landslides. Given the high risk of injury, fatality, and damage to the infrastructure, the documentation of the extent of the slope failures is crucial. In the Malaysian National Slope Master Plan 2009-2023 (PWD, 2009), it is recommended to update the landslide inventory every five years, and several landslide mapping techniques are listed. Airborne remote sensing is recommended as a tool for collecting landslide information on a national level. Long-term records of landslides are not complete. The first landslide in the records dates back to December 07, 1919 (Jaapar, 2006) and from 1973 to 2007,440 landslides were reported, with about 600 fatalities. However, thousands of minor slope failures were not properly documented (PWD, 2009). Fig. 2.6 presents some field photos showing different landscapes, with indications of landslide movements. 


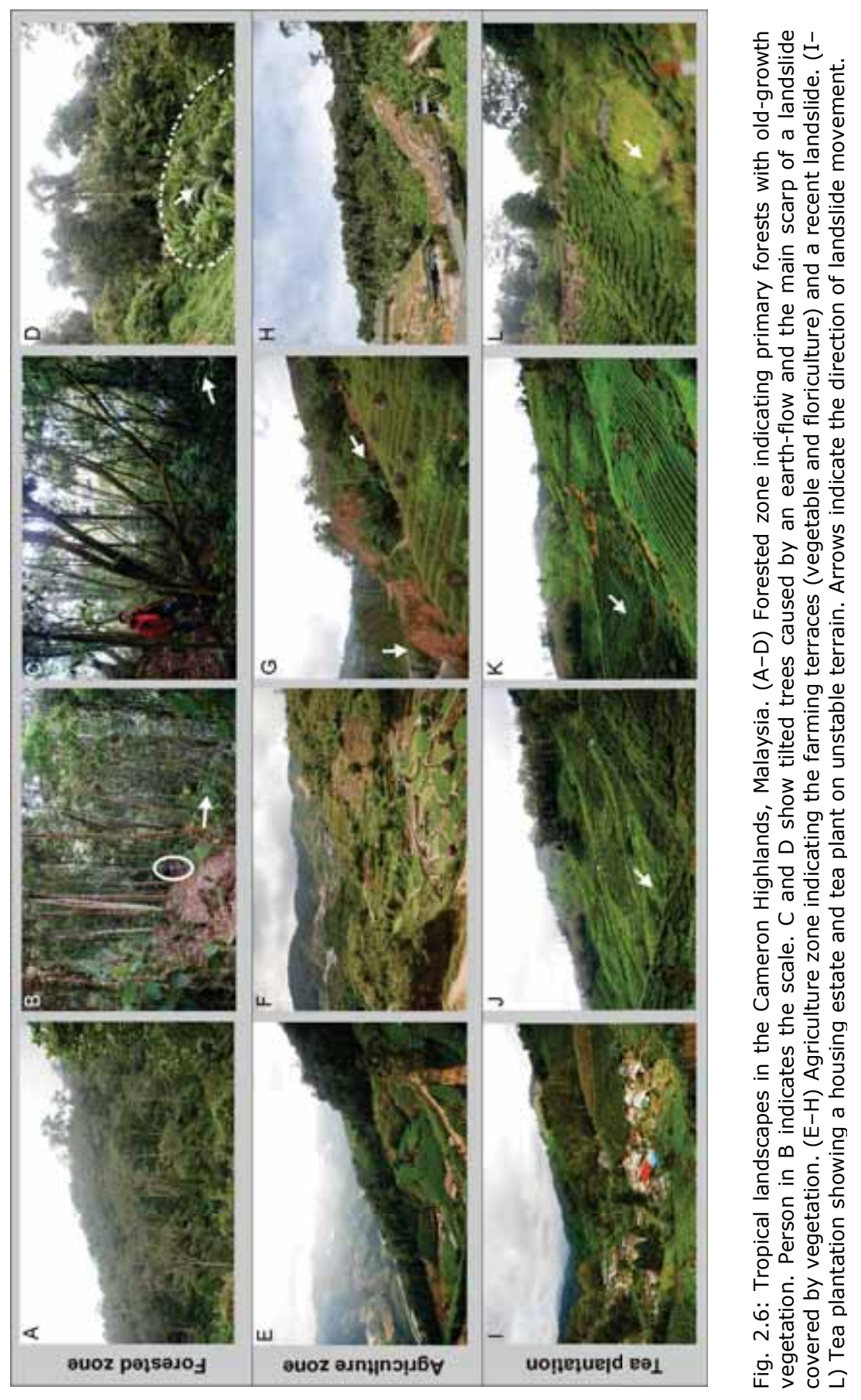


The forested zone consists of old-growth forests (Fig. 2.6A-D), with very dense vegetation, and multi-storey canopies, as well as rejuvenated forests in locations which might have been affected by landslides, forest fires, or illegal deforestation activities. The upland agriculture zone (Fig. 2.6E-H) is sparsely covered by woody vegetation, which often indicates the breaklines resulting from the man-made terraces built for farming activity (Fig. 2.6F). The agricultural zone also features plastic-covered green houses for vegetable and floriculture cultivation. The tea plantation area is characterized by an undulating topography, with well managed slopes, with few larger trees and a proper accessibility for harvesting (Fig. 2.6I-L). 


\section{Chapter 3}

\section{Airborne laser scanning of forested landslides characterization: Terrain model quality and visualization*}

\subsection{Introduction}

Landslides occur under a wide range of environmental conditions, including forested mountainous landscapes. Landslides often cause extensive damage and many casualties. Hence, it is important to identify landslides and assess the landslide susceptibility, hazard and risk. Landslide inventory maps are prepared by interpreting the geomorphic features of landslides on remote sensing imagery supported by field surveys. These maps yield insight into the locations of landslides, their typology, failure mechanisms, causal factors, frequency of occurrence, volumes and historic damage (Van Westen et al., 2008). For sparsely or non-vegetated areas, various landslide mapping techniques are available, e.g. using single or multi-temporal aerial photographs (Brardinoni et al., 2003; Van Westen and Lulie Getahun, 2003; Prokesova et al., 2010), high spatial resolution satellite images (Nichol et al., 2006), or satellite-based synthetic aperture radar (Rott, 2009). In forested terrain, these techniques are less effective to identify landslides. Under closed forest canopies, visual interpretation of distinctive landslide morphology is limited.

Over the last few years, Airborne Laser Scanning (ALS) became available and is used to map landslide morphology and activity in areas that are partly or completely covered by dense vegetation (Sekiguchi and Sato, 2004; Van Den Eeckhaut et al., 2005; Glenn et al., 2006; Schulz, 2007; Van Den Eeckhaut et al., 2007).

The ability of ALS to penetrate the forest canopy and its independence of solar incidence angle makes ALS superior to image-based photogrammetric techniques for acquiring a high resolution digital terrain model (DTM) in forested terrain (Kraus, 2007) and the high spatial resolution of ALS outperforms the use of synthetic aperture radar (SAR). The interpretability of

* This chapter is based on:

Razak, K.A., Straatsma, M.W, Van Westen, C.J., Malet, J.P., de Jong, S.M (2011) Airborne laser scanning of forested landslides characterization: Terrain model quality and visualization. Geomorphology 126, 186-200. 
landslides depends on the quality of the DTM. Reported vertical accuracies of vegetated and sloping terrain vary between $0.20 \mathrm{~m}$ and $2.00 \mathrm{~m}$ (Huising and Gomes Pereira, 1998), $0.26 \mathrm{~m}$ for deciduous forest (Hodgson and Bresnahan, 2004), $0.57 \mathrm{~m}$ (Kraus and Pfeifer, 1998), $0.31 \mathrm{~m}$ for conifer forest (Reutebuch et al., 2003) and $0.31 \mathrm{~m}$ for shrub and conifer trees (Wang and Glenn, 2009). So far no detailed assessment on DTM has been carried out to reveal the suitability of ALS and derived DTMs to accurately map landslidemorphological features.

ALS data is typically delivered as a very large dataset of points (clouds) with $\mathrm{X}, \mathrm{Y}, \mathrm{Z}$ coordinates (easting, northing and elevation). Various filter types are used to extract trees, houses or the bare earth surface under trees from the dataset. Filtering of ground points from the ALS point is an important step in the accurate geomorphologic mapping of landslides. Generally, ALS-derived DTMs have been used to characterize landslide morphology and activity (McKean and Roering, 2004; Glenn et al., 2006; Kasai et al., 2009).

Several algorithms have been developed for DTM extraction from ALS point clouds (Sithole and Vosselman, 2004). In spite of the ability to automatically classify ground points and non-ground points, complex scenarios such as the preservation of discontinuities, vegetation on slopes, low vegetation and influence of outliers, still require further improvement of the filtering algorithms (Sithole and Vosselman, 2004) and some manual editing is often carried out by the data vendor. The selection of the appropriate filtering algorithm depends on the type and complexity of the landscape (Sithole and Vosselman, 2004; James et al., 2007). An optimal method for landslide inventory mapping is currently not known. Especially, the preservation of important landslide characteristics, such as scarps, cracks, rock blocks and back-tilting of the surface, while removing vegetation is a challenging task. Therefore the first objective of this paper is to test the performance of two well-known DTM filters, the hierarchical robust interpolation and progressive TIN densification, to quantify the error in the DTMs in rugged forested terrain focusing on geomorphological features of forested landslides. For this we acquired very high resolution ALS data of 170 points $/ \mathrm{m}^{2}$ to exclude point density as a limiting factor and to allow the determination of the appropriate point density for landslide mapping.

The second part of the paper evaluates various visualization methods of an ALS-derived DTM of a large complex landslide. Different visualization techniques are discussed in the literature: monoscopic images (e.g. shaded relief, color composite, openness) and 3D model (stereoscopic images, 3D point cloud visualization) approaches. Our second objective is to qualitatively assess the visual interpretability of a landslide DTM with respect to activity, scarps, rock blocks, displaced material and composition of the main slides 
and sub-slides using different visualization techniques. The evaluation was carried out by different image interpretation experts. Examples are taken from the Bois Noir landslide in the southern French Alps (Chapter 2), which is a complex landslide area (Flageollet et al., 1999; Thiery et al., 2007).

\subsection{Methods}

\subsubsection{Data collection}

\section{Field measurements}

A field campaign was carried out in June 2009, during which terrain heights were measured using a Leica differential GPS system 1200. A total station was used to measure under dense canopies where the GPS signal was too weak for accurate positioning. We established two geodetic base stations to create a local geodetic network. Locations were selected based on open sky view for optimal reception of the GPS signals and to avoid the delayed signals affected by multipath effects. A 24-hour static observation was carried out for each geodetic station. Horizontal and vertical accuracy of this tool with static observation mode is about 3 and $10 \mathrm{~mm}$ at $0.5 \mathrm{ppm}$, respectively.

Post-processing on the GPS data was done by taking the coordinate references from three available permanent GPS stations of RENAG (REseau NAtional GPS) located nearest to the study area. Position and baseline time series for the evaluation on the validity of the stations for reference are available online at http://webrenag.unice.fr. Horizontal and vertical precision of geodetic stations are on average 8 and $13 \mathrm{~mm}$, respectively. Using these base stations, real-time kinematic (RTK) GPS was used to measure the terrain height. The GPS data was processed using strategy schemes implemented in Topcon Tools software ver. 7.2. The RAF98 geoid model was used to convert the ellipsoidal height into orthometric height. All the coordinates were projected into the local coordinate system, Lambert zone III using Lambert Conformal Conic with NTF (Nouvelle Triangulation de France) as datum.

In case it took too long or was not possible to get an accurate value using RTK-GPS, a total station was used. The position of the total station was determined using the two geodetic base points set up close to the forest boundary. From there, points under the dense tree canopy were measured and their accuracy is dependent on the geodetic station. A total of 332 points were collected over the study area; they were distributed over geomorphological features such as scarps, cracks, blocks, depletion zones and accumulation zones (Fig. 2.2; Chapter 2). Two tree plots were measured, resulting in the terrain height at the location of 101 individual trees. Also a 
number of points were taken to represent the terrain height outside the geomorphological features.

\section{ALS acquisition}

The ALS campaign was carried out under snow-free conditions in July 2009, using a helicopter flying about $300 \mathrm{~m}$ above the ground. An airborne handheld laser scanning system provided by the Helimap company was used. This system has been developed specifically for the mapping over mountainous forested areas (Vallet and Skaloud, 2004). A RIEGL VQ-480 laser scanner with a pulse repetition rate of up to $300 \mathrm{kHz}$ was used to record full waveform laser data. Positioning was done using a Topcon Legacy GGD capable of tracking GPS and GLONASS positioning satellites. The orientation of the aircraft was determined using the iMAR FSAS inertial measurement unit (see Table 3.1 for details). In order to increase the point density seven flight lines were flown resulting in 50 million points. We used last pulse data that amounted to 35 million points with a mean point density of 140 points $\mathrm{m}^{-2}$, which is still far above any commercial application of ALS data.

Table 3.1: Metadata for the airborne laser scanning campaign

\begin{tabular}{ll}
\hline Acquisition (month/year) & July 2009 \\
Laser Scanner & Riegl VQ480i \\
IMU system & iMAR FSAS - record $500 \mathrm{~Hz}$ \\
GPS system & Topcon Legacy - record $5 \mathrm{~Hz}$ \\
Laser pulse repetition rate & $300 \mathrm{kHz}$ \\
Measurement rate & Up to $150000 \mathrm{~s}^{-1}$ \\
Beam divergence & $0.3 \mathrm{mrad}$ \\
Laser beam footprint & $75 \mathrm{~mm}$ at $250 \mathrm{~m}$ \\
Field of view & $60^{\circ}$ \\
Scanning method & Rotating multi-facet mirror \\
\hline
\end{tabular}

\subsubsection{Quantitative assessment of landslide DTM accuracy}

In this study, we evaluated two common filters for bare-earth extraction (Sithole and Vosselman, 2004): hierarchical robust interpolation (HRI) and progressive TIN densification (PTD). Both filters execute automatically without manual editing and work on point clouds directly without gridding the data, so no information is lost by point to grid conversion. We tested the effect of different filter settings and assessed the result quantitatively against field reference data and qualitatively using different visualizations and knowledge from expert image interpreters. 
Parameterization of Hierarchical Robust Interpolation

Robust interpolation was originally developed for ALS data in forested areas (Kraus and Pfeifer, 1998). A hierarchical approach was originally proposed by Pfeifer et al. (2001) and has similar structure to the image pyramids, but the reduction function operates on the laser point data. The HRI method was embedded in SCOP++ software and has the capability to automatically extract points belonging to the ground surface and classify the non-ground points into several classes such as buildings, vegetation and low points.

At three different hierarchical levels that increase in resolution, four steps are carried out to extract ground points: thin out, filter, interpolate, and sort out/classify. In the thin out step, the original data are thinned out to a low density point cloud. A grid is overlaid over the point cloud and for each cell, the lowest or most central point is chosen. In the filter step, a DTM is determined by applying the method of Kraus and Pfeifer (1998), which works by iteratively computing a local average. Weights are based on the residual value relative to the DTM in the previous iteration. The weight function gives a low weight to points with a large residual and high weight to points with a small residual. Fig. 3.1A shows a schematic diagram of a weight function which involves lower and upper branches for parameterization. The weight function has half of its maximum value at $h$ and the weight function is cut off at tolerance, $t$. Next, a new DTM is defined by applying the linear prediction algorithm, and in each step it is compared to the data of a higher resolution. In the sort out step, points within a certain vertical buffer are taken for the next iteration, and others are excluded. For the basic setting, we use $0.25 \mathrm{~m}$ as grid resolution and $0.15 \mathrm{~m}$ for mean accuracy of the point clouds. The value of the mean accuracy is considered by taking into account the mean errors produced by the differential GPS, inertial measurement unit and laser scanner system.

We proposed an iterative approach based on the HRI method, which we will refer to as the landslide filter. This filter is capable of dealing with the complexity of terrain, especially in a rugged forested area for landslide mapping. Besides that, we used two predefined parameterizations embedded in SCOP++, called as a HRI-default filter and a forest filter in this thesis (Table 3.2). The forest filter is suggested for vegetated areas, whereas the HRI-default filter works best for areas with a mix of forest and open terrain. 


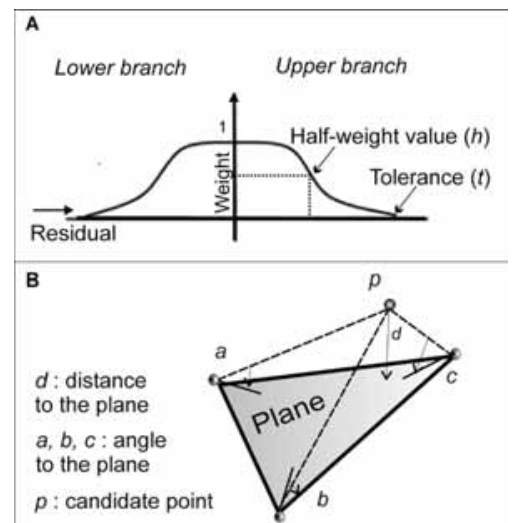

Fig. 3.1: Parameterization of hierarchical robust interpolation (HRI) and progressive TIN densification (PTD) methods. A) Weight function of the HRI method, showing the half-weight value $(h)$ and tolerance $(t)$ for residual calculation. B) Triangle of identified ground points indicate angles $(a, b$, and $c)$ and distance to the plane $(d)$ of the PTD method.

The landslide filter implements the robust interpolation in three schemes. Every scheme uses different parameters for the four steps as mentioned earlier and a number of points within the buffer zone as data input. Herein, buffer zone refers to classified points (points on the ground and the points in between at the certain height of above and below the ground surface). We assume that within the buffer zone, there are ALS points that belong to the landslide diagnostic features such as ALS points on the crown cracks and main scarps beneath the dense vegetation. In the first scheme, non-ground points are filtered out and only those points within $0.45 \mathrm{~m}$ buffer zone (taken from the ground surface to $0.225 \mathrm{~m}$ above and below it) are classified. This improved the estimate of the DTM. Therefore in the subsequent iterations more stringent limits were imposed on the filtering. For example, buffer zones of 0.2 and $0.1 \mathrm{~m}$ are used during the second and third scheme, respectively, and the values of $h$ and $t$ decrease further. By implementing this strategy, the residual to the true DTM becomes increasingly accurate. The DTM was less affected by vegetation or non-ground points for the second and third scheme. Hence, the bare-earth points are classified more accurately and the DTM accuracy is improved. 
Table 3.2: Parameterization of weight functions, thinning output and buffer zones for the landslide filter, forest filter and HRI-default filter

\begin{tabular}{|c|c|c|c|c|c|c|}
\hline \multirow{3}{*}{$\begin{array}{l}\text { Step / } \\
\text { Filter }\end{array}$} & \multicolumn{4}{|c|}{ Filter Step - weight function } & \multirow{3}{*}{\begin{tabular}{|l|}
$\begin{array}{l}\text { Thin out } \\
\text { Step }\end{array}$ \\
$\begin{array}{l}\text { Cell size } \\
(\mathrm{m})\end{array}$ \\
\end{tabular}} & \multirow{3}{*}{$\begin{array}{l}\begin{array}{l}\text { Classify } \\
\text { Step }\end{array} \\
\begin{array}{l}\text { Buffer zone } \\
\text { (m) }\end{array}\end{array}$} \\
\hline & \multicolumn{2}{|c|}{ Upper branch } & \multicolumn{2}{|c|}{ Lower branch } & & \\
\hline & $\begin{array}{l}\text { Half-weight } \\
(\mathrm{m})\end{array}$ & \begin{tabular}{|l|}
$\begin{array}{l}\text { Tolerance } \\
(\mathrm{m})\end{array}$ \\
\end{tabular} & $\begin{array}{l}\text { Half-weight } \\
(\mathrm{m})\end{array}$ & $\begin{array}{l}\text { Tolerance } \\
(\mathrm{m})\end{array}$ & & \\
\hline & \multicolumn{6}{|c|}{ First Hierarchy } \\
\hline \multicolumn{7}{|l|}{ Landslide filter } \\
\hline $1^{\text {st }}$ Scheme & 0.80 & 2.40 & - & 3.60 & 3 & 0.45 \\
\hline $2^{\text {nd }}$ Scheme & 0.56 & 1.68 & - & 2.52 & 3 & 0.20 \\
\hline $3^{\text {rd }}$ Scheme & 0.40 & 1.20 & - & 1.80 & 3 & 0.10 \\
\hline Forest filter & 0.80 & 2.40 & - & 3.60 & 6 & 0.45 \\
\hline HRI-default filter & 0.80 & 2.40 & - & 3.60 & 3 & 0.45 \\
\hline & \multicolumn{6}{|c|}{ Second Hierarchy } \\
\hline \multicolumn{7}{|l|}{ Landslide filter } \\
\hline $1^{\text {st }}$ Scheme & 0.30 & 0.90 & 1.20 & 1.20 & 2 & 0.45 \\
\hline $2^{\text {nd }}$ Scheme & 0.21 & 0.63 & 0.84 & 0.84 & 2 & 0.20 \\
\hline $3^{\text {rd }}$ Scheme & 0.15 & 0.45 & 0.60 & 0.60 & 2 & 0.10 \\
\hline Forest filter & 0.30 & 0.90 & 1.20 & 1.20 & 3 & 0.45 \\
\hline HRI-default filter & 0.30 & 0.90 & 1.20 & 1.20 & 2 & 0.45 \\
\hline & \multicolumn{6}{|c|}{ Third Hierarchy } \\
\hline \multicolumn{7}{|l|}{ Landslide filter } \\
\hline $1^{\text {st }}$ Scheme & 0.15 & 0.30 & 0.23 & 0.45 & 0.25 & 0.45 \\
\hline $2^{\text {nd }}$ Scheme & 0.11 & 0.30 & 0.16 & 0.45 & 0.25 & 0.20 \\
\hline $3^{\text {rd }}$ Scheme & 0.08 & 0.30 & 0.11 & 0.45 & 0.25 & 0.10 \\
\hline Forest filter & 0.15 & 0.30 & 0.23 & 0.45 & 0.25 & 0.45 \\
\hline HRI-default filter & 0.15 & 0.30 & 0.23 & 0.45 & 0.25 & 0.45 \\
\hline
\end{tabular}

\section{Parameterization of Progressive TIN Densification}

The PTD method was developed by Axelsson (2000). It has been implemented in the Terrascan software and operates on point data. Starting with a sparse TIN, based on neighbourhood minima, the TIN is progressively densified to represent more local detail. In each iteration, points are added to the existing TIN if they are below predefined thresholds. The thresholds are determined on the basis of the angle points $(a, b, c)$ of the TIN facets and the distance $(d)$ to the plane (Fig. 3.1B). The procedure to add candidate points $(p)$ to the TIN is done continuously until all points exceed the thresholds. Parameterization of PTD consists of the selection of the maximum slope of the study area, the lowest points in a large grid, the maximum number of iterations for distance and angle to the plane, and threshold for the edge length. This predefined parameterization will be referred to as PTD filter.

Due to the use of local minima, the PTD method is sensitive to below terrain blunders, which need to be removed before filtering. We removed all blunders points, defined as points with the next lowest points within the local window. Points $0.5 \mathrm{~m}$ lower than any neighbouring point within a $5 \mathrm{~m}$ radius are used. We set the maximum slope angle to $86^{\circ}$, the iteration angle to $10^{\circ}$, and the distance to the plane to $1.5 \mathrm{~m}$. For the iteration angle, the edge length was set to less than $5 \mathrm{~m}$ in order to avoid adding unnecessary points 
and to reduce the use of memory and computation time. These choices are based on point density and terrain characteristics over the study area.

Quantitative error assessment

The vertical accuracy of the different DTMs was first determined by computing the RMSE (root mean square error) between field points and a DTM as defined in Eq. (3.1):

$$
R M S E=\sqrt{\frac{\sum_{i=1}^{n}\left(Z_{\mathrm{GPS}_{i}}-Z_{\mathrm{ALS}}\right)^{2}}{n}}
$$

where $n$ is the number of field reference points, ZGPS are the terrain heights of points measured by GPS, ZALS are the predicted heights from the terrain model. RMSE was calculated for forested and open terrain and in both cases a further subdivision was made for scarps, cracks, rocks and ground surface. In addition, the DTM was evaluated under dense canopy at the locations of the tree plots. This procedure was applied to the DTMs derived from the four different filters.

The effect on the spatial representation of the four different DTM filters was assessed by computing the differences between the results from the landslide filter and the other filters. The last quality aspect evaluated is the density analysis of filtered points. The point density of the ground points is computed based on the average number of points within one square meter.

\subsubsection{Qualitative assessment of DTM interpretability}

The qualitative assessment of the ALS-derived DTMs produced by the different ALS filtering parameterization was carried out in two ways. Firstly, we assessed the interpretability of geomorphological features on a hybrid DTM. A hybrid DTM consists of a regular grid, intermeshed with break lines, form lines, border lines and spot heights (SCOP++, 2008). Such DTMs have been used in many landscape studies, (e.g. Hollaus et al., 2006; Szekely et al., 2009). We assessed the interpretability of cracks, scarps, rock blocks, depletion zones and accumulation zones.

Secondly, we asked three expert interpreters to evaluate the interpretability of the different DTMs. The DTMs were provided to the expert image interpreters without informing them on the applied filtering methodology. The evaluation was done on the basis of a stereoscopic model and shaded relief images. The interpretability of different DTMs was rated based on the degree of morphological appearance and a landslide inventory map was created using DTM that was rated highest. The image interpretation was done using a 
screen visualization technique with 3D anaglyph glasses. A landslide map indicates the outlines of geomorphological units, roads, cracks, drainage network, and landslide activity.

\section{Visualization in 2D}

The interpretability of the images depends on the DTM visualization techniques. Here we compared four different visualization techniques based on a gridded DTM with a $0.25 \mathrm{~m}$ cell size.

- Shaded relief map (Horn, 1981). This technique applies an azimuth of $310^{\circ}$ and an altitude of $40^{\circ}$ for the sun's position.

- Color composite map (Smith and Clark, 2005). It is based on three shaded relief images with an azimuth in the West, North-West and North direction. Linear stretching was applied to the image.

- Openness map (Yokoyama et al., 2002). This technique generates an angular measure of surface form, unbiased from solar irradiation. It is computed from the zenith and nadir angles along eight DTM azimuths. Positive and negative openness indicates the convex and concave features of topography, respectively.

- Red relief image (Chiba et al., 2008). This technique produces a red image by adjusting the chrome value of red on the topographic slope and its brightness on the openness value. This image was prepared by Asia Air Survey Co. Ltd. using openness distance of 10 times of the grid resolution size of $0.25 \mathrm{~m}$ to optimize the visualization.

\section{Visualization in 3D}

Two types of 3D visualization were also produced and evaluated. The two 3D visualizations are one static and one dynamic presentation. Visualization in three dimensions was carried out using the following two techniques:

- Stereoscopic model (Smith and Clark, 2005). A shaded relief and openness map and the DTM have been used to generate a stereoscopic view of the area.

- 3D point cloud visualization (Vosselman and Klein, 2010). This visualization technique offered a dynamic representation of the 3D point cloud as implemented in the Quick Terrain Modeler software version 7.1. The high density point clouds can visualize the representation of the relief and disrupted trees affected by landslides.

Analysis of ALS point density for landslide recognition

In this study, the point density of all ALS data was 140 points $\mathrm{m}^{-2}$. We have checked landslide interpretability of the ALS data at different point densities. The ground point dataset with an average of 53 points $\mathrm{m}^{-2}$ was thinned out progressively to derive eight data sets. The initial density was substantially 
reduced to end up with a density that is commonly used for generating ALSderived DTMs. The eight datasets were categorized based on point grouping that have been used as thinning strategy. Horizontal distance of $0.25,1,3$, $5,7,9,11$ and $13 \mathrm{~m}$ were used during the point grouping routine. At each thinning level, all the points within the given horizontal distance were grouped, and the thinning process stops after all the points were grouped. Next, the central points in each group were also selected for the thinning dataset. This process was done using the algorithm implemented in Terrascan software. The eight datasets have point densities varying between 1.69 and 27.20 points $\mathrm{m}^{-2}$.

Each thinned dataset was used to create a $1 \mathrm{~m}$ resolution DTM by using a natural neighbour interpolation technique. This interpolator is suitable to deal with rough terrain and is an essential step for the recognition of the morphological features (Pirotti and Tarolli, 2010). The original DTM and the eight thinned ALS-derived DTMs were given to expert-image interpreters for suitability assessment. Diagnostic morphological features have been checked for this assessment in order to examine the suitability of ALS point density for landslide recognition. This assessment is informative for the users who want to order and use the ALS data for mapping landslides beneath vegetation.

\subsection{Results}

This study aimed at evaluating the use of various ALS-derived DTMs for landslide mapping and identification of morphological features of landslides. The main results are presented and discussed in this section.

\subsubsection{Quantitative assessment}

The vertical accuracy of the four produced DTMs varied between 0.28 and $0.87 \mathrm{~m}$ compared to the field data and depended on the different morphological features and the applied filters (Table 3.3). For all morphological features the PTD filter outperformed the filters based on HRI with RMSE being lower than that for the best HRI parameterization by 0.02 to $0.04 \mathrm{~m}$. The landslide filter showed the best results of the different HRI parameterizations. The errors for cracks and scarps were lower when no vegetation was present, but for rock blocks RMSE values were comparable between the open and forested terrain. The two tree sampling plots also showed the PTD as the best filter and the landslide filter as the best HRI parameterization (Table 3.4). 
Table 3.3: Quantitative assessment of the vertical accuracy of morphological landslide features with different filter parameterization. Units are in meters

\begin{tabular}{|c|c|c|c|c|c|c|c|c|}
\hline & \multicolumn{2}{|c|}{ Cracks } & \multicolumn{2}{|c|}{ Scarps } & \multicolumn{2}{|c|}{ Rocks } & \multicolumn{2}{|c|}{$\begin{array}{l}\text { Ground } \\
\text { surface }\end{array}$} \\
\hline & No. & RMSE & No. & RMSE & No. & RMSE & No. & RMSE \\
\hline \multicolumn{9}{|l|}{ Open terrain } \\
\hline Landslide filter & \multirow{4}{*}{5} & 0.33 & \multirow{4}{*}{5} & 0.40 & \multirow{4}{*}{18} & 0.33 & \multirow{4}{*}{94} & 0.34 \\
\hline Forest filter & & 0.33 & & 0.39 & & 0.39 & & 0.35 \\
\hline HRI-default filter & & 0.33 & & 0.87 & & 0.41 & & 0.35 \\
\hline PTD filter & & 0.29 & & 0.36 & & 0.32 & & 0.31 \\
\hline \multicolumn{9}{|l|}{ Forested terrain } \\
\hline Landslide filter & \multirow{4}{*}{35} & 0.38 & \multirow{4}{*}{12} & 0.51 & \multirow{4}{*}{9} & 0.38 & \multirow{4}{*}{53} & 0.33 \\
\hline Forest filter & & 0.38 & & 0.51 & & 0.37 & & 0.34 \\
\hline HRI-default filter & & 0.38 & & 0.51 & & 0.38 & & 0.34 \\
\hline PTD filter & & 0.35 & & 0.50 & & 0.31 & & 0.28 \\
\hline
\end{tabular}

Table 3.4: Quantitative assessment of the vertical accuracy of vegetation features with different filter parameterization. Units are in meters

\begin{tabular}{|lcccc|}
\hline & \multicolumn{3}{l}{ Tree - Plot A } & \multicolumn{2}{l|}{ Tree - Plot B } \\
\cline { 2 - 5 } & $\begin{array}{l}\text { Number of } \\
\text { points }\end{array}$ & $\begin{array}{l}\text { RMSE } \\
\text { (meter) }\end{array}$ & $\begin{array}{l}\text { Number } \\
\text { of points }\end{array}$ & $\begin{array}{c}\text { RMSE } \\
\text { (meter) }\end{array}$ \\
Landslide filter & & 0.34 & & 0.36 \\
Forest filter & 22 & 0.40 & 79 & 0.37 \\
HRI-default filter & & 0.41 & & 0.37 \\
PTD filter & & 0.32 & & 0.33 \\
\hline
\end{tabular}

Fig. 3.2 shows a line profile extracted from the DTMs produced by the four filters over an area covering crown cracks, main scarps and vegetated terrain. The location of the line profile ( $\left.a-a^{\prime}\right)$ is shown in Fig. 2.2 (Chapter 2). This area was delineated by the interpreters as a recent slide clearly showing an active scarp and crown cracks on the image. Nine GPS points were collected here for validation. The landslide filter worked well for this area by preserving the crack on the upper scarp and the terrain morphology on the area below the scarp. The PTD filter showed a smoothening effect but still followed the roughness of the ground surface. In contrast, the forest and HRI-default filters still contain about ten points on the vegetation which was not properly filtered out (Fig. 3.2).

The original point density of last pulse data was 140 points $\mathrm{m}^{-2}$. The point density of the ground points varied between 22 points $\mathrm{m}^{-2}$ and 76 points $\mathrm{m}^{-2}$ depending on the filters (Table 3.5). The point density of the filtered data using parameterization of the landslide filter was about 52 points $\mathrm{m}^{-2}$, and $64 \%$ of the point cloud was filtered out during the automatic filtering process. For the second and third scheme of the landslide filter, the number of points was reduced to $46 \%$ and $36 \%$ of the original data. Point density of extracted ground points using the forest and HRI-default filters are about 76 points $\mathrm{m}^{-2}$ and 75 points $\mathrm{m}^{-2}$, respectively. In contrast, point density analysis of the PTD 
method shows that the ALS points were reduced by $85 \%$ after the filtering process. Less ground points resulting from the PTD filter led to insufficient points to represent the diagnostic landslide morphological features and thus, produce less accurate landslide DTM for forested landslide recognition.

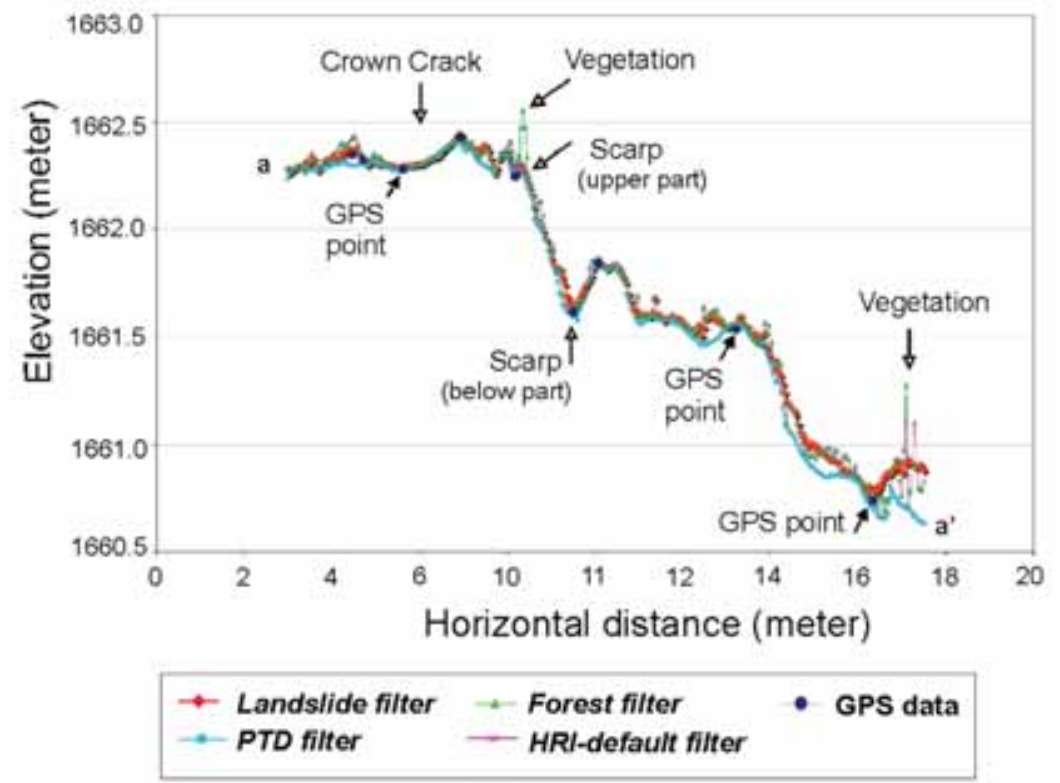

Fig. 3.2: Profile through the study area showing the results of the four filters together with the GPS measurements over a complex area. Location of line profile $(a-a)$ is shown in Fig. 2.2 (Chapter 2).

The differences between the DTMs generated by the landslide filter and the other filters were computed to evaluate the spatial effect of the different filters (Fig. 3.3). The major height difference between the landslide and PTD filters were mostly found over the zone of depletion as depicted in the two subset area in Fig. 3.3A. It shows that the landslide filter preserves small scale morphological features on such areas better than the PTD filter. In Figs. 3.3B, C, height differences between the landslide filter and both default filters indicate that most of the active landslide areas show altitude differences up to $0.15 \mathrm{~m}$, whereas, in forested area, the height difference is up to $0.30 \mathrm{~m}$. Significant height differences also showed up in areas with a higher slope and along the stream incisions. Consequently, the Figs. 3.3B,C show more points that are not completely filtered out over open terrain and forested area. 

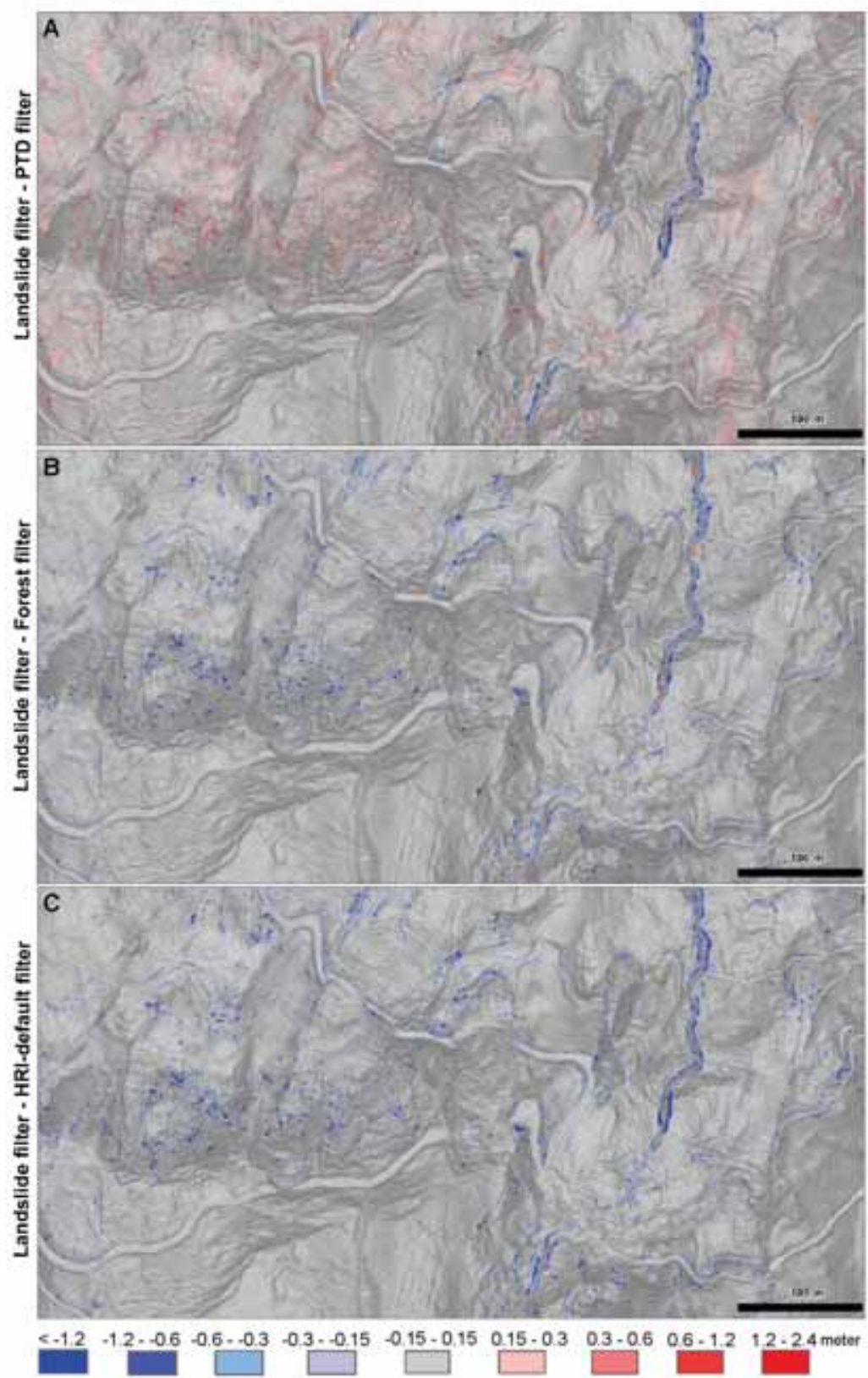

Fig. 3.3: Height differences between terrain models generated from the landslide filterand A) PTD filter, B) forest filter and C) HRI-default filter. Positive values indicate that the DTM from the landslide filter is higher than the one from the other filter. 
Table 3.5: Point density of ALS ground points extracted using four different filters

\begin{tabular}{|l|l|l|}
\hline & $\begin{array}{l}\text { ALS data input } \\
\text { (million points) }\end{array}$ & $\begin{array}{l}\text { Filtered ground points } \\
\text { (average points } \mathrm{m}^{-2} \text { ) }\end{array}$ \\
\hline Landslide filter & & \\
First Scheme & 35.1 & 75 \\
Second Scheme & 19.2 & 68 \\
Third Scheme & 18.9 & 53 \\
\hline Forest filter & 35.1 & 76 \\
\hline HRI-default filter & 35.1 & 75 \\
\hline PTD filter & 35.1 & 22 \\
\hline
\end{tabular}

\subsubsection{Qualitative assessment of ALS-derived DTMs}

The qualitative analysis on the generated DTMs by different filtering parameter settings was carried out based on shaded relief images of the hybrid DTM model as shown in Fig. 3.4. The reference image is the terrain model generated by the landslide filter. Fig. 3.4A presents an area with a number of shallow cracks in the terrain. Each of the filters was capable of identifying the cracks although the HRI-default filter and the forest filter still showed some vegetation that was not properly filtered out. Fig. 3.4B indicates that the landslide and PTD filters were slightly better in eliminating trees compared to the other two filters. The accumulation zones in the complex landslide can be recognized on each of the filter products. The displaced material and the disrupted road are seen on the subset images (Fig. 3.4C). In Fig. 3.4D, the landslide filter shows slightly better results than the other filters for an escarpment area. However, as can be seen in Fig. $3.4 \mathrm{E}$, the trade-off for the good performance is that both the landslide and PTD filters were worse for detecting isolated rock blocks in the area. The PTD filter also showed a smoothening effect due to insufficient ground points over the test area.

\subsubsection{Expert interpretations of DTMs}

The three experts on image interpretation that evaluated the results from the various filters agreed that the ALS-derived image generated using the landslide filter was the best for landslide interpretation. The PTD-derived DTM showed less information over the deposition and accumulation zones, whereas, the forest and HRI-default filters are not completely filter out the trees. 


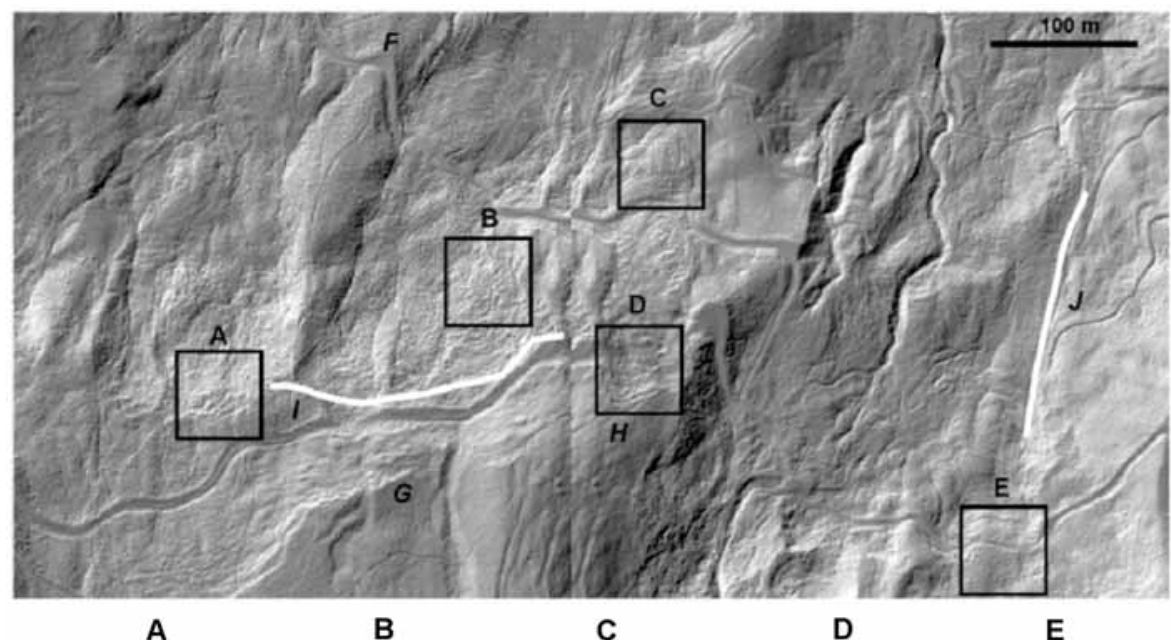

Cracks Depletion zone Accumulation zone Scarps Rock blocks
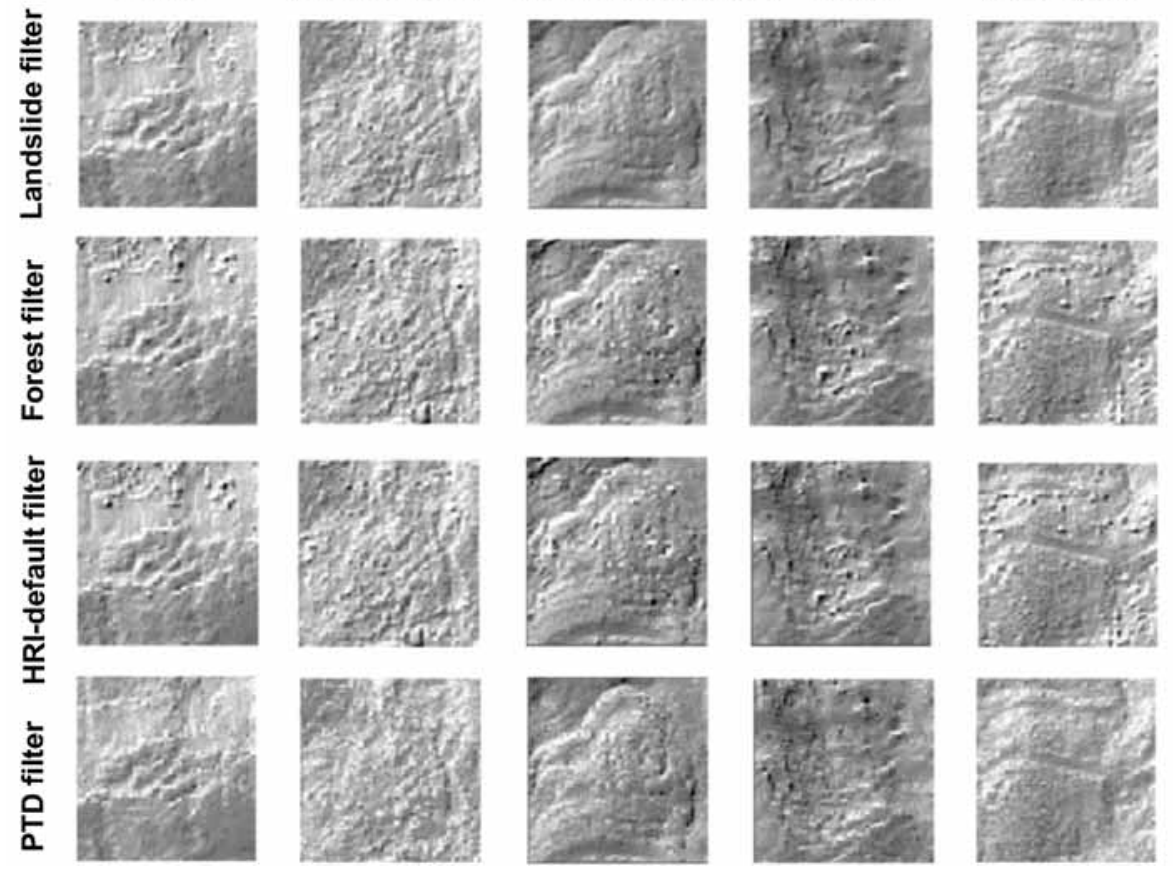

Fig. 3.4: Examples of the representation of the shaded relief images from hybrid DTM models from the four filters for different landslide features. See text for explanation.

Fig. 3.5 shows the diagnostic features of landslides on openness images derived from DTM constructed with the landslide filter. The presence of clear cracks (A), semicircular niches followed by concave slopes (B), flow lobes 
with concentric patterns (C), hummocky terrain (D) and several secondary geomorphological features can be clearly observed. The recognition of small cracks might be the best feature that can be interpreted from these images, which provides additional information as compared to the interpretation of optical images (e.g. aerial photos or satellite images). The forest cover hides most of these landslide features, except for the few active zones, and makes the interpretation of the landslides very difficult from optical images.

Mapping landslide types is also possible, since the diagnostic features were interpretable on the images with a spatial resolution of $0.25 \mathrm{~m}$. Most of the landslides in the study area had a source area where cracks were developed with a radial pattern, followed by a rotational landslide scarp (Fig. 3.5B). Most of the landslides are flow-type slides, and the landslide rigid body turned progressively into a flow-type body characterized by lobes with concentric ridges and cracks (Fig. 3.5C). There were also indications of mass flows that reached less steep slopes and that could not extend laterally, producing pressure ridges with higher elevations, and large cracks in the upslope part (Fig. 3.5F). Another clear feature indicating flow-type behaviour was found in the East of the study area, where the mass flow of a larger landslide that enters the area from the South was separated from the surrounding terrain with lateral ridges (Fig. 3.5E).

The classification of landslide activity is more difficult based on only monoscopic images of filtered ALS data. As the information on vegetation characteristics was removed, it is not possible to use the presence of disrupted vegetation as a possible diagnostic feature. It is advisable to combine the interpretation of ALS-derived images with aerial photographs to get the best results. One of the best features that can be used in this case was the state of the roads and tracks that pass through the area. Interrupted roads (Fig. 3.5J) can be found in several places indicating recent landslide activity that took out the road surface. Also the downslope movement of the road surface on a landslide (Fig. 3.5K) was a clear diagnostic feature. The freshness of landslide features can only be used to classify the landslide in different classes of activity and relative age, although in this area most of the features appear rather fresh indicating that the entire area has been subjected to landslide activity very recently (Lopez Saez et al., 2011). 


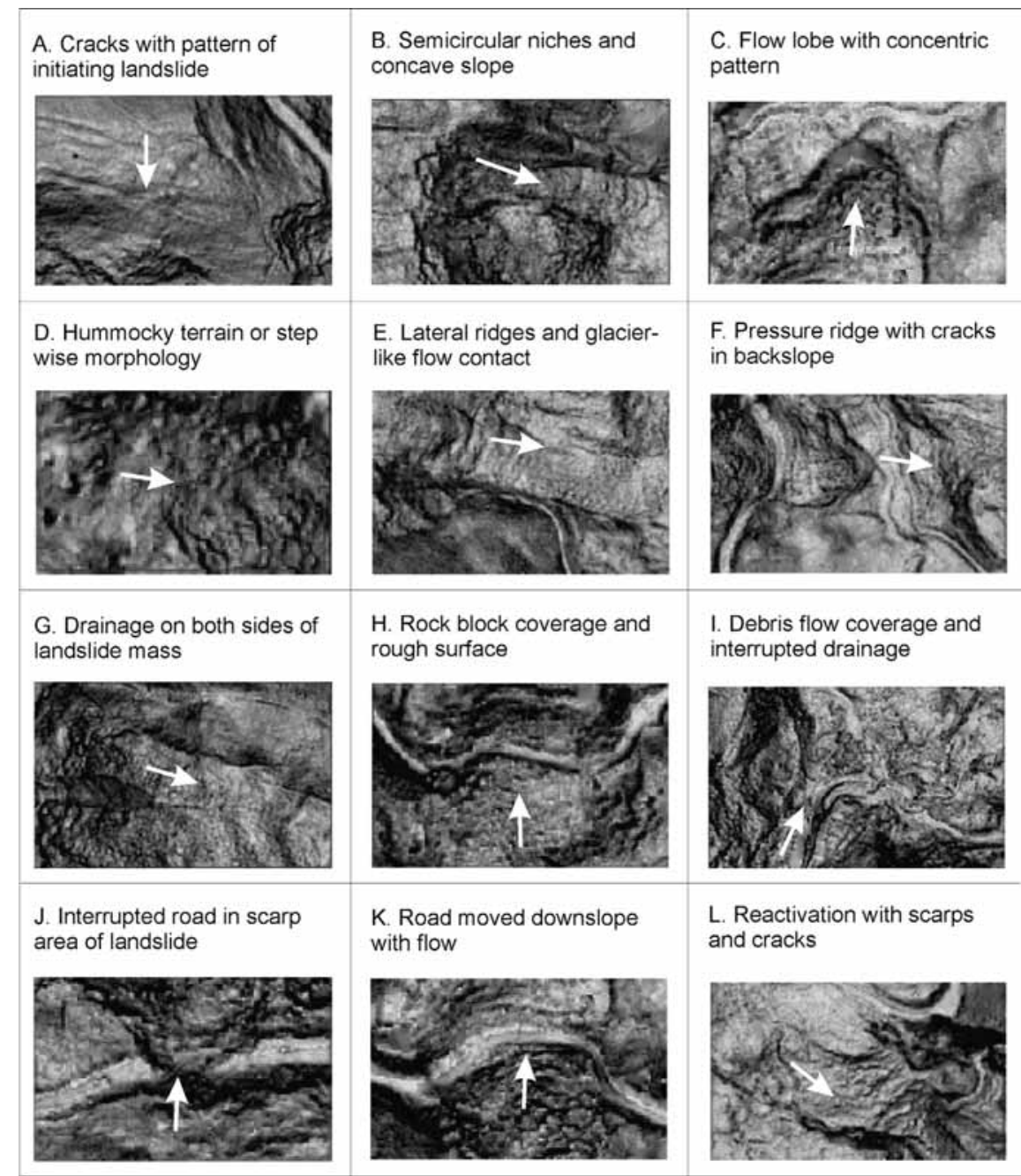

Fig. 3.5: Diagnostic features for the interpretation of landslide type and activity using the openness image from ALS, as indicated by expert image interpreters. The white arrows indicate the direction of landslide movement.

With the help of the openness map it was possible to map out the various phases of landslide activity, as many features were intersected by scarps and flow patterns of more recent events. This allowed the reconstruction of the various phases of landslide activity. The interpretation indicates that the landslide history has been very complex with many phases of mass flows that overlap or are reactivated (Fig. 3.5L). There are a number of aspects that are still unclear in the image and need further evaluation. This is partly because the image is covering part of a larger landslide complex (Bois Noir) and that 
there are features of older landslide phases which can only be properly interpreted when a larger area is evaluated.

A complete geomorphological interpretation of the sample area is presented in Fig. 3.6. One of the questions that remained after interpreting the images is whether a number of ridge features ( $F$ and $G$ in Fig. 3.4) have a structural geological control (for instance showing the bedding or the main local discontinuity of the underlying rocks) or are related to older landslide features. Given the importance of landslides in the area and the relatively large depth of the landslide features, it is more likely that these ridges are related to larger scale instability that can only be interpreted well when looking at the image of the entire Bois Noir landslide slope segment. Also the relationship between the most recent landslide activity and larger scale instability features ( $H$ in Fig. 3.4) should be further investigated. It appears that the recent landslide near $H$ is actually occurring in a landslide block that is located directly upslope. The line of reactivation ( $I$ in Fig. 3.4) seems to be related to an older landslide mass coming from upslope, as well as the large glacier-like flow structure ( $J$ in Fig. 3.4). The area between $H$ and $J$ is considered as a large flow accumulation which has had several stages of reactivation.

The landslide inventory map (Fig. 3.6) was prepared by the expert interpreters. The map combines the relative age of the landslides with morphological features and the landslide types. The areas indicated as "nonlandslide area" are the side slopes and ridges between the landslide masses. They could be part of a larger, and older, landslide complex, but this can only be interpreted from images of a larger area. The source area is characterized by a large density of small cracks. They appear upslope of the actual active landslide area. The active landslides appear in a linear zone, probably related to a step in a larger landslide complex, and seriously affect the forest road in four places, two times in the scarp area and two times in the accumulation area of the active landslides. The eastern part of the area consists of a large mass flow, which is reactivated in several places. 


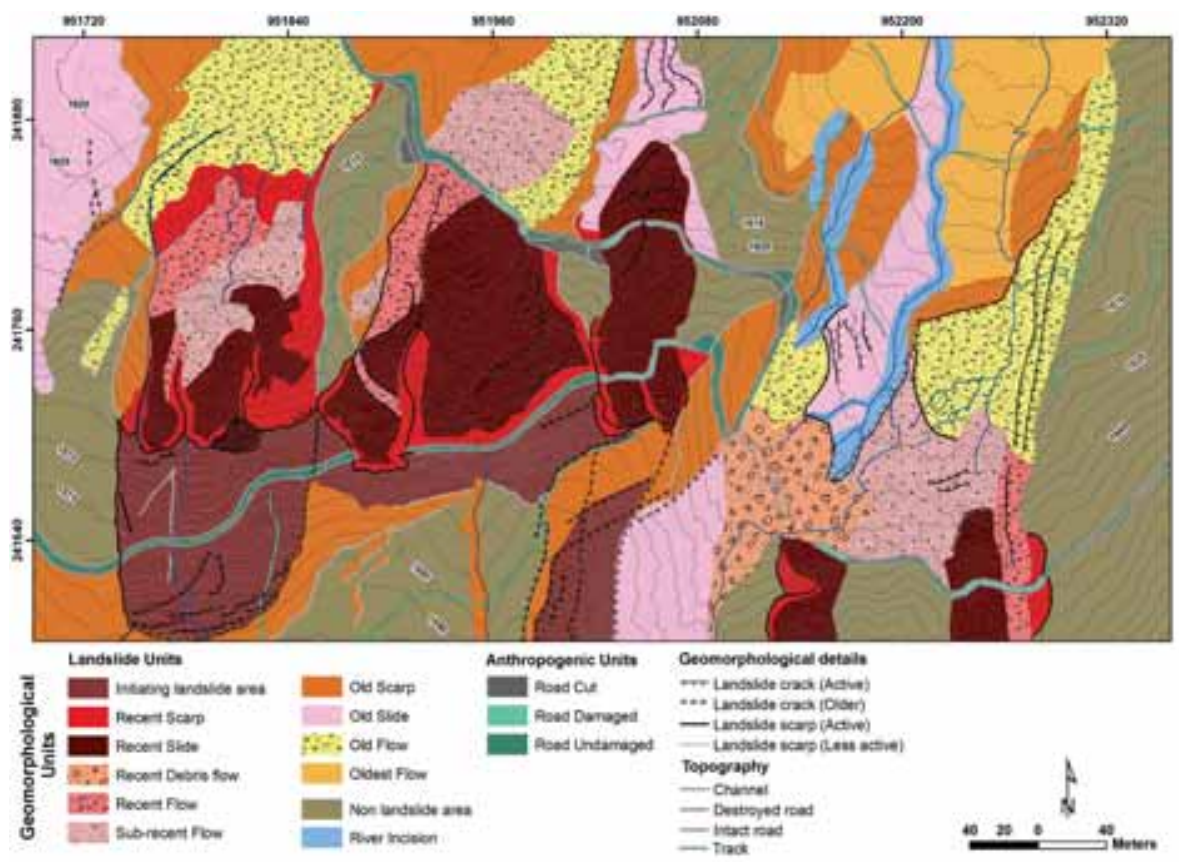

Fig. 3.6: Geomorphological map with classification of landslides created by the expert image interpreters.

\subsubsection{Visualization methods}

The different 2D visualisations of the study area are presented in Fig. 3.7. The shaded relief image is less effective in highlighting micro-morphological features and it is difficult to identify features that occur parallel to the source areas of the landslides due to the illumination direction. This image requires a directional light source. The colour composite technique significantly improves the quality of the image in terms of visibility of some morphological features such as flow pattern and hummocky topography. The openness image is recognized by the image interpreters to be more appropriate for landslide visualization.

Based on the qualitative assessment carried out on monoscopic images by expert image interpreters, many more macro- and micro-morphological features can be found on the openness map compared to the shaded relief map. The red relief image has similar interpretability as the openness map, but the image interpreters found the overall red colour to be disturbing in the image interpretation process. Small details are visible in the scarps and accumulation zone. 

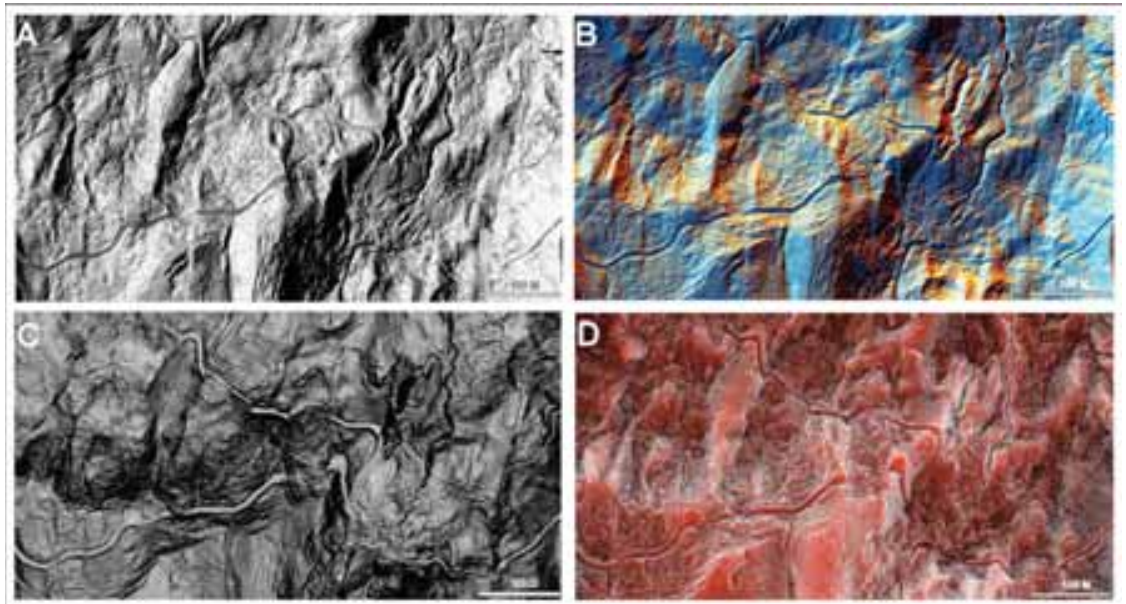

Fig. 3.7: Illustrations of the various visualization methods used for landslide interpretation. A) Shaded relief map. B) Colour composite map. C) Openness map. D) Red relief image map.

The 3D visualisations of the non-filtered and filtered datasets are shown in Figs. 3.8 and 3.9. The stereoscopic model presented as an anaglyph in Fig. 3.8A shows that most of the landslide morphologies are hidden beneath dense vegetation, whereas geomorphological features under forest are clearly seen in Fig. 3.8B. Fig. 3.9A presents 34.2 million points cloud over the nonfiltered dataset, whereas 9.2 million points represent the ground points are depicted in Fig. 3.9B. It presents the scarps that were forming in the rough terrain. However, for landslide interpretation the 3D point cloud representation is less useful than the anaglyph images produced from the openness image.

\subsubsection{Effect of ALS point density on landslide recognition}

The thinned out data sets ranged from a point density of 1.69 to 27.20 points $\mathrm{m}^{-2}$ (Table 3.6). Fig. 3.10 shows a detail of the Bois Noir area, visualized as openness images. Three datasets are shown, the original, and thinned out data sets at levels 3 and 8 . The visual assessments by experts started on the dataset with level 8 then followed by the other levels including the original dataset. The experts all agreed that the thinned dataset could be used to recognize the major geomorphological indicators of landslide activity. However, in order to differentiate the minor relief, recognize individual landform and properly assess the landslide activity, point densities at level 13 are required. 


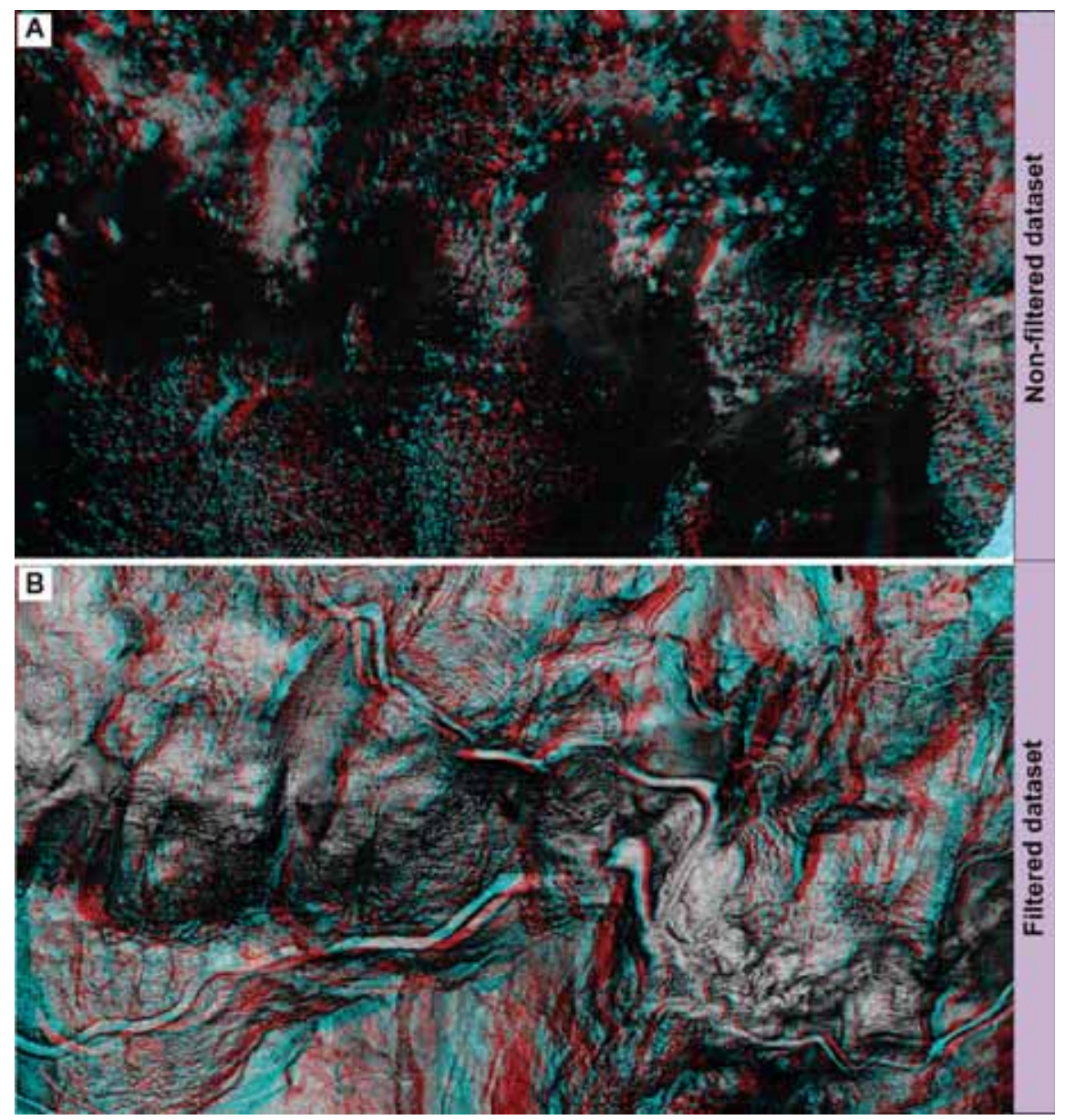

Fig. 3.8: Stereoscopic models of non-filtered and filtered dataset. A) Anaglyph image showing dense vegetation covered the landslide area. B) Digital terrain model visualized as an openness image showing the morphology of forested landslides. Both images need to view with red-blue anaglyph glasses. 


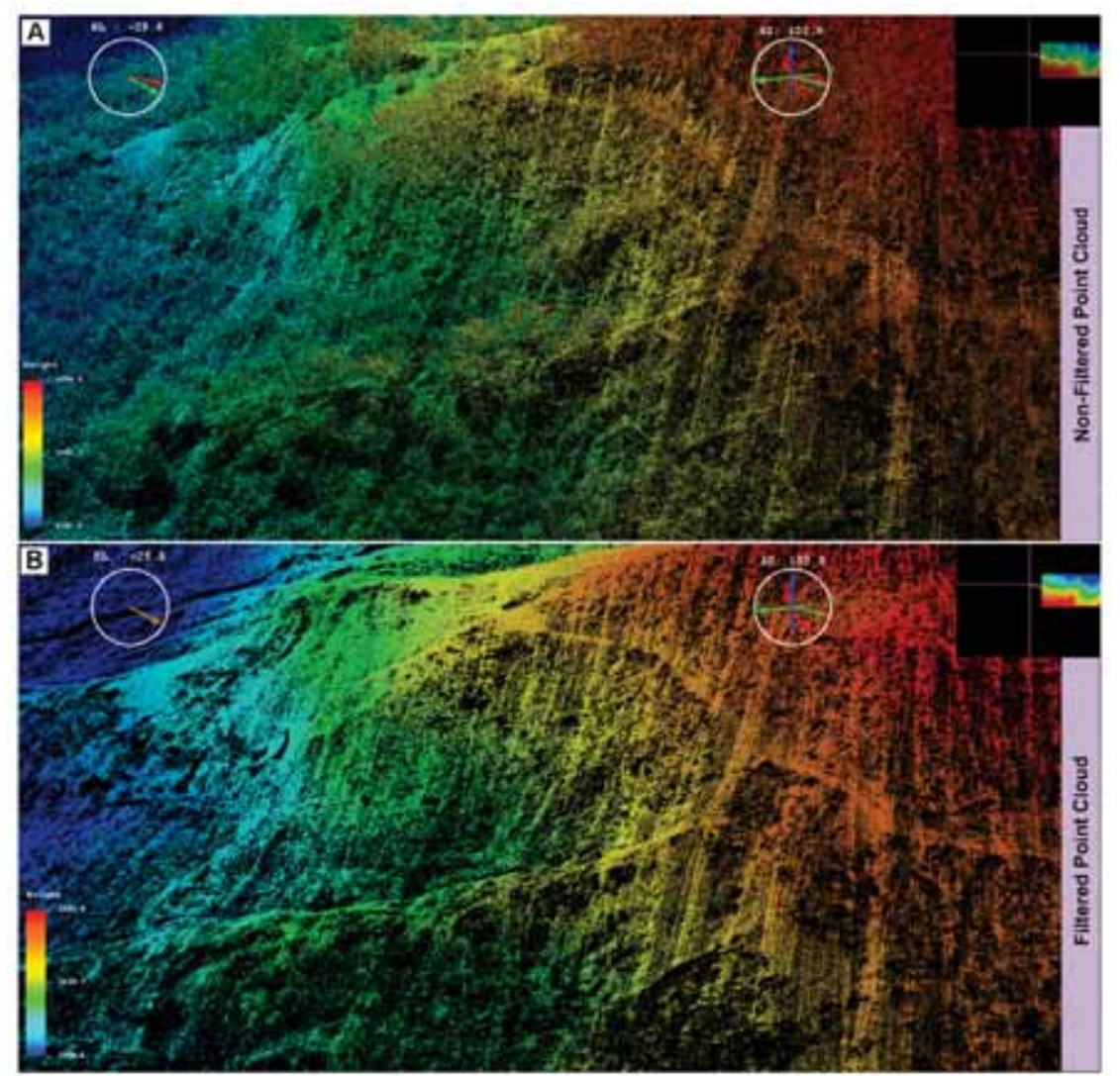

Fig. 3.9: 3D point cloud visualization of Bois Noir landslide in France. A) 34.2 million points cloud represents the non-filtered dataset. B) Filtered ground points resulting in 9.2 million points cloud over the complex landslides.

Table 3.6: Thinning data with different average point density for landslide mapping. The original points are 12.6 million points with point density 53 points $m-2$

\begin{tabular}{clccc}
\hline & $\begin{array}{c}\text { Thinning } \\
\text { Level }\end{array}$ & $\begin{array}{c}\text { Horizontal distance } \\
\text { (meter) }\end{array}$ & $\begin{array}{c}\text { Average point density } \\
\left(\text { points } \mathrm{m}^{-2}\right)\end{array}$ & $\begin{array}{c}\text { No. of points } \\
\left(\mathrm{x} 10^{6}\right)\end{array}$ \\
\hline 1 & 0.25 & 27.20 & 6.50 \\
2 & 1 & 12.37 & 2.96 \\
3 & 3 & 5.69 & 1.36 \\
4 & 5 & 3.80 & 0.91 \\
5 & 7 & 2.84 & 0.69 \\
6 & 9 & 2.32 & 0.55 \\
7 & 11 & 2.00 & 0.46 \\
8 & 13 & 1.69 & 0.40 \\
\hline
\end{tabular}



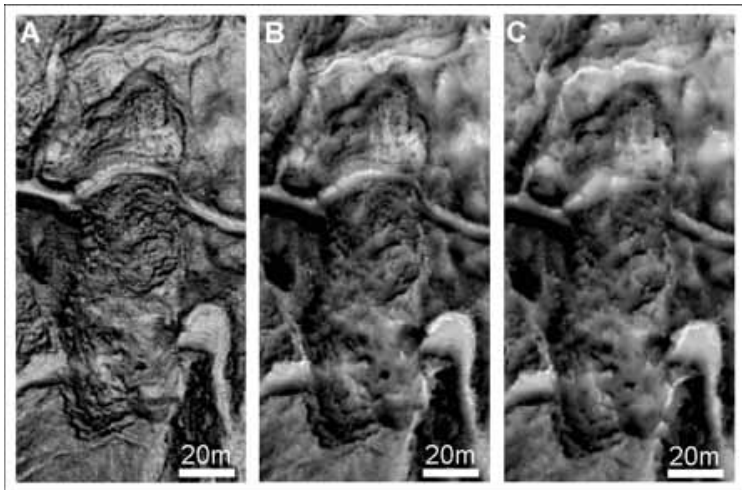

Fig. 3.10: Three examples of an openness map made from different point densities. A) Original dataset. B) Thinned level 3. C) Thinned level 8 (See also Table 3.6 for explanation of thinning levels).

\subsection{Discussion and conclusions}

In this study, we evaluated the suitability of various types of ALS-derived DTMs for mapping landslides and for identifying morphological features of landslides. We used a quantitative measure for expressing the accuracy of the landslide DTMs based on ALS data and we investigated the usefulness of different visualisation techniques on the interpretability of the landslide morphology. The vertical accuracy of the DTM varied between 0.28 and 0.36 $\mathrm{m}$ for the PTD filter. The accuracy depends on the types of geomorphological features. Our results are an improvement in accuracy compared to the previous studies that reported $0.57 \mathrm{~m}$ (Kraus and Pfeifer, 1998) and $0.46 \mathrm{~m}$ (Hodgson et al., 2003) vertical error over forested area. Reutebuch et al. (2003) and Wang and Glenn (2009) reported similar results for sloping forested terrain.

The results from the different filter parameterizations of the HRI method were slightly less accurate, but still in the range between 0.30 and $0.40 \mathrm{~m}$. The PTD filter yielded slightly lower RMSE than the landslide filter: about 0.28 and $0.33 \mathrm{~m}$ for morphological preservation and elimination of the trees, respectively. However, the landslide filter showed a better visualization for landslide recognition as indicated by expert image interpreters.

Pfeifer and Mandlburger (2009) stated that the evaluation of an ALS-derived DTM under forest is difficult and expensive because it requires a higher precision of the ground control points than the ALS dataset and that reference points should be well distributed over the study area. In this work, we succeeded however to carry out a thorough accuracy assessment. Under a dense canopy, the GPS signal was indeed too weak for a few cases to reach 
a high accuracy. We solved this problem by linking measurements acquired by a total station to GPS points outside the forest canopy.

The interpretation of slope movements from the ALS-derived DTM is based on the recognition or identification of elements associated with slope movements and the interpretation of their significance to slope instability. The ALSderived DTM offers a significant improvement for landslide recognition and classification in forested terrain, as compared to optical images. Small morphological features, such as cracks, lateral ridges, pressure ridges and step wise morphology are clearly recognizable and gives the image interpreter unprecedented detail. Also the type of landslide is easily recognized from the detailed DTM.

The trade-off between the four different filters is that trees were properly filtered out in the landslide and PTD filters, but rock blocks and the edges of incised channels are also filtered out. The HRI-default and forest filters maintained more of the trees, rock and channel edges. This trade-off is not shown in the accuracy assessment, but only showed up while interpreting the gridded DTM. This suggests that the HRI method with landslide filter parameterization would be a good method for DTM extraction of forested landslides, but that a separate filter should be applied when there is an interest in rock blocks and step edges.

The assessment of landslide activity was more difficult using just the DTM. This could be done much better if two ALS datasets were available from two different periods. Vegetation characteristics are important indicators of activity and these are normally obtained from aerial images. However, also with high density ALS data the distribution pattern of irregular trees can be a good indicator for assessing landslide activity. The shape of the tree stem and the orientation of the tree may also be influenced by landslides. Backtilting of trees indicate a rotational slide, whereas bended stems indicate slow motion of the top soil. These topics are currently being investigated.

While differences in the RMSE values differed little between the filters, the method of visualisation had a large effect on the interpretability of the landslide. A stereoscopic model was used to visualize the landslides. The 3D view of the landscape gave a much stronger impression of the landscape dynamics than any of the monoscopic images. The interpretability of the 3D point cloud visualization was also less attractive than the stereo image due to the varying point densities across the area. For vegetation assessment the raw point cloud would be superior as at such a high point density the shape of the tree is clearly recognizable. The openness image showed most of the details in the area. It has a more natural view than the composite image and has the added advantage that the openness can be combined in a 
stereoscopic view as it is monochromatic. Shaded relief images proved less attractive due to the dependence on solar angle and the loss of detail in the end result.

The required point density for landslide interpretation depends on the purpose of the study. Gross morphological features of landslides are easily distinguished at a point density of 1.69 points $\mathrm{m}^{-2}$. Detailed analysis of morphological features requires a point density more than 5.69 points $\mathrm{m}^{-2}$. However for vegetation analysis, very high density ALS data are preferable to enable detailed characterization of the shape of tree stems and branches (Bucksch and Lindenbergh, 2008).

This research has shown the quality of an ALS-derived DTM for landslides mapping under a dense forest canopy. The generation of a detailed landslide inventory in forested terrain is considered important for landslide hazard assessment. This method should also be suitable in tropical areas where the re-vegetation of landslides proceeds rapidly. Furthermore, the vegetation characteristics, particularly on irregular trees extracted from high density ALS data could be used to assess the landslide activity beneath densely vegetated area. 


\section{Chapter 4}

\section{Generating an optimal DTM from airborne laser scanning data for landslide mapping in a tropical forest environment}

\subsection{Introduction}

Landslides have been recognized as important geomorphic processes which form a major landscape component of the humid tropical mountain environments (Thomas, 1994). In such areas, landslides may damage physical structures and cause loss of lives. In Southeast Asia, landslides occur frequently in areas with steep hillslopes, high rainfall intensities, seasonally dry periods, and unstable soils, which are hindrances for managing upland forests and agricultural lands (Douglas, 1999; Sidle and Ochiai, 2006).

Landslide inventory mapping is routinely done based on (i) visual monoscopic or stereoscopic aerial or satellite image interpretation, (ii) automated or semi-automated classification of satellite imagery based on spectral and topographic characteristics, (iii) field investigation, (iv) historical records, (v) visual interpretation of Airborne Laser Scanning (ALS) derived shaded relief images, and (vi) Radar interferometry (Van Westen et al., 2008; Guzzetti et al., 2012). Field mapping yields greater accuracy if aided by GPS and sophisticated instrumentation such as a laser rangefinder binocular (Santangelo et al., 2010), but has limitations in terrain coverage and is time consuming as well as expensive (Haneberg et al., 2009; Santangelo et al., 2010). Image analysis using aerial photos, optical satellite, and radar images can efficiently cover a large area but results in poor mapping of landslides in rugged forested terrain (Fookes et al., 1991; Wills and McCrink, 2002; Brardinoni et al., 2003; Van Den Eeckhaut et al., 2007).

In a tropical environment, landslide mapping for large areas is difficult because the landslides are covered by multi-storey dense forest canopies and the weather conditions (cloudy and rainy) are often unfavourable for optical remote sensing. Landslides in tropical forests are rapidly covered by

* This chapter is based on:-

Razak, K.A., Santangelo, M., Van Westen, C.J., Straatsma, M.W., de Jong, S.M. (2013). Generating an optimal DTM from airborne laser scanning data for landslide mapping in a tropical forest environment. Geomorphology 190, 112-125. 
vegetation regrowth. Hence, soon after their occurrence the evidence of landslides are obscured in optical images. The lack of reliable landslide inventory maps hampers the assessment of landslide hazard and risk which may subsequently complicate the implementation of mitigation measures. Therefore, it is essential to test and evaluate new tools for mapping the location and extent of landslides beneath dense vegetation in the tropics.

ALS is one of the most important geospatial data acquisition technologies that have been introduced recently (Petrie and Toth, 2008). ALS has revolutionized the acquisition of terrain data because it can collect explicit topographic data over wide areas at an unprecedented accuracy within a relatively short time. With its ability to penetrate the space between forest foliage to the ground and its independence of solar incidence, ALS is superior over passive optical (e.g. aerial-photograph, satellite images) and active radar sensors (e.g. interferometric synthetic aperture) for generating a highresolution digital terrain model (DTM) in forested terrain (Kraus and Pfeifer, 1998; Hodgson et al., 2003; Kraus, 2007; Chapter 3).

The essential step towards DTM generation is the classification of ground points and non-ground points (e.g. buildings and trees). It is also known as the filtering process, which is important because the extracted point clouds have a direct impact on the quality of the digital terrain modeling and subsequent products (Chapter 3 ). Although humans are cognitively able to identify points representing the ground surface, the manual or semiautomatic filtering is not practically feasible for large point clouds. Despite the availability of automated filtering algorithms, a number of difficult scenarios are reported such as for dense vegetation on slopes, high surface roughness, preservation of sharp ridges, low vegetation, complex objects at convex slopes, and steep forested terrain (Huising and Gomez Pereira, 1998; Sithole and Vosselman, 2004). These cases are predominantly observed for recognizing landslides in tropical environments. Therefore, the selection of an appropriate filtering algorithm and its parameterization is required for such complex landscapes (Sithole and Vosselman, 2004; James et al., 2007). So far, there have been relatively limited studies to properly evaluate the quality of ALS-derived DTMs in the tropics (Blair and Hofton, 1999; Hofton et al., 2002; Clark et al., 2004; Haneberg et al., 2009), particularly for mapping and classifying the tropical landslides.

Landslide inventory mapping has made significant steps forward due to the availability of ALS data, because the use of shaded relief images created from ALS-derived DTMs allowed for a much better recognition of diagnostic features for landslide interpretation, even under dense forest (Sekiguchi and Sato, 2004; Van Den Eeckhaut et al., 2005; Ardizzone et al., 2007; Van Den Eeckhaut et al., 2007; Schulz, 2007; Kasai et al., 2009). However, none of 
these studies has examined the developed approaches of landslide mapping in tropical environments with a relatively low point density.

The main objective of this study is to evaluate the potential of airborne laser scanning for generating landslide inventory maps under tropical forests in the Cameron Highlands, Malaysia. A description of the study area with respect to geology, geomorphology, and vegetation was given in Chapter 2. We quantitatively and qualitatively assessed DTMs for landslide recognition and classification. We applied three progressively stringent filters to extract ground points, and examined four different surface interpolation methods to create gridded DTMs. The statistical measures of vertical accuracy were computed using field reference data based on differential Global Positioning System (GPS) and a Total Station for all DTMs with respect to three different land-cover classes. Expert image interpreters created the landslide inventory maps and assessed the interpretability of the different DTMs.

\subsection{Data and methods}

\subsubsection{Airborne laser scanning measurement}

The ALS data were acquired by the Department of Survey and Mapping of Malaysia (JUPEM) as a national pilot survey over the Cameron Highlands in June 2004 using the Optech Airborne Laser Terrain Mapper (Optech ALTM) 3100 (see Table 4.1 for details). In this study, we used a point cloud of about 113 million points with a mean point density of 1.83 points $\mathrm{m}^{-2}$. All the strips were projected onto the local Malaysia Rectified Skew Orthomorphic (Malaysia RSO) projection system (Mugnier, 2009). Pre-processing of the point cloud was performed to eliminate isolated points (e.g. flying birds, transmission lines, and water droplets from low-level clouds).

\subsubsection{Field validation terrain height data}

A total of 448 ground-surveyed terrain height points were collected during field campaigns in July 2009 and January 2011 using a GPS (Topcon Hiper Pro) and a Total Station (TS; Nikon DTM-352). Heights ranged between 875 and $1670 \mathrm{~m}$ above sea level. Of the 448 field-measured terrain heights $47 \%$ was under forests, $39 \%$ in agricultural areas, and $14 \%$ in tea plantations. 
Table 4.1: Metadata for the airborne laser scanning campaign in the Cameron Highlands

\begin{tabular}{|l|l|}
\hline $\begin{array}{l}\text { Airborne laser scanner and its } \\
\text { accuracy }\end{array}$ & $\begin{array}{l}\text { Optech ALTM } 3100 ; \text { average horizontal accuracy } \\
0.30 \mathrm{~m} \text {; vertical accuracy } 0.20 \mathrm{~m} \text { at } 1200 \mathrm{~m} \text { with } \\
\text { one sigma }\end{array}$ \\
\hline $\begin{array}{l}\text { Inertial measurement unit } \\
\text { (IMU) system and its accuracy }\end{array}$ & $\begin{array}{l}\text { ALTM IMU records at } 200 \mathrm{~Hz} \text { with an accuracy of } \\
0.015^{\circ} \text { roll/pitch and } 0.03^{\circ} \text { heading }\end{array}$ \\
\hline $\begin{array}{l}\text { Positional geodetic system and } \\
\text { its accuracy }\end{array}$ & $\begin{array}{l}\text { Trimble } 4000 \mathrm{SSi} \text { records at } 10 \mathrm{~Hz} \text { with static } \\
\text { accuracy of } 5 \mathrm{~mm} \mathrm{(horizontal)} \mathrm{and} 10 \mathrm{~mm} \\
\text { (vertical) }\end{array}$ \\
\hline Laser pulse repetition rate & $100 \mathrm{kHz}$ \\
\hline Measurement rate & Up to 100000 pulses per second \\
\hline Beam divergence & Dual divergence 0.3 mrad \\
\hline Laser beam footprint & $0.08 \mathrm{~m}$ at $250 \mathrm{~m}$ \\
\hline Scan angle & Up to $25^{\circ}$ \\
\hline Scanning method & Oscillating plane mirrors (saw-tooth pattern) \\
\hline
\end{tabular}

We applied a purposive sampling scheme to acquire terrain height as it was impossible to collect them randomly or systematically on a regular grid due to poor accessibility of large parts of the mountainous area. More points were selected around known landslide locations. A combination of GPS techniques such as real-time-kinematic (RTK), rapid-static and static observations was used depending on the density of vegetation coverage. In areas completely covered by dense forest, a local surveying scheme using a TS was utilized. The average accuracies for the RTK-GPS and total station observations were 0.15 and $0.09 \mathrm{~m}$, respectively. We used four existing permanent control stations established by JUPEM in order to setup several geodetic base stations for a local geodetic network within the study area. Horizontal and vertical accuracy of the geodetic stations were on average 12 and $25 \mathrm{~mm}$, respectively. The coordinates of the reference points were projected onto the Malaysia RSO coordinate system.

\subsubsection{ALS filtering and its parameterization}

We chose the hierarchic robust interpolation (HRI) method as implemented in the SCOP++ software (TUV, 2012) for DTM extraction from the raw point cloud, as the method is specifically developed for forested environments (Kraus and Pfeifer, 1998). HRI was extended in a hierarchical approach by Pfeifer et al. (2001). A standard HRI processing routine required three different hierarchical levels, which increase in resolution. Four processing steps are iteratively carried out at three hierarchical levels (pyramidal approach): (i) thinning out, (ii) filtering, (iii) interpolation, and (iv) sorting/classification (TUV, 2012). HRI uses a linear prediction algorithm with individual accuracies for each measurement. From the robust least square adjustment, a weighting function was applied to compute weights based on the residuals. The ground points are more likely to be below the modelled surface (a rough surface computed with equal weights), have positive residuals, and are given more weight. On the contrary, points above the 
modelled surface (e.g. negative residuals) yield small weights and have less influence on the subsequent iterations.

We modified the extraction of bare-earth points by using three subsequent filtering steps instead of one. Progressively stringent parameters were chosen following the method described in Chapter 3. For the Malaysian tropical dataset we introduced modifications of the parameterization (Table 3.2) in order to adapt to the lower point density, the complexity of under-storey vegetation, and the ruggedness of the terrain. We used a $1 \mathrm{~m}$ grid resolution, $0.35 \mathrm{~m}$ for the mean accuracy, and different parameters for the weighting function and buffer zone. A detailed parameterization for filtering used in this study is shown in Table 4.2. This led to four point clouds: the raw point cloud and the extracted points after the first, second and third filtering step.

\subsubsection{Surface interpolation methods to create gridded DTMs}

The ground points extracted at each filter step were used to generate 1-m grid DTMs using four surface interpolation techniques: (i) the linear prediction derived from the SCOP++ (SCP), (ii) the inverse distance weighting (IDW), (iii) the natural neighbor (NEN) and (iv) the topo-to-raster (T2R). The ALSderived DTMs were quantitatively and qualitatively assessed with respect to landslide interpretation in the tropics.

The SCP is implemented in the SCOP++ processing modules for DTM derivation. This interpolator is based on linear prediction also known as linear least-square interpolation (Kraus and Mikhail, 1972). It captures the nonsmooth terrain surfaces (e.g. breaklines, ridges, and troughlines). Briese (2004) provided details on this method. The IDW, NEN and T2R were implemented in the 3D Analyst extension of ESRI ArcGIS. These interpolators were chosen to get a balance between reasonable computational times and accuracy. The IDW and NEN are deterministic interpolation methods, which are often used to derive DTMs from ALS points in rugged forested terrain (Clark et al., 2004; Pirotti and Tarolli, 2010; Chapter 3). IDW (Isaaks and Srivastava, 1989) is a multivariate interpolation and the computation of assigned values to unknown points required a weighted average of the values available at the known scattered set of points. The basic equations of IDW are (Shepard, 1968): 
Table 4.2: A modified landslide filter parameterization for filtering process implied in the Malaysian tropical environment (Inset figure showing the weight function used in the filter step). The output grid resolution was set to $1 \mathrm{~m}$, and mean expected accuracy of the ALS data was set to $0.35 \mathrm{~m}$. Units in meter

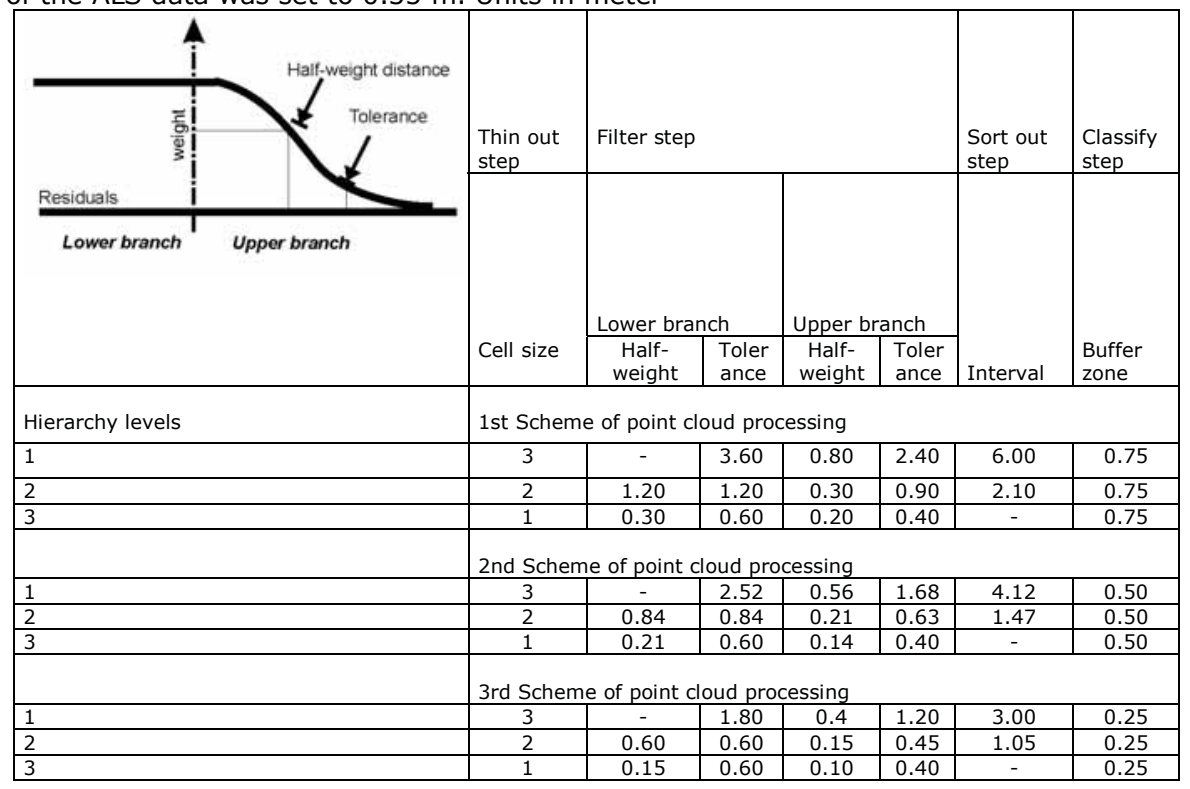

$\rho(x)=\sum_{i=0}^{n} \frac{q_{i}(x) \rho_{i}}{\sum_{j=0}^{n} q_{i}(x)}$

$q_{i}(x)=\frac{1}{d\left(x, x_{i}\right)^{r}}$

Where $p(\mathbf{x})$ is a interpolated value at given points, $x$ is an arbitrary points, $x_{i}$ is a known value, $d$ is a given distance in the form of metric operator from $x_{i}$ to $\mathrm{x}, \mathrm{n}$ is the total number of known points used in the interpolation, and $r$ is a real number (positive) or known as a power parameter.

IDW was applied using a power of 2, following Clark et al. (2004) who also created a DTM for a tropical forested region. The number of neighboring points was set to four to limit selection of points on a different morphological unit further away.

The NEN method is based on so-called area-stealing interpolation (Sibson, 1981; Watson, 1988; Ledoux and Gold, 2004). It is weighted average 
interpolation technique that uses geometric relationships in order to choose and weight nearby points. The points used to estimate the value of an attribute at location $x$ are the natural neighbour of $x$, and the weight of each neighbour is equal to the natural neighbour coordinates of $x$ with respect to this neighbour (Ledoux and Gold, 2004). The NEN method is based on Voronoi tessellation of a discrete set of spatial points. The basic equation of the NEN method is:

$f(x, y)=\sum_{i=1}^{n} \omega_{i} f\left(x_{i}, y_{i}\right)$

Where $f(x, y)$ is the interpolated function value at $(x, y), \omega_{i}$ are the weights and $f\left(x_{i}, y_{i}\right)$ are the known value at the $i$-th point $\left(x_{i}, y_{i}\right)$. The weights are computed by determining the ratios of volumes 'stolen' when placing $(x, y)$ into the tessellation. This method has advantages over the simpler interpolation methods such as nearest neighbor, and it performs well even if the data are highly anisotropic (Ledoux and Gold, 2004). In ESRI ArcGIS, $f(x, y)$ are determined by finding the closest of input to query points and applying weights to the based on proportionate areas to interpolate a value. The weights are calculated based on the proportion of overlap between the constructed neighboring Voronoi (Thiessen) polygons and initial polygons. This method tends to smooth the surface except at locations of the input samples or within the range of samples used (Ledoux and Gold, 2004), given that the method is data dependent and has many desirable properties as an interpolation function (Sibson, 1981; Piper, 1993).

The T2R interpolator is based on the ANUDEM program developed by Hutchinson (1989) specifically designed for generating a hydrologically correct continuous surface. This method implements a discretized thinplate spline technique (Wahba, 1990) and has the advantage that it follows abrupt changes in terrain, such as streams and ridges. Hutchinson (1989) implemented a drainage enforcement technique, which firstly identifies pits and saddles from sparse and scattered terrain data. D8 technique of the steepest gradient was used to trace a path from the neighbor to either a pit or the edge of the grid for all the downhill neighbors around each saddle. The elevation along the path is set to create an approximately linear descent, and then a finite element interpolation method was used. However, the method is likely to smooth out some prominent surface features (Hutchinson, 1989). 


\subsubsection{Quantitative assessment of ALS-derived DTMs}

We quantitatively assessed the DTMs errors in two different ways. Firstly, the vertical error was computed for each DTM by subtracting DTM elevation from the elevation of field-measured points. Three statistical measures of vertical accuracy were computed: root-mean-square error (RMSE), mean-square error (MSE) and mean-absolute-percentage error (MAPE) (Isaaks and Srivastava, 1989; Mayer and Butler, 1993).

$$
\begin{aligned}
& R M S E=\left\{\left[\left(z_{i}-\hat{z}_{i}\right)^{2}\right] / n\right\}^{0.5} \\
& M A E=\left(\sum\left|z_{i}-\hat{z}_{i}\right| / n\right) \\
& M A P E=100\left[\sum\left(\left|z_{i}-\hat{z}_{i}\right| /\left|z_{i}\right|\right)\right] / n
\end{aligned}
$$

Where $z_{i}$ represents the observed value, $\hat{z}_{i}$ is the predicted value, and $n$ is the number of pairs. RMSE provides an accuracy index at a global level (Burrough, 1986) which can be used to estimate the effect of sampling and interpolation errors (Wechsler and Kroll, 2006). The DTM accuracy was further computed per slope class and per land cover type. Secondly, with respect to the extracted ground points at each filter step, we analyzed the spatial effect of progressive filtering by computing the height difference between the DTMs and summarized per land cover type.

\subsubsection{Landslide interpretability of ALS-derived DTMs}

The suitability of the different DTMs for landslide recognition was evaluated based on visual interpretation by three expert landslide interpreters. They used monoscopic and stereoscopic ALS-shaded relief images. A description of the methods for generating monoscopic and stereoscopic ALS images for landslide visualization under densely forested area can be found in Chapter 3. Based on the results derived from the expert opinions, a list of morphological features and situations was made under which the optimal filter and associated surface interpolation has been indicated with respect to landslide mapping. Interpretability rating was defined as: (i) good, (ii) fairly good, and (iii) poor, for each map. Good referred to the clearest evidence of diagnostic features appearing on the images, which enabled them to distinguish stable from unstable with confidence. In contrast, poor interpretability yielded a relatively high uncertainty to identify the landslide margins and subsequent units. Moreover, landslide types and states of activity were more difficult to determine. For the fairly good rate, the conditions provided less or unclear 
evidence of landslide diagnostic features, although the presence of slope failures can still be assumed.

The qualitative map comparison was carried out based on the diagnostic features identified at three landslide kinematic zones. The landslide source zone (LSZ) refers to the area above the landslide scarp which is representative for the condition in which the landslide took place. The landslide depletion zone (LDZ) is the area below the crown of the landslide where the surface topography was lowered as a consequence of mass movement. The landslide accumulation zone (LAZ) is the area where mass movement materials are deposited on top of the pre-existing surface. Additional morphological features found outside these zones were recorded under "other diagnostic geomorphological features" (OGF) such as tectonic and lineament features.

The image interpretation criteria are solely based on the tone, texture and pattern, which allow inferring a series of geomorphologic signatures, like semicircular niches, cracks, primary and secondary scarps, flow related morphologies, lateral channels, convex-concave profile slopes, hummocky topography, levees, displaced materials, interruptions in the drainage pattern, and disrupted roads (Wills and McCrink, 2002; Van Den Eeckhaut et al., 2007; Chapter 3). For a complex and large landslide, the interpreters adopted morphological criteria rather than photographical ones (e.g. related to surface roughness and land use pattern), such as a horse-shoe drainage pattern, debris cones on the borders of the landslide deposit, restricted main stream valley, and a concave-convex profile slope, which can be easily associated with the presence of a very large mass movement.

A digital stereo on-screen interpretation was utilized at different scales depending on the interpretability of macro- and micro-morphological landslide features. The direction of movement of the mapped landslides and the landslide types were indicated and classified, following the landslide classification by Varnes (1978). For each interpreted element, the identification certainty was indicated. The stereo images were also used to interpret the lineaments and geological setting in the study area.

The activity of the landslides was interpreted by evaluating the freshness of the diagnostic features, the relation with other visible landslide processes (to differentiate reactivated landslides), and by visually comparing the stereo images of the shaded relief with stereo images of high-resolution optical IKONOS satellite data. The IKONOS images were taken between February and June 2001. Fig. 4.1 presents the available data for the image interpreters, for the area I in Fig. 2.5B. Fig. 4.1A shows the satellite image depicts the agriculture terraces and buildings next to the edge of the forest 
margin, the point density before and after the filtering (Figs. 4.1B,G), and shaded relief images after each filtering step (Figs. 4.1D,E,F) and the tree attributes (Fig. 4.1H).

During the landslide interpretation, the existing landslide inventory prepared by Pradhan and Lee (2010) was used as a reference. Their compilation of more than 21 years of landslide inventory resulted in a total of 324 landslides in their study area of $293 \mathrm{~km}^{2}$ (Pradhan, 2010; Pradhan and Lee, 2010; Pradhan et al., 2010). 55 landslides were located in our study area of 100 $\mathrm{km}^{2}$. Given the fact that this inventory was compiled at 1:25000 scale, we encountered considerable positional errors in the location of the landslides, when overlaying them on the $1 \mathrm{~m}$ resolution maps derived from our ALS analysis. We corrected these errors by positioning them on the right location with appropriate attributes using visual image interpretation. 

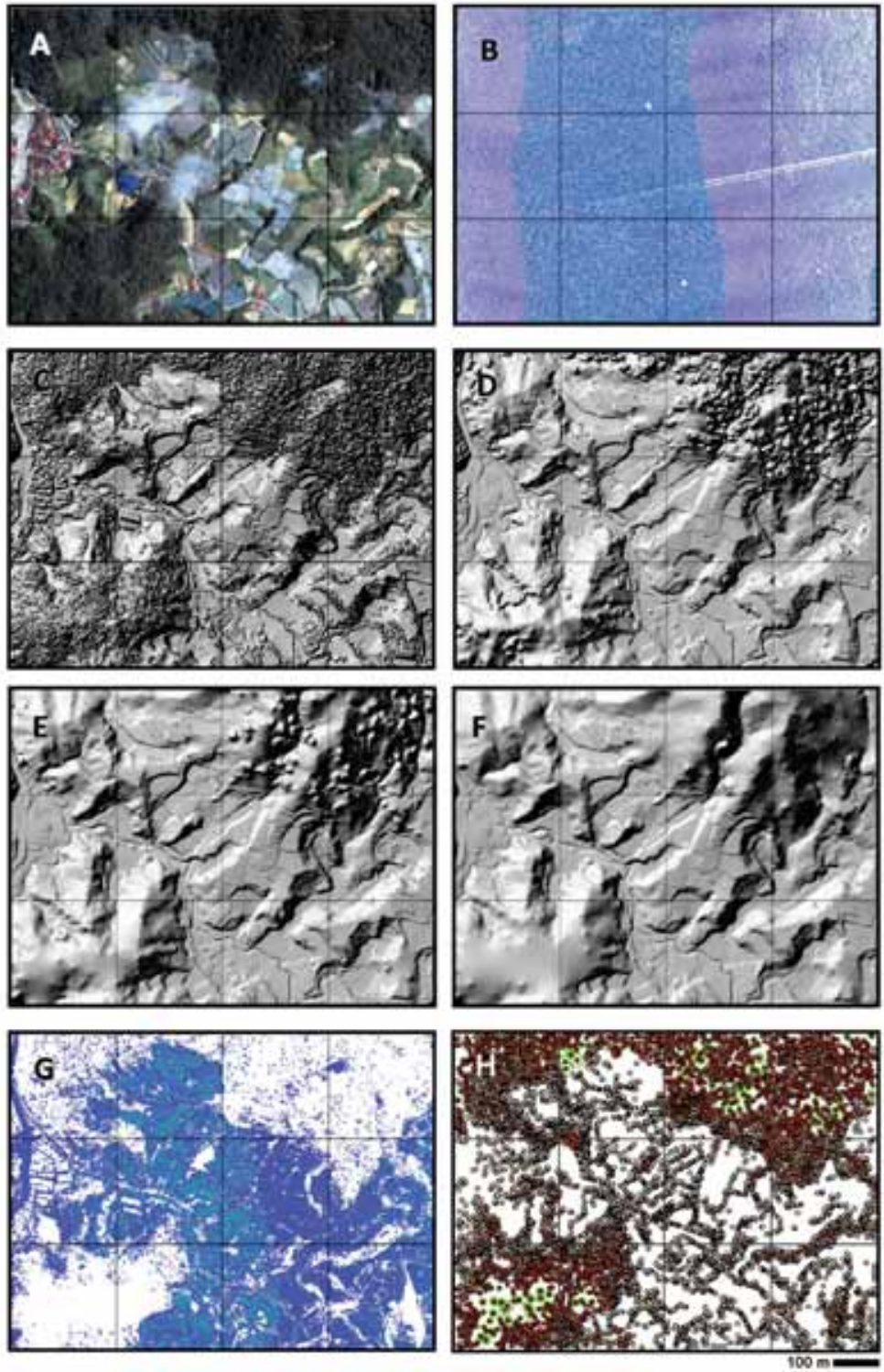

Fig. 4.1: Examples of the spatial data used for qualitative assessment of landslides from ALS-derived images. The location corresponds to I in Fig. 2.5B. A) High-resolution satellite image depicting the agricultural terraces up to the edge of forest margin and buildings. B) and $G$ ) the point density of the original (mean, 1.83 points $\mathrm{m}^{-2}$ ) and filtered ALS data (mean, 0.34 points $\mathrm{m}^{-2}$ ), respectively. C) A shaded relief of ALSderived DSM. D) E) and F) the first, second and third filter images derived from the SCP-derived products, respectively. $\mathrm{H}$ ) Tree location with indication of its height up to $58 \mathrm{~m}$ (in red) and crown width up $16 \mathrm{~m}$ (in green). 


\subsection{Results}

\subsubsection{Quantitative assessment of the ALS-filtered data}

The ALS-derived DTMs had overall RMSE vertical errors ranging from 0.886 to $4.203 \mathrm{~m}$, with a large error computed in the forested terrain $(5.915 \mathrm{~m}$ RMSE) (Table 4.3). The SCP image at the third filter yielded the most accurate DTM with the lowest overall RMSE $(0.886 \mathrm{~m})$. As expected, larger vertical errors were found after one round of filtering, independent of the interpolator, with an average RMSE of $4.045 \mathrm{~m}$. The second and third filters resulted in an average RMSE of 2.178 and $1.416 \mathrm{~m}$, respectively. After the first filtering step, the T2R-derived DTM depicted the lowest overall RMSE (3.909 $\mathrm{m}$ ) across the landscape. The NEN-derived DTM was significantly more accurate $(1.971 \mathrm{~m})$ than others after the second filtering step, whereas the $\mathrm{T} 2 \mathrm{R}$ had a large error. The SCP method always reveals the best results after three filtering steps. The IDW-derived DTM had the highest overall RMSE value $(2.016 \mathrm{~m})$ after the third filter step compared to the other interpolation techniques. All ALS filters depicted lower vertical errors in the tea plantation compared to forest and agriculture zones.

An important result of comparing the surface interpolation methods is that an optimum DTM accuracy is found for agriculture and tea zones. The lowest errors obtained in the NEN and IDW after the second filtering step, whereas the T2R and SCP had the lowest errors after the third filtering step in both zones. The fact that there is no single best method for DTM generation, made it necessary to use qualitative measures for DTM interpretability of geomorphological features.

We found that the ALS-derived DTM error was not evenly distributed across the landscape (Fig. 4.2). The DTM errors were less for slopes below $30^{\circ}$ than the overall RMSE ( $0.886 \mathrm{~m}$ for SCP after three filters), and increased nonlinearly with steeper slopes. About $64 \%$ of the landslides occurred in the area with a slope between 21 and $40^{\circ}$, and showed an overall RMSE of $0.87 \mathrm{~m}$. The DTM error increased to a RMSE of $1.53 \mathrm{~m}$ for slopes over $40^{\circ}$. However, only $17 \%$ of the landslides were located in this slope class.

The original ALS data in the forested area occupied more points and not surprisingly, the retrieval of ground points in this zone resulted in 16, 9, and $5 \%$ of the points for the first, second and third filters, respectively. The original point density in the tea plantation was lower compared to other landcover types. The filtering in the tea plantation depicted 83,76 , and $53 \%$ of ground points after the first, second, and third filters, respectively. Similarly, the bare-earth extraction in the agriculture zone ranged between 83 to $60 \%$ of ground points. 


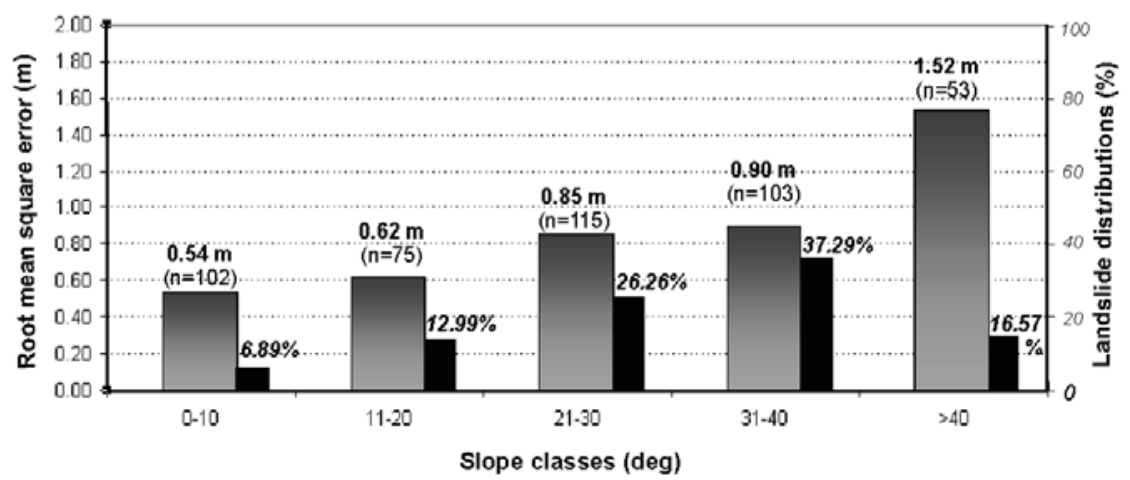

Fig. 4.2: DTM error (RMSE) presented with respect to slope gradient and distribution of landslides (black bars). A number of field-measured terrain height indicated in brackets.

Nine map comparisons were carried out to determine the height differences after subsequent filtering, separated by land cover class (Table 4.4). The largest height differences were found in the forested terrain for all DTMs between the first and third filter for all interpolation methods. The height difference between the second and third filtering steps resulted in small discrepancy across the landscape. The negative height differences ranged between -0.224 to $-0.008 \mathrm{~m}$ and were predominantly found in the tea plantation and agriculture zones. The NEN, SCP, and IDW depicted the lowest height differences for the forest, agriculture, and tea plantation zones, respectively.

\subsubsection{Landslide interpretability of ALS-derived images}

Fig. 4.3A gives an example of the ALS-derived images for the four surface interpolators and the three different filters with the interpreted landslides. Fig. 4.3B shows shaded relief of ALS-derived DSMs visualized as anaglyph images for three filters derived from the IDW interpolation. The location of the subset area, which is completely covered by forest, corresponds to II in Fig. 2.5B. A large portion of the trees is still visible after the first filtering step for all the surface interpolations. Generally the IDW tends to show more rough surfaces, which are more prominent at the third filter compared to other surface interpolators. Contrarily, the NEN and T2R images presented relatively smooth surfaces on the sloping terrain, ridges and top of mountains. 
Table 4.3: The vertical accuracy of ALS-derived DTMs summarized for the three land cover types $(\mathrm{SCP}=\mathrm{SCOP}++$ linear prediction; NEN = Natural neighbour; $\mathrm{T} 2 \mathrm{R}=$ Topoto-Raster; IDW = Inverse distance weighting). Units in meter.

\begin{tabular}{|c|c|c|c|c|c|c|c|c|c|c|c|c|c|}
\hline \multirow[t]{2}{*}{$\begin{array}{l}\text { Inter- } \\
\text { polators }\end{array}$} & \multirow[t]{2}{*}{$\begin{array}{c}\text { ALS } \\
\text { filters }\end{array}$} & \multicolumn{3}{|c|}{$\begin{array}{c}\text { Forested zone } \\
(\mathrm{N}=187)\end{array}$} & \multicolumn{3}{|c|}{$\begin{array}{l}\text { Agriculture zone } \\
(N=175)\end{array}$} & \multicolumn{3}{|c|}{$\begin{array}{c}\text { Tea plantation zone } \\
(\mathrm{N}=62)\end{array}$} & \multicolumn{3}{|c|}{$\begin{array}{c}\text { Total for all zones } \\
(\mathrm{N}=\mathbf{4 4 8})\end{array}$} \\
\hline & & RMSE & MSE & MAPE & RMSE & MSE & MAPE & RMSE & MSE & MAPE & $\begin{array}{l}\text { Overall } \\
\text { RMSE }\end{array}$ & \begin{tabular}{|l} 
Overall \\
MSE
\end{tabular} & $\begin{array}{l}\text { Overall } \\
\text { MAPE }\end{array}$ \\
\hline \multirow[t]{3}{*}{$\mathrm{SCP}$} & $1^{\text {st }}$ filter & 5.915 & 3.072 & & 1.209 & 0.799 & 0.080 & 1.074 & 0.578 & & & 1.822 & 0.159 \\
\hline & $2^{\text {nd }}$ filter & & & & & 0.733 & & & & & & & 104 \\
\hline & & & & & & & & & & & & & \\
\hline \multirow[t]{3}{*}{ NEN } & & & & & & & & & & & & & \\
\hline & $2^{\text {nd }}$ filter & 2.627 & & & & & & & & & & & \\
\hline & $3^{\text {rd }}$ filter & 1.38 & 0.585 & 0.0 & 1.213 & 0.572 & 0.078 & 1.2 & 0.561 & & 1. & & 0.085 \\
\hline \multirow[t]{3}{*}{ T2R } & $1^{\text {st }}$ filter & 5.514 & 2.823 & 0.248 & 1.726 & 0.771 & 0.102 & 1.7 & 0.660 & 117 & & 1.722 & 0.173 \\
\hline & & & & & & & & & & & & & \\
\hline & & & & & & & & & & & & & \\
\hline \multirow[t]{3}{*}{ IDW } & $1^{\text {st }}$ filter & & & & & & & & & & & & 0.163 \\
\hline & $2^{\text {nd }}$ filter & 2.790 & 1.228 & & & 0.551 & 0.077 & & & & 2.1 & & 0.108 \\
\hline & $3^{\text {rd }}$ filter & 2.611 & 0.219 & 0.141 & 1.282 & 0.606 & 0.079 & 1.181 & 0.525 & 0.083 & 2.016 & 0.412 & 0.109 \\
\hline
\end{tabular}

Table 4.4: Statistics of height differences for all surface interpolations presented based on land cover types $(\mathrm{SCP}=\mathrm{SCOP}++$ linear prediction; $\mathrm{NEN}=$ Natural neighbour; $\mathrm{T} 2 \mathrm{R}$ $=$ Topo-to-Raster; IDW = Inverse distance weighting). Units in meter

\begin{tabular}{|c|c|c|c|c|c|}
\hline No & $\begin{array}{l}\text { Pair-wise maps } \\
\text { for three land cover }\end{array}$ & \begin{tabular}{|l} 
SCP \\
(Mean \pm SD)
\end{tabular} & $\begin{array}{l}\text { NEN } \\
(\text { Mean } \pm \text { SD) }\end{array}$ & $\begin{array}{l}\text { T2R } \\
\text { (Mean } \pm \text { SD) }\end{array}$ & $\begin{array}{l}\text { IDW } \\
(\text { Mean } \pm \text { SD) }\end{array}$ \\
\hline \multicolumn{6}{|c|}{ Forested terrain } \\
\hline 1 & First - second filter & $2.733 \pm 5.348$ & $1.063 \pm 3.316$ & $2.783 \pm 5.206$ & $3.124 \pm 5.776$ \\
\hline 2 & Second - third filter & $1.156 \pm 3.370$ & $2.481 \pm 5.419$ & $1.250 \pm 3.474$ & $1.374 \pm 4.128$ \\
\hline 3 & First - third filter & $4.074 \pm 6.601$ & $4.041 \pm 6.605$ & $4.200 \pm 6.654$ & $4.705 \pm 7.408$ \\
\hline \multicolumn{6}{|c|}{ Agriculture zone } \\
\hline 4 & First - second filter & $-0.008 \pm 0.598$ & $-0.191 \pm 1.158$ & $0.017 \pm 0.845$ & $-0.031 \pm 0.718$ \\
\hline 5 & Second - third filter & $0.023 \pm 0.616$ & $-0.012 \pm 0.523$ & $-0.027 \pm 0.733$ & $0.004 \pm 0.627$ \\
\hline 6 & First - third filter & $0.030 \pm 0.799$ & $-0.071 \pm 0.797$ & $0.034 \pm 1.039$ & $0.062 \pm 0.779$ \\
\hline \multicolumn{6}{|c|}{ Tea plantation } \\
\hline 7 & First - second filter & $-0.039 \pm 0.600$ & $-0.213 \pm 1.177$ & $0.123 \pm 0.919$ & $-0.137 \pm 0.653$ \\
\hline 8 & Second - third filter & $-0.081 \pm 0.545$ & $0.064 \pm 0.451$ & $-0.224 \pm 0.871$ & $0.019 \pm 0.528$ \\
\hline 9 & \begin{tabular}{|l|} 
First - third filter \\
\end{tabular} & $-0.179 \pm 0.713$ & $-0.133 \pm 0.735$ & $-0.151 \pm 0.951$ & $-0.066 \pm 0.582$ \\
\hline
\end{tabular}

The expert knowledge revealed that the ALS-derived image generated using the IDW interpolator was the best among the tested images for landslide recognition. The ranking of landslide interpretability based on ALS-derived DTMs is given in Table 4.5. For the three landslide kinematic zones, the NEN and T2R images provided less clear evidence of diagnostic landslide features including the neotectonic activities (e.g. displaced terraces, landslide occurring along lines, shutter ridges, and subsidence zones with horsts and grabens). The IDW produced more noisy terrain models but without a heavy smoothing of the relief. Contrarily, the NEN, T2R and SCP generated sharper surfaces but smoothed the relief more than the IDW. The image interpreters indicated that images derived from the IDW interpolator were more suitable for landslide detection than the other images. 

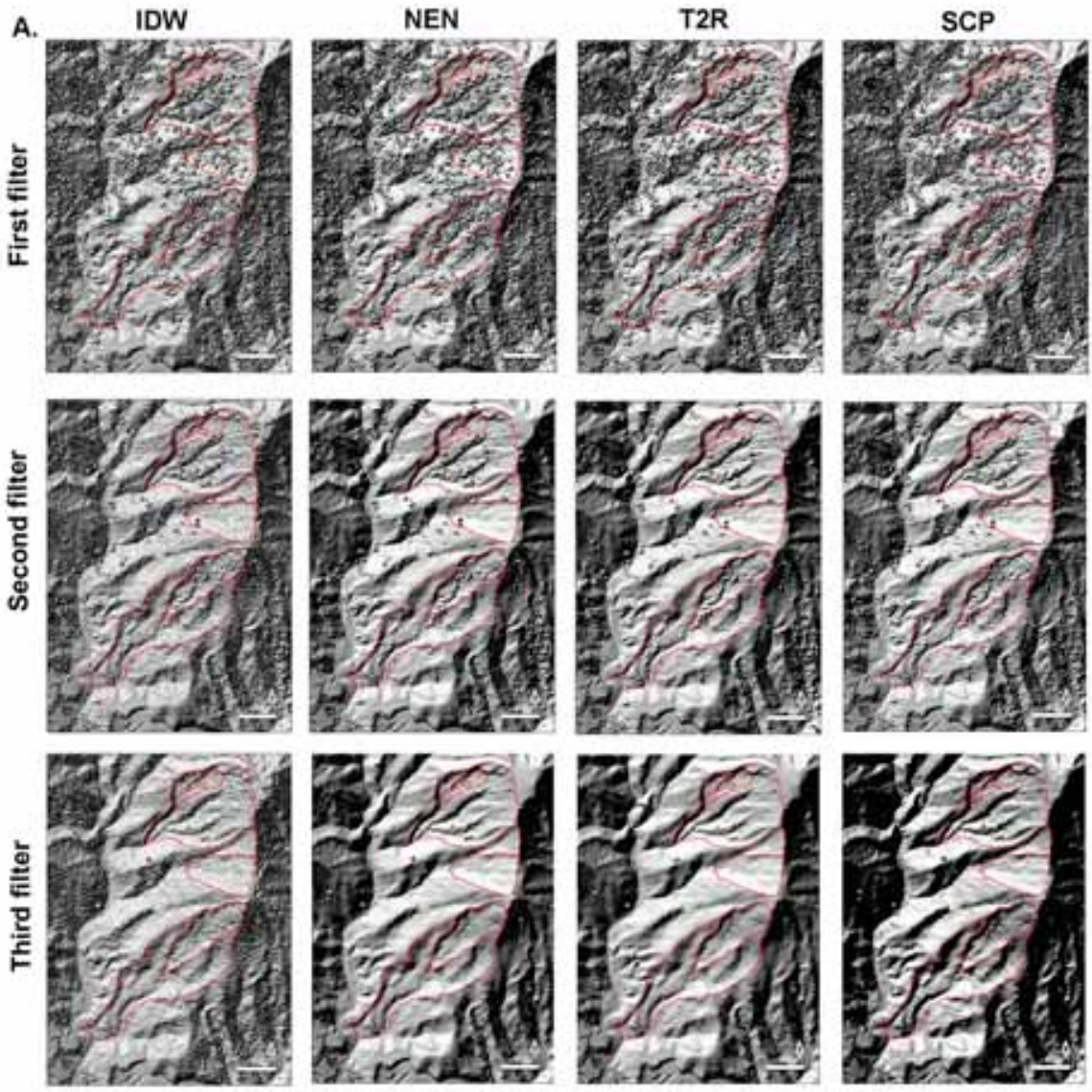

B. Hillshade DSM
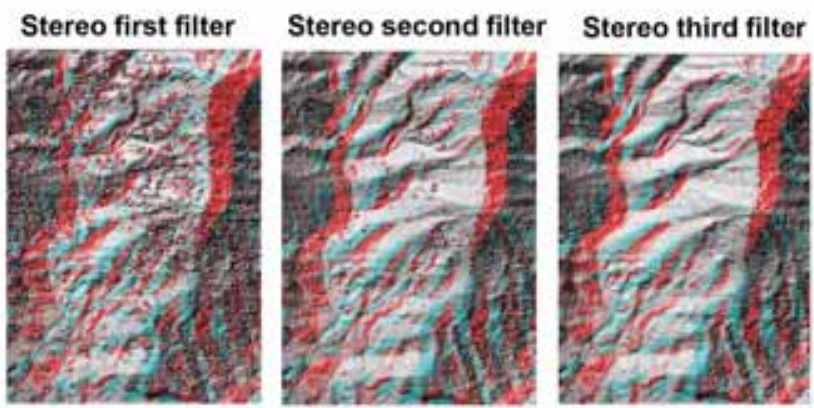

Fig. 4.3: A) 12 shaded relief maps made with three filters and four surface interpolations for a subset of the study (II in Fig. 2.8B; Chapter 2). B) Original ALS image and three images of the successive filters using the IDW interpolator presented as blue and red anaglyph relief images. See text for an explanation. 
Table 4.5: Qualitative assessment of filters and surface interpolators ( $G=$ Good, FG $=$ Fairly Good, P= Poor, LSZ =Landslide source zone, LDZ = landslide depletion zone, $\mathrm{LAZ}=$ landslide accumulation zone, $\mathrm{OGF}=$ other diagnostic geomorphological features)

\begin{tabular}{|l|l|l|l|l|l|l|l|l|l|l|l|l|}
\hline \multicolumn{3}{|c|}{ First filter } & \multicolumn{3}{c|}{ Second filter } & \multicolumn{5}{c|}{ Third filter } \\
\hline & LSZ & LDZ & LAZ & OGF & LSZ & LDZ & LAZ & OGF & LSZ & LDZ & LAZ & OGF \\
\hline SCP & FG & FG & FG & FG & P & FG & FG & P & P & FG & FG & P \\
\hline NEN & P & P & P & P & P & P & P & P & P & P & P & P \\
\hline T2R & P & P & P & P & P & FG & FG & P & P & P & P & P \\
\hline I DW & FG & FG & FG & FG & G & G & G & FG & G & G & G & FG \\
\hline
\end{tabular}

A total of 561 landslides were mapped using the stereoscopic ALS-derived shaded relief image. Surprisingly, the ALS landslide map revealed about ten times more landslides in the Cameron Highlands than had been mapped previously using aerial photographs and satellite images. About $48 \%$ of the slope failures were characterized as shallow flow types. Around $26 \%$ of the mapped landslides were verified in the field; a map validation is usually performed on a limited portion of the mapped landslides, mainly less than $15 \%$ (Galli et al., 2008). The ALS-derived image also unveiled about 125 neotectonic features. Examples of ALS images derived from three ALS filters resulting in different quality of landslide interpretability are given in Figs. 4.44.6. In an old-growth tropical rainforest (Fig. 4.4A), the ALS image derived from the second filter is preferable for a detailed landslide interpretation (see Fig. 4.4C), as it clearly revealed most of the diagnostic landslide features hidden. The second filter product succeeded in removing the vegetation while preserving the micro-morphology of old landslides. It allowed the recognition of landslide morphology under forests. Contrarily, the quality of the third filter image is reduced and its topography is dramatically changed making the landslide interpretation rather difficult (Fig. 4.4D). A large part of this image is very smoothed and artifact effects are distracting the interpretation, such as 'fallen tree' and 'dotted needles' patterns. The second filter (Fig. 4.4B) is also difficult to interpret as vegetation patches are still largely visible.

For image interpretation in an agricultural area, with trees on the steeper hillslopes, the situation is again different. The image generated from the first filter gave a better contrast for landslide interpretation (Fig. 4.5B) whereas the second filter (Fig. 4.5C) and the third filter (Fig. 4.5D) led to linear artifacts that could be erroneously interpreted as landslide scarps. Fig. 4.6 gives an example of landslide freshness as shown by the clear diagnostic features of recent landslides activities labelled $a$ to $g$. The location corresponds to III in Fig. 2.5B (Chapter 2). 

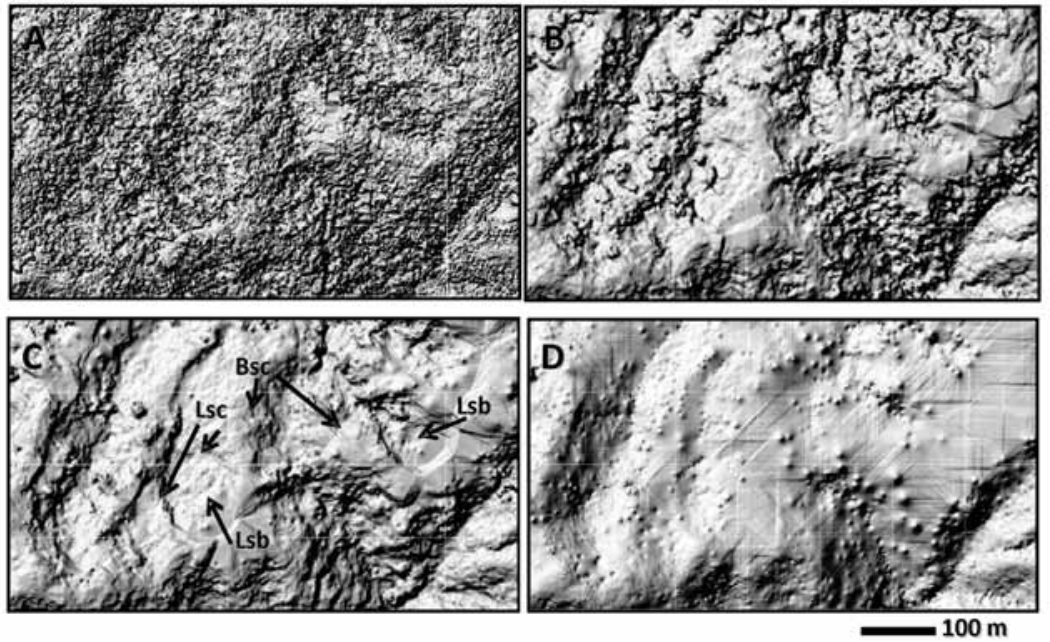

Fig. 4.4: Quality of IDW-derived DTMs affecting the landslide interpretability. A) Shaded relief of ALS-derived DSM indicating a dense tropical rainforest area. B) Vegetation patches are still present after the first filtering. C) Diagnostic landslide features are clearly visible derived from the second filter. D) Poor DTM resulting from the third filtering step, with many artifacts and high smoothing effects. The location corresponds to III in Fig. 2.5B; Chapter 2.

\subsection{Discussion}

Accurate and interpretable topographic information of the Earth's surface is important for landslide studies. Understanding the effect of ALS filtering for terrain modeling is of pivotal importance for determining the reliability of landslide inventory maps. In this study, we evaluated the various types of ALS-derived DTMS as a result of applying different ALS filter parameterizations and surface interpolations for recognizing and classifying landslides in a tropical mountainous region in Malaysia. A hierarchical robust filtering algorithm with an appropriate parameterization was used to generate reliable ALS-derived DTMs for landslide interpretation in dense evergreen forests with complex undergrowth.

In monsoon-dominated regions, landslide topographic signatures can be rapidly obscured by tropical vegetation. In this study, we showed that the stereoscopic ALS-derived DTM can be a very good source for forested landslide characterization, although it is evidently problematic to recognize shallow landslides and debris flows beneath forests (Brardinoni et al., 2003). It allowed mapping and classifying a large number of complex landslides and geomorphological features (neotectonic and lineament). The total number of landslides mapped using ALS data is substantially higher than that of 
previously published landslide inventory compiled over 21 years (e.g. Pradhan and Lee, 2010).
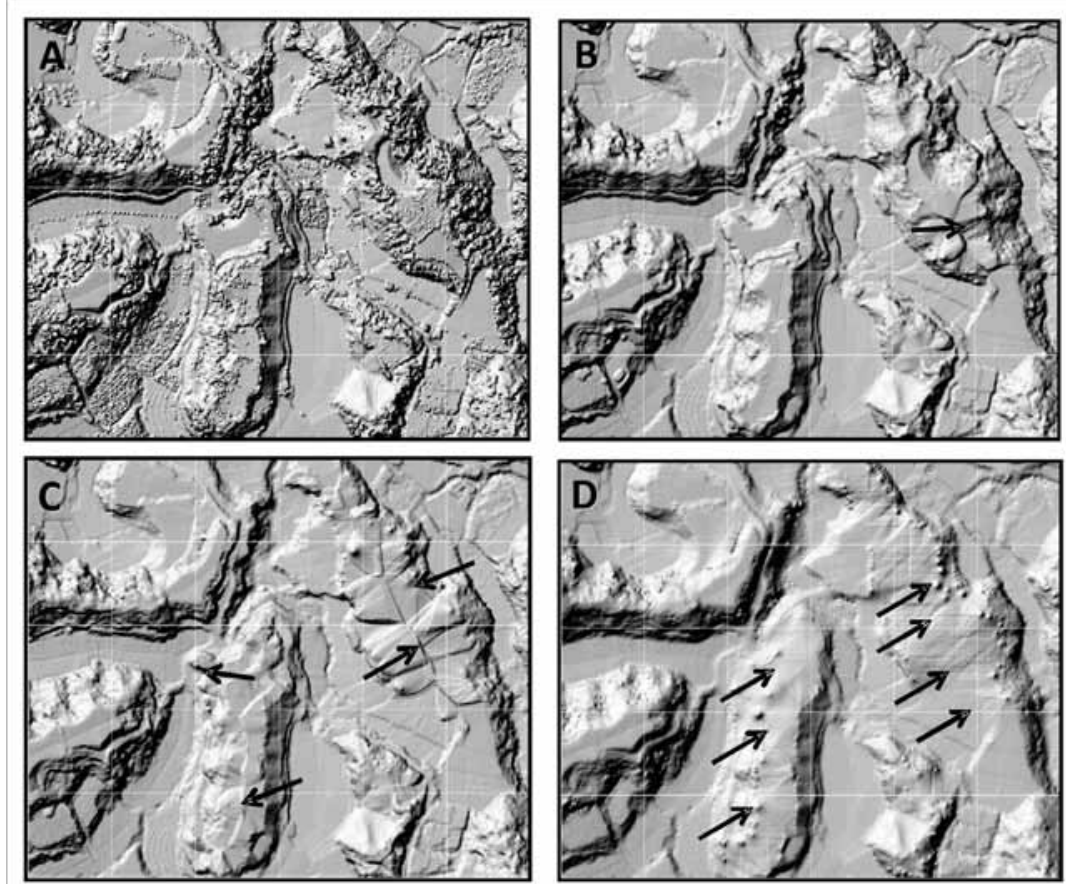

Fig. 4.5 ALS filtering results displayed as shaded relief images for a sparsely vegetated terrain susceptible to landslides (location IV in Fig. 2.5; Chapter 2). A) Original ALS data. B) Result of the first filter allows a better landslide interpretability. C) Second filter derived image with arrows indicating artifacts that would lead to wrong landslide interpretations. D) Third filter result with arrows showing large smoothing effects and artifacts.

Use of incomplete landslide inventories resulting from undetected landslides poses significant problems on landslide hazard analysis (Van Westen et al., 2008). Van Den Eeckhaut et al. (2007) found that $85 \%$ of landslides in the Flemish Ardennes are located under forest, resulting from poor landslide inventory compiled from aerial photo interpretation (API). Brardinoni et al. (2003) reported that undetectable landslides from API can represent up to $85 \%$ of the total number of failures and significant volume (up to $30 \%$ ) of debris to the amount mobilized.

Given that the quality of filtered ALS points has a direct impact on derivative products, the field validation data should be collected independently, and with a higher precision (Pfeifer and Mandlburger, 2009). Error assessment of ALS-based DTMs is difficult, time-consuming, and expensive, and it is even more so in a rainforest. In this study, however, we succeeded to collect 448 
validation points using different space-based geodetic measurements techniques (e.g. Static, RS and RTK) coupled with a high precision local surveying tool (e.g. Total Station). This approach is relatively fast, accurate, and more practical compared to optical levelling techniques, such as used in tropical forests by Hofton et al. (2002).
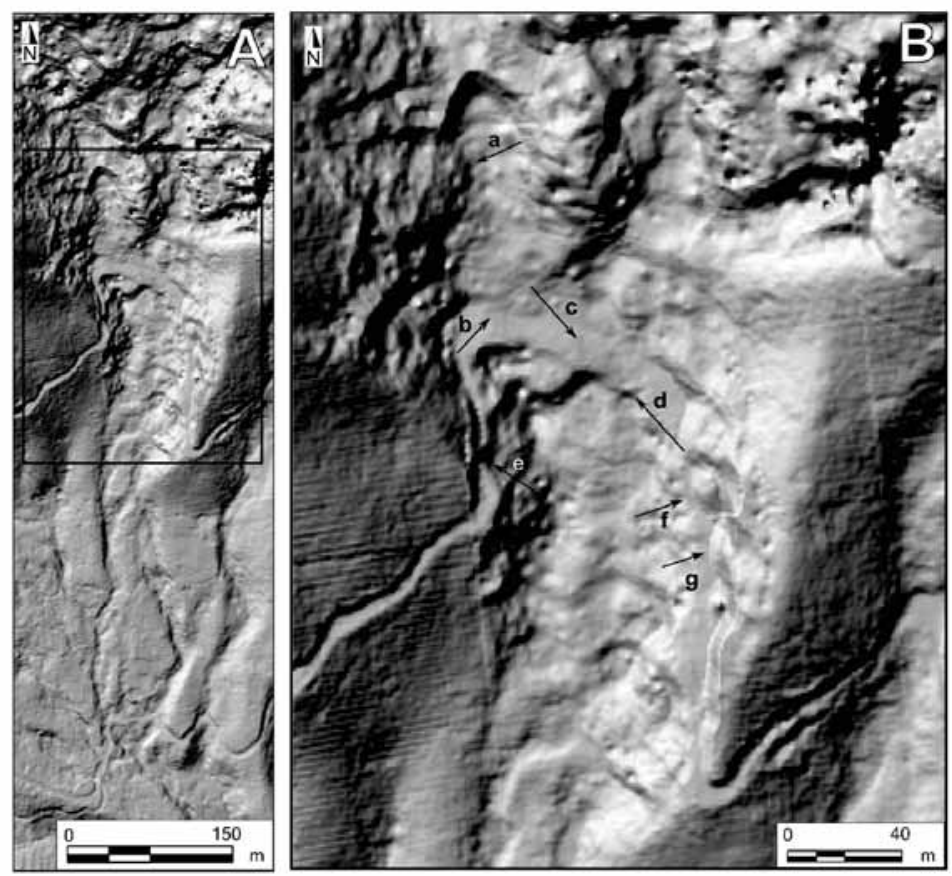

Fig. 4.6: Diagnostic features for recent landslide activity revealed by an ALS-derived image. A) Image of area $\mathrm{V}$ in Fig. 2.5B. B) Close up view. Arrows indicate points where landslide features were detected: i) arrow a indicates a lateral landslide deposit that partially covered the escarpment, and depletion zone of the slope failure indicated by arrow b; (ii) arrows b, c, f, g indicate landslide deposit partially blocking a road; (iii) arrows e and $d$ indicate two slope failures which have partially eroded a road.

The vertical accuracy of twelve DTMs (four interpolators for each filter) varied between 4.203 and $0.886 \mathrm{~m}$ of overall RMSE. The accuracy differed depending on the completeness of filtering to remove the vegetation and the surface interpolation techniques used. These results are an improvement compared to Clark et al. (2004) who reported a DTM with an overall RMSE of $2.29 \mathrm{~m}$ in the tropical wet forest in Costa Rica. The DTM accuracy of a smallfootprint ALS sensor data evaluated in this study is much better than a largefootprint LVIS sensor data with an overall RMSE of $5.64 \mathrm{~m}$ (Hofton et al., 2002) and the stereo-radargrammetry technique (Baghdadi et al., 2005; Chen et al., 2007) acquired in tropical rainforest regions. 
Clark et al. (2004) found higher errors with higher slope in the Costa Rican rainforest and we found a similar pattern in our study area. Interestingly, we found $83 \%$ of landslides to be located at slopes below $40 \%$ where a low DTM error $(<1 \mathrm{~m})$ was reported. This is important as a threshold angle of slope steepness is often used in determining the landslide initiation, and the shallow and rapid landslides prevailed in the aforementioned slope gradient (Sidle and Ochiai, 2006).

The large errors obtained in the rugged forested terrain are due to dense undergrowth on the slopes, structurally complex trees, steep terrain, and sharp edges. These conditions are challenging for all bare-earth extraction algorithms (Sithole and Vosselman, 2004). Furthermore, we observed that only few points represented the ground surface under very dense forest, even though first and last return data were recorded. Locally point density was reduced by heavy low altitude cloud cover, leading to smoothing effects. Contrarily, the filtering in the tea plantation zone performed well, even after the first filter. This is because of HRI algorithm in which its filter characteristics (e.g. points-to-points operation, surface-based filter structure) can filter out the points relatively easy in the tea plantation zone, as most of the tea is likely to have same plant height, planted in a systematic way, with few tall trees randomly scattered over the area.

The landslide interpretation using the ALS-derived images is based on the recognition of elements associated with slope movements and the identification of their significance to slope instability. We observed that landslide recognition was not the same for each level of filtering. The third filtering step even led to a significant reduction in interpretability, while overall the vertical error did reduce. A clear trade-off for automatic filtering was observed between the amount of vegetation removed and the amount of micro-morphology retained in the images that allowed a better landslide interpretation. Non-ground features (e.g. trees and buildings) were removed in the third filter step; however it resulted in artifacts and excessive smoothing. Slope failures can still be mapped in such images but result in incomplete landslide inventory maps with high uncertainties. Contrarily, the less stringent filtering, i.e., the first and second filters better depicted the general slope morphology, reducing the artifacts with respect to the third filter. More diagnostic landslide features were represented coupled with clear indications of micro-morphology, although vegetation pattern is sometimes still visible on the images. Hence a purely quantitative error assessment does not lead to the best DTM for landslide inventory mapping.

The qualitative assessment of ALS-derived DTMs revealed that IDW-derived images preserved macro- and micro-morphological features much better as compared to other surface interpolation methods assessed in this study. It is 
worth mentioning that an optimal ALS image applicable for landslide identification is also dependent on the scale of observation and dimension of the geomorphologic features. In most of the cases, a combination of different image sources or scales is required to reduce uncertainty in landslide mapping. Moreover, the analysis proved that the suitability of DTMs for landslide mapping for each filtering step is also a function of (i) the size of the morphological features (ii) the degree of tropical vegetation cover (iii) the type of geomorphological features to be observed, i.e. neotectonic alignments.

\subsection{Conclusion}

Mapping landslides in humid tropical mountainous regions is a difficult task due to the poor accessibility, the rapid re-vegetation, and cloudy weather conditions. In this study we presented and evaluated a novel method using ALS-based DTMs resulted from various filtering parameterizations and surface interpolations for landslide inventory mapping in an equatorial mountainous landscape.

We showed that a small-footprint ALS system enabled identification and classification of complex landslides beneath dense vegetation, but care should be taken in filtering the data in a equatorial evergreen rainforest. We quantitatively assessed the terrain models associated to landslides with 448 field-measured terrain height points, resulting in a lowest overall RMSE of $0.886 \mathrm{~m}$ across the landscape, which is an improvement over previous studies. The presented method is favorable for dense, structurally complex forests as other satellite-, or airborne remote sensing techniques perform poorly in these areas. Compared to the previous mapping efforts, the ALSderived images revealed 10 times more landslides and previously unknown neotectonic features in a tropical populated region with poor seismic data.

A combination of filtering steps is needed for optimal landslide identification under dense tropical forests. Less stringent filtering produced a DTM that revealed more diagnostic micro-morphology, but also left some of the vegetation in the DTM. A low RMSE alone is not a good indication for landslide interpretability and should not be the aim of any data analyst. The experts found that the IDW-derived DTM is preferable for landslide interpretation. The fact that there is no single best method for DTM generation, made it necessary to the use of qualitative measures for DTM interpretability of distinctive landslide geomorphology. We concluded that the density of the laser point and the resulting ground point density after filtering are key parameters for producing a DTM applicable for landslide mapping. 
The acquisition of precise terrain information has been of utmost importance for a better understanding of tropical landslides in equatorial forest environments. The reported accuracy and expert knowledge on ALS-derived DTMs posed in the present study are crucial aspects to properly determine the reliability and uncertainty of landslide inventory maps. Replicability still strongly depends on the quality of the DTM interpretation, and the time spent on the task. Given the complexity of the terrain, automating the inventorisation will still be challenging in the tropics. The method of the present study is recommended for all forested mountainous terrain affected by landslides in tropical and sub-tropical regions. 


\section{Chapter 5}

\section{Airborne laser scanning derived landslide inventory in the tropics: Map compilation and uncertainty analysis}

\subsection{Introduction}

Landslides occur over a wide variety of spatial and temporal scales across all continents. They vary in terms of the type, size, volume, length of runout, speed of movement, materials involved, and the triggering mechanism (Soeters and Van Westen 1996). Although landslide maps are extremely important for estimating future hazard and risk and for reducing damage and victims (Brabb and Harrod 1989; Brabb 1991) it is estimated that currently still less than $1 \%$ of the sloping areas in the world are covered by landslide inventory maps (Guzzetti et al. 2012). Such landslide maps should show the locations of landslides, the topology and geometrical characteristics, the possible failure mechanism, the state of activity and frequency of occurrences, the causal factors, and the historical damage (Wieczorek 1984; Guzzetti et al. 2000; Van Westen et al. 2008; Guzzetti et al. 2012).

Landslide inventories are carried out using a variety of techniques. A recent overview of the methods used for landslide inventory mapping is given by Guzzetti et al. (2012). Visual interpretation of stereoscopic imagery remains the most widely used method, and results in the best inventories when carried out by expert interpreters (Cardinali et al. 2002). Nowadays, many parts of the world are covered by high resolution imagery, which can be downloaded, and combined in a Geographical Information System (GIS) with a Digital Terrain Model (DTM) to generate stereoscopic images essential for landslide survey and interpretation.

One of the most important recent developments is the use of shaded relief images produced from Airborne Laser Scanning (ALS) DTMs. Objects (e.g. vegetation and constructions) at the earth surface have been removed from these ALS data to facilitate visual interpretation of landslide phenomena

* This chapter is based on:-

Razak, K.A., Van Westen, C.J., Santangelo, M., Damen, M., Abd Talib, J., Endut, N.B., Cardinalli, M., Straatsma, M.W., de Jong, S.M. Airborne laser scanning derived landslide inventory in the tropics: Map compilation and uncertainty analysis. Submitted to Earth Surface Processes and Landforms. 
(Haugerud et al. 2003; Ardizzone et al. 2007; Van den Eeckhaut et al. 2009; Razak et al. 2011).

Despite remarkable efforts of compiling and updating landslide inventory maps at regional, national or global scales, only little effort is made to quantify their quality (Carrara et al. 1992; Guzzetti et al. 2000; Guzzetti et al. 2002). There are no standards defined for the method that should be used for landslide inventory mapping, and for expressing the accuracy (Galli et al. 2008). The accuracy of a landslide inventory depends on the completeness of the map, and the geographical and thematic correctness of the information depicted on the map (Guzzetti et al. 2012).

The completeness refers to the proportion of landslides compiled in a particular inventory as compared to the real areal extent of the landslides. This is a complicated issue as there is generally no true and error free landslide inventory map to compare with. The completeness not only refers to the presence or absence of all landslides, but also to the presence of relevant attribute information. In many mountainous areas, landslides are one of the most important landscape processes, and over a long period of time, many slopes may have experienced landslide processes in one form or another. One of the most complicating factors is that the geomorphological expression of landslides is slowly getting less clear due to weathering, soil erosion, vegetation regrowth and anthropogenic modification. Therefore a fully complete landslide inventory map is probably a utopia, unless it is made for a specific period of time (Van Den Eeckhaut et al. 2007; Guzzetti et al. 2012). The accuracy of an inventory depends on multiple factors (Guzzetti et al. 2012): i) the scale, date and quality of the materials or data used to make the inventory from, ii) the type, scale and quality of the topographic base map used as a reference for the landslide information, iii) the tools used to interpret and analyze the imagery i.e., stereoscopes and computer 3D visualization devices, iv) the skills and experience of the interpreters, and v) the time spend on the inventory.

The geographical correctness relates to an accuracy measure of a landslide in a map corresponding to its position, size, area and shape of the same landslide in the field (Santangelo et al. 2010). An important aspect is whether inventory maps depict landslides as points or as polygons. This has important implications for further analysis, e.g. for size-frequency analysis. If landslides are mapped as polygons it is very relevant whether initiation and accumulation areas are mapped separately, which is quite relevant when using them as input for susceptibility and hazard analysis. Another important component associated to the geographic accuracy is related to the landslide topology, especially for landslides with several phases of reactivation on top of each other. The thematic correctness refers to the conformity of the 
attribute information associated to each slope failure, with respect to the description of the type, age, depth, volume, and activity.

Carrara et al. (1992) emphasized that the uncertainty or error of landslide mapping is larger in areas with old, dormant landslides, covered by dense vegetation, and landslide zones modified by intense farming activities. These factors of uncertainty are predominately observed in populated tropical environments. In these areas, landslide mapping using image interpretation from aerial-photographs or satellite images is difficult as diagnostic landslide features fade quickly by subsequent erosion or vegetation growth. Tropical vegetation regenerates very rapidly masking the distinctive landslides diagnostic features within a few years for larger landslides and within a few months for shallow slope failures. This complicates the survey of landslides under tropical vegetation (Guzzetti et al. 2012).

Landslides in humid regions are often triggered by very intense and prolonged monsoon rainfall, the landscape is characterized by progressive weathering, steep slopes, rapid vegetation growth, and anthropogenic activities. These characteristics complicate the work of landslide interpreters, even using high resolution ALS data, and may result in landslide maps affected by a relatively large positional error. Cruden and Varnes (1996) emphasized that not all landslides are clearly or easily recognizable, simply because of a large variability of landslide phenomena. Wills and McCrink (2002) underlined that there are always landslides that have very subtle expression and are not recognized in heavily forested terrain. For deepseated landslides under forest, recognizing the exact extent of the failed mass may not be easy even for fresh slope failures (Guzzetti et al. 2012).

So far, very few studies have analyzed the reliability of landslide inventory maps in tropical areas compiled through image interpretation of aerial photographs or satellite-images (e.g. Fookes et al. 1991). Recently, the application of ALS has proven to be a very useful new tool to prepare and update landslide inventory maps in a tropical landscape (Chapter 4). The removal of vegetation from ALS data and the use of stereoscopic interpretation of ALS-derived hillshading images proved to be a very effective tool to map and classify even old and dormant landslides beneath tropical forest (Chapter 4). However, no studies have tried to quantify the uncertainty of landslide inventory maps produced from ALS data in a tropical mountainous region.

The aim of this chapter is to quantitatively evaluate the positional mismatch and completeness of ALS-derived landslide inventory maps compiled by means of expert-based visual image analysis for a test area in the Cameron Highlands, Malaysia. Six expert interpreters prepared geomorphological (i.e. 
"historic", sensu Malamud et al., 2004) landslide inventory maps based on systematic visual interpretation of stereoscopic ALS-derived images. Two reference landslide maps in forested (secondary and old-growth) and partly forested (agriculture and tea plantation) areas were carefully defined. The existing landslide inventory map compiled by Pradhan and Lee (2010) was also incorporated in the quantitative map comparison analyses.

\subsection{Data and methods}

\subsubsection{Airborne laser scanning data and DTM generation}

In this study, we used an ALS point cloud of 113 million points with a mean point density of 1.83 points $\mathrm{m}^{-2}$ that was provided by the Department of Surveying and Mapping of Malaysia (JUPEM). The ALS campaign was carried out by JUPEM over the Cameron Highlands in June 2004, using an Optech ALTM 3100 laser scanner, ALTM IMU, and Trimble 4000SS positional system. The ALS system can measure up to 100,000 pulses per second, and has a saw-tooth scanning pattern. The data and maps were compiled in a local coordinate system, the Malaysia Rectified Skew Orthomorphic projection system (Mugnier, 2009).

The ALS bare earth extraction was carried using the hierarchical robust interpolation algorithm embedded in the SCOP++ software (TUV, 2012). The software had a stepwise filter parameterization, appropriate for dense vegetation and a low point density (Chapter 4). The accuracy of the ALSderived DTM was quantitatively assessed with 448 ground-surveyed reference points collected using high precision differential GPS and a total station. The landslide DTM had an overall RMSE of $0.886 \mathrm{~m}$ (Chapter 4 ). The DTM was used to generate hillshading images for the study area, with a spatial resolution of $1 \mathrm{~m}$. The hillshading image and DTM were used to produce a stereopair with the ILWIS software (ILWIS, 2012).

\subsubsection{ALS-derived landslide inventories and reference maps}

Hard- and softcopy ALS-derived hillshading images were given to six image interpretation experts, and they were asked to make a landslide inventory map for the study area. The experimental scheme of image interpretation was summarized and coded as indicated in Table 5.1.

The interpreters received a guideline to map the landslides based on diagnostic morphological features such as semi-circular niches, cracks, primary and secondary scarps, convex and concave slopes, hummocky topography and displaced material zone (Soeters and Van Westen 1996; 
Chapter 3). Also, interrupted drainage lines and disrupted roads were used as indicators. Landslide interpretation was performed by carefully delineating the landslide margins and storing them as polygons. Some of the interpreters also provided the additional information, e.g. the landslide types, accumulation and depositional areas and the direction of the landslide movement. Lineaments were also recognized and stored in a separate map. To avoid bias in the experimental landslide interpretation, the interpreters had no access to other landslide maps for the area.

The interpreters were free to choose their preferred method of image interpretation. All landslide interpreters made use of stereoscopic images to identify and map the landslides in the study area. Interpreters Map 1 and Map 2 used only hardcopy stereo images because of limited performance of hardware and inaccessibility to appropriate software for landslide identification. Their landslide inventory maps were digitized using ESRI ArcGIS 10 software and the data were stored in a GIS. Interpreters Map 3, Map 5 and Map 6 carried out a digital on-screen interpretation with a variety of visualization techniques at scales ranging from $1: 25000$ to $1: 500$, whereas Map 4 used a mirror stereoscope to produce outlines. These were subsequently digitized and stored in a GIS.

Interpreters Map 1, Map 2, Map 3, and Map 4 used a relatively short period, of two to three days to complete the landslide map. They also used a single hillshading image which was derived from the most accurate ALS image (RMSE 0.866 m; Chapter 4). Interpreters Map 5 and Map 6 used more time ( 5 to 8 days) and produced a more detailed interpretation than the other interpreters. In addition, they were provided with ALS-derived hillshading images resulting from all three DTM filtering steps and three methods for surface interpolations (Chapter 4). However, they were both not able to complete the inventory for the entire area. Therefore, Map 5 concentrated on mapping landslides in the partly vegetated areas (agriculture and tea plantation) and Map 6 focused on the landslides in the forested area. Map 6 also indicated the certainty of each mapped landslide, its type, depth and relative age, detailed morphological (sub)-units, structural lineament, and neotectonic features.

\subsubsection{Existing landslide inventory map}

The existing landslide inventory map (Pradhan and Lee, 2010a) was used and referred as Map 7 (Table 5.1). It contained 55 small landslides in the study area, mainly occurring along the roadcuts. This inventory was compiled by means of visual interpretation of archived aerial photographs (with scales ranging from $1: 10000$ to $1: 50000$ ), satellite images (SPOT 5 panchromatic, IKONOS, and RADARSAT), landslide archives over the past 21 years. In 
addition, several field campaigns were carried out in the period 2006 to 2008 (Pradhan and Lee 2010; Pradhan et al. 2010), using a standard field data collection with dGPS. This inventory has been used for regional landslide susceptibility mapping (Pradhan and Lee 2010; Pradhan et al. 2010; Pradhan 2010) and landslide hazard analysis (Pradhan and Youssef 2010; Pradhan 2010).

\subsubsection{Quantitative assessment of tropical landslide inventories}

We analyzed the geographical uncertainty by calculating the percentage of mapping error (ME) as presented by Carrara et al. (1992). The overall mapping error is also referred to as positional mismatch, or geographical discrepancy. This method is widely used to quantitatively assess the uncertainty of generated landslide inventory maps in various regions (e.g. Ardizzone et al. 2002; Van Den Eeckhaut et al. 2007; Galli et al. 2008; Santangelo et al. 2010). The ME index can be calculated (Eq. 5.1) as:

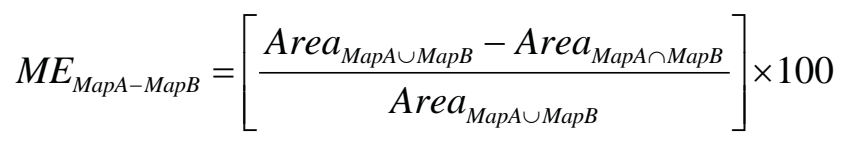

where $\cap$ and $\cup$ are the symbols for the intersection and union, respectively, of two maps (Maps A, B), Area $a_{M a \cup M b}$ is the area of landslide polygons

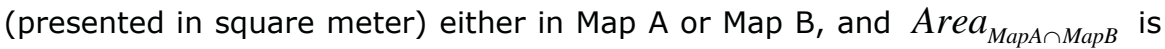
the area of landslide polygons $\left(\mathrm{m}^{2}\right)$ indicated as a landslide in both Map A and Map B. We performed pairwise geographical union and intersection of the landslide maps using ESRI ArcGIS 10. Carrara et al. (1992) indicated that the overall mapping error represents the total error associated to interpretation, classification, topographic locations, digitizing and georectification. 
Table 5.1: Characteristics of the landslide inventory maps available in the Cameron Highlands, Malaysia

\begin{tabular}{|c|c|c|c|}
\hline $\begin{array}{l}\text { Landslide inventory } \\
\text { and code }\end{array}$ & \begin{tabular}{|l|} 
Method of \\
compilation
\end{tabular} & Type of data used & $\begin{array}{l}\text { Interpretation } \\
\text { modes }\end{array}$ \\
\hline $\begin{array}{l}\text { Map 1: ALS-derived } \\
\text { landslide inventory }\end{array}$ & $\begin{array}{l}\text { Visual interpretation } \\
\text { using a mirror } \\
\text { stereoscope and tracing } \\
\text { papers }\end{array}$ & $\begin{array}{l}\text { Stereo-pair colour } \\
\text { composite ALS } \\
\text { images (hardcopy) }\end{array}$ & $\begin{array}{l}\text { Stereoscopic } \\
\text { interpretation }\end{array}$ \\
\hline $\begin{array}{l}\text { Map 2: ALS-derived } \\
\text { landslide inventory }\end{array}$ & $\begin{array}{l}\text { Visual interpretation } \\
\text { using an anaglyph glass } \\
\text { on ALS images and } \\
\text { tracing paper }\end{array}$ & $\begin{array}{l}\text { Anaglyph hill- } \\
\text { shading ALS images } \\
\text { (hardcopy) }\end{array}$ & $\begin{array}{l}\text { Stereoscopic } \\
\text { interpretation }\end{array}$ \\
\hline $\begin{array}{l}\text { Map 3: ALS-derived } \\
\text { landslide inventory }\end{array}$ & $\begin{array}{l}\text { Digital stereo on screen } \\
\text { landslide interpretation }\end{array}$ & $\begin{array}{l}\text { Anaglyph hill- } \\
\text { shading ALS images } \\
\text { (softcopy) }\end{array}$ & $\begin{array}{l}\text { Stereoscopic } \\
\text { interpretation }\end{array}$ \\
\hline $\begin{array}{l}\text { Map 4: ALS-derived } \\
\text { landslide inventory }\end{array}$ & $\begin{array}{l}\text { Visual interpretation } \\
\text { using a mirror } \\
\text { stereoscope and later } \\
\text { transferred into a GIS } \\
\end{array}$ & \begin{tabular}{|l|} 
Stereo-pair color \\
composite ALS \\
images (hardcopy)
\end{tabular} & $\begin{array}{l}\text { Stereoscopic } \\
\text { interpretation }\end{array}$ \\
\hline $\begin{array}{l}\text { Map 5: ALS-derived } \\
\text { landslide inventory - } \\
\text { Reference map in } \\
\text { agriculture and tea } \\
\text { areas }\end{array}$ & \begin{tabular}{|l|} 
Digital stereo on-screen \\
landslide interpretation
\end{tabular} & $\begin{array}{l}\text { Anaglyph hill- } \\
\text { shading ALS images } \\
\text { (softcopy) }\end{array}$ & $\begin{array}{l}\text { Stereoscopic } \\
\text { interpretation }\end{array}$ \\
\hline $\begin{array}{l}\text { Map 6: ALS-derived } \\
\text { landslide inventory - } \\
\text { Reference map in } \\
\text { forested terrain }\end{array}$ & $\begin{array}{l}\text { Digital stereo on-screen } \\
\text { landslide interpretation }\end{array}$ & $\begin{array}{l}\text { Anaglyph hill- } \\
\text { shading ALS images } \\
\text { (softcopy) }\end{array}$ & $\begin{array}{l}\text { Stereoscopic } \\
\text { interpretation }\end{array}$ \\
\hline $\begin{array}{l}\text { Map 7: Existing } \\
\text { landslide inventory }\end{array}$ & \begin{tabular}{|l|} 
Visual interpretation on \\
optical images, \\
historical data and field \\
mapping in non-forested \\
areas.
\end{tabular} & $\begin{array}{l}\text { Aerial-photos, } \\
\text { satellite-, radar } \\
\text { images and } \\
\text { fieldwork }\end{array}$ & \begin{tabular}{|l} 
Mono- and \\
stereoscopic \\
interpretations
\end{tabular} \\
\hline
\end{tabular}

To overcome the lack of a generally accepted true landslide inventory map, we selected different reference data for forest and for partly vegetated areas. In the forested terrain, we used Map 6 as the reference map as we consider it the most detailed and correct one since it was compiled by carefully examining different ALS-derived images that resulted from different filter parameterizations and surface interpolations (Chapter 4). In the partly vegetated areas (agriculture and tea plantation) we used Map 5 as the reference map. Moreover we also compared the ALS-derived maps with the existing landslide inventory maps. Fig. 5.1 shows the areas of interest indicating the land cover map that was used in presenting the quantification of map uncertainty.

\subsubsection{Comparison of size-frequency distributions}

Frequency-size statistics of the different inventories have also been computed to compare the different inventories, and to support considerations on the degree of completeness of the presented landslide inventories. In general an inverse relationship exists between landslide area and frequency of 
occurrence in a specific area (Malamud et al., 2004; Ghosh et al., 2012). This has been observed for many landslide types, patterns, and triggering mechanisms, and in different geological, geomorphological, lithological, climatic and environmental settings. The size-frequency distribution is calculated using the following equation:

$\rho\left(\mathrm{A}_{L}\right)=\frac{1}{N_{L T}} \frac{\delta N_{L}}{\delta A_{L}}$

Where $\delta N_{L}$ is the number of landslides with areas between $A_{L}$ and $A_{L}+\delta A_{L}$ and $N_{L T}$ is the total number of landslides in the inventory. The bin width $\delta A_{L}$ is the range of landslide areas that are grouped together. The bin width increases with increasing area $A_{L}$ so that bin widths are approximately equal on a logarithmic scale.

In this research, probability density functions are fitted with the Double Pareto distribution function of Stark and Hovius (2001), and with the Inverse Gamma function of Malamud et al. (2004). The computation was done using an R script available as Web Processing Service (Rossi et al., 2012; Marchesini et al., 2012), which implements parametric and non-parametric approaches to estimate the probability density and frequency density of landslide size. Double Pareto models of probability density of the landslide area, $p\left(A_{L}\right)$, were obtained through maximum likelihood estimation (Rossi et al., 2012). We chose to compare the distributions based on the parameters a (which represents the slope of the heavy tail of the distribution, the higher the value, the higher the slope), and $\bar{A}$, the area of the most frequent landslide in the estimated distributions (i.e. the rollover point). The service is accessible through the web using a local client, and is capable of handling landslide inventory ESRI shapefiles.

\subsection{Results}

The output of the analyses presents the geographical accuracy and the completeness of the landslide inventory maps. First, the summary statistics of the individual landslide maps are presented, followed by the error assessment. The completeness was assessed based on the output of the sizefrequency distribution. 


\subsubsection{Expert-based landslide inventory mapping using ALS data}

The results of the landslide inventory mapping are shown in Fig. 5.1 and Table 5.2. The number of landslides mapped using ALS data ranged between 68 (Map 1) and 561 (Map 5). The two reference maps (Map 5 and Map 6) had a much larger number of landslides as compared to the other interpreted maps (Maps 1-4), even though they did not cover the entire area. The overlapping areas of the reference maps (refer to the two red tones) and other maps (different colors) can be seen in the southern parts of forested and agriculture area (Fig. 5.1A, B). The number of landslides mapped from ALS images is substantially larger than those from the existing inventory ( 55 only). On average, the total area affected by landslides was rather high for the agriculture and forested areas respectively. Also this is substantially larger than for the existing landslide inventory ( 0.4 percent of the total area), which indicates that the ALS-derived images allow the recognition of many more landslides that are missed using a conventional technique. Map1 seems to be exaggerating the landslide size substantially as it had the lowest number of landslides and the largest landslide area of all ALS-derived maps.

The results of a descriptive statistics of the ALS-derived landslide inventories and the existing map for the three land use types are given in Tables 5.3-5.5. It can be concluded that the number of landslides in the reference maps is always substantially larger than in the other ALS-derived maps. The total area mapped as landslide area varies considerably, depending on the interpreter, and can be either underestimated (due to the limited number of landslides mapped) or overestimated (due to the extreme size of landslides mapped). The total number of landslides in the existing map was much lower than the reference map based on ALS data. This is an important indication that ALS maps can produce better inventories especially in forested terrain, as the ALS-derived DTM allows to recognize landslide features beneath tropical vegetation that are impossible to recognize using optical images. 

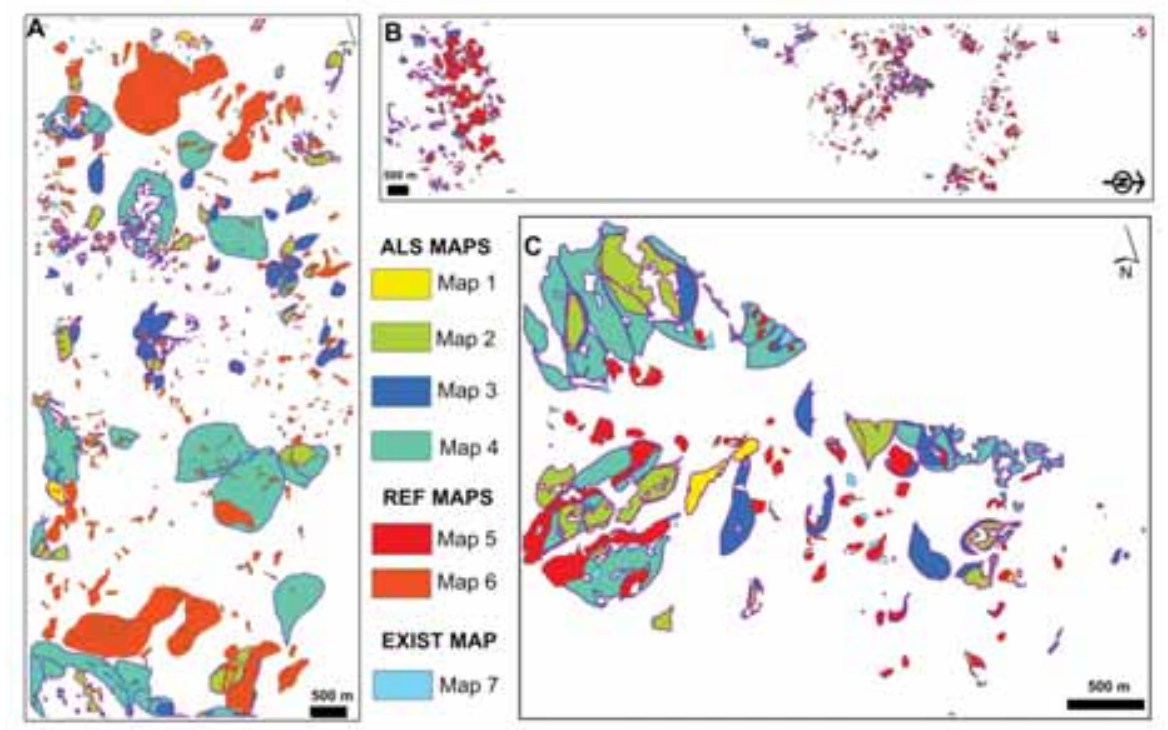

Fig. 5.1: Landslide inventory maps presented based on land cover types. A) Forested terrain. B) Agriculture area. C) Tea plantation area. Two different reference maps were used: i) Map 6 for forested area, ii) Map 5 for agriculture and tea plantation zones. The areas of interest of A, B, C represented three land cover classes (Fig. 2.5; Chapter 2).

Table 5.2: Characteristics of the ALS-based reference maps, ALS-based inventory maps and the existing landslide inventory map in the Cameron Highlands, Malaysia

\begin{tabular}{|l|c|c|c|}
\hline & $\begin{array}{l}\text { Total number of } \\
\text { mapped landslides }\end{array}$ & $\begin{array}{l}\text { Total area affected by } \\
\text { landslide area (ha) }\end{array}$ & $\begin{array}{l}\text { Percent of } \\
\text { affected area }\end{array}$ \\
\hline ALS-based reference maps & 11.6 \\
\hline $\begin{array}{l}\text { Map 6 } \\
\text { (forested area) }\end{array}$ & 453 & 541.6 & 10.9 \\
\hline $\begin{array}{l}\text { Map 5 } \\
\text { (partly vegetated) }\end{array}$ & 561 & 1093.1 & 12.4 \\
\hline ALS-based inventory maps & & 4.8 \\
\hline Map 1 & 68 & 1242.9 & 4.9 \\
\hline Map 2 & 93 & 475.8 & 2.6 \\
\hline Map 3 & 113 & 263.2 & 0.4 \\
\hline Map 4 & 153 & 38.3 & \\
\hline Existing inventory map & 55 & \multicolumn{5}{l}{} \\
\hline Map 7 & \multicolumn{5}{|l}{} \\
\hline
\end{tabular}


Table 5.3: Summary statistics of landslide inventory maps for forested terrain

Table 5.3: Summary statistics of landslide inventory maps for forested terrain
\begin{tabular}{|l|l|l|l|l|l|l|}
\hline & \multicolumn{5}{|c|}{ ALS-derived landslide inventory maps } & $\begin{array}{c}\text { Existing } \\
\text { map }\end{array}$ \\
\cline { 2 - 7 } & Map 1 & Map 2 & Map 3 & Map 4 & $\begin{array}{c}\text { Map 6 } \\
\text { (Ref.) }\end{array}$ & Map 7 \\
\hline $\begin{array}{l}\text { Total number of } \\
\text { mapped landslides }\end{array}$ & 39 & 47 & 51 & 54 & 358 & 36 \\
\hline $\begin{array}{l}\text { Total mapped } \\
\text { landslide area (ha) }\end{array}$ & 618.7 & 181.8 & 145.8 & 2632.0 & 449.4 & 13.7 \\
\hline $\begin{array}{l}\text { Percent of landslide } \\
\text { area (\%) }\end{array}$ & 16.3 & 4.8 & 3.8 & 2.63 & 11.9 & 0.3 \\
\hline $\begin{array}{l}\text { Smallest mapped } \\
\left.\text { landslide (10 } \mathrm{m}^{2}\right)\end{array}$ & 1.1 & 0.7 & 2.0 & 1.0 & 5.0 & 0.9 \\
\hline $\begin{array}{l}\text { Largest mapped } \\
\text { landslide (ha) }\end{array}$ & 87.5 & 23.8 & 20.3 & 167.5 & 85.6 & 1.4 \\
\hline $\begin{array}{l}\text { Perimeter mapped } \\
\text { landslide (10 } \mathrm{m} \text { ) }\end{array}$ & 73.6 & 44.2 & 40.9 & 83.2 & 150.1 & 13.0 \\
\hline
\end{tabular}

Table 5.4: Summary statistics of landslide inventory maps for agricultural areas

\begin{tabular}{|l|l|l|l|l|l|l|}
\hline & \multicolumn{5}{|c|}{ ALS-derived landslide inventory maps } & \multicolumn{1}{|c|}{$\begin{array}{c}\text { Existing } \\
\text { map }\end{array}$} \\
\cline { 2 - 7 } & Map 1 & Map 2 & Map 3 & Map 4 & $\begin{array}{c}\text { Map 5 } \\
\text { (Ref.) }\end{array}$ & Map 7 \\
\hline $\begin{array}{l}\text { Total number of } \\
\text { mapped landslides }\end{array}$ & 32 & 52 & 73 & 121 & 525 & 36 \\
\hline $\begin{array}{l}\text { Total mapped } \\
\text { landslide area (ha) }\end{array}$ & 101.2 & 68.5 & 54.7 & 63.9 & 352.3 & 16.1 \\
\hline $\begin{array}{l}\text { Percent of } \\
\text { landslide area (\%) }\end{array}$ & 11.9 & 24.8 & 17.4 & 15.4 & 66.5 & 2.3 \\
\hline $\begin{array}{l}\text { Smallest mapped } \\
\text { landslide (10 } \mathrm{m})\end{array}$ & 10.6 & 11.4 & 2.0 & 1.0 & 1.0 & 0.2 \\
\hline $\begin{array}{l}\text { Largest mapped } \\
\text { landslide (ha) }\end{array}$ & 29.4 & 6.8 & 3.4 & 7.2 & 21.2 & 1.3 \\
\hline $\begin{array}{l}\text { Perimeter mapped } \\
\text { landslide (10 } \mathrm{m} \text { ) }\end{array}$ & 43.8 & 56.81 & 48.7 & 62.7 & 285.0 & 13.1 \\
\hline
\end{tabular}

Table 5.5: Summary statistics of landslide inventory maps for tea plantation area

\begin{tabular}{|l|l|l|l|l|l|l|}
\hline & \multicolumn{5}{|c|}{ ALS-derived landslide inventory maps } & \multicolumn{1}{c|}{$\begin{array}{c}\text { Existing } \\
\text { map }\end{array}$} \\
\cline { 2 - 7 } & Map 1 & Map 2 & Map 3 & Map 4 & $\begin{array}{c}\text { Map 5 } \\
\text { (Ref.) }\end{array}$ & Map 7 \\
\hline $\begin{array}{l}\text { Total number of } \\
\text { mapped landslides }\end{array}$ & 16 & 18 & 20 & 22 & 60 & 14 \\
\hline $\begin{array}{l}\text { Total mapped } \\
\text { landslide area (ha) }\end{array}$ & 151.8 & 46.6 & 67.1 & 25.7 & 42.1 & 5.4 \\
\hline $\begin{array}{l}\text { Percent of landslide } \\
\text { area (\%) }\end{array}$ & 25.9 & 7.9 & 11.5 & 4.4 & 7.2 & 0.9 \\
\hline $\begin{array}{l}\text { Smallest mapped } \\
\text { landslide (10 } \mathrm{m}^{2} \text { ) }\end{array}$ & 4.7 & 2.0 & 1.0 & 1.0 & 1.0 & 1.3 \\
\hline $\begin{array}{l}\text { Largest mapped } \\
\text { landslide (ha) }\end{array}$ & 24.8 & 7.3 & 16.4 & 6.6 & 6.9 & 0.7 \\
\hline $\begin{array}{l}\text { Perimeter mapped } \\
\text { landslide (10 } \mathrm{m} \text { ) }\end{array}$ & 37.5 & 19.1 & 22.3 & 13.0 & 26.1 & 4.2 \\
\hline
\end{tabular}


The different results presented in Figs. 5.2 and 5.3 illustrate that landslide recognition and classification are not straightforward, even for expert image interpreters. Sufficient time, appropriate interpretation tools and proper geomorphological knowledge are required for a better image interpretation of landslides in a tropical forested terrain. Otherwise it leads to a substantial uncertainty in landslide mapping. Fig. 5.2 shows a comparison of the appearance of four different geomorphologic features depicted on DTMs derived through Inverse Distance Weighting (IDW) interpolation of filtered ALS data (Chapter 4).

Figs. 5.2(A) and (B) show that the main landslide features (escarpment and deposition area) are not clearly distinguishable from an initial filtering step due to a partial removal of the dense vegetation cover that still obscures the surface, and landslide detection is affected by large uncertainty. For the same maps, a second filtering step seems to better highlight the terrain surface, without changing the general appearance of the slopes. When subsequent filter steps are applied, this results in the removal of all vegetation, but also leads to the smoothing of the terrain surface, making landslide recognition more uncertain. 

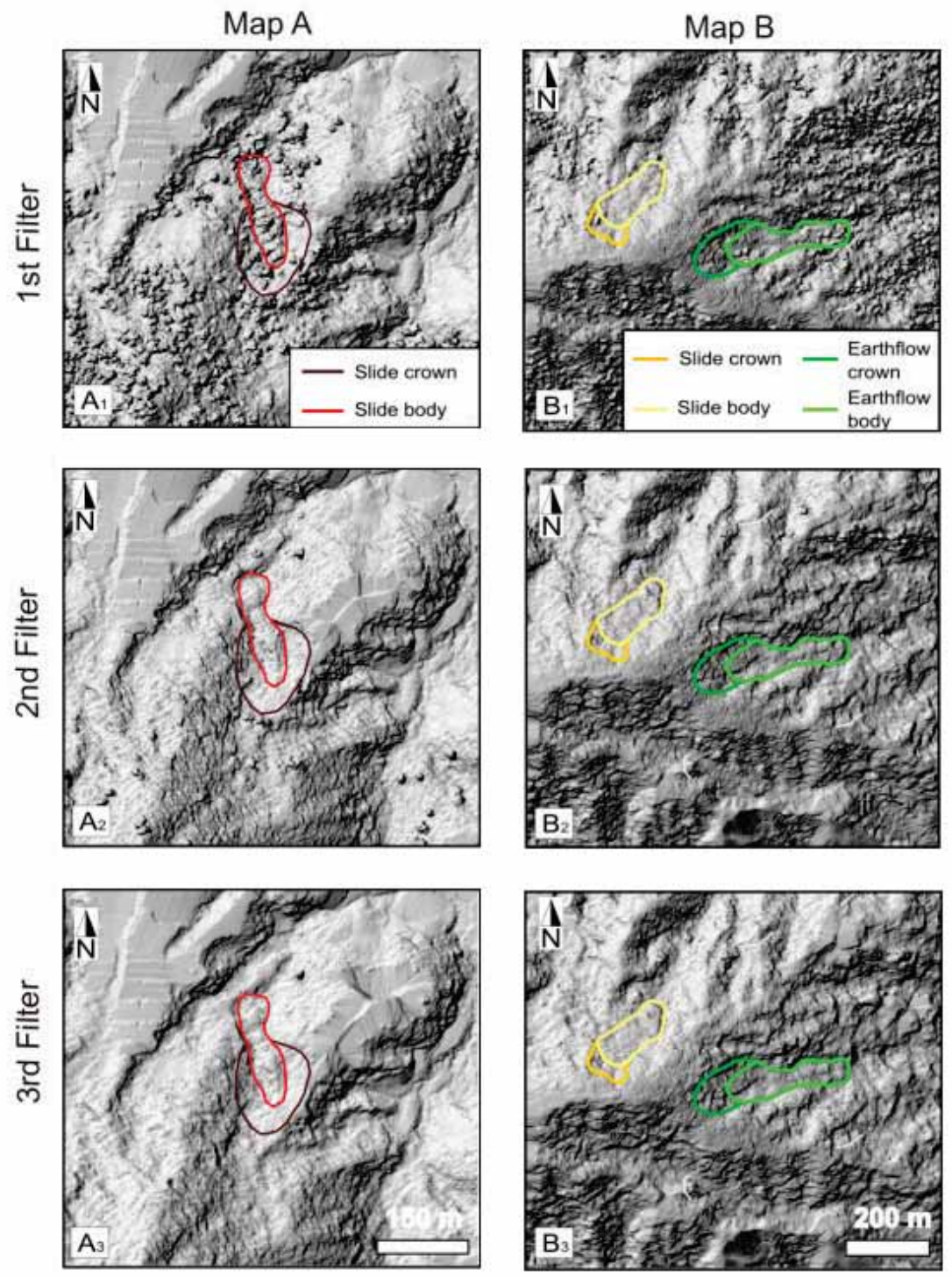

Fig. 5.2: Classification of landslide types and tectonic features derived from IDWderived DTMs for different ALS filters. A) Slide-earthflow was mapped with indication of crown and body zones. B) Slide and flow types of landslides in sparsely vegetated terrain.

Fig. 5.3 illustrates that very large, and apparently older and modified landslide complexes have morphological signatures that can be recognized from ALS-derived images, by observing the envelope of the slope shape and 
curvatures, and the pattern of the drainage network, even on low filtered images. Very small landslides are completely obscured by the vegetation and can be recognized only in highly filtered images. Figs. 5.3 (A) and (B) show a large landslide, recognized by adopting morphological criteria, related to surface roughness, land use pattern, a horse-shoe shaped drainage pattern, debris cones on the borders of the landslide deposit, restricted main stream valley, and a concave convex profile slope, which can be associated to the presence of an ancient large mass movement. In Figs. 5.3(C) and (D) two smaller landslides are portrayed, which form part of a larger, more complicated landslide complex with several stages of reactivation. In this case the first filter step proved to be unsuitable for landslide detection, while the minimum vegetation removal necessary for an appropriate image interpretation was reached by the second filter step. Figs. 5.3(E) and (F) show that small landslides are more distinct at the third level of filtering. Hence, image suitability for landslide detection is also dependent on the scale of observation and dimension of the geomorphologic features.

The results of the comparison of the landslide inventory maps by visual interpretation of ALS-hillshading images revealed that careful interpretation of such images is essential, and a range of different image products should be used to obtain the best results. Landslide interpretations based on a single type of ALS-derived image, or done without sufficient investment of time led to highly uncertain maps. However, ALS-derived inventory maps allow the identification of many more landslide features as compared to conventional inventory methods, especially for forested areas. An important point is that the landslides mapped from ALS images can also be older landslide complexes, which are now completely covered by dense vegetation.

\subsubsection{Error assessment of landslide inventory maps}

In order to make a quantitative analysis of the errors in the ALS-derived landslide inventory maps we made 45 pair-wise map comparisons, and calculated the mapping error. The results are presented in Tables 5.6 to 5.8. The error varied between 72 to $99 \%$, with the largest errors obtained in the forested terrain. The assessment in comparison to the reference maps resulted in mismatches ranging from 82 to $99 \%$, with the largest errors found in the forested terrain as well (Table 5.6). This indicates that the ALSderived maps (Map 1 to Map 4) seem to be of substantially lesser quality as compared to the reference maps (Map 5 and Map 6). Map 1-4 did not include many landslides in the reference maps. 

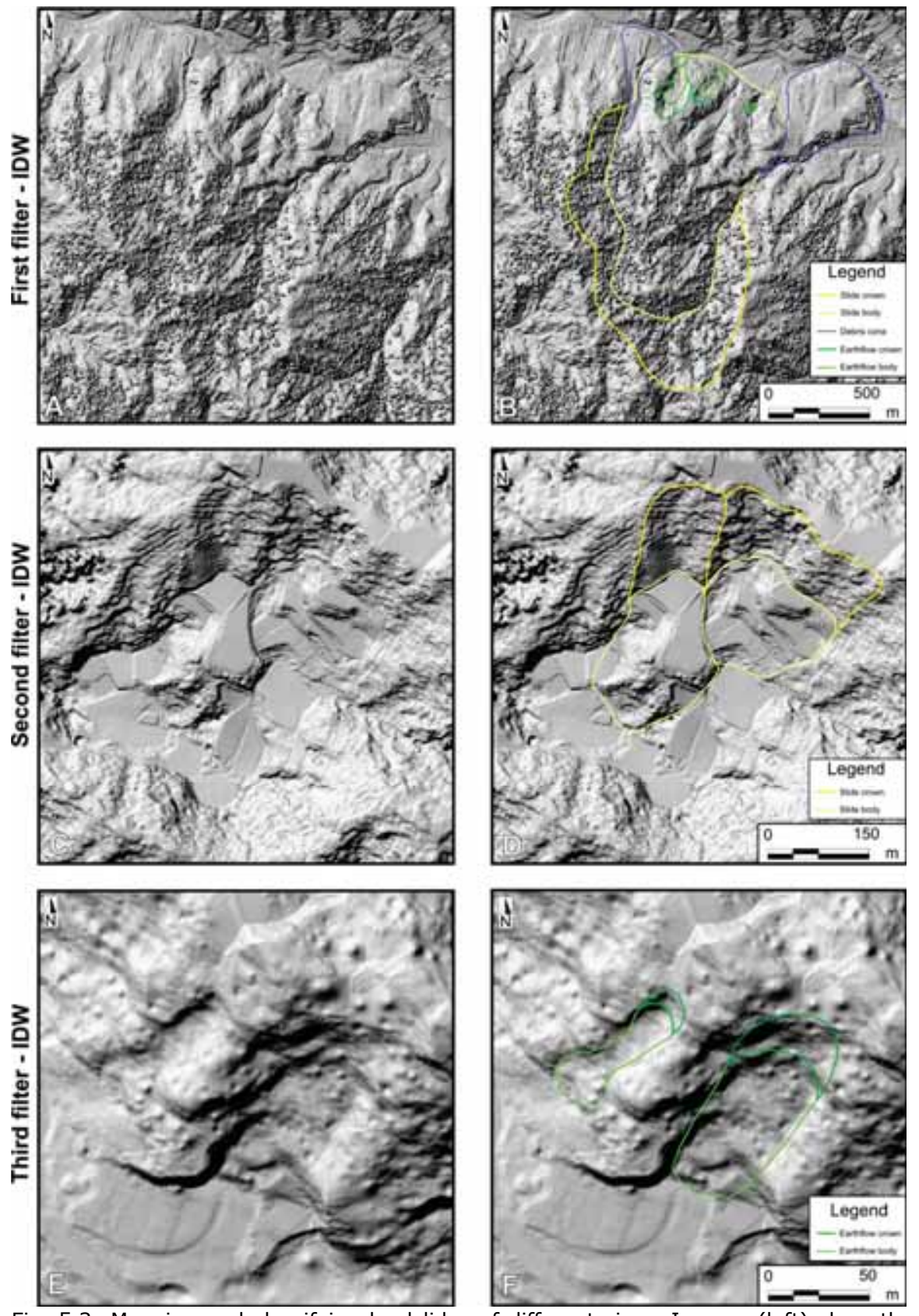

Fig. 5.3: Mapping and classifying landslides of different sizes. Images (left) show the image without landslide indication. An expert mapping is indicated (right). The size of the landslides determines, among the other factors, the best filter for landslide detection. 
The comparison of the individual ALS-derived inventories also resulted in very large discrepancies, indicating that they differ greatly. This is once again evidence that the use of ALS-derived hillshading maps is not a guarantee for success. Careful and dedicated image interpretation is required, using several products and carried out by skillful interpreters, that take sufficient time for interpretation.

Table 5.6: Mapping errors calculated for the pair-wise of landslide inventory maps presented based on forested terrain zone

\begin{tabular}{|l|c|c|c|c|c|}
\hline $\begin{array}{c}\text { Mapping error } \\
(\%)\end{array}$ & \multicolumn{3}{|c|}{ Among the ALS inventories } & $\begin{array}{c}\text { Existing } \\
\text { inventory }\end{array}$ \\
\cline { 2 - 6 } & Map 1 & Map 2 & Map 3 & Map 4 & Map 7 \\
\hline Map 6 & 95.82 & 94.51 & 93.39 & 99.65 & 99.43 \\
\hline Map 1 & & 95.72 & 90.12 & 98.55 & 99.01 \\
\hline Map 2 & & & 76.65 & 99.55 & 99.51 \\
\hline Map 3 & & & & 96.16 & 98.12 \\
\hline Map 4 & & & & & 99.31 \\
\hline
\end{tabular}

The geographical uncertainty was higher in the forested areas, as compared to the agricultural and tea plantation areas, due to the effect of smoothing of the DTM in the vegetation removal process. Landslide inventories from ALS maps for agricultural areas and tea plantation showed mapping errors between 84 to $93 \%$ and 82 to $98 \%$, respectively. The degree of mapping error of existing landslide map is higher in all map comparisons.

Table 5.7: Mapping errors calculated for the pair-wise of landslide inventory maps presented based on agriculture zone

\begin{tabular}{|l|c|c|c|c|c|}
\hline $\begin{array}{c}\text { Mapping error } \\
(\%)\end{array}$ & \multicolumn{3}{|c|}{ Among the ALS inventories } & $\begin{array}{c}\text { Existing } \\
\text { inventory }\end{array}$ \\
\cline { 2 - 6 } & Map 1 & Map 2 & Map 3 & Map 4 & Map 7 \\
\hline Map 5 & 89.56 & 93.23 & 90.56 & 84.68 & 98.82 \\
\hline Map 1 & & 92.31 & 86.81 & 94.70 & 99.01 \\
\hline Map 2 & & & 79.85 & 94.10 & 99.64 \\
\hline Map 3 & & & & 85.89 & 98.20 \\
\hline Map 4 & & & & 99.39 \\
\hline
\end{tabular}

Table 5.8: Mapping errors calculated for the pair-wise of landslide inventory maps presented based on tea plantation zone

\begin{tabular}{|l|c|c|c|c|c|}
\hline $\begin{array}{c}\text { Positional } \\
\text { mismatch } \\
(\%)\end{array}$ & \multicolumn{4}{|c|}{ Among the ALS inventories } & $\begin{array}{c}\text { Existing } \\
\text { inventory }\end{array}$ \\
\cline { 2 - 6 } & Map 1 & Map 2 & Map 3 & Map 4 & Map 7 \\
\hline Map 5 & 98.67 & 97.32 & 82.22 & 87.14 & 99.49 \\
\hline Map 1 & & 92.18 & 72.07 & 92.25 & 99.00 \\
\hline Map 2 & & & 86.09 & 97.11 & 98.46 \\
\hline Map 3 & & & & 85.34 & 99.50 \\
\hline Map 4 & & & & & 100 \\
\hline
\end{tabular}


A low positional error was found in the tea plantation area because the quality of ALS-derived DTM over the tea-landscape is better compared to other land cover types (Chapter 4) resulting in a larger degree of similarity of landslide maps. The existing landslide inventory map had very large positional errors (98 to $100 \%$ ) as compared to the ALS-derived reference inventory maps. This is due to the fact that the existing inventory has far less landslides than the reference inventories.

\subsubsection{Frequency-size distributions of landslide inventories}

Frequency-size statistics of all inventories were computed and the Double Pareto Model of probability density of the landslide area was obtained through maximum likelihood estimation. Fig. 5.4 shows the landslide frequency size statistics of the six landslide inventory maps produced by interpretation of ALS-derived images. The box plot and Table 5.9 show that (i) the area ranges covered by the different landslide inventories are much smaller for Maps 1 to 4 than for Maps 5 and 6, and that (ii) Maps 4 to 6 have a median of the $10^{3} \mathrm{~m}^{2}$ order, while the median of Maps 1 to 3 is one order of magnitude greater. These elements point out different approaches of the image interpreters. Maps 1 to 3 portray fewer landslides, generally larger than $10^{4} \mathrm{~m}^{2}$, while landslide inventories 4 to 6 report a larger number of slope failures. Analysis of frequency-size statistics (Fig. 5.4 and Table 5.9) indicated the consistency of reference maps (Maps 5 and 6) compared to other ALS-derived landslide inventory maps.

The reference maps portray slope failures ranging in area between four orders of magnitude $\left(10^{5}\right.$ to $10^{2} \mathrm{~m}^{2}$ ) (Table 5.9), and also show the lowest rollover size. Assuming a length to width ratio (the along slope length divided by the across slope width) of 1 for the smaller landslides, the deviation from the power-law scaling for $A_{L}=2 \times 10^{2} \mathrm{~m}^{2}$ (Maps 5 and 6 ) occurs for linear dimensions of $\sim 15 \mathrm{~m}$, which corresponds to a distance of $3 \mathrm{~cm}$ at the maximum visualization scale of $1: 500$, and to 15 pixels in the ALS-derived DTMs. Rollover values for Maps 1 to 4 imply that landslides smaller than $10^{4}$ $\mathrm{m}^{2}$ (for Maps 1 and 2) and $10^{3} \mathrm{~m}^{2}$ (for Maps 3 and 4) were not consistently mapped, and are incomplete for slope failures smaller than $\bar{A}$. 

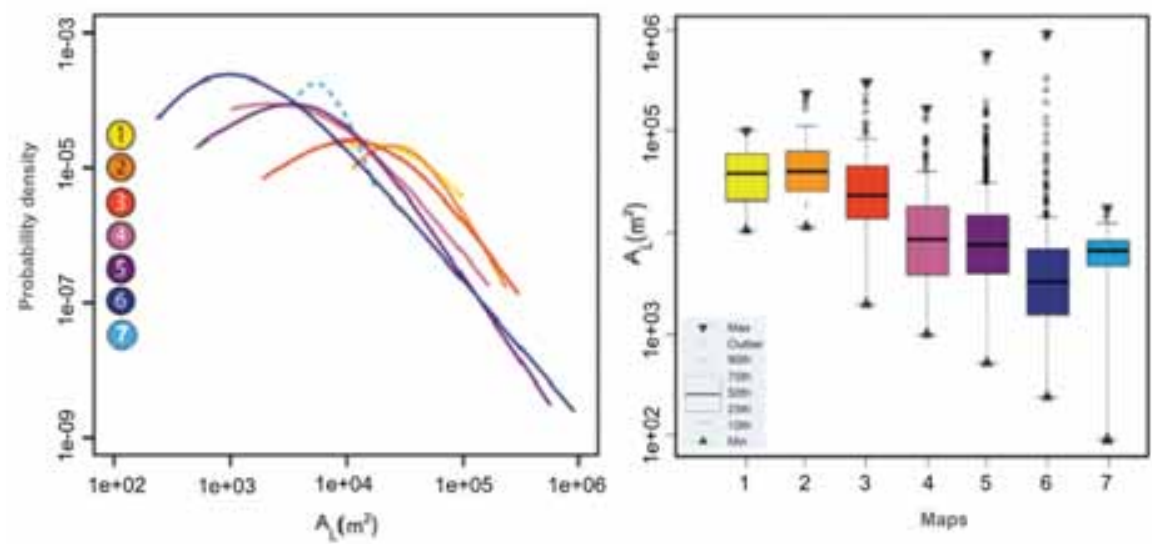

Fig.5.4: Statistics of landslide size. A) Comparison of Double Pareto probability density models, $\mathrm{p}\left(A_{\mathrm{L}}\right)$ for Maps 1 to 7 . B), Box plots comparison of landslide areas, $A_{\mathrm{L}}$, for Maps 1 to 7 . ALS-derived landslide maps (Maps 1-6) and existing landslide map (Map 7).

In conclusion frequency-size statistics point out that Maps 1 to 4 are much more incomplete than Maps 5 and 6, especially for smaller landslides, while Maps 5 and 6 still remain incomplete for $A_{L} \approx 2 \times 10^{2} \mathrm{~m}^{2}$, a considerable value for geomorphological inventories (see Malamud et al., 2004). In Fig. 5.4H, frequency size probability distributions have been plotted on the same graph, to allow the reader a better visual comparison. It is worth to mention that inventory maps 5 and 6 were produced for different land cover type, nevertheless they show similar distributions, whereas maps 1 to 4 were all compiled for the entire study area, but show different frequency-size distributions.

\subsection{Discussion and conclusions}

In this study, we investigated the differences in landslide inventory maps in several ways. First, we compared ALS-derived inventories carried out on a single ALS-derived product (Map 1-4) with the reference inventories (Map 5, $6)$. The reference inventories were carried out using a series of different ALSderived products, and resulted in more detailed maps. The intercomparison and comparison were performed for different forested area, agricultural area and tea plantations separately. Secondly we compared the ALS-derived reference maps with an existing landslide inventory map of Pradhan and Lee (2010). 
Table 5.9: Comparison of the frequency statistics of landslide area. Standard error values $(\varepsilon)$ of a are also reported. $\bar{A}$ is the size (area) of the most frequent landslide in the estimated distributions. $\mathrm{N}_{\mathrm{L}}=$ Landslide frequency; $A_{\mathrm{MIN}}=$ minimum landslide size; $\mathrm{A}_{\mathrm{MAX}}=$ maximum landslide size

\begin{tabular}{cccccc}
\hline \multirow{2}{*}{ Map } & \multirow{2}{*}{$\mathbf{N}_{\mathrm{L}(\#)}$} & $\begin{array}{c}\mathbf{A}_{\text {MIN }} \\
\left(\mathbf{m}^{2}\right)\end{array}$ & $\mathbf{A}_{\mathrm{MAX}}\left(\mathbf{m}^{2}\right)$ & \multicolumn{2}{c}{$\begin{array}{c}\text { Double pareto (Stark and Hovius, } \\
2001)\end{array}$} \\
\hline & & & & $\mathbf{\alpha} \pm \boldsymbol{\varepsilon}$ & $\overline{\mathbf{A}}\left(\mathbf{m}^{2}\right)$ \\
\cline { 4 - 6 } Map1 & 68 & $1.06 \times 10^{4}$ & $9.94 \times 10^{4}$ & $1.26 \pm 0.050$ & $1.08 \times 10^{4}$ \\
Map2 & 93 & $1.14 \times 10^{4}$ & $2.38 \times 10^{4}$ & $2.06 \pm 0.020$ & $1.17 \times 10^{4}$ \\
Map3 & 113 & $1.95 \times 10^{3}$ & $3.02 \times 10^{5}$ & $1.36 \pm 0.011$ & $2.29 \times 10^{3}$ \\
Map4 & 153 & $1.01 \times 10^{3}$ & $1.67 \times 10^{5}$ & $1.18 \pm 0.005$ & $1.16 \times 10^{3}$ \\
Map5 & 561 & $2.52 \times 10^{2}$ & $5.73 \times 10^{5}$ & $1.54 \pm 0.011$ & $7.86 \times 10^{2}$ \\
Map6 & 453 & $2.40 \times 10^{2}$ & $9.28 \times 10^{5}$ & $1.02 \pm 0.006$ & $4.11 \times 10^{2}$ \\
Map7 & 55 & $3.40 \times 10^{3}$ & $1.8 \times 10^{4}$ & $3.57 \pm 0.010$ & $3.69 \times 10^{3}$ \\
\hline
\end{tabular}

The results showed more landslides compared to the existing map based on conventional techniques, independent of the interpreter. Many of the landslides were not visible in optical images, or through field investigations, as they were old and re-vegetated, but did show on the ALS DTM. Results of the ALS maps are remarkably good even when only a relatively low ALS point density is available. Despite the difficulty to recognize shallow landslides and debris flows under forest canopy (Brardinoni et al. 2003; Korup 2005), we demonstrated the use of ALS data to map and classify a large number of landslides and geomorphological features in the tropics. For example, $48 \%$ of the slope failures in the database were characterized as shallow flow types and newly found neotectonic features (Chapter 4). In comparison to a previously published landslide inventory (Pradhan and Lee 2010), the total number of landslides mapped using ALS data is substantially higher, not only in the forested areas, but also in the case of other land cover types. Unfortunately it was not possible to compare the two reference maps (Map 5 and Map 6) as these were made for different areas, and didn't overlap. Due to this it is also not possible to indicate how consistent these maps are. Future work is required to evaluate this.

It is not known under which conditions many of the large landslides that are currently covered by dense vegetation have occurred. We have considered two possible scenarios. The first one is that they have been triggered by very extreme rainfall events. However, there are no clear evidences for such extreme rainfall-triggered landslide events from meteorological stations or from archives in this area. The other hypothesis is that these landslides might be quite old and are related to earlier periods during the Holocene, which might have been characterized by different climatic conditions, and a less 
dense vegetation cover than nowadays. More research on the relative age of the abundant and apparently old landslides would be required.

A further interesting geomorphological feature revealed during the ALSimage interpretation was the presence of clear neotectonic features in the study area, such as displaced terrace levels, shutter ridges, horst and graben structures, and disrupted drainage channels along tectonic lineaments (Fig. 5.5). The ALS image revealed a substantial level of seismic activity in the recent past, as the morphological features are quite clear and recent since they are not eroded away. However, since the area has no record of historic seismic events, more research is needed on the neotectonic activity and possible relationship with landslide activities.

A
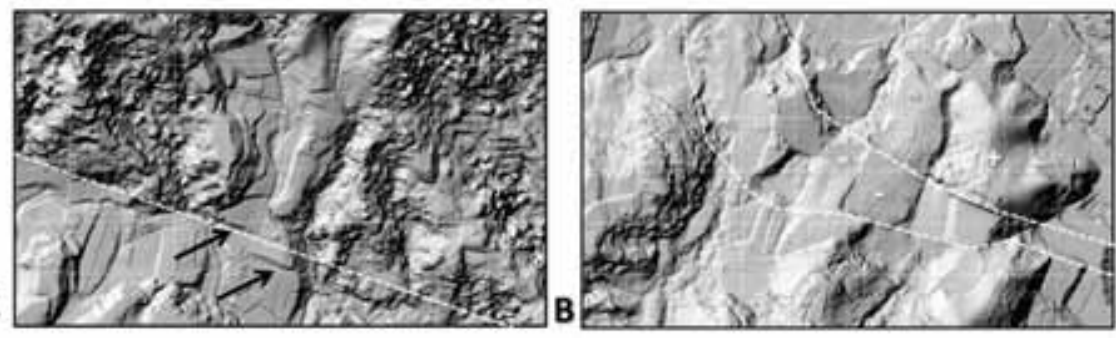

Fig. 5.5: Evidence of neotectonic features in the study area. A) Displaced terrace levels along a fault line, B) Horst and graben structures.

The method applied in this research can be used to quantify the positional mismatch between two different landslide inventories in the tropics. But in order to evaluate the error an inventory should be compared with a reference map, which is error-free in itself. Most of the time a reference map is not complete, but still considered to be the best approximation of the true landslide inventory (Van Den Eeckhaut et al. 2007; Guzzetti et al. 2012). Acquiring a good reference map is generally a large problem, as also in our case the two reference maps, although derived by international experts on image interpretation, and using a series of ALS-derived products, cannot be guaranteed to be free of errors and omissions. Furthermore, frequency-size distributions of the reference maps showed that these inventories were incomplete for $A_{L} \approx 2 \times 10^{2} \mathrm{~m}^{2}$. The inventory mapping took a considerable amount of time, and both teams were not able to map the entire study area of $93 \mathrm{~km}^{2}$. Therefore the interpreters concentrated on areas with different land cover types, where one reference map focused on forested areas, and the other on agricultural areas and tea plantations. As these are located in different parts of the study area, it was not possible to compare the two reference maps with each other. 
Van Den Eeckhaut et al. (2007) assessed the consistency of landslide maps derived from ALS images in the temperate forest environment (Flemish Ardennes, Belgium). Even in such temperate forest and relatively smooth landscape, the large dissimilarity between ALS-derived and conventional landslide inventory maps was reported up to $82 \%$, and even larger $(91 \%)$ when compared among the interpreted maps. In the northern Apennines, Ardizzone et al. (2002) evaluated the positional similarities and discrepancies of three landslide maps resulting in large positional error ranging between $55-65 \%$, and a location mismatch of up to $80 \%$ for all overlain maps.

We conclude that the degree of dissimilarity of landslide maps is relatively high even for those compiled by local expert image interpreters using stereoscopic ALS images. Quantifying the skills and experience of the interpreters is difficult and remains subjective. We selected interpreters with a long experience in landslide interpretation and local knowledge about the area. Despite that, we encountered that some of the resulting landslide inventories have very large mismatches. For instance, Map1 tends to map entire first order watershed areas as single landslides, on the basis of a few diagnostic features.

Although the landslide interpreters have long been working on image interpretation (aerial-photos and satellite images) and have sufficient knowledge on the local landscape, landslide recognition and classification using ALS data required different interpretation skills and experience. ALS is considered a relatively new landslide mapping technique (Guzzetti et al. 2012) and mostly depends on the interpretability (scale and dimension) of diagnostic morphological features on the ALS images. Guzzetti et al. (2012) underlined that a large number of landslide inventory maps have been produced in several parts of the world, but still standards to prepare landslide inventory maps do not exist, not even for visual analysis of stereoscopic aerial photographs. If aerial photo-interpretation needs the development of skills and standards, it is even more so for landslide mapping using ALSderived images, which requires sufficient experience and training. Unfortunately image interpretation skills receive poor emphasis these days in the curricula of most of the physical geography courses worldwide.

The analysis of the inverse relationship between the size and frequency of the landslides using probability density functions showed that Maps 1 to 4 differ strongly from each other and from the reference maps, in terms of the "rollover", of the minimum landslide size and of the slope of the heavy tail distribution (Table 5.9, Fig. 5.4). Possible explanations for these differences in the size distribution may include: Firstly, the different methods used for image interpretation (i.e. computer screen or paper). The hardcopy landslide interpretation may be limited by the quality and scale of the printed image. A 
low resolution, and small scale print limits the minimum detectable landslide size. In particular, slope failures smaller than $10^{3} \mathrm{~m}^{2}$ (Map 4) and $10^{4} \mathrm{~m}^{2}$ (Maps 1 and 2) could not be detected. This caused the minimum landslide area of hardcopy inventories to be considerably larger than for softcopy maps. Map 3 was the exception as it produced directly using on-screen digitizing method. Secondly, the number of images used in the interpretation i.e. different filters or different interpolation maps, influenced the interpretability some morphological features. The best results were obtained with multiple levels of terrain filtering and interpolation methods. Thirdly, the focus of the inventory on recent landslides only, or event inventories rather than geomorphological inventories. Mapping recent landslides leads a to focus on features that are typical of "fresh" landslides, such as road blockages, fresh escarpments, vegetation discontinuities showing a nongeometrical shape (typical of anthropic activity), levees, or a typical sharpness of the deposit. A morphological inventory leads to recognizing landslides that include older ones, which can have been partly dismantled or eroded by river action. Lastly, the experience of the geomorphologists and the effort they have put into the work also affected the quality of the final map. The landslide mapping required a complex analysis, which is performed by the image interpreter, who takes into account as many variables as he can detect, to recognize and classify landslides, but also to find reasons why certain landforms cannot be landslides. The higher the experience, the more reliable the outcome will be.

Time and funds also affected the quality of landslide inventory maps. Fiorucci et al. (2011) reported that two months were required to complete an eventbased landslide inventory map using ALS data in an area of only $10 \mathrm{~km}^{2}$ in Collazzone, Italy. In our study only limited time was given to the landslide interpreters to produce the final landslide inventory maps for a tropical mountainous region of $93 \mathrm{~km}^{2}$. A complete overview of the temporal, technological, economical and human resources needed for completing a landslide map is given in Galli et al. (2008). It has to be noted that the rate of map production is a proxy for estimating the personnel cost for the production of a landslide map (Guzzetti et al., 2012), whereas in our study, the landslide interpretation was carried out without any costs involved, as the interpreters did the work in their spare time.

In contrast to site-specific studies where extensive field investigation can map all existing landslides, producing a landslide map at medium scales must rely on geomorphological features to identify landslides. The results of the present study revealed that ALS data with low point density is useful to map and classify slope failures in tropical mountainous landscapes dominated by landslides. Great care should be taken by the expert-based analysis of ALS data for landslide interpretation under tropical vegetation. It should be 
carried out by dedicated landslide interpreters, with sufficient time and knowledge of the landscape. A (semi)-automatic method for extracting landslides based on ALS derivatives coupled with object-oriented analysis will be an alternative and more efficient mapping approach, but automatic mapping has proven to be quite problematic in mountainous areas (Van Den Eeckhaut et al., 2012), and it is even more so in a tropical rainforest environments. 


\section{Chapter 6}

\section{Landslide susceptibility assessment using laser scanning-derived maps in a tropical environment}

\subsection{Introduction}

In a tropical environment, landslides play a significant role in landform evolution and have been recognized as major landscape components of the humid tropical morphogenic system (Thomas, 1994). Landslides may cause substantial damage to the infrastructures (e.g. roads, buildings), and result in the loss of lives. In the tropical countries of Southeast Asia like Malaysia, landslides frequently occur in upland forests and agricultural lands which are characterized by steep slopes, high rainfall intensities, seasonally dry periods, and high weathering rates (Douglas, 1999; Sidle and Ochiai, 2006). Landslides are often associated with recent changes in land use, and especially road construction is one of the most important factors that trigger landslides in tropical areas.

Risk avoidance, the minimization of development in landslide prone areas, is the most effective and economical way to reduce landslide risk (Crozier, 2005). Therefore predictive modeling of landslide susceptibility and hazard is of vital importance, especially in rapidly developing regions, where complete avoidance is not an option. Predictive modeling aims at identifying the areas that are susceptible to future landslides based on the relationships between past and present landslide occurrences and a set of environmental factors. A landslide susceptibility map (LSM) allows us to establish regulations for landuse management over the different susceptibility zones (Brabb, 1984; Ardizzone et al., 2002).

Many methods have been proposed to evaluate landslide susceptibility at different mapping scales such as direct geomorphological mapping, heuristic approaches, statistical classification methods (e.g. probability approach) and process-driven (e.g. geotechnical modelling) (e.g. Carrara et al., 1995; Soeters and Van Westen, 1996; Chung and Fabbri, 1999; Guzzetti et al., 1999; Nefeslioglu et al., 2008a; Nefeslioglu et al., 2008b; Van Westen et al., 2008). The statistical methods, which are often used at medium scale $(1: 25,000$ to $1: 50,000)$ are based on the analysis of the relationship between a set of geo-environmental factors that control slope instability, and an 
inventory of historical landslide occurrences (Cardinali et al., 2002; Thiery et al., 2007).

The reliability of LSMs, that are generated using statistical methods, depends most of all on the quality and completeness of the landslide inventory used as input, and on the geomorphological understanding of the relationship between landslides and the causal factors. The reliability also depends on the quality of the spatial data layers, the amount of available data, and the scale of data used (Ayalew and Yamagishi, 2005; Van Westen et al., 2008). As the statistical methods are based on the assumption that the susceptibility to landslides depends on the relationships between past landslide events and a set of causal factors, care should be taken to apply them in environments that undergo rapid changes, such as deforestation, or road construction (Brabb et al., 2000; Van Westen et al., 2005; Guzzetti et al., 2012).

Landslide mapping has evolved by the use of airborne laser scanning (ALS), which allow experienced image interpreters to recognize and classify landslides also in rugged and forested terrain (see Chapters 3, 4, and 5; Razak et al., 2011, 2013). ALS data can be used to extract terrain features, including the small topographic indicators of landslides (such as scarps, semicircular niches, cracks, bulging topography etc.). ALS data have been used for landslide mapping in areas covered by forest in temperate regions (Sekiguchi and Sato, 2004; Van Den Eeckhaut et al., 2005; Van Den Eeckhaut et al., 2007; Schulz, 2007; Kasai et al., 2009; Razak et al., 2011a). However, limited studies have presented the use of ALS derived data for landslide susceptibility assessment in the tropics.

The main objective of this study is to evaluate the suitability of ALS data for creating LSMs in tropical forested areas. The second objective is to evaluate the effect of different landslide inventory maps, generated independently, on the resulting landslide susceptibility maps. The third objective is to evaluate the use of an optimal landslide inventory in relation to possible changes in the terrain conditions in the coming period as a basis for the landslide susceptibility assessment. The developed methods were tested in a densely forested section of the Cameron Highlands covering a strip of $100 \mathrm{~km}^{2}$ in Peninsular Malaysia (see Chapter 2 for the characteristics of the study area).

\subsection{Methods}

\subsubsection{Airborne laser scanning campaign and data}

We used ALS data provided by the Department of Survey and Mapping Malaysia (JUPEM) of the Cameron Highlands, Malaysia. The ALS data were acquired in June 2004 using the Optech Airborne Laser Terrain Mapper 
(Optech ALTM) 3100 laser scanning system. A detailed specification of the ALTM system was depicted in Table 4.1. The study area was sampled by 113 million points with a mean point density of 1.83 points $\mathrm{m}^{-2}$ over $100 \mathrm{~km}^{2}$.

We extracted the ALS ground points using a specific filtering parameterization for forested landslides (Chapter 4). In order to accommodate to the lower point density, the complexity of terrain and undergrowth vegetation in the tropics we have modified the parameters, as explained in Chapter 4.

A gridded bare surface model with a $1 \mathrm{~m}$ cell length was generated using a linear least-square interpolation method which was originally developed by Kraus and Mikhail (1972) in SCOP++ software (TUV, 2012). The terrain model was quantitatively assessed with 448 field measured terrain heights collected using GPS and Total Station, resulting in a root mean square error (RMSE) of $0.866 \mathrm{~m}$ (Chapter 4).

\subsubsection{Landslide inventory mapping}

The ALS-derived landslide inventory map (LIM) was produced by means of visual analysis of ALS images by expert image interpreters (see details in Chapter 4). The landslide interpreters made used a set of ALS-derived hillshading images generated with three different filter steps and three methods for surface interpolations for recognizing landslides located beneath forests and other vegetated areas (e.g. tea plantation and agriculture zones). A digital on-screen interpretation based on stereoscopic images was implemented at scales ranging from $1: 25,000$ to 1:500. Landslide margins were delineated and represented as polygons. The LIM contained polygon attributes for erosion, or deposition, and landslide types following the landslide classification by Varnes (1978). A list of diagnostic landslide features based on morphological, vegetation and drainage pattern is shown in Chapters 3 and 4 . Structural lineaments and neotectonic features were also identified in the images.

Apart from the ALS landslide inventory, we also used an existing landslide inventory with landslides which have been reported in the past decades, and which are mostly concentrated along the roads in the study area. It was produced based on visual interpretation of archived aerial photographs with scales ranging from $1: 10,000$ to $1: 50,000$, satellite images, e.g. SPOT 5 panchromatic, IKONOS, RADARSAT, landslide archives over the past 21 years, and several field-campaigns (Pradhan and Lee, 2010; Pradhan et al., 2010). This inventory has been used for regional landslide susceptibility mapping (Pradhan and Lee, 2010; Pradhan et al., 2010; Pradhan, 2010) and landslide hazards analysis (Pradhan and Youssef, 2010; Pradhan, 2010). 


\subsubsection{Landslide conditioning factors}

Four groups of landslide conditioning factors (LCFs) have been used that are coupled to landslide susceptibility (Regmi et al., 2010; Van Westen et al., 2008; Table 6.2). In total 22 LCF's were computed, all based on ALS data.

\section{Topographic factors}

We generated the topographic conditioning factors based on the ALS-derived DEM, such as slope gradient (SLG), slope aspect (SLA) and plan curvature (PLC). These primary topographical attributes were calculated using embedded algorithms in ESRI ArcGIS. The slope gradient map was produced by computing the maximum rate of change between each cell and its neighbour, and the aspect map identified the steepest downslope direction. The topographic curvature is defined the rate of change of slope and aspect in a particular direction (Wilson and Gallant, 2000). The PLC was generated as the second derivative of the DEM. A positive curvature indicates a convex plan-form. Zero curvatures corresponding to flat terrain, or to planar slopes.

\section{Hydrological terrain factors}

Hydrological related terrain factors used in this susceptibility analysis are sediment transport index (STI), topographic wetness index (TWI) and distance to drainage network (DRN). These hydrological or flow accumulation-based terrain parameters were calculated using compound topographic indices as implemented in the ILWIS software (ILWIS, 2012). The STI is often used to reflect the erosive power of the overland flow. The TWI describes the propensity for an area to be saturated to the surface given its contributing area and slope characteristics. A high resolution digital elevation model (DEM) derived from low density ALS data is suitable to generate hydrological related terrain factors. STI, TWI, and DRN derived from ALS data can be a good measure of water-related attributes such as surface water, sub-surface water and groundwater (Regmi et al., 2010). High fluctuation of water-related attributes may changes the pore water pressure to exceed the critical threshold that could potentially trigger landslides. Similarly, the soil moisture and the erosive power of water flow can be estimated by the stream power indexes (Moore et al., 1991). We also took into account the sediment transport index as it empirically resembles the Universal Soil Loss Equation and could potentially be used to highlight instability areas (Moore and Wilson, 1992).

\section{Geological factors}

The existing structural lineament information was mainly based on aerialphoto interpretation carried out by the Department of Mineral and Geosciences (JMG) Malaysia (Pradhan and Lee, 2010). However, it was too coarse for the working scale in the present study. Therefore we obtained a 
new lineament map made by experts using stereoscopic ALS-derived images and compared this with the existing map. We constructed a colour composite of three shaded relief images with an azimuth in the West, North-West and North direction and applied a linear stretching to the image. A multi-direction hillshading method was used to avoid problems in identifying lineaments that run parallel to the illumination direction in case of a single illumination (Oguchi et al., 2003). Even though the lithology, soil type and soil depth are important aspects controlling the landslides, it was not possible to use the existing maps in the susceptibility analysis due to their coarse scale and lack of detail (e.g. only two lithological units in the entire study area). Generation of more detailed maps was not feasible for this relatively large area in a forested, rugged and mountainous region.

\section{Anthropogenic factors}

ALS data is particularly useful when non-ground features (buildings, roads, vegetation types) are extracted to provide reliable data on anthropogenic factors related to landslide susceptibility and the elements-at-risk for landslides (e.g., buildings and roads). We differentiated forest types due to the expected causal relations with landslide controlling factors in the study area, as conversion of old-growth forests to plantations and regeneration of secondary forests may reduce the rooting strength, and thus increase landslide potential (Sidle and Ochiai, 2006; Sidle et al., 2006). The conversion of tropical forests to commercial agricultural lands (e.g. vegetables and floriculture) can also have significant effects on slope stability. Similarly, the agriculture zones in the study area are often characterized by poorly designed and managed terraces, coupling with water concentration in this area, which are likely to increase the susceptibility to landslides. The land cover map generated from ALS data consisted of six classes: buildings, roads, tea plantation, agriculture area, secondary forest and old-growth forest.

\section{Building mapping}

Buildings were derived using the edge detection and region growing techniques implemented in the SCOP++ software (TUV, 2012). It is part of the terrain modeling, where non-terrain points are subsequently classified as buildings. Building outlines may be derived from those points that are classified as buildings using region growing. SCOP++ requires three parameters to be set to determine building outlines: cell size, minimum building size, and minimum slope (Table 6.1 ). The cell and building size are dependent on the density of the point cloud and the minimum number of buildings required to be detected. Minimum slope is used as a threshold to detect the edges and boundaries of the buildings. First, the edge of a building is detected based on computation of the steepest gradient. Then the algorithm starts searching and the points are included that are likely to be 
part of the building geometry. The Hierarchical Robust Interpolation (HRI) method is applied that involves three different hierarchical levels that increase in resolution, for which the building filter was executed, while the terrain model was generated.

Table 6.1: Building filter parameterization used for the building extraction in the study area

\begin{tabular}{lccc}
\hline Parameters/stages & $\begin{array}{c}\text { Cell sizes } \\
\text { (meter) }\end{array}$ & $\begin{array}{c}\text { Minimum building size } \\
\text { (square meter) }\end{array}$ & $\begin{array}{c}\text { Minimum slope } \\
\text { (tangent) }\end{array}$ \\
\hline First stage & 3.0 & 9.0 & 1.1 \\
Second stage & 2.0 & 9.0 & 1.0 \\
Third stage & 2.0 & 9.0 & 0.9 \\
\hline
\end{tabular}

In principal, three main parameterizations were set using maximum thresholds in the first stage and the values were decreased in the second and third processing stages following the standard HRI processing routine in the SCOP++ software. The processing steps were the filtering and classification of the bare Earth model. The default settings provided by the SCOP++ software for buildings in a forested landscape were used initially. Later on these were modified, based on the point density of the available ALS data, local knowledge on building geometry and topographical elements. For simplifying the building footprints, we applied the Douglas-Pecker algorithm (Douglas and Pecker, 1973) implemented in GIS for noise removal.

\section{Road mapping}

The existing road map provided by the Public Works Department Malaysia (PWD) was out of date and unreliable for the working scale. Therefore, the road map was updated using the ALS-derived products. In this study, we used a new visualization technique, called topographic openness which was developed by Yokoyama et al. (2002)(see Chapter 3 for explanation). This map can be viewed as a stereoscopic or an anaglyph image using red and blue glasses. Roads were visually mapped with the help of such ALStopographic openness images, with primary roads referring to main transportation routes in the area, while the rest are identified as secondary roads. As a part of road mapping, we also mapped the road cut zones by analyzing the roads in the vicinity of steep slopes using GIS spatial analyses and visual analysis.

\section{Vegetation mapping}

For vegetation mapping we used the TreeVaW software (Tree Variable Window), an integrated ALS processing software package for detecting dominant single trees and estimating tree height and crown width (Popescu et al., 2002; Popescu and Wynne, 2004). TreeVaW is an automated processing routine run in the IDL-ENVI software. It works on a gridded 
normalised canopy height model ( $\mathrm{nCHM})$, which is computed as the difference between the digital surface model (DSM) and Digital Terrain Model (DTM) at a $1 \mathrm{~m}$ grid resolution. The tree attributes (position, height, and crown width) and altitude information were used in GIS to classify old-growth and secondary forests following the Malaysian forest classification described by Wyatt-Smith (1995). Old-growth forests are typically taller than secondary forest (e.g. more than $30 \mathrm{~m}$ ) and located at relatively high elevation (e.g. more than $900 \mathrm{~m}$ above the mean sea level) and associated to common tree species (dipterocarp forest family) with undergrowth consists largely of woody plants - seedlings and sapling trees, shrubs and young woody climbers. The stemmed palms (e.g. Arenga westerhoutti), stemless palms (e.g. Licuala spp.) and rattans (e.g. Calamus castaneus) are the main species in the secondary forest.

After generating the two forest classes, we used the results produced from the filtering and classification steps in SCOP++ and identified the tea plantation zones using a GIS tool with clear diagnostic features as the tea will most likely have the same plant height and is planted in a systematic way. After classification of buildings, roads, old-growth forests, secondary forests, and tea plantations, the agriculture zone was extracted and carefully checked with respect to ALS-derived hillshade DSM, DTM and high resolution satellite images.

\section{Classification accuracy}

Classification accuracy of the land cover map was determined using reference data collected from visual image interpretation and fieldwork. To assess the quality of the land cover map produced from the ALS data, the reference data was independently acquired by digitizing polygons based on digital high resolution satellite images, and by overlaying the DSM upon the classified raster image. Small homogeneous polygons were mapped in the field that best represented each class. A total of 300 reference polygons were purposively selected and compared with the final classification and summarized in a confusion matrix. The quality assessment of buildings and roads was made additionally to the results presented in Razak et al. (2011B) focusing on the most important elements-at-risk for landslides (buildings and roads). We used a reference data set generated from a stereoscopic visual interpretation of ALS-derived DSM and further validated the results using dynamic 3D point cloud visualization for assessing extracted buildings.

A stereoscopic model was produced with a combination of a shaded-relief of the DSM and the ALS-derived DTM. Further details about the artificial stereo image generating technique can be found in Van Westen et al. (2004). The $3 \mathrm{D}$ point cloud is capable to provide a geometrically accurate dataset which is much better than the one provided by photogrammetric products (Leberl et 
al., 2010). Point clouds with a large number of points can be dynamically visualized in a 3D model using the Quick Terrain Modeler software. A reference dataset derived from the stereoscopic visualization was simultaneously evaluated with the 3D point cloud.

To evaluate the performance of the extracted buildings, we analysed the results of the quantitative assessment of building extraction (Lee et al., 2003; Rottensteiner et al., 2005; Sohn and Dowman, 2007) in relation to the reference buildings mapped using the following equations (Eqs. 6.1,6.2,6.3):-

$$
\begin{array}{ll}
\text { Completeness } & =\left(\frac{T P}{T P+F N}\right) \times 100 \\
\text { Correctness } & =\left(\frac{T P}{T P+F P}\right) \times 100 \\
\text { Quality percentage } & =\left(\frac{T P}{T P+F N+F P}\right) \times 100
\end{array}
$$

Where, TP (True Positive) is the number of building footprints classified by both datasets, FN (False Negative) is the number of building footprints classified only by the reference dataset, FP (False Positive) is the number of building footprints classified only by the ALS building extraction method. The completeness is referring to the percentage of correctly classified building footprints, whereas the correctness is the ratio of the correctly classified building areas (TP) with respect to the total building areas classified by the reference data and by the automatic method (TP+FP). These factors indicate a measure of building extraction performance.

The accuracy of ALS-derived roads was measured based on 32 field-surveyed GPS points in this area. The validation data was collected in July 2009. The terrain heights of these points were measured using a Topcon Hiper Pro, using a real-time kinematic technique with horizontal and vertical accuracy of about $10 \mathrm{~mm}$ and $20 \mathrm{~mm}$, respectively. The statistical measurement of root mean square is sufficient for an analysis of height differences. The gradient of ALS-derived road was carefully analyzed and compared with the field data.

\subsubsection{Landslide susceptibility analysis}

According to the guidelines for landslide susceptibility, hazard and risk zoning published by the Joint Technical Committee on Landslides and Engineered Slopes (Fell et al., 2008), landslide susceptibility and hazard mapping at medium to small $(1: 25,000$ to $1: 250,000)$ scale may be applicable with

intermediate zoning level for advisory purposes. Considering recent landslide 
literature, at this scale of analysis multivariate statistical techniques are the most commonly used tool in landslide susceptibility analysis (Yesilnacar and Topal, 2005; Nefeslioglu et al., 2008a; Nefeslioglu et al., 2008b).

Among these techniques, logistic regression analysis is one of the most applied methods in landslide susceptibility analysis (Yilmaz, 2009; Das et al., 2011; Nefeslioglu and Gokceoglu, 2011). Logistic regression is useful for predicting the presence or absence of a characteristic or outcome based on values of a set of predictor variables. Logistic regression has the advantage compared to the linear regression model, that the variables may be either continuous or discrete, or any combination of both types, and they do not necessarily need to have a normal distribution.

The relationship between landslide occurrence and its dependency on several variables can be quantitatively as:

$\rho=1 /\left(1+e^{-z}\right)$

Where $\rho$ is the estimated probability of landslide occurrence. 
Table 6.2: Landslide conditioning factors derived from ALS data categorized as topographic-, hydrological-, anthropogenic-, and geological structure-related factor maps coupled with significance for landslide susceptibility mapping

\begin{tabular}{|c|c|c|c|}
\hline $\begin{array}{l}\text { Category } \\
\text { of } \\
\text { factors }\end{array}$ & Attributes & $\begin{array}{l}\text { Type and data range used in } \\
\text { LR equation }\end{array}$ & $\begin{array}{r}\text { Relevance for landslide } \\
\text { susceptibility }\end{array}$ \\
\hline \multirow{4}{*}{ 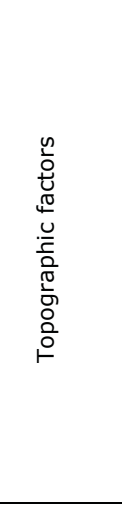 } & $\begin{array}{l}\text { Topographic elevation } \\
\text { (TOE) }\end{array}$ & Continuous (meters) & $\begin{array}{r}\text { Climate, vegetation, and } \\
\text { potential energy }\end{array}$ \\
\hline & Slope gradient (SLG) & Continuous (degrees) & $\begin{array}{r}\text { Gravity driven phenomena, } \\
\text { overland and sub-surface } \\
\text { flow velocity }\end{array}$ \\
\hline & Slope aspect (SLA) & $\begin{array}{l}\text { Binary East (SLE) (45-135 } \\
\text { Degrees) } \\
\text { Binary South (SLS) (135-335 } \\
\text { Degrees) } \\
\text { Binary West (SLW) (225-315 } \\
\text { Degrees) } \\
\text { Binary North (SLN) (315-45 } \\
\text { Degrees) }\end{array}$ & $\begin{array}{r}\text { Soil moisture, solar } \\
\text { insolation, } \\
\text { evapotranspiration, flora } \\
\text { and fauna distribution }\end{array}$ \\
\hline & Plan curvature (PLC) & Continuous (dimensionless) & $\begin{array}{r}\text { Converging, diverging flow, } \\
\text { soil water content, and soil } \\
\text { characteristics }\end{array}$ \\
\hline \multirow{3}{*}{ 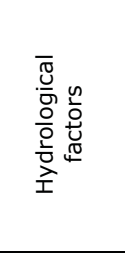 } & $\begin{array}{l}\text { Sediment transport } \\
\text { index (STI) }\end{array}$ & Continuous & $\begin{array}{r}\text { Runoff, potential energy, } \\
\text { sedimentation }\end{array}$ \\
\hline & $\begin{array}{l}\text { Topography wetness } \\
\text { index (TWI) }\end{array}$ & Continuous & Soil water content \\
\hline & $\begin{array}{l}\text { Distance to drainage } \\
\text { network (DRN) }\end{array}$ & $\begin{array}{l}\text { Binary } \\
\text { Up to } 75 \mathrm{~m} \text { (DRN75) }\end{array}$ & $\begin{array}{l}\text { Hydrologic processes, } \\
\text { hillslope undercutting }\end{array}$ \\
\hline \multirow{7}{*}{ 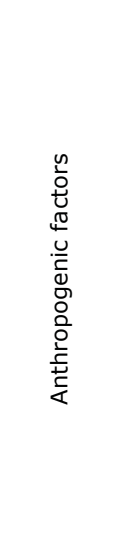 } & $\begin{array}{l}\text { Land cover type-1 } \\
\text { Buildings (LBU) }\end{array}$ & Binary & \multirow{7}{*}{$\begin{array}{r}\text { Vegetation, soil and water } \\
\text { flow, pore-water pressure, } \\
\text { evapotranspiration }\end{array}$} \\
\hline & $\begin{array}{l}\text { Land cover type-2 } \\
\text { Roads (LRO) }\end{array}$ & Binary & \\
\hline & $\begin{array}{l}\text { Land cover type-3 Tea } \\
\text { plantations (LTP) }\end{array}$ & Binary & \\
\hline & $\begin{array}{l}\text { Land cover type- } 4 \\
\text { Agriculture (LAG) }\end{array}$ & Binary & \\
\hline & $\begin{array}{l}\text { Land cover type-5 } \\
\text { Secondary forests (LSF) }\end{array}$ & Binary & \\
\hline & $\begin{array}{l}\text { Land cover type- } 6 \text { Old- } \\
\text { growth forests (LOF) }\end{array}$ & Binary & \\
\hline & $\begin{array}{l}\text { Distance to Road-cuts } \\
\text { (ROC) }\end{array}$ & $\begin{array}{l}\text { Binary } \\
0-200 \mathrm{~m} \text { (ROC200) } \\
200-400 \mathrm{~m}(\text { ROC400) } \\
400-600 \mathrm{~m}(\text { ROC600) } \\
600-800 \mathrm{~m}(\text { ROC } 800)\end{array}$ & \\
\hline 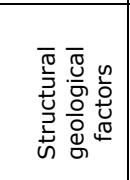 & $\begin{array}{l}\text { Distance to lineaments } \\
\text { (LIN) }\end{array}$ & $\begin{array}{l}\text { Binary } \\
0-100 \mathrm{~m} \text { (LIN100) } \\
100-200 \mathrm{~m} \text { (LIN200) } \\
200-300 \mathrm{~m} \text { (LIN300) } \\
300-400 \mathrm{~m} \text { (LIN400) } \\
400-500 \mathrm{~m} \text { (LIN500) }\end{array}$ & $\begin{array}{r}\text { Geological controlling } \\
\text { pattern }\end{array}$ \\
\hline
\end{tabular}


The probability varies from 0 to 1 on an S-shaped curve and $z$ is the linear combination that involves fitting an equation as follows:

$z=b_{o}+b_{1} x_{1}+b_{2} x_{2}+\ldots b_{n} x_{n}$

Where $b_{o}$ is the intercept of the model, $b_{i}(\mathrm{i}=1,2, \ldots, \mathrm{n})$ are the regression coefficients of the logistic regression model, and the $x_{i}(\mathrm{i}=0,1,2, \ldots, \mathrm{n})$ are the independent variables. The linear model is a logistic regression of presence or absence of landslides based on the independent variables (prefailure conditions).

In order to evaluate the spatial distribution of landslide susceptibility, we applied logistic regression for two situations: using the existing landslide inventory map and the ALS-derived landslide inventory map. The first stage in multivariate landslide susceptibility modelling is the preparation of a data matrix including the relevant conditioning factors. The resolution of the grid was $1 \times 1 \mathrm{~m}$, which would result in more than 90 million spatial units when we would take this as the basis for the analysis. Obviously, this would be too computationally demanding. However, topographic parameters having high spatial computational resolutions are also crucial and desired in landslide susceptibility evaluations. Therefore we reduced the model grid cell size to 10 x $10 \mathrm{~m}$, resulting in a total of 854,527 grid cells. In the data matrix, the columns constitute the relevant independent variables and presence/absence data from the LIM, while the rows are the cases corresponding to each individual grid cell.

In total, 22 different independent variables were evaluated as landslide conditioning factors (see Table 6.2). The landslides were sampled, using the method presented by Nefeslioglu et al. (2012), by extracting the grid cells located one pixel upslope $(10 \mathrm{~m})$ from the rupture zone of the mapped landslides. Ten percent of the landslide cells were separated as validation data, and $90 \%$ was used for developing the model. In order to produce the final training data, an equal amount of non-presence data was sampled at random for each of the two landslide inventories. A backward conditional stepwise algorithm was implemented during the training stage.

In order to evaluate the overall spatial performance of the produced LSMs, a threshold independent technique, using ROC curves, was used. Evaluation of the ROC curves is one of the most common accuracy estimation techniques in natural hazard assessments (Begueria, 2006). The area under ROC curves $(A \cup C)$ is interpreted as the degree of the accuracy of the prediction. The minimum value of AUC 0.5 represents no improvement over random 
assignment while the maximum value of which is 1 indicates complete discrimination.

\subsection{Results}

\subsubsection{Landslide inventory mapping}

A total of 1014 landslides were mapped using the stereoscopic hillshading images derived from the ALS (See Chapter 5 for details). The actual number of landslides is probably much more, since the landslide inventory is composed of two individual inventories generated by two groups for different parts of the study area. The landslides were mapped under dense forest cover, and revealed that a large part of the landscape shows clear evidence of past landslide activity. It is important to mention here that the ALS derived landslide inventory does not contain information on the (relative) age of occurrence of landslides. The landslide features recognized under dense tropical forest cover might be considerably old. As we are also able to clearly recognize landforms related to tectonic activity, whereas the area doesn't have any historic seismic activity, this is an indication that landforms, including landslides, under tropical forest may be conserved for a considerable period.

The existing landslide inventory map is based on historical landslide occurrences from the past 21 years. The inventory contains 55 landslides, which are mainly concentrated along the roads. The ALS-derived landslide inventory map revealed about 18 times more landslides in the study area than the existing landslide inventory. Based on the ALS-inventory $22.5 \%$ of the total area is affected by landslides which is substantially larger than for the existing landslide inventory ( $0.4 \%$ of the total area). It indicates that the ALS-derived images allow the identification of many more landslides especially in locations covered by vegetation. However, also in the zones covered by low vegetation (e.g. the tea plantations) the ALS-derived interpretations revealed many more landslides. The existing inventory map and the ALS-derived inventory show a very large degree of mismatch (98 $\%)$. This is due to the fact that the existing inventory has far less landslides than the reference inventories (see Chapters 4 and 5). A large number of the historical slope failures (48\%) was characterized as shallow flows, which usually begin with small scale translational slides. The landslides mapped from ALS images can also be older landslides, which are much larger and deep seated, and which are now completely covered by vegetation.

\subsubsection{Generation of landslide conditioning factor maps}

In this study, four groups of factor maps were generated: topographic-, hydrological-, anthropogenic-, and geological-related factor maps. The 
topographic-factor maps are shown in Fig. 6.1. The anthropogenic and geological factor maps are shown in Fig. 6.2. The land cover classification derived from ALS was compared with the published land cover map by Pradhan and Lee (2009)(See Fig. 6.3C). The map was used in creating a landslide susceptibility map in the Cameron Highlands. The ALS land cover map had an average accuracy of $88.5 \%$. User's and producer's accuracy are ranging from 86 to $90 \%$ (Table 6.5). The produced ALS derived land cover map has more classes (especially the secondary forest- and agriculture lands) compared to the land cover map by Pradhan and Lee (2010) who used a SPOT 5 image with $10 \mathrm{~m}$ spatial resolution captured in July 2004 (see Fig. $6.3 \mathrm{C}$ ) and verified with field survey. Their land cover map shows fewer classes, and most of the area is under primary forests. Their map also contains a class "rubber plantation", which we were not able to find in the study area.

In the field, we observed that illegal farming activity takes place in areas where the secondary forests are converted into agriculture lands without the proper approval from local authorities, and the original terrain has been rapidly modified for developing agriculture terraces. It is worth mentioning that many current reported landslides occurred in these particular land cover classes.

In this research, buildings and roads are independently extracted and evaluated due to the interest on the elements-at-risk for landslides in the study area. Some examples of ALS-derived building extraction are shown in Fig. 6.4. We extracted 137 buildings with height of up to $20 \mathrm{~m}$. The building footprint area ranged between 9 and $3875 \mathrm{~m}^{2}$. The buildings were detected at the rate of $88.6 \%$ (completeness) and $90.0 \%$ in correctness. We attained higher correctness performance than the completeness due to the tendency of the building filter to produce less false positive than false negatives. The overall success of the extracted buildings was $80.7 \%$. 


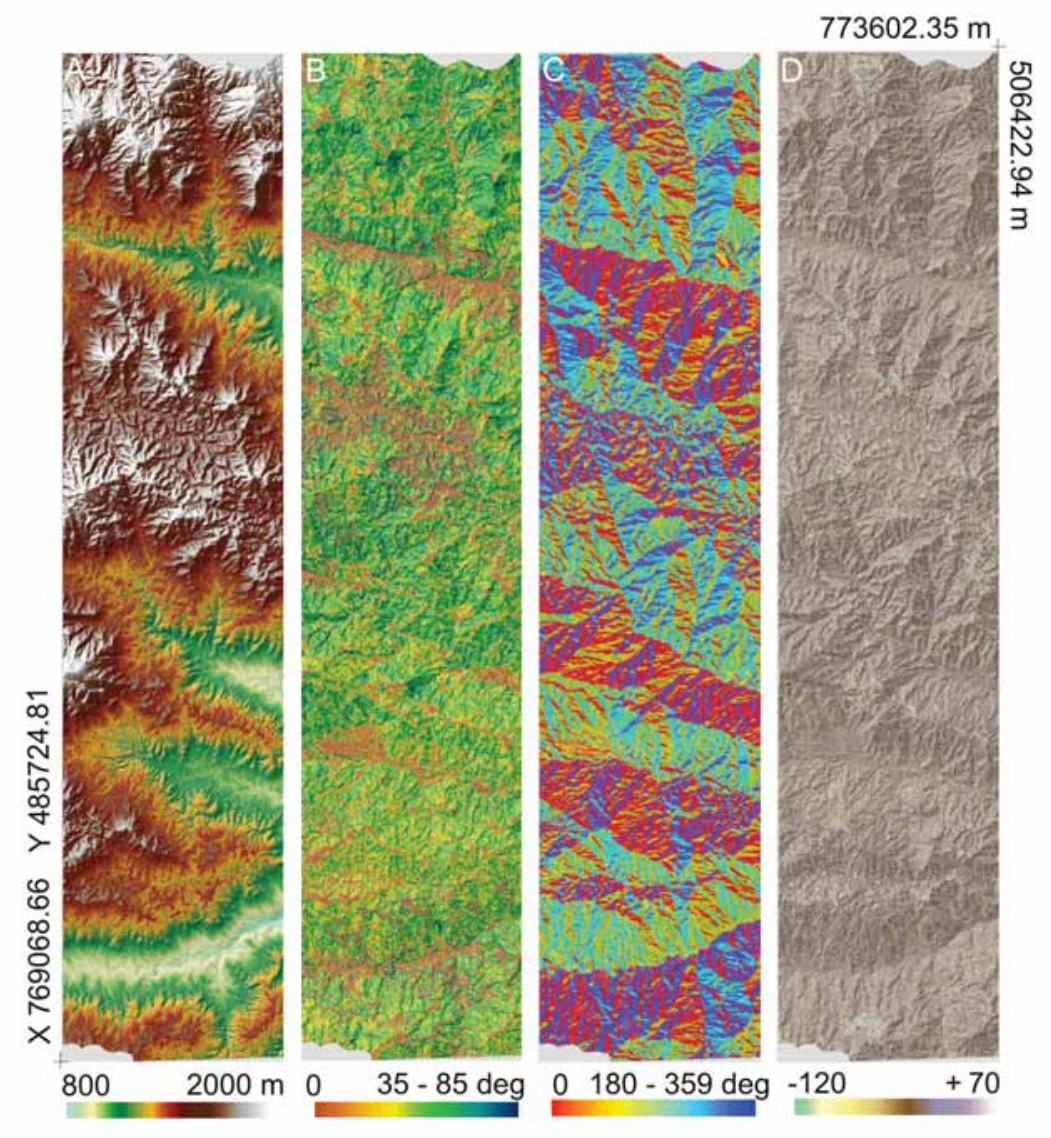

Fig. 6.1: Topographic factor maps derived from ALS data. A) Topographic elevation: B) Slope Gradient: C) Slope aspect: D) Plan curvature. 


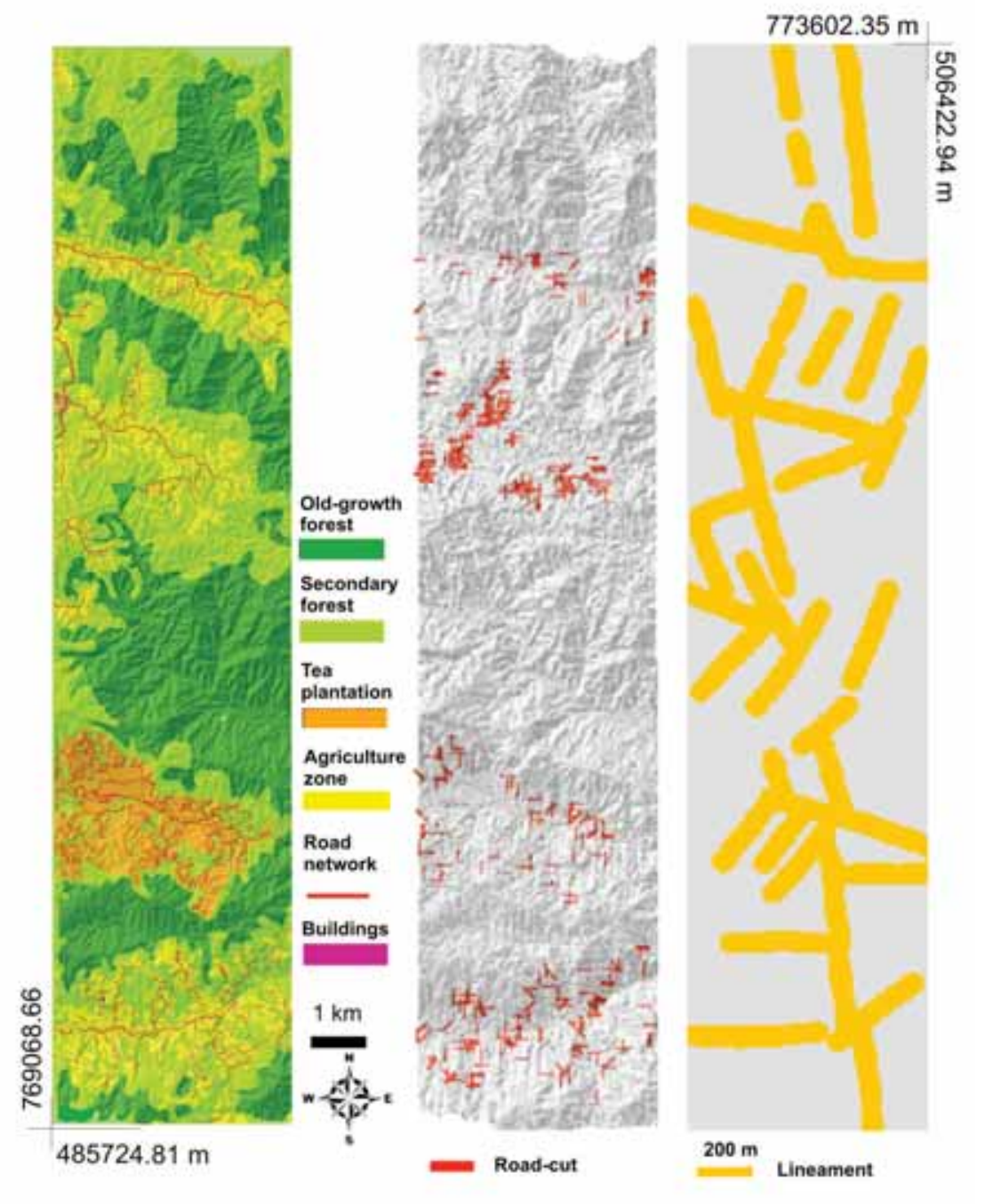

Fig. 6.2: Landslide factor maps derived from ALS data, A) Land-cover; B) Road-cuts; C) Distance to lineaments. 

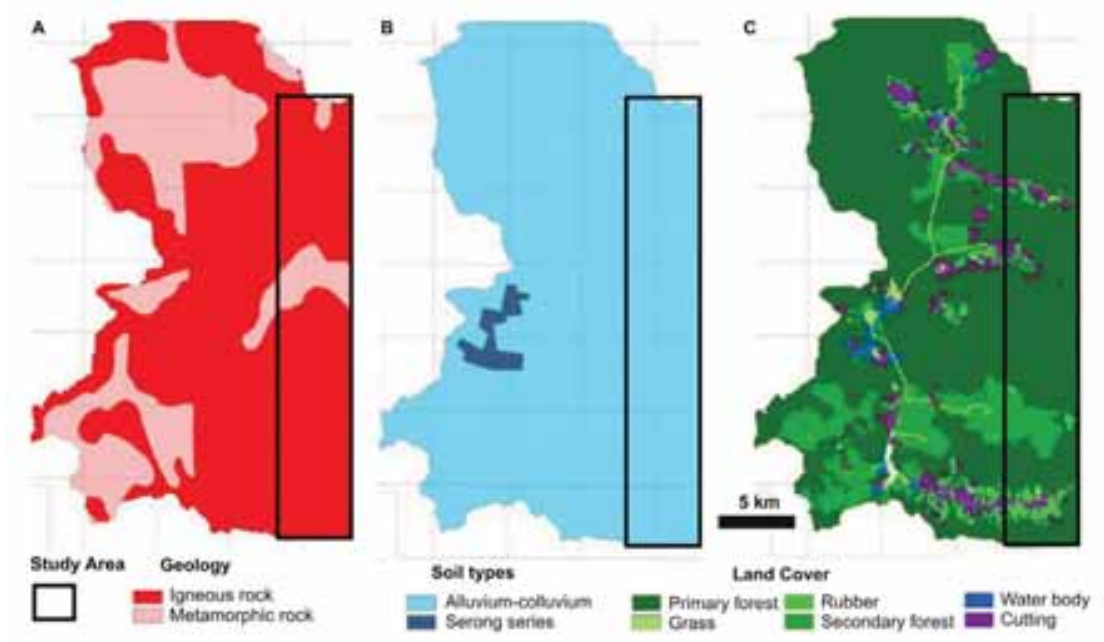

Fig. 6.3: Existing factor maps (modified from Pradhan and Lee, 2009) in the Cameron Highlands. A) Geology: B) Soil types: C) Land cover derived from SPOT-5 image.

Table 6.3: Classification accuracy of the land cover map produced using ALS data

\begin{tabular}{|l|l|l|l|l|}
\hline & $\begin{array}{c}\text { Tea } \\
\text { plantation (\%) }\end{array}$ & $\begin{array}{c}\text { Agriculture } \\
(\%)\end{array}$ & $\begin{array}{c}\text { Secondary } \\
\text { forest (\%) }\end{array}$ & $\begin{array}{c}\text { Old-growth } \\
\text { forest (\%) }\end{array}$ \\
\hline Producer's accuracy & 88.9 & 88.6 & 87.4 & 89.0 \\
\hline User's accuracy & 86.7 & 89.7 & 87.4 & 90.2 \\
\hline
\end{tabular}
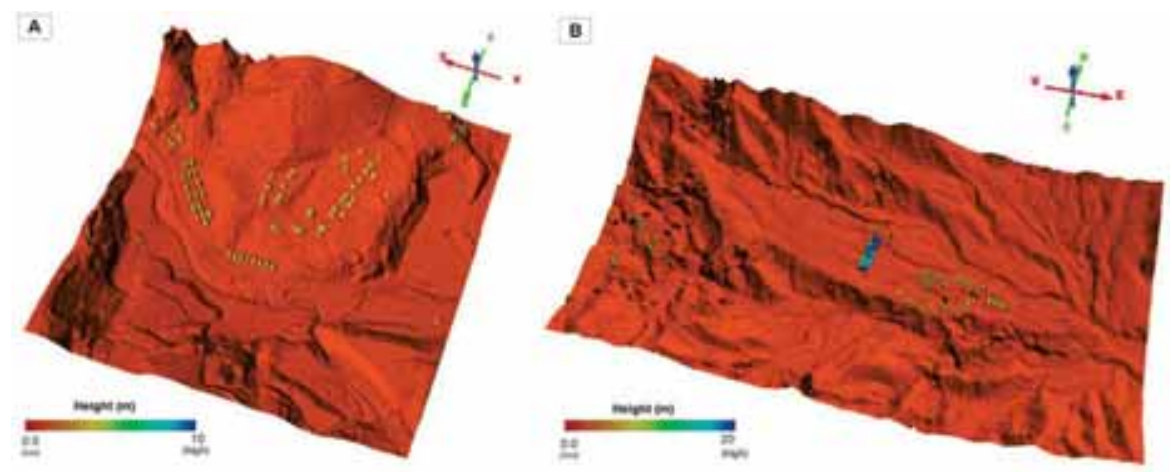

Fig. 6.4: Examples of extracted buildings from ALS data- in agricultural zone (A) and tea plantation $(B)$.

Ma (2005) reported an average of $86.5 \%$ correctly detected buildings in an area with low topographic roughness. With a combination of multi-spectral data and a high resolution orthophoto, Rottensteiner et al. (2005) achieved 94 and $80 \%$ for completeness and correctness, respectively. Sohn and Dowman (2007) found an overall quality of $80.5 \%$ with detection rate of 
$88.3 \%$ and more than $90 \%$ for correctness. The result presented here is promising because the building extraction was done in a tropical area with a low density ALS data.

In this research, the produced road map resulted in a $58 \%$ increase in the total road length in comparison to the existing road map published by PWD. The mean road gradient ranged between 4 and $32^{\circ}$, with a standard deviation of $13.6^{\circ}$. The accuracy was $0.68 \mathrm{~m}$ (RMSE) compared to the 32 GPS points measured in the field. White et al. (2010) reported similar results using 126 reference points. This assessment is one way to evaluate the produced road map from the remotely sensed data. In the field, we observed that location of the roads have significant relationship with the past and present landslide occurrences, largely reported occur along the cut-slopes.

From the ALS-derived hillshading image four times more geological lineaments were mapped as compared to the national geology map, which was based on aerial-photos and satellite image interpretation coupled with field investigation. Major lineaments are mostly oriented northwest to southeast in the study area. Interpretation of ALS data also revealed evidences of neo-tectonic activities (e.g. subsidence zones with horsts and grabens, shutter ridges, displaced terraces).

\subsubsection{Landslide susceptibility analyses}

The landslide inventories presented earlier were used to generate two landslide susceptibility maps (Fig. 6.5). In both cases all landslides were used, without differentiating them according to the type. Also the total landslide areas were used, and not only the scarp areas. In order to produce the final training data, an equal amount of non-landslide points were sampled randomly for each landslide inventory. We computed the backward conditional logistic regression equations for the models using the two landslide inventories.

For the ALS-derived landslide inventory the following equation was used:

$\mathrm{Z}_{\mathrm{ALS}}=(\mathrm{TOE} \times 0.0005)+(\mathrm{SLG} \times 0.0212)-(\mathrm{PLC} \times 0.0032)+(\mathrm{STI} \times 0.0067)-$ $($ TWI $\times 0.0287)-($ LBU $\times 1.9909)-($ LTP $\times 0.1973)+($ LAG $\times 0.2167)+($ SLE $\times 0.0728)+($ SLS $\times 0.2829)+($ SLW $\times 0.3179)-($ SLN $\times 0.1051)-($ DRN75 $x$ $0.0780)-(\operatorname{LIN} 100 \times 0.0779)+(\operatorname{LIN} 200 \times 0.1566)+(\operatorname{LIN} 300 \times 0.2875)+$ $($ LIN400 $\times 0.5997)+($ LIN500 $\times 0.3405)+($ ROC200 $\times 0.3048)-($ ROC400 $x$

$0.1219)+($ ROC600 $\times 0.3781)+($ ROC800 $\times 0.1213)-0.386722468182$

For the historical landslide inventory the following equation was used:

$\mathrm{Z}_{\mathrm{HIS}}=(\mathrm{TOE} \times 0.0014)+($ LBU $\times 20.3006)+($ LRO $\times 0.5636)-($ LOF $\times 1.8077)$

$-($ SLE $\times 0.3318)+($ DRN75 $\times 0.3310)+(\operatorname{LIN} 100 \times 1.1477)+($ LIN200 $x$ 
$1.0704)+(\operatorname{LIN} 300 \times 1.1292)+(\operatorname{LIN} 400 \times 1.2953)+(\operatorname{ROC} 200 \times 21.2156)+$ $($ ROC400 $\times 20.6344)+($ ROC600 $\times 19.6558)-22.990563$

Table 6.4: Factors used in the logistic regression equations using the ALS-derived inventory and the historical landslide inventory

\begin{tabular}{|l|l|l|l|}
\hline & Meaning & \multicolumn{1}{|c|}{$\begin{array}{c}\text { ALS derived } \\
\text { landslide } \\
\text { inventory (ALI) }\end{array}$} & $\begin{array}{c}\text { Historical } \\
\text { landslide } \\
\text { inventory (HLI) }\end{array}$ \\
\hline TOE & Topographic elevation & 0.0005 & 0.0014 \\
\hline SLG & Slope Gradient & 0.0212 & - \\
\hline SLE & Slope aspect : East & 0.0728 & -0.3318 \\
\hline SLS & Slope aspect: South & 0.2829 & - \\
\hline SLW & Slope aspect: West & 0.3179 & - \\
\hline SLN & Slope aspect: North & -0.1051 & - \\
\hline PLC & Plan curvature & 0.0032 & - \\
\hline STI & Sediment transport index & 0.0067 & - \\
\hline TWI & Topography wetness index & -0.0287 & - \\
\hline DRN75 & Distance to drainage network & -0.0780 & 0.3310 \\
\hline LBU & Buildings & -1.9909 & 20.3006 \\
\hline LRO & Roads & - & 0.5636 \\
\hline LTP & Tea plantations & -0.1973 & - \\
\hline LAG & Agriculture & 0.2167 & - \\
\hline LSF & Secondary forests & - & - \\
\hline LOF & Old-growth forests & - & -1.8077 \\
\hline ROC200 & $0-200$ m from roads & 0.3048 & 21.2156 \\
\hline ROC400 & $200-400$ m from roads & -0.1219 & 20.6344 \\
\hline ROC600 & $400-600$ m from roads & 0.3781 & 19.6558 \\
\hline ROC800 & $600-800$ m from roads & 0.1213 & - \\
\hline LIN100 & $0-100$ m from lineaments & -0.0779 & 1.1477 \\
\hline LIN200 & $100-200$ m from lineaments & 0.1566 & 1.0704 \\
\hline LIN300 & $200-300$ m from lineaments & 0.2875 & 1.1292 \\
\hline LIN400 & $300-400$ m from lineaments & 0.5997 & 1.2953 \\
\hline & & & \\
\hline & & & \\
\hline
\end{tabular}

The resulting landslide susceptibility maps are shown in Fig. 6.5. It is clear that these two maps have very different patterns. The HLI susceptibility map contains large parts of the area that have very low landslide susceptibility. This is due to the fact that the HLI contains landslides that have mainly occurred along the roads. Apart from the roads several buffer zones at different distance from roads and from lineaments determine the susceptibility pattern. The pattern of the landslide susceptibility map for the ALI is much more complex, which is also caused by the wide distribution of the ALI inventory throughout the study area.

The landslide susceptibility analysis shows that no single landslide recorded in the historical inventory occurred in the forested area, which is mainly due to 
the fact that these landslides were not mapped using aerial photointerpretation. With ALS data, many more landslides can be found beneath forests and technically providing a much better scenario on landslide distribution over the region. However, limited characteristics of each landslide or even with unknown ages may lead to a different way of treating such data input in the susceptibility analysis.

The accuracy of the susceptibility maps is presented in Table 6.5 and Fig. 6.6. From the 1014 landslides in the ALS-derived map only $59 \%$ were correctly classified in the landslide susceptibility map, compared to $90 \%$ of the 55 landslides in the historical inventory. Also the AUC value for the susceptibility maps generated from the historical landslide inventory is much higher than that for the ALS derived map.

Table 6.5: Accuracy assessment of the landslide susceptibility maps considering the correctly classified landslides and the area under ROC curve statistics

\begin{tabular}{|l|l|l|l|}
\hline $\begin{array}{c}\text { Landslide inventory } \\
\text { used }\end{array}$ & \multicolumn{1}{|c|}{$\begin{array}{c}\text { Number of } \\
\text { landslides }\end{array}$} & \multicolumn{1}{|c|}{$\begin{array}{c}\text { Correct classification } \\
\text { percentage for the } \\
\text { landslide data }\end{array}$} & $\begin{array}{c}\text { Area under ROC } \\
\text { curve (AUC) }\end{array}$ \\
\hline $\begin{array}{l}\text { ALS-derived } \\
\text { landslide map }\end{array}$ & 1014 & $59 \%$ & 0.613 \\
\hline $\begin{array}{l}\text { Historical landslide } \\
\text { inventory map }\end{array}$ & 55 & $90 \%$ & 0.836 \\
\hline
\end{tabular}




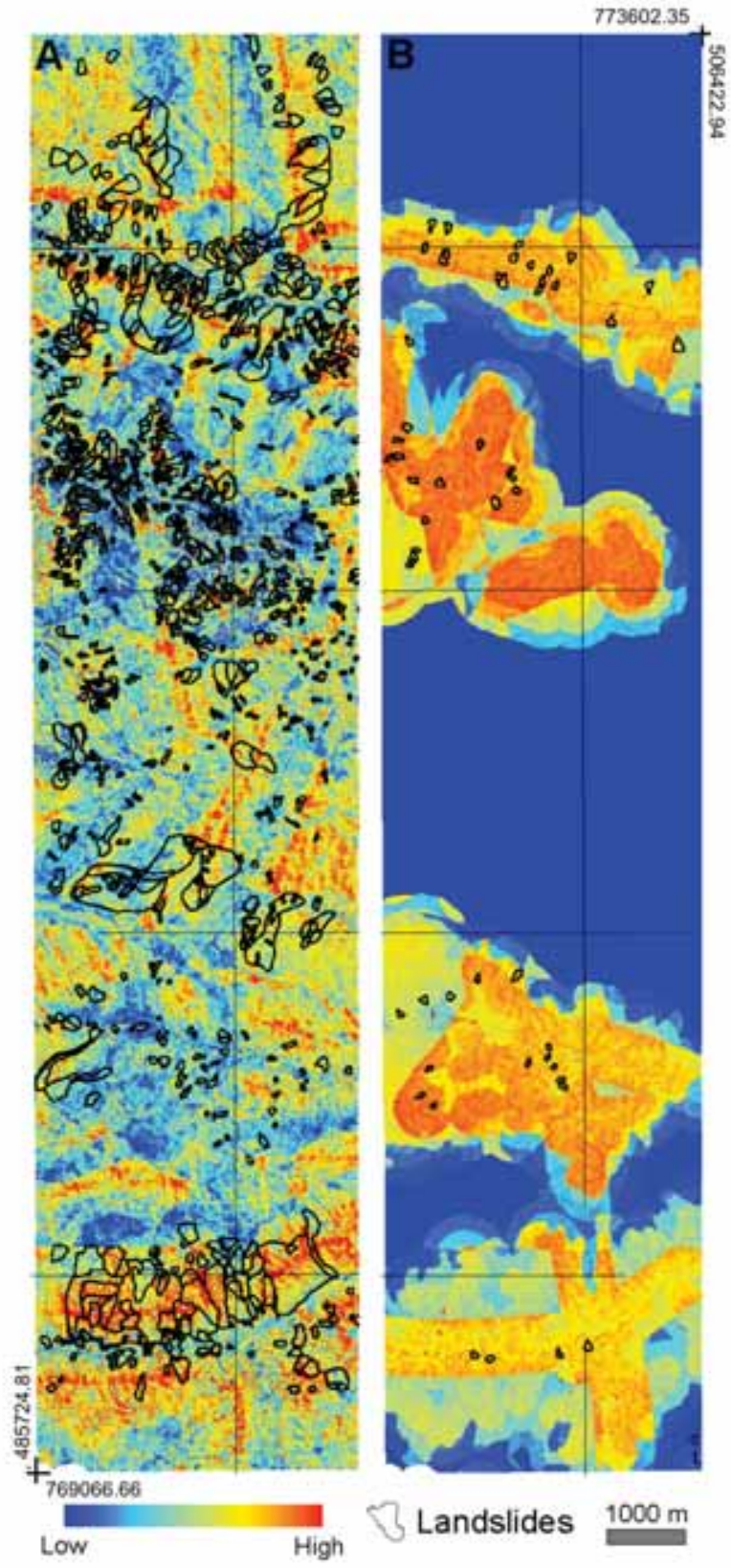

Fig. 6.5: Landslide susceptibility maps generated using different landslide inventories. A) ALS landslide inventory; B) Historical landslide inventory map. 
A)

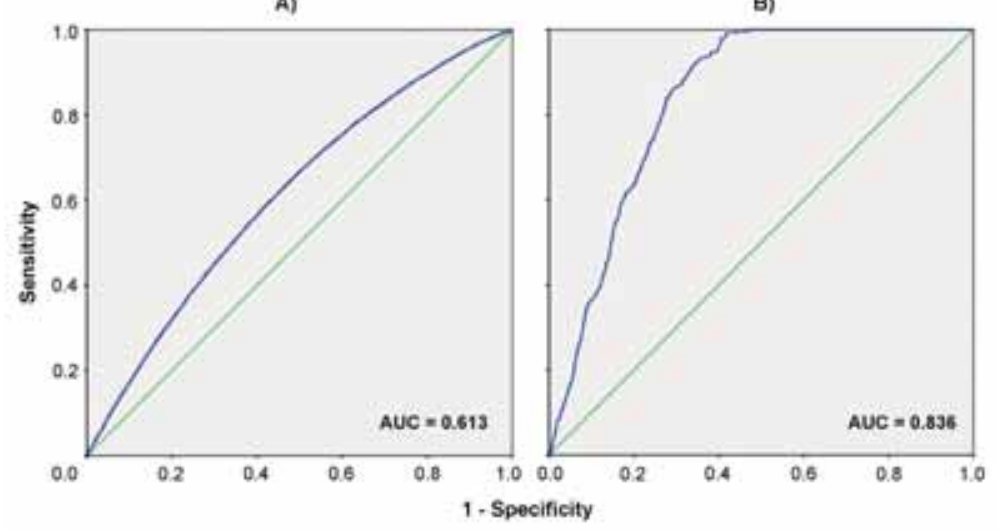

Fig. 6.6: ROC curves for landslide susceptibility maps produced based on: A) ALSderived landslide inventory map, and (B) historical landslide inventory.

\subsection{Discussion and conclusions}

The results from the landslide susceptibility assessment show that one has to be very careful with the interpretation of the susceptibility maps and the related accuracy measures. When comparing the two landslide inventory maps, it is clear that the ALS derived inventory contains many more landslides, which are more equally distributed throughout the study area, and for which the date of occurrence is not clear. The landslides might have occurred under quite different conditions than that prevails today. Therefore the use of factors that are representative of the current situation might lead to misleading results. For instance the vegetation cover might have been considerably different at the time of occurrence of these landslides, than the tropical forest cover that is prevailing today. Also there exists a possibility that these landslides might have been triggered by earthquakes in the past. This could be related to the evidences of neotectonic landforms based on ALS derived stereo-image interpretation.

The factor maps used in this study do not seem to be able to provide the unique combinations of conditions under which the landslides occurred in the past. This can be due to several reasons. One important factor is that the landslides mapped from the ALS images consist of different types, which may have specific combinations of causal factors. Also the landslides occur throughout the area, in different slope classes, topographic conditions and land cover classes, so that no clear signatures can be seen in the resulting susceptibility map, and therefore it has a very low predictive power.

The historical landslide inventory on the other hand consists of a limited data set of landslides that have occurred along the road, mainly in relation to the 
collapse of road cuts, or failure of the upslope part of these cutslopes. The landslides have been extracted from archives, and cover a period of 21 years. The susceptibility map has a clear pattern, related to the existing road network. However, this landslide susceptibility map doesn't imply that the areas further away from the road are safe in terms of landslide occurrence. If a new road would be constructed in the areas that are now indicated as having a low landslide susceptibility, this would alter the initial conditions and this could lead to the occurrence of landslide in those locations.

This study clearly indicates that it is highly relevant to generate a comprehensive landslide inventory, including landslides that have occurred longer ago. However, these should not be used in a subsequent landslide susceptibility assessment, as the conditions under which they have occurred might be substantially different than those prevailing now or in the near future. Therefore the best way to generate landslide susceptibility maps, is to use the historical landslide inventory as a basis for the statistical analysis, and to use the ALS derived inventory later as a separate legend class in the susceptibility map.

The initial aim of this study was to investigate whether it is possible generate most of the input data for landslide susceptibility assessment (consisting of the landslide inventory and the conditioning factor maps) from ALS data and used them for landslide susceptibility analysis. The existing topographic map produced by the JUPEM has $10 \mathrm{~m}$ contour interval; and is outdated in parts of the area, where recent road and building construction has taken place. The altitude information depicted on a topographic map for forested areas is often not very accurate (Will, 2002) and even more so in a tropical rainforest landscape. Kraus (2007) noted that the accuracy of ALS-derived altitude is superior to photogrammetric-derived data in densely forested and built-up areas as the latter depends on the natural sunlight, flying height, camera types, and the poor visibility of ground points from at least two imaging positions. Low density ALS data can also provide very useful information related to the vegetation, anthropogenic and geological factors. The vegetation characteristics were extracted from ALS data and are more accurate than the use of normalized difference vegetation index maps (NDVI), which are generated from satellite images and are widely applied in landslide susceptibility studies.

Anthropogenic activities are considered one of the most important causative factors for landslides (Douglas, 1999; Chow et al., 2003; Pradhan and Lee, 2010). In the field we observed a detrimental effect of human activities such as the conversion of forest to intensive agricultural activities (e.g. vegetables, floriculture, and tea plantation) and road construction. In the field, we also observed that a large number of landslides have occurred on the secondary 
roads, which are often used for local agriculture activity, and not always wellmaintained by the local government agencies. The relation between roads and landslide occurrence was very clear when using the recent historical landslide inventory, but the relation was completely lost when using the larger ALS derived landslide inventory map.

It is crucial to incorporate the road-cut information into a susceptibility modelling for predicting future landslides (Petley et al., 2007). In literature landslides are reported to occur much more frequent (with a maximum up to 350 times) than in virgin forests (Gray and Megahan, 1981; Amaranthus et al., 1985; Larsen and Parks (1997). In future work, the road condition (e.g. good, partly damage, and damage) should also be taken into consideration for predicting the future landslides. The distance buffers used around the roads should in future research be limited to the direct surrounding and the slopes that are influenced by the road cuts only. The result of the susceptibility assessment seemed to show better results for the map based on historical data in comparison to the ALS data. The historical landslide inventory contains substantially less landslides with smaller sizes that have occurred mainly along the main roads or the ones that caused fatalities. The ALS-derived landslide inventory maps, on the other hand, contain many more landslides, which are distributed all over the area, and have a very different size-frequency distribution. The ALS derived inventory map does not contain information on the relative age of the landslides, and that is also the main problem in using such a map in a susceptibility assessment. Statistical susceptibility assessment assumes that conditions that have led to landslides in the past can be used to predict landslides in the future. A landslide susceptibility map is generated for the coming years, and assumes that the conditions that are used in the assessment remain constant. For instance the construction of a new road in areas indicated as low susceptible in the map generated using the historical inventory (See Fig. 6.5B) will alter the land cover conditions considerably and therefore the susceptibility level.

Based on the landslide susceptibility maps produced in this research, some further research is required. In particular, to test several more scenarios on different factors maps for different landslide input maps. For examples, the land use class agriculture, the road related factors, the forest related factors, the importance of buildings as causal factors for landslides, including cutslopes behind buildings. The landslide susceptibility assessment requires a data set of landslides in combination with the various terrain factors that were existing when the landslides occurred. This requires a landslide data set with known ages, and the ALS derived map contains a large number of landslides that might be very old, and may have been conserved under the dense forest vegetation for a considerable number of years. Therefore using 
the complete set of landslides without knowing their relative age is problematic.

The role of land cover as a contributing factor in landslide susceptibility assessment in tropical areas should be reconsidered. Too often researchers only use a (recent) land cover map, without taking into account land cover changes that might be more indicative for landslide occurrence. Therefore it is important to generate land cover maps from different time periods and use the land cover changes in relation to the landslides that have occurred in the same period of time. Unfortunately in this study no older land cover maps were available.

The factor maps used in landslide susceptibility assessment are often the ones that are relatively easy to obtain. For instance the topographic and hydrologic factors derived from Digital Elevation Models, or land cover classes derived from (satellite) images. However, it is much more difficult to incorporate the very relevant factors related to lithological types, weathering zones, soil types and soil depth. In this study these were largely ignored, due to lack of data. Future work should also concentrate on the use of ALS data for deriving indicators for soil type and soil depth mapping, in combination with field information and geostatistical analysis (Kuriakose, 2010). Further research is also needed to separate the landslide types and generate different susceptibility maps for different sets of causal mechanisms.

We conclude that ALS data can be an important contribution to generate both landslide inventory maps and contributing factors maps used in landslide susceptibility assessment. In combination with good historical information, the ALS-derived landslide susceptibility map can give a more complete picture than using only recent historical landslide inventories (Pradhan and Lee, 2010). The interpretation of stereoscopic ALS-derived images is a promising tool to identify old landslides hidden under forest canopy (Brardinoni et al., 2003; Korup, 2005). These should not be included directly in the statistical modelling but should be included in the final susceptibility map as a separate legend class, indicating the location of past landslides.

A higher accuracy indicator of a landslide susceptibility map, e.g. a higher value of the AUC, is not an absolute indicator for the quality of the map. The quality of the input data, both in terms of the landslide inventory and the factor maps used, and their temporal variation are equally important to consider. 


\section{Chapter}

\section{Tree growth anomalies induced by landslides: Insight from high-density airborne laser scanning data}

\subsection{Introduction}

Landslides play a significant role in short- and long-terms geomorphic evolution and hillslope morphology in mountainous landscapes. Landslides can be life threatening to inhabitants and cause damage to infrastructures. These mass-wasting processes also contribute to forest disturbances, and increase the heterogeneity of forest ecosystems in space and time (Frolking et al., 2009). It is important to document and map the extent of the slope failures, and analyse their activity.

Landslide activity analysis is a crucial aspect of landslide inventory mapping and it is important for assessing landslide susceptibility, hazard, and risk. Modern remote sensing based approaches have revolutionized landslide hazard and risk assessment in mountainous regions. Remote sensing enables the parameterization of morphology, vegetation, and drainage conditions of the slopes (Soeters and Van Westen, 1996). In particular, vegetation characteristics are by far less investigated, because they are limited by the capability of remote sensing instruments to detect variability of the 3Dforest-structure (Frolking et al. 2009).

\footnotetext{
* This chapter is based on:-

Razak, K.A., Bucksch, A., Damen, M., Van Westen, C.J.W., Straatsma, M.W., de Jong, S.M (2013) Characterizing tree growth anomaly induced by landslides using LIDAR. In: Landslide Science and Practice: Landslide Inventory, Susceptibility and Hazard Zoning, (Eds.) Margottini, C., Canuti, P., Sassa, K. Springer-Verlag Berlin Heidelberg, Germany, 235-241.

Razak, K.A., Bucksch, A. (2013) High density airborne lidar estimation of disrupted trees induced by landslides. In: Proceedings of IEEE International Geoscience and Remote Sensing Symposium, Melbourne, 21-26 July 2013.

Gode, A., Razak, K.A., (2013). Characterization of forest canopy gaps caused by landslides using high density airborne laser scanning. In: Proceedings of International Symposium \& Exhibition on Geoinformation (ISG 2013). Kuala Lumpur, Malaysia 24-25 September 2013.
} 
The characterization of tree growth anomalies caused by landslides is a key component in the assessment of landslide activity in forested mountainous landscapes. Parise (2003) described that trees can be good indicators of local deformation and different epochs of displacement. To relate tree anomalies to landslide occurrence and activity, the identification and characterization of disrupted trees in a rugged terrain is crucial. Landslide activity assessment is traditionally undertaken by comparing the morphological and vegetation characteristics from stereoscopic images of different years, in concert with field verification. Although field mapping yields greater accuracy, it is limited to smaller areas at the expense of high labor costs (Haneberg et al., 2009). Particularly identifying the location and geometry of affected trees is a major problem. Remote sensing based approaches are the only means for mapping, monitoring and characterizing landslides over larger and inaccessible areas. Airborne laser scanning (ALS) is among the growing topographic mapping techniques, but few attempts have been made to analyse vegetation indicators from ALS data as an indicators of landslide processes. Mackey et al. (2009) manually identified the location of individual trees from a single ALS image and five historical aerial photos. These trees were tracked to determine their displacement over 42 years in order to quantify decadal-scale slide deformation. The authors also remarked that a large number of trees could not be identified on ALS and aerial photos, due to canopy occlusions and low quality of data sources. Mackey and Roering (2011) objectively analyzed the local morphology of complex landslides using low density ALS data in a temperate environment region, and addressed the difficulty to distinguish landslide activity, i.e., active and dormant without additional information on feature activity.

Van Den Eeckhaut et al. (2009) demonstrated the local reactivation due to landslide activity by observing tree distortions associated to dendrometry and dendrochronology studies. Dendrometry is the branch of botany that is concerned with the measurement of the various dimensions of trees, such as their diameter, size, shape, age, overall volume, thickness of the bark, as well as the statistical properties of tree stands (Wikipedia, 2013). Dendrochronology is the formal term for tree ring dating, the archaeological dating method that uses the growth rings of long-lived trees as a calendar. The method requires samples in the form of tree discs or cores. Discs are is used for recognizing locally missing tree rings, but are lethal for the tree, coring results in less destruction for the trees, but it provides less information. The quality and quantity of tree samples taken during the data acquisition are important aspects for acquiring reliable results (Braker, 2002; Stoffel and Bollschweiler, 2008). These methods, however, are time consuming and require an intensive field investigation and subsequent laboratory analysis, resulting in a relatively low number of samples, small examined area, and limitations with respect to tree species. 
Biochemically, trees optimize the amount of light penetrating the photosynthetic active areas, which results in a vertical growth direction. Tree deformations induced by geomorphic processes have been discussed mostly related to irregularities in the tree-ring pattern caused by ecological and mechanical stress (Stoffel, 2006; Van Den Eeckhaut et al., 2009). The former describes the influence on the entire tree population in an area, whereas the latter gives insight into the individual trees affected by a particular geomorphic process.

Various bioindicators for landslides exist, such as inclination and orientation of the tree trunk, canopy gaps, tree growth termination and suppression, asymmetric tree crown, root breakages, swelling, epicormic shoot, and branchiness (Shroder, 1978; Braam et al., 1987; Clark, 1990; Wiles et al., 1996; Van Den Eeckhaut et al., 2009). Fantucci (1999) reported that stem tilting is one of most common effects as a result of landslide activity. The physical reactions can be used to describe a relationship of stressed vegetation and the different landslide types in the areas. Tilted trees were used to express the landslide type with a translational sliding, whereas bended trees are a result of rotational-slide type. Trees in rotated blocks or reverse slopes are often inclined upslope, toward the upper area. Disturbed trees attempt to recover a vertical growth direction after a tilting event (Mattheck 1993; Carrara and O'Neill, 2003; Stefanini, 2004). The reaction wood growth can be observed in the tree rings, and from the curvature of trunk. Further information on the typical tree response to earth surface processes, see Stoffel (2006) and Stoffel and Bollschweiler (2008) for an extensive review. The existence of forest canopy openings or small, local gaps is important in the study of forest ecosystems (Runkle, 1981).

Forest canopy gaps can be defined depending on the causes of the gaps and types of detection methods used. However, there is no universal definition of what constitutes a canopy gap (Marthers et al., 2008). Runkle (1981) defined gaps in the field as the ground area of a canopy opening extending to the vertical projection of the canopy of the surrounding trees. Blackburn and Milton (1996) defined forest gaps in remote sensing imagery as an open space between high canopies, and above the low vegetation. Forest canopy gaps can also be defined in the context of small scale forest disturbances, as holes or opening in the forest canopy at a certain height, due to fall or death of one or more trees (Vepakomma et al., 2008; Frolking et al., 2009). Gaps are often defined either from field measurement or from remote sensing imagery (Broadbent et al., 2008). In practice, ground measurements are costly and time consuming, and the interpretation of spectral remote sensing imagery may be hampered by shadows, lack of contrast, or varying sun incidence angles (Runkle, 1991; Fox et al., 2000; Vepakomma et al., 2008; Koukoulas and Blackburn, 2004). Koukoulas and Blackburn (2004) developed 
a method to detect gap features in a broad leaved deciduous forest, using an ALS-derived canopy height model (CHM). Zhang (2008) implemented a mathematical morphology-based approach for extracting gaps in mangrove forests using ALS data. Gap fraction has not been evaluated for forested landslides.

A stand of trees displaced from their normal vertical alignment and/or tilting at various orientation angles is frequently referred to as so-called "drunken trees" phenomenon (De Villiers, 2001; Alexandrowicz and Margielewski, 2010). Typically, this phenomenon results from melting permafrost, frost heaving, forested active rock glaciers and earthquakes. However, few studies have been published related to landslide related "drunken tree" phenomena. So far, no literature was found that related laser-derived parameters to tree growth anomalies caused by landslides.

Airborne laser scanning (ALS) data has been widely used for mapping, classifying, and characterizing landslides that are located in the areas sparsely or completely covered by dense vegetation (Schulz, 2007; Van Den Eeckhaut et al., 2007; Kasai et al., 2009; Chapter 3, 4). ALS has also been used in many studies of vegetation vertical structure, tree height, biomass and wood volume (Lefsky et al., 2002; Lowman and Rinker, 2004; Frolking et al., 2009). Few attempts have been made to utilize ALS data to represent tree structures that may be indicative of landsliding, because the required very high point density of ALS data and the relatively small market value of these stands.

The objective of this study is to provide a better insight into the use of high density ALS (HDALS) data: (i) to accurately map different types of landslides and kinematic zones, (ii) to characterize disrupted trees induced by landslides, and (iii) to evaluate the statistical difference of relationship of ALS-derived disrupted trees in landslide and non-landslide areas. HDALS data was used to identify individual trees and to characterize: i) forest canopy gaps, ii) dissimilarities of tree height, and iii) single tree irregularities (e.g. tree inclination and orientation). We developed and tested the methodology over the forested landslides in the Bois Noir. A detailed description of the study area was given in Chapter 2.

\subsection{Materials and methods}

This section describes the data and methods to link vegetation anomalies to landsliding. The methods comprise of four major components (Fig. 7.1): data acquisition (ALS and field), landslide topographic analysis, extraction of ALSderived disrupted trees, statistical tests of each tree growth anomaly and 
activity assessment with the support of, morphological changes (2007-2009 ALS data) and field evidences.

\subsubsection{Airborne laser scanning measurement}

Using the RIEGL laser system, the HDALS dataset was acquired in July 2009 in Bois Noir (Table 7.1). The ALS campaign was carried out by the Helimap company using a helicopter flying about $300 \mathrm{~m}$ above the ground. Data were acquired in several flight lines over the same area to increase the point density of the ALS data. We obtained about 214 million points with a mean point density of 170 points $\mathrm{m}^{-2}$.

Table 7.1: Characteristics of the high density airborne laser scanning campaign in Bois Noir, France

\begin{tabular}{|l|l|}
\hline Acquisition (month/year) & July 2009 \\
\hline Laser Scanner & Riegl VQ480i \\
\hline IMU system & $\begin{array}{l}\text { iMAR FSAS } \\
\text { (record data at } 100 \mathrm{~Hz} \text { ) }\end{array}$ \\
\hline GPS system & $\begin{array}{l}\text { Topcon Legacy } \\
\text { (record data at } 5 \mathrm{~Hz} \text { ) }\end{array}$ \\
\hline Laser pulse repetition rate & $300 \mathrm{kHz}$ \\
\hline Measurement rate & Up to $150 \mathrm{kHz}$ \\
\hline Beam divergence & $0.3 \mathrm{mrad}$ \\
\hline Field of view & $60^{\circ}$ \\
\hline Scanning method & Rotating multi-facet mirror \\
\hline Point density & 170 points $\mathrm{m}^{2}$ \\
\hline
\end{tabular}

\subsubsection{Landslide DTM and inventory mapping}

The DTM for the study areas was generated using the method described in Chapter 3. The DTM, with a $25 \mathrm{~cm}$ cell size, was visualized in stereo, overlaid with the topographic openness map. As indicated in Chapters 3 to 5 , the interpretation of slope movements from ALS-derived images was based on manual identification of elements associated with slope movements and interpretation of their significance to the slope instability process. ALSderived images were evaluated at scales ranging from 1:30000 to $1: 2000$ and the mapping was executed at scales 1:3000 to 1:5000. We also used an existing landslide inventory in Bois Noir (Thiery et al., 2003, 2004) for reference, which was made through air-photo interpretation (1:25000-scale), field surveys $(2002,2003)$ and historical records. ALS-derived landslide map was verified in the field. The landslide and non-landslide zones were used to analyze the statistical significance of differences in extracted tree growth anomaly parameters. 


\subsubsection{Field data collection}

Field campaigns were carried out in June 2009, June 2010, and September 2011 to measure biometric data of 560 individual trees. We applied a purposive sampling scheme, because neither a random nor a systematic scheme proved feasible given the ruggedness and poor accessibility of the terrain. About $60 \%$ of the tree samples were collected on landslides, the remainder was located on the stable areas nearby. The measured single tree attributes consisted of location $(x, y, z)$, tree height $(\mathrm{TRH})$, tree inclination (TRI), tree orientation at breast height (TRO), diameter at breast height $(\mathrm{DBH})$, tree canopy width (TCW), and forest canopy gaps (FCG).

\section{Geolocation of trees}

Accurate geolocation of reference data was required to link field measurements to ALS-derived products. In order to accurately position individual trees, a combination of differential GPS (Leica GPS system 1200) and total station (Sokkia reflectorless SET4130R3) was used. We utilized different GPS techniques i.e. real-time kinematic (RTK), rapid-static and static, depending on the density of the vegetation cover. A local surveying scheme using a total station was established to measure trees with a dense canopy.

Two available permanent GPS stations of RENAG (REseau NAtional GPS) and two geodetic reference stations established in the Bois Noir catchment were used to create local geodetic stations. Geodetic reference stations were setup and used as control stations at a catchment scale, whereas local geodetic stations were setup for small study plots. Partly open sky view of their locations was chosen for acquiring optimal reception of the GPS signals and reducing multi-path effects. An observation of 6-12 hours for each geodetic station was required. Post-processing on the GPS data was performed by using the coordinate references from the RENAG stations. Horizontal and vertical precision of geodetic stations were on average 8 and $13 \mathrm{~mm}$, respectively. 


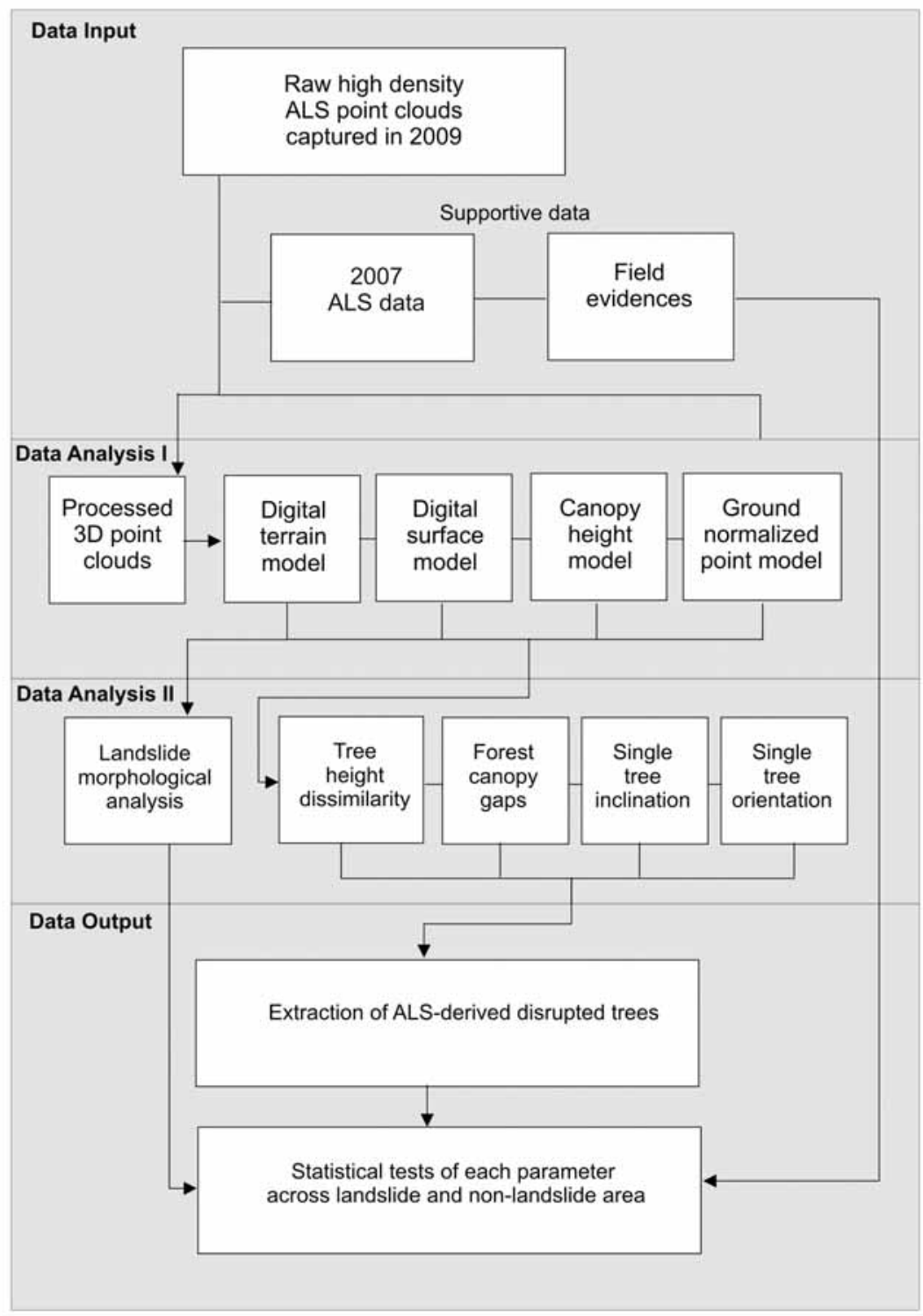

Fig. 7.1: A methodological flow-chart for assessing landslide activity using ALS-derived disrupted vegetation with supportive data.

The canopy density limited the reception of the GPS signal, which made the time required for geolocation very long. Therefore, a total station was set up in an open spot. Position and northing of the total station was determined 
using the GPS. Geolocation of individual trees was subsequently carried out with the total station. All the coordinates were projected onto the Lambert zone III using Lambert Conformal Conic with the NTF (Nouvelle Triangulation de France) datum.

\section{Measurements of tree attributes}

Each measured single tree was characterized by 13 attributes (Table 7.2). Tree height was measured using a Nikon handheld laser range finder. Several readings of the crown apex were taken for each single tree. The mean of the tree heights was subsequently logged. Only dominant trees were considered because the fieldwork in September 2011 was taken two years after the ALS flight campaign, and rapid development of undergrowth vegetation during this time would complicate the analysis. We measured the inclination and orientation at a height of $1.3 \mathrm{~m}$. Also measurements of tree diameter were made at $1.3 \mathrm{~m}$ height (so called breast height). Tree inclination was measured ranging between 0 (straight) and 90 degrees (fallen tree). A field compass was used to measure the orientation of disturbed trees $\left(0-360^{\circ}\right)$.

For sampling forest canopy gaps, field measurements were carried out following the procedure given by Runkle (1992). We measured along $25 \mathrm{~m}$ line transects and gap positions were recorded using GPS and total station. The length of major and minor axis of gaps was measured using a measuring tape, and fish-eye photos were taken for each gap as reference (Fig. 7.3). Later the area of canopy gaps was computed based on the aforementioned parameters collected in the field. The gaps should have sky exposed between the tree crowns. We determined the canopy gaps in the field based on two thresholds: height of understory should not exceed $5 \mathrm{~m}$ and the vegetation in the vicinity has to be higher than $7 \mathrm{~m}$. In total, we collected 43 FCG in 10 transects covering both landslides and non-landslide areas.

\subsubsection{Extraction of tree height and gap fraction from ALS data}

We utilized the TreeVaW (Tree Variable Window) software, an integrated ALS processing software package for detecting dominant single trees and estimating tree height and crown width (Popescu et al., 2002; Popescu and Wynne, 2004). TreeVaW requires a gridded canopy height model ( $\mathrm{CHM})$, that spatially explicit represents the vegetation height above the ground. The CHM was computed by subtracting the digital terrain model (DTM) from the digital surface model (DSM), the highest return per pixel, which represents the top of the canopy. All the models were generated with a $0.15 \mathrm{~m}$ cell size. Given the fact that HDALS data was used in this study, the error in the rasterization (conversion from point data to regular grids) is expected to be small given the high point density. 
Table 7.2: Tree variables measured in the landslide and non-landslide sites (N/C: N: numerical data; C: categorical data)

\begin{tabular}{|l|l|l|l|}
\hline Variable & Unit & N/C & Method \\
\hline Tree location (TRL) & $\begin{array}{l}\text { Local coordinate } \\
\text { system }(\mathrm{m})\end{array}$ & $\mathrm{N}$ & dGPS and total station \\
\hline Tree height (TRH) & $\mathrm{m}$ & $\mathrm{N}$ & $\begin{array}{l}\text { Nikon handheld laser range- } \\
\text { finder }\end{array}$ \\
\hline Tree crown width (TCW) & $\mathrm{m}$ & $\mathrm{N}$ & Measuring tape \\
\hline $\begin{array}{l}\text { Tree diameter at breast } \\
\text { height (DBH) }\end{array}$ & $\mathrm{cm}$ & $\mathrm{N}$ & Calliper \\
\hline Tree inclination (TRI) & degree & $\mathrm{N}$ & Suunto PM5 clinometer \\
\hline $\begin{array}{l}\text { Tree orientation (TRO) } \\
\text { fegree }\end{array}$ & $\mathrm{N}$ & $\begin{array}{l}\text { Suunto KB-14 azimuth } \\
\text { compass }\end{array}$ \\
\hline $\begin{array}{l}\text { Forest canopy gaps } \\
\text { (FCG) - location }\end{array}$ & $\begin{array}{l}\text { Local coordinate } \\
\text { system (m) }\end{array}$ & $\mathrm{N}$ & GPS, total station \\
\hline $\begin{array}{l}\text { Forest canopy gaps - } \\
\text { major and minor axis }\end{array}$ & $\mathrm{m}$ & $\mathrm{N}$ & Measuring tape \\
\hline $\begin{array}{l}\text { Forest canopy gaps - } \\
\text { neighbouring trees }\end{array}$ & - & $\mathrm{N}$ & Determined in the field \\
\hline Tree species & - & $\mathrm{C}$ & Expert knowledge \\
\hline Plot location & $\begin{array}{l}\text { Landslide, non- } \\
\text { landslide }\end{array}$ & $\mathrm{C}$ & Determined in the field \\
\hline $\begin{array}{l}\text { Landslide types and } \\
\text { activity }\end{array}$ & $\begin{array}{l}\text { Classification by } \\
\text { Varnes (1978) }\end{array}$ & $\mathrm{C}$ & Determined in the field \\
\hline
\end{tabular}

TreeVaW carries out a single tree delineation using an adaptive technique for local maximum focal filtering. This technique works on the assumption that the highest point in a local neighbourhood constitutes the highest leaf or twig in the crown apex. The algorithm reads the height value at each pixel and calculates dynamically the variable window size to search the local maximum based on biometric relationship between tree height and crown size, i.e., the higher the tree the larger the crown width. Outputs are delivered as position $(x, y)$ of single trees, tree height, and crown radius. 

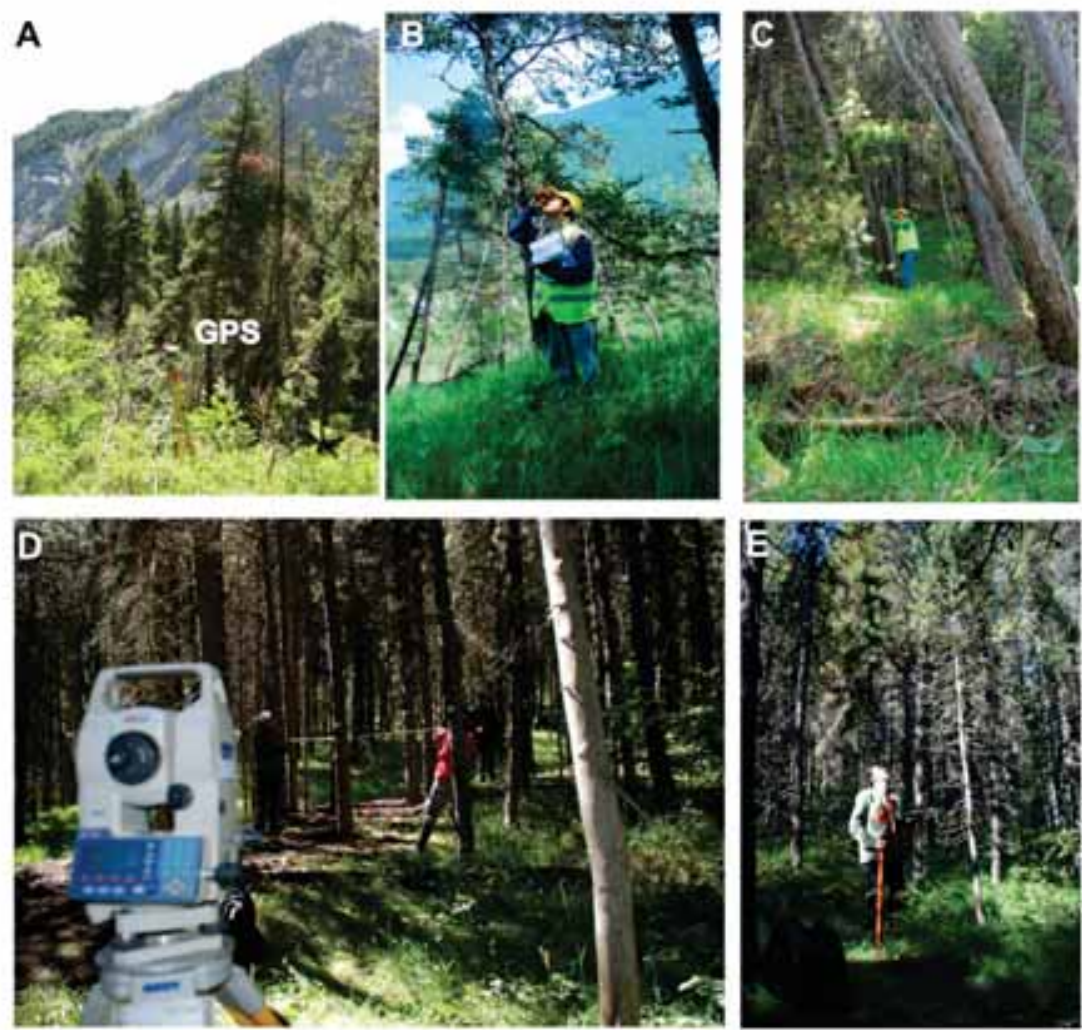

Fig. 7.2: Field photos showing the data collection for tree inventories related to landslides. A) GPS observation in Bois Noir , B) Tree height measurement using a laser range finder, C) Single tree irregularity (inclination and orientation) measurement, E) Geolocation of trees using a total station, F) Canopy gaps identification in Bois Noir area.
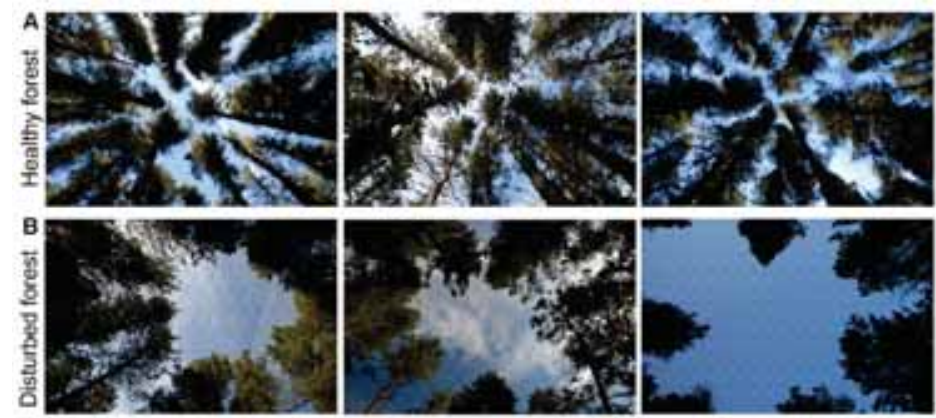

Fig. 7.3: Forest canopy gaps across the healthy and disturbed forests. A) Canopy gaps are relatively small in the stable area. B) Large gaps created in the landslide area. 
TreeVaw tree height prediction was evaluated against field measured tree heights for 560 trees by means of a linear regression analysis. Tree position, crown width and height were used in the evaluation, and the closest trees from the field data were chosen. TreeVaw tree height was used as independent variable, and field tree height was the dependent variable. The root mean square error (RMSE), and the coefficient of determination $\left(R^{2}\right)$ (Mayer and Butler, 1993) are presented, where RMSE provides an estimate of the overall error, and $R^{2}$ provides the strength of the linear relationship.

Analyzing forest canopy gaps induced by landslides

To identify forest canopy gaps, we used gap indicator function $G$ for a given cell at $(x, y)$ on the CHM (Vepakomma et al., 2008) defined as (Eq. 7.1):

$G(x, y)=\left\{\begin{array}{l}\text { if }, \operatorname{CHM}(x, y)<a \\ 0 \text { otherwise }\end{array}\right\}$

where $\mathrm{a}=5 \mathrm{~m}$ was set as height threshold.

To identify forest canopy gaps, a multi-step approach (segmentation, and classification, reshaping) was used in eCognition Developer 8, which is object-based image analysis software (Baatz and Schäpe, 2000). The first was to separate forested areas from non-forested areas, because large gaps may also be caused by roads, or other land non-forested land cover. The chessboard segmentation was applied to the CHM to create homogeneous segments. The segments were classified into forested (including gaps), and non-forested (i.e., gullies, roads, meadows, and bare-soils) using a classification algorithm so called an assign class. The removal of non-forested areas was done using the remove objects algorithm in a reshaping step. Forested segments with a height of less than $5 \mathrm{~m}$ were classified as a gap. This led to elongated gap shapes in case a small opening between two trees linked two larger gaps. To remove these links between two gaps the gap map was filtered using a morphological opening filter, followed by a morphological closing filter. In the next step, canopy gaps classes were merged into a single class using the merge region algorithm. A detailed parameterization of rule sets is given in Gode (2012). In ArcGIS, we produced vector outlines of the gaps and computed gap area using standard GIS routines. Gaps smaller than $1 \mathrm{~m}^{2}$ in size were eliminated, based on the assumption that smaller gaps could be the result of penetration of the laser pulse into the tree crowns.

\subsubsection{Tree inclination and orientation from skeletonization}

Tree inclination and orientation were calculated by skeletonizing the point cloud of a single tree using the SkelTre software (Bucksch et al., 2010; 
Bucksch, 2011). A skeleton is a 3D line topology describing the tree shape, and consists of the trunk and braches of the tree (Fig 7.4). Ideally, the skeleton is centered within tree trunk and branches and is connected whenever the tree is connected. Skeletonizing is achieved by creating a octree, which subdivides the point cloud into cubical octree cells (not shown in Fig. 7.4). Each octree cell encloses a subset of the original point cloud. Further information about the octree is given in Bucksch et al. (2010). The face dual of the octree cells is the octree-graph to be retracted to the 3D topology of the skeleton (Fig. 7.4B). The required input parameter is the minimum cell size to terminate the octree subdivision, set to $1 \mathrm{~m}$ in this study. The retraction process is driven by the selection of suited vertex pairs to be averaged by a set of rules until the final skeleton is derived (Bucksch et al., 2010). The output of SkelTre is a graph consisting of vertices and edges (Fig. 7.5a). Each vertex is embedded into a local weighted center of gravity of the point cloud and is associated with a Cartesian $x y z$-coordinate in an Euclidean space. The neighborhood relation between the vertices is expressed by linking neighboring vertices with an edge (Bucksch et al., 2010; Bucksch, 2011). The skeleton graph is rooted at the vertex having the lowest z-coordinate value (Fig. 7.5a), which is assumed to be the start of the tree trunk on the ground.

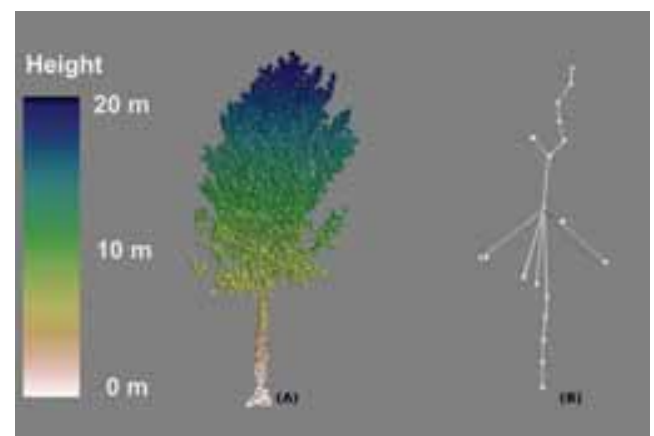

Fig. 7.4: A delineated HDALS tree (A) and the derived SkelTre-Skeleton (B) used to access point cloud points at predefined height levels along the tree trunk.

Skeltree did not have a single tree delineation algorithm included, and required a point cloud of a single tree as input. Different automatic single tree delineation methods were tested to generate input for SkelTre: the normalized cut segmentation (Reitberger et al., 2009), and TreeVaW (Popescu et al, 2002). However, these algorithms did not provide 3D point clouds that represented only a single tree, as these methods assumed the trees to be near vertical. Because tilted trees did not meet this requirement many additional laser points would be included for a delineated tree. These additional points strongly influenced the derived skeleton. Therefore, we manually delineated a set of 560 trees in Quick Terrain Modeler software. 
This manual step rules out the application to large areas, but for the goal of this research it suffices.

The inclination (TRI) and orientation (TRO) of the tree were determined from the skeleton at $1.3 \mathrm{~m}$ height to match the height these parameters were measured in the field. The inclination is the angle derived from analysing the edge $e$ crossing the $1.3 \mathrm{~m}$ tree height from the root vertex. Edge e connects vertices $v_{1}$ and $v_{2}$, where the z-value of $v_{1}$ is smaller than the z-value of $v_{2}$. The vector $m_{e}=\left(v_{2}-v_{1}\right)$ is taken to compute the inclination of the tree trunk as the deviation from the vertical in degrees (Fig. 7.3a). The orientation angle is derived from the parallel projection of $m_{e}$ onto the $x y$-plane of the same edge. The angle between the projected vector $m_{e}$ in the direction of the negative $y$-axis is taken as the orientation angle (Fig. 7.3b), which coincides with the northing on a compass.

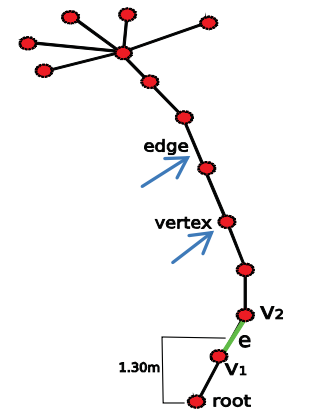

(a)

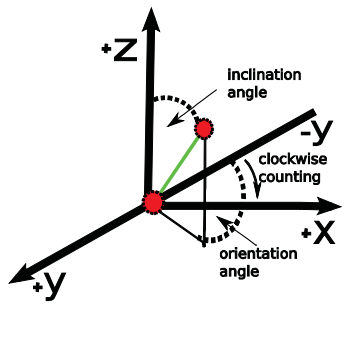

(b)

Fig. 7.5 (a) A schematic skeleton graph of a delineated tree. The edge e connecting the vertices $\mathrm{v} 1$ and $\mathrm{v} 2$ around $1.30 \mathrm{~m}$ height is shown in green and a single tree orientation is computed as a direction from the root to the crown top vertices. (b) Calculation of the inclination and orientation angles.

Predictive quality of the SkelTre-derived inclination and orientation was determined using linear regression. Field reference data were used as dependent variable and SkelTre output as independent variable. The regression computations were taken into consideration the directional and scalar data types. We also reported the RMSE and the $R^{2}$ in the result section.

\subsubsection{Indication of landslide activity}

This section describes the statistical tests of each ALS parameter indicative to landslide activity. To support the landslide activity assessment, we used morphological changes between 2007 and 2009 from ALS data. The historic forest-landslide archive, as presented in Chapter 2 gives a good overview of events, but these are not georeferenced in any way. 
The effect of landslides on tree growth anomalies was assessed based on the field measurements of the tree data, and based on the HDALS-derived metrics of the trees, subdivided in two classes: landslide, and non-landslide. These classes were used in an independent-samples Mann-Whitney $U$ test. Our hypothesis is that, the trees in landslide areas differ in tree height, gaps, inclination and orientation compared to the trees in the stable terrain. In one of the study sites in Bois Noir (see the location in Fig. 2.4), stable and unstable areas were mapped by means of expert-based visual analysis.

Morphological changes also indicate landslide activity. Therefore, we used two ALS DTMs $(2007,2009)$ over the Bois Noir area, and analysed changes in terrain height in the overlapping area. The ALS data acquired in 2007 had about 0.9 million points with a mean point density of 1 points $\mathrm{m}^{-2}$. The subtracted height differences were used to quantitatively investigate the surface deformation which can provides clues on landslide activity in the study area.

\subsection{Results}

\subsubsection{Morphological characterization of landslide zones}

Interpretation of the 2009 DTM revealed that nearly all hill slopes appear to have been affected by mass-movements, as most slopes show typical micromorphology related to landslide activity. Stereoscopic ALS-derived images were used to map and classify a large number of landslides in the Bois Noir area (Fig. 7.6).

About $60 \%$ of the total area showed clear signs of recent slope instability. Rock falls and debris flows are prevalent in the southern part of the catchment, whereas the rest of the study area is largely dominated by slideand flow type movements. HDALS data was used to update the existing landslide inventory that was based on aerial photographs and satellite images in Bois Noir catchment (e.g. Thiery et al., 2004, 2007). It allowed a much better recognition of the individual morphological components of landslides as the HDALS data represents the terrain in a lot of detail whereas the optical data has serious limitations in densely forested areas. 


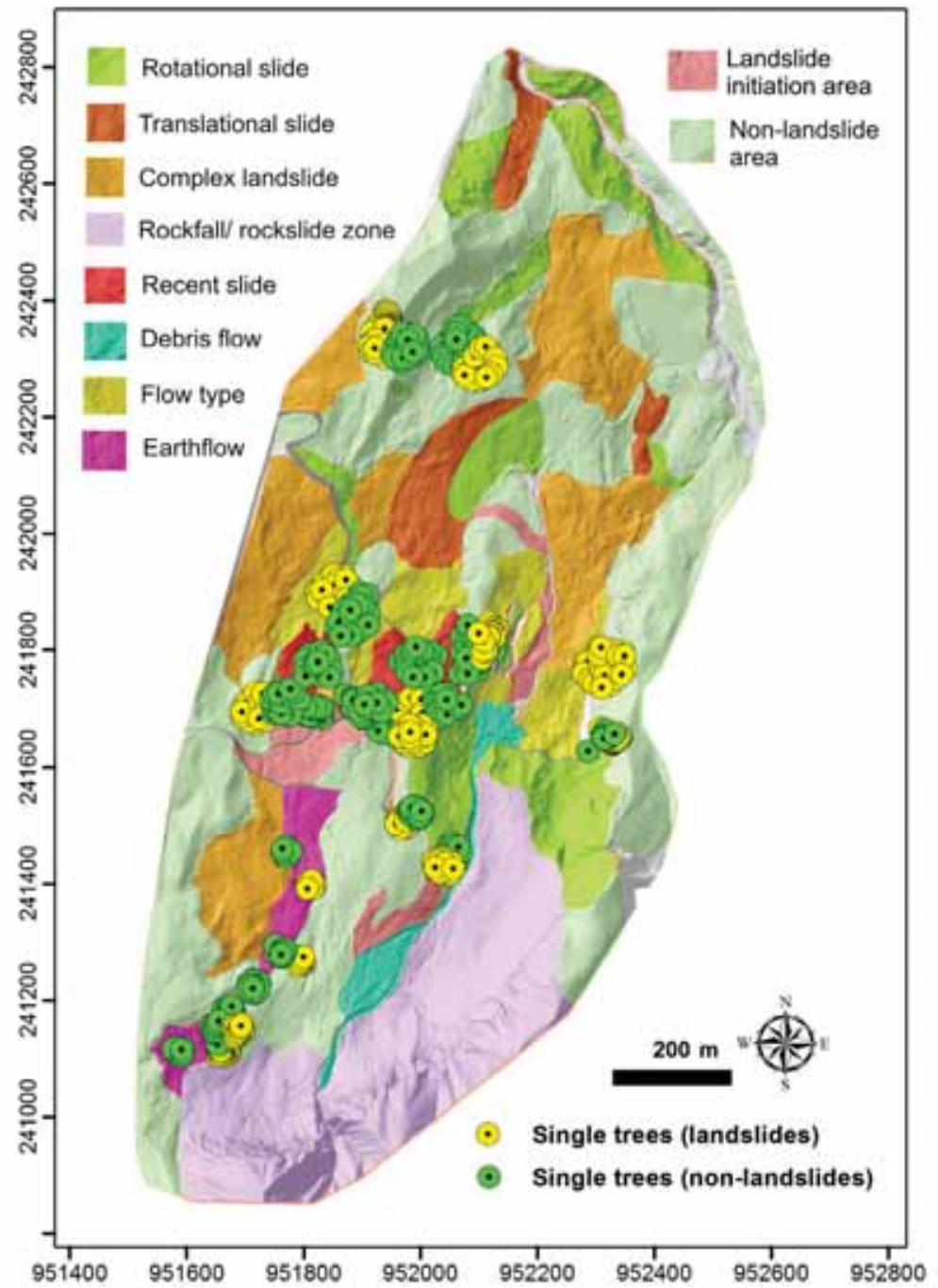

Fig. 7.6: Landslides and non-landslide areas with indication of different types of slope failures as revealed by HDALS data in Bois Noir, Barcelonnette.

\section{Analyzing altitude differences using ALS data from different years}

ALS data from two years (2007 and 2009) were used to generate two DTMs, for the Bois Noir area which were subsequently subtracted in order to be able to detect displacements (Fig. 7.7). The overlap area of the two DTMs was smaller than the 2009. The altitude difference between the two years ranged between -5.9 and $6.6 \mathrm{~m}$. The largest elevation difference that can be observed in the area was in the accumulation area of a flow-type mass 
movement, where up to 6.6 meters of landslide materials were deposited. Flow-type behaviour was largely found in the eastern part of the study area and often characterized by lobes with concentric ridges and cracks. Lopez Saez et al. (2011) indicated that most of the landslide features in Bois Noir appear rather fresh and they show signs of recent landslide activity.

The difference map also shows signs of misalignment of the two DTMs. An example can be seen in the north (see red arrows in the Fig. 7.7), where negative differences show on the west facing slope, and positive differences on the east face. Both slopes were classified as non-landslide areas (Fig. 7.6). A sharp boundary separated the two regions. This implies east to west misalignment between the two flight strips that covered this area. The alteration of positive and negative differences was less visible in other regions.

\subsubsection{Field data analysis}

The distribution of tree species in the Bois Noir area based on the field data collection was about 75\% (420) Pinus uncinata, 15\% (82) Pinus sylvestris, and $10 \%$ (58) Larix decidua. Larix decidua is relatively taller with large diameter breast height $(\mathrm{DBH})$ compared to other tree species. The descriptive statistics of the field data collected in Bois Noir show that landslides affect the tree metrics (Table 7.3).

Trees in the landslide areas are relatively lower, have smaller crowns and diameter breast height, and are more inclined. In the Bois Noir area, large canopy gaps were presented in the landslide area, with a mean canopy gap area of $65 \mathrm{~m}^{2}$, whereas the value was only $16 \mathrm{~m}^{2}$ in the non-landslide areas. All tree parameters indicative to landslides in Bois Noir are significantly different at $95 \%$ confident level, with exception of tree crown width and diameter breast height. Both parameters showed $\rho$-values higher than 0.05 (see Table 7.3). 


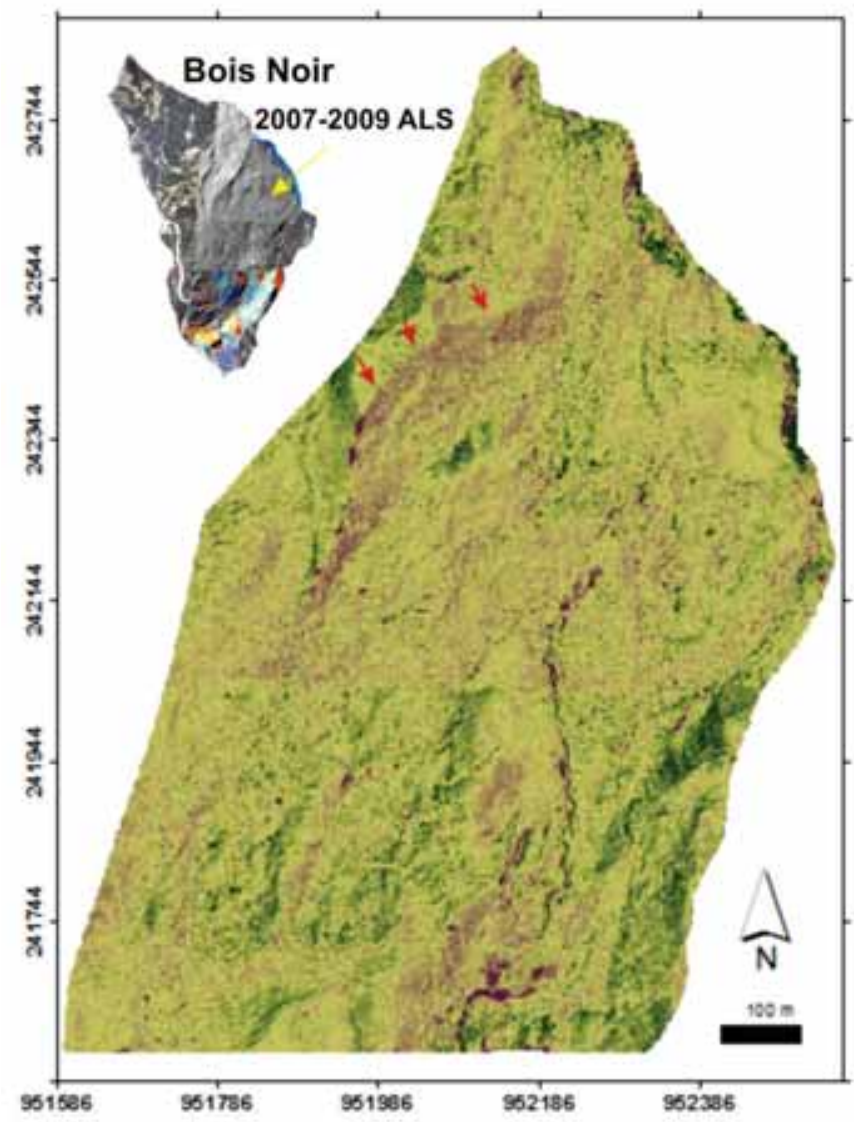

Fig. 7.7: Spatial height difference map computed from ALS DTM 2009 and 2007 in Bois Noir area, Barcelonnette France. See text for explanation.

\subsubsection{Tree height and canopy gaps}

The single tree delineation using TreeVaW resulted in about 80,000 individual trees. Prediction of field-measured tree height with linear regression showed a coefficient of determination of 0.80 , with a RMSE of $1.4 \mathrm{~m}$ (Fig. 7.7a). TreeVaW under-predicts the tree height at tree heights between 5 to $12 \mathrm{~m}$. Overall, this result is comparable to those presented by Popescu et al. (2002), who predicted dominant tree height, with $R^{2}$ value of 0.84 in the healthy forest characterized by gentle slopes. 
Table 7.3: Descriptive and Mann-Whitney U statistical tests of field-measured individual trees in landslide and non-landslide zones in the Bois Noir area, France ${ }^{a}$

\begin{tabular}{|l|l|l|l|l|l|l|l|}
\hline & No. & TRH & TCW & DBH & FCG & TRI & TRO \\
\hline $\begin{array}{l}\text { Landslide } \\
\text { plots }\end{array}$ & 340 & 9.5 & 4.0 & 6.4 & 65.3 & 64 & 25 \\
\hline $\begin{array}{l}\text { Non- } \\
\text { landslide } \\
\text { plots }\end{array}$ & 220 & 13.2 & 4.2 & 7.0 & 16.4 & 5.5 & 65 \\
\hline \begin{tabular}{l}
$\rho$-value \\
\hline
\end{tabular} & 0.001 & 0.080 & 0.110 & 0.005 & 0.008 & 0.011 \\
\hline
\end{tabular}

${ }^{a}$ with TRH $=$ Tree height in $\mathrm{m}, \mathrm{TCW}=$ Tree canopy width in $\mathrm{m}, \mathrm{DBH}=$ Diameter breast height $\mathrm{cm}, \mathrm{FCG}=$ Forest canopy gaps in $\mathrm{m}^{2}$, TRI $=$ Tree inclination in degree, $\mathrm{TRO}=$ Tree orientation in degree.
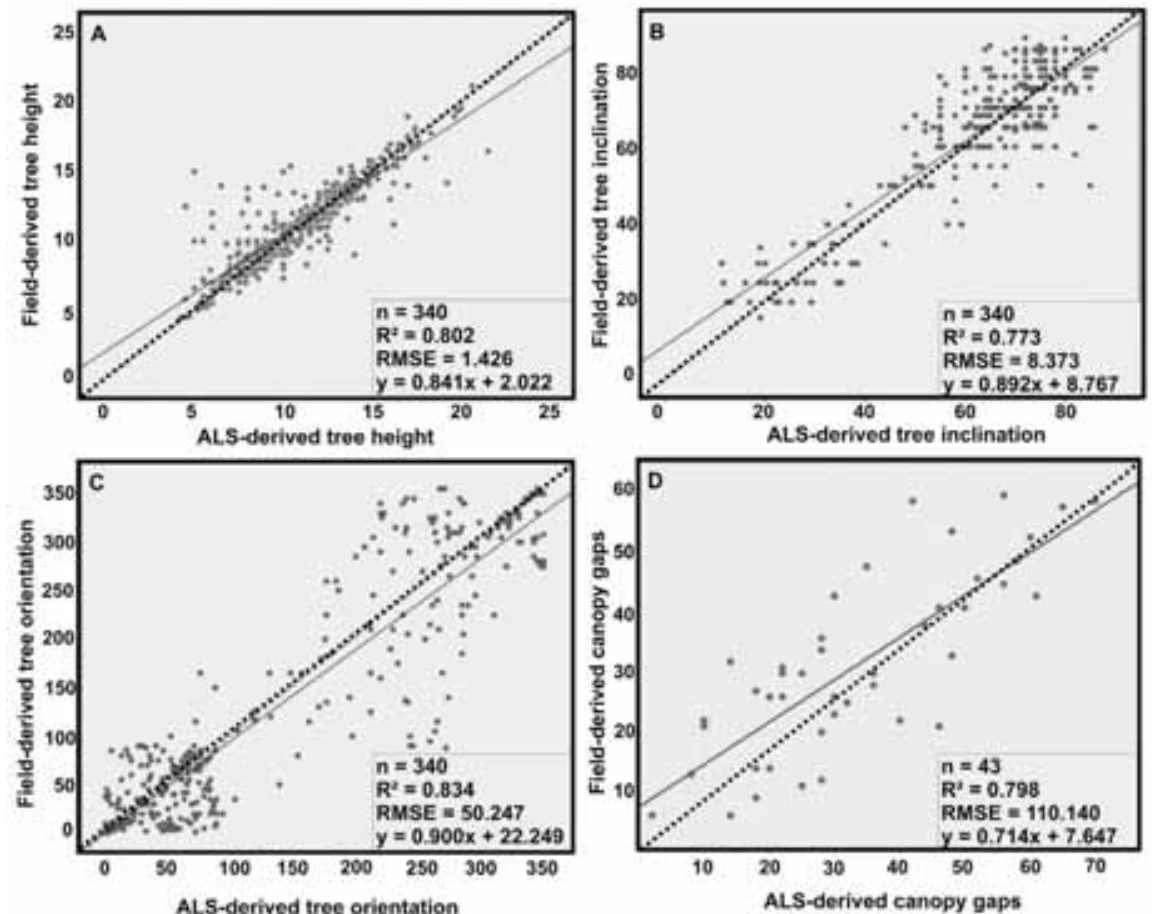

Fig. 7.8: Scatter plots of ALS-derived tree growth anomalies versus field-derived data in the Bois Noir area. A) Tree height (TRH). B) Tree inclination (TRI). C) Tree orientation (TRO). D) Forest canopy gaps (FCG). Dashed lines represent $y=x$, solid lines give the regression lines.

Forest canopy gaps were extracted using an object oriented method. Fig. 7.8D shows the scatter plot of ALS-derived canopy gaps versus field canopy gaps. The coefficient of determination for canopy gaps was 0.798 , with gaps were under-predicted across the study area. In the field, we observed that 
the shapes of canopy gaps varied depending on the landslide types. For example, rock falls resulted in gaps that are elongated in the downslope direction, whereas complex landslides (e.g. rotational slide followed with earthflow) are likely to produce small gaps that are scattered over the area.

\subsubsection{Tree inclination and orientation}

Tree inclination (TRI) was predicted using the SkelTre skeletonization. The inclinations of the edges at $1.3 \mathrm{~m}$ correlated well with the reference data. The linear regression showed a coefficient of determination of 0.77 with a RMSE of $8.37^{\circ}$ (Fig. 7.8B). The slope of the regression line was close to 1 indicating no bias in the method. Relatively few trees had inclinations between $10^{\circ}$ and $40^{\circ}$. In this range field inclinations were higher than the prediction of SkelTre. The tree orientation at breast height (TRO) was also compared against the field reference data (Fig. 7.8C).

To visualize the joint distribution of the orientation and inclination of a set of trees we used a stereoplot (Fig. 7.9). A stereoplot shows the orientation of a tree as the northing. The inclination is indicated by the distance to the origin of the graph, with the origin giving a horizontal tree, and the edge of the plot giving a vertical tree. In the field, we observed drunken trees in a long and narrow landslide transport zone of a complex earthflow (see the location in Fig. 2.4; Chapter 2). Fig 7.9 presents a stereoplot of drunken trees in the active landslide area in Bois Noir with indication of tree point clouds. Fig. 7.9B shows irregular trees oriented predominantly towards the North-East. Given a single tree delineation method that produces clean points representing tilted trees, this method can be applied over larger areas and linked vegetation to different landslide types.

\subsubsection{Disrupted trees and landslide activity}

Statistical tests of ALS-derived disrupted trees

In order to analyze whether the tree characteristics measured from HDALS data are significantly different for active landslide zones and non-active landslide zones, statistical Mann-Whitney $U$ tests were carried out. The results are shown in Table 7.4. Mean rank refers to mean rank score for each group of data and the significance of the difference is implied when the $p$ value is below 0.05 . The results show that all four forest parameters related to landslide disturbances have significant differences between active landslide zone and non-landslide zones. Trees in active landslide areas are more inclined than in the stable areas, smaller, and the forest has larger gaps than in the neighbouring non-landslide areas at the $95 \%$ confidence level. The hypothesis that no differences are present was refuted. This result for ALSbased bio-indicators of landslide presence confirms the field-based relations presented in Table 7.3. 


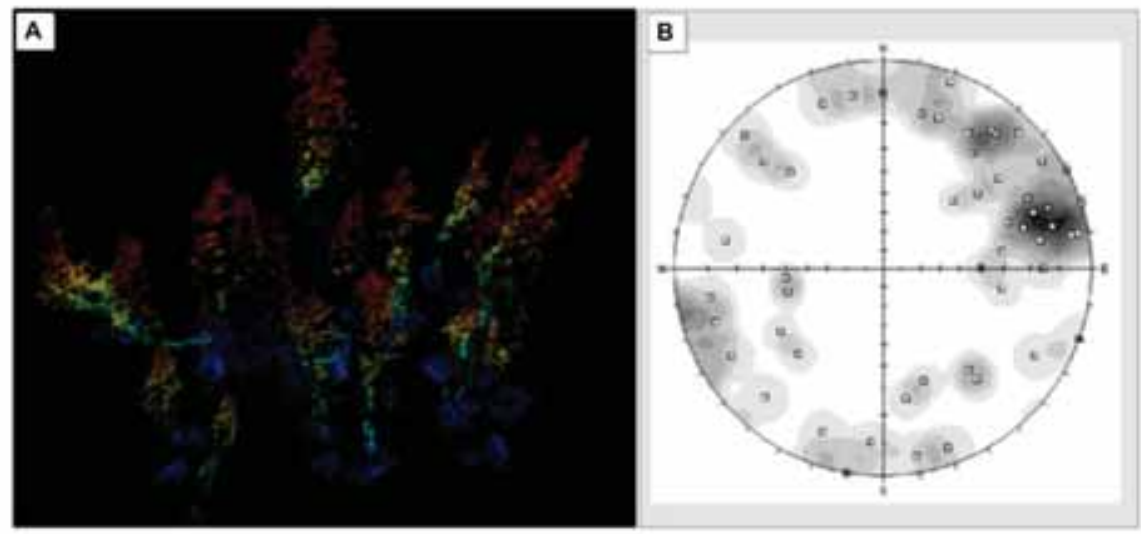

Fig. 7.9: Drunken trees characterized by HDALS. A) Point cloud of disrupted trees. B) A stereoplot showing the disrupted trees oriented at different angles.

Table 7.4: Mann-Whitney $U$ tests for tree structural parameters associated to landslide disturbance

\begin{tabular}{|l|l|l|l|l|l|}
\hline \multirow{2}{*}{ Parameter } & \multicolumn{2}{|l|}{ Landslide area } & \multicolumn{2}{l|}{ Non-landslide area } & \multirow{2}{*}{-value } \\
\cline { 2 - 5 } & $\mathrm{n}$ & Mean rank & $\mathrm{N}$ & Mean rank & \\
\hline Tree height & 340 & 396.42 & 220 & 186.93 & 0.001 \\
\hline Forest canopy gaps & 25 & 27.02 & 18 & 16.03 & 0.002 \\
\hline Tree inclination & 340 & 375.85 & 220 & 210.17 & 0.011 \\
\hline
\end{tabular}

\subsection{Discussion}

In the Bois Noir area, HDALS data were used to identify and map landslides beneath dense vegetation resulting in a more accurate representation of slope failures as compared to a previous landslide inventory based on aerial photographs and satellite images (Thiery et al., 2004, 2007). It allowed a better recognition of kinematic zones of a complex landslide. The rate of erosion and accumulation over a period of two years was measured using two HDALS data sets from different years. This analysis allowed to quantify the surface displacement and to correlate this with the vegetation anomalies.

Individual tree delineation using the TreeVaW software, based on the variable window filter algorithm, was capable to identify the individual trees above a threshold of 3 meters, and to estimate the tree height and crown width. The tree detection and height estimation results are comparable to those reported by Popescu et al. (2002), who predicted dominant tree height, with value of 0.84 in the healthy forest characterized by gentle slopes. The accuracy of the estimated tree heights in this study $\left(R^{2}=0.80\right)$ was slightly lower, because most of the trees are located on undulated terrain, with slope angles up to 50 degrees and surface roughness of up to $0.40 \mathrm{~m}$.. Both from the HDALS 
dataset as well as from the field measurements we measured that a large number of trees are disrupted, irregular (e.g. tilted or bended) and often tend to entangle their crown areas. These factors have direct impact in reducing the accuracy of tree height estimation from ALS data in landslide prone areas. The tree height measurements, using a laser range-finder, may also introduce a considerable error, as it is often difficult to identify the apex of the tree crown from a distance inside a forested area. In the Bois Noir area, the tree density is very high coupled with a steep topography, which negatively affected the tree height readings.

In this study, we presented an object-oriented image analysis method to extract the forest canopy gaps, resulted with a $\mathrm{R}^{2}$ of 0.79 compared to the field observations. Our results are slightly less accurate compared to the studies by Gaulton and Malthus (2010) who reported an overall accuracy of $88 \%$ in Picea sitchensis plantation in the UK and Vepakomma et al. (2008) with an accuracy of $96 \%$ in mature forests in Canada. Both studies were carried out in managed forests with a relatively flat terrain and the canopy gaps are caused by different disturbance agents such as forest fires, spruce budworm outbreaks, wind-throw, and tree-falls. However, in our study area, a complex interaction between the landslide processes and the forest ecosystem made the canopy gaps detection rather difficult. The canopy gaps have no consistent shape as several reactivations of landslides may took place. Future research may be directed towards the link between gaps, landslide types, and tree species.

In the field, we observed that the trees in landslide affected areas are significantly lower, and more inclined, while the gaps between them were larger. Based on HDALS data in Bois Noir, the SkelTre skeletonization method was capable to extract the tree inclination and orientation with an $R^{2}$ of 0.77 and 0.83 , respectively. The quality of the estimated tree irregularity is influenced by the quality of delineated single trees. The number of ALS points representing the tree stem is also crucial. The SkelTre software provided better results when more points represented the tree structure. Inaccurate results were derived if the data input had insufficient number of points on the trunk, especially at the lower tree stem. In this respect, the best results were found for Pinus uncinata, the dominant tree species. This species has a clear trunk and big branches, in contrast to Larix decidua, which has a low canopy base height, irregular twigs, and heavy leaves on branches. Insufficient points on the stem contributed to large residuals in the tree inclination and orientation predictions. Also, disrupted trees located on steep slopes or areas with a high local surface roughness are relatively difficult to delineate, which limited the performance of the SkelTre-skeletonization method. For large scale application of this method a preprocessing step would be required to clean point clouds of individual trees. 
Statistical tests of ALS-derived disrupted vegetation characteristics (tree height, forest canopy gaps, tree inclination and orientation) proved that there are clear differences between the extracted parameters in active landslide and non-landslide zones across the study areas at the $95 \%$ confidence level. The results were very similar to those reported by Van Den Eeckhaut et al. (2009), who statistically analyzed variables related to dendrometry data.

In this study, it was shown that landslides have a clear effect on tree irregularity, and gap size. This is the first study that showed that inclination and orientation can be extracted from ALS data. The next step would be to develop a predictive model that incorporates these parameters in the prediction of landslide activity. A number of challenges remain that need to be tackled before operationalizing such a model. Firstly, automation SkelTre input generation to enable application of the skeletonization to larger areas. Secondly, patterns of irregular trees need to be pinned to specific processes. In addition to landsliding, trees may also be affected by illness, snow pressure, avalanches, wind fall, rock fall, debris flows, or selective logging. If each dominant and subdominant tree were to be skeletonized and attributed with characteristics, the spatial patterns in these characteristics can be used in a predictive model. Thirdly, the point density of this study (170 points $\mathrm{m}^{-2}$ ) is not yet mainstream in large area ALS campaigns. High point densities will be required whenever the skeletonization is used as a method.

\subsection{Conclusions}

In this study, we showed the utilization of HDALS data for accurately mapping complex landslides and characterizing disrupted trees caused by landslides in a temperate environment. The methods were developed in the Bois Noir area characterized by Callovo-Oxfordian marls in the Barcelonnette Basin (Southern French Alps). High density ALS has proven to be a very important data source to physically characterize complex structural vegetation attributes. With a substantial point density across the forested landslides, we presented results based on methods developed using pixel-, object oriented-, and point cloud-based techniques. These techniques were used to retrieve tree height, canopy gaps, inclination and orientation, which are associated to growth disturbance. Field validation and ALS-derived data distinctly separated the signature of tree anomalies in the landslide area compared to healthy forests.

The extraction of tree irregularities induced by landslides was performed by analyzing the tilting and bending of disturbed trees, as affected trees attempt to regain the geotropic growth resulting with externally visible evidence. Based on field data, significant differences exist between landslide and nonlandslide areas with a $95 \%$ confidence interval for tree height, inclination, 
orientation, and forest canopy gaps. Canopy width and diameter at breast height were not significantly different at $95 \%$. Here the first successful extraction of tree inclination and orientation from ALS data was presented. Based on analysis of the ALS data significant differences were found for tree height, inclination, orientation, and forest canopy gaps as well. Still the challenges here are to (1) produce high quality single tree delineation method and an automatic processing module involving the SkelTre skeletonization, and (2) analyse patterns in tree irregularities to pin these patterns to specific processes. These are subject to future research works.

Tree growth disturbances can be caused by other earth surface processes such as pressure of snow-pack, prevailing winds, extremely meteorological conditions, competition or disposal of neighbouring trees, presence of heavy, branches higher on the stem, and root penetration (Shroder, 1978; Van Den Eeckhaut et al., 2009; Lopez Saez et al., 2011). Differentiating the tree shape in response to the aforementioned of earth surface processes in a larger area can also be a subject of future research.

We conclude that high density ALS is state-of-the-art for geometrically retrieving vegetation structures subjected to forest disturbances (e.g. landslides) in a forested mountainous region. It is a promising tool to remotely characterize the tree growth anomalies induced by complex landslides. Quantification of landslide activity analysis from a single ALS is a possible follow up. This should include setting up and testing a predictive model. 


\section{Chapter 8}

\section{Synthesis and conclusion}

The increasing availability, quality and affordability of airborne laser scanning (ALS) data have triggered this research on the suitability of ALS for the assessment of landslide inventories, hazards and risks. This study investigated the possibilities to identify and survey landslides in temperate and tropical environments using ALS data. Emphasis was put on landslide mapping in areas partially or completely covered by forest. This chapter presents a synthesis: main research objectives, results and conclusions are presented together with recommendations for further research.

\subsection{Landslide DTM quality and interpretability}

\section{DTM quality of forested landslides}

The possibilities to generate a suitable high-quality DTM for mapping and classification of forested landslides in temperate and tropical environments using ALS data were investigated. Expert knowledge was required for parameterizing the ALS DTM filter suitable for landslide mapping. We developed an iterative approach based on the hierarchical robust interpolation (HRI as embedded in SCOP ++ ), and compared it to standard parameterizations available in the SCOP++ software, and one default filter from the progressive TIN densification (PTD) method. The newly developed filter, called HRI-landslide filter, was developed for a temperate pine forest in Bois Noir, France, and an ALS point density of 140 points $\mathrm{m}^{-2}$. The landslide filter parameterization was subsequently adapted for a study in the tropics (Cameron Highlands, Pahang, Malaysia). The modification of filter parameterization was needed to adapt to a point density of 1.8 points $\mathrm{m}^{-2}$, more complex vegetation, and the ruggedness of the terrain. Table 8.1 summarizes the results of the DTM vertical accuracy assessment for two study areas (Bois Noir in France and Cameron Highlands in Malaysia) and compares the results with values reported in the literature.

The vertical accuracy of the DTM varied between 0.28 and $0.34 \mathrm{~m}$ for Bois Noir using the landslide filter (Chapter 3). In the Cameron Highlands the overall RMSE varied between 4.20 and $0.89 \mathrm{~m}$ (Chapter 4) based on a modified version of the landslide filter to adapt to denser vegetation and a lower point density. The obtained accuracies are a slight improvement compared to the studies reported in the literature (Table 8.1). The preservation of small diagnostic features for landslide classification, i.e. 
primary and secondary scarps, cracks, and displacement structures, is challenging and essential for accurate landslide mapping.

Table 8.1: Comparison of the results of DTM vertical accuracy assessment

\begin{tabular}{|c|c|c|c|c|c|}
\hline Study area & Forest type & Filter type & $\begin{array}{l}\text { No of } \\
\text { data }\end{array}$ & $\begin{array}{c}\text { RMSE } \\
\text { (m) }\end{array}$ & Reference \\
\hline Bois Noir, France ${ }^{a}$ & Pine & HRI-landslide & 332 & 0.33 & Chapter 3 \\
\hline Bois Noir, France $^{a}$ & Pine & $\begin{array}{c}\text { TIN } \\
\text { densification }\end{array}$ & 332 & 0.28 & Chapter 3 \\
\hline Bois Noir, France ${ }^{a}$ & Pine & HRI-default & 332 & 0.34 & Chapter 3 \\
\hline Bois Noir, France ${ }^{a}$ & Pine & HRI-forest & 332 & 0.34 & Chapter 3 \\
\hline $\begin{array}{c}\text { Cameron } \\
\text { Highlands, } \\
\text { Malaysia }\end{array}$ & Tropical & $\begin{array}{l}\text { Modified HRI- } \\
\text { landslide }\end{array}$ & 448 & 0.89 & Chapter 4 \\
\hline Vienna, Austria & - & $\begin{array}{c}\text { Robust } \\
\text { interpolation }\end{array}$ & 466 & 0.57 & $\begin{array}{c}\text { Kraus and } \\
\text { Pfeifer (1998) }\end{array}$ \\
\hline North Carolina & $\begin{array}{l}\text { Deciduous } \\
\text { and pine }\end{array}$ & - & 1470 & 0.46 & $\begin{array}{c}\text { Hodgson et } \\
\text { al. (2003) }\end{array}$ \\
\hline $\begin{array}{c}\text { Western } \\
\text { Washington State }\end{array}$ & Conifer & - & 347 & 0.32 & $\begin{array}{l}\text { Reutebuch et } \\
\text { al. (2003) }\end{array}$ \\
\hline $\begin{array}{c}\text { North East Costa } \\
\text { Rica }\end{array}$ & Tropical & $\begin{array}{l}\text { Local } \\
\text { minimum }\end{array}$ & 3859 & 2.29 & $\begin{array}{c}\text { Clark et al. } \\
(2004)\end{array}$ \\
\hline
\end{tabular}

a values taken from Table 3.3, ground surface under forested terrain. The RMSE for scarps, cracks and rocks is up to $0.2 \mathrm{~m}$ higher.

\section{DTM quality for geomorphological interpretation}

In Bois Noir, various types of DTMs were produced and their usefulness for visual interpretation was qualitatively evaluated. Expert knowledge was applied to evaluate the interpretability of the DTM in terms of geomorphological features and to create landslide inventory maps. The best interpretation was based on a stereoscopic visualization of the topographic openness on top of the bare earth model. In the Cameron Highlands, the interpretability of the DTM in geomorphological terms was determined by the point density of the original data, vegetation density, DTM filter algorithm and parameterization, and interpolation from point data to raster-based end products. The density information of ALS points (before-and-after filtering) and vegetation cover played a crucial role in generating an optimal DTM for landslide mapping.

A clear trade-off was found between removal of vegetation points and preservation of important terrain points belonging to landslide morphological features. The selection of an appropriate filter algorithm and its parameterization is pertinent and depends on the type and complexity of the landscape (Sithole and Vosselman, 2004). Results indicated that, to produce 
the best ALS-based DTM for landslide interpretation, it is necessary to use a combination of filtering steps, especially in forested mountainous areas. The quantitative and qualitative assessment clearly indicated that a purely quantitative error assessment, e.g. vertical accuracy did not lead to the best DTM for landslide inventory mapping (Chapter 4). Visual interpretation of distinct landslide geomorphology is one of the preferable quality evaluation methods. No single best and holistic method for DTM production exist for different types of landslides and for different environmental conditions.

\section{Minimum and optimal point density for mapping landslides}

The dependence of the interpretability of the DTMs on the point density of the original point cloud was assessed for the Bois Noir study area by thinning out the point cloud. Major geomorphological indicators of landslides were easily distinguished at a point density of 1.69 points $\mathrm{m}^{-2}$. However for a detailed analysis of morphological features for landslide activity assessment a point density of 6 points $\mathrm{m}^{-2}$ or better is required. In the Cameron Highlands, low density ALS data ( 1.8 points $\mathrm{m}^{-2}$ ) was used for extracting ground points associated to landslides and DTM generation for landslide mapping. The quality of the DTM is substantially improved if the point densities increase three times or more, especially in rugged and forested mountainous areas. In spite of the good results it remains difficult to accurately map, classify and characterize old tropical landslides. Re-activation of landslides, erosional processes, anthropogenic activity and vegetation growth is hampering observations and increase the uncertainty of landslide inventory maps.

\subsection{Uncertainty in ALS-based landslide inventory maps}

Landslide inventory maps provide essential information for landslide susceptibility, hazard and risk assessment. For operational use the quality of these maps must be known. Four different inventories were generated by different experts using visual analysis of ALS images and compared to reference data (Chapter 5).

Methods for quantitative map comparison of landslide inventories To quantify the uncertainty of landslide maps, an experimental study of map correctness and completeness was organised. No single standard exists for determining the accuracy of landslide maps (Galli et al., 2008). Moreover, large errors are expected in the areas with old, dormant landslides, intensive terrain modification by farming activity and areas covered by dense vegetation in tropical areas (Carrara et al., 1992).

The error in ALS-derived landslide maps was computed using positional mismatch (mapping error) and frequency-size distribution analysis. For the 
evaluation of the mapping error overlapping areas were determined and divided by the total landslide area. This was carried out for three land cover classes. The analysis of the frequency-size distribution gives insight in the completeness of landslide maps. Creating reference data to support the positional mismatch method was a major challenge. Reference maps were created for forests, agriculture and for tea plantations. The reference maps were produced by dedicated interpreters using a variety of ALS images.

Positional mismatch and completeness of landslide maps produced by multi-scale visual analysis of stereoscopic ALS images

The geometrical accuracy of the landslide inventories was computed by comparing the positional mismatch in a pair wise manner (Tables 5.6-5.8; Chapter 5). When compared to the reference maps, the best ALS-derived inventory map had a mismatch of $93 \%$ for forest, $82 \%$ for tea plantations, and $85 \%$ for agricultural areas. The worst mismatches were 99, 99, and $93 \%$ for forest, tea plantations, and agricultural area, respectively. However, these results were obtained for different inventories. When compared to the existing landslide inventory (Map 7, Tables 5.6-5.8) even larger mapping errors (98 to 100\%) were found for the ALS-based inventories. This can be explained by the fact that the existing inventory contains far less landslides than the reference inventories and hence map comparison results in very large discrepancies. A true reliable reference map is difficult to produce and this hampered accuracy estimates of ALS-derived maps.

This study provided a first indication on mapping errors of landslide maps in tropical regions. At first sight, the reported mapping errors seem very high, but errors in the same order of magnitude were found by Van Den Eeckhaut et al. (2007) for a temperate region. They reported 50-93\% mapping errors for an area in the Flemish Ardennes, Belgium. For the Apennines, Ardizzone et al. (2002) reported positional mismatches up to $80 \%$. Our lowest mapping error is above the arbitrary $70 \%$ mapping error, defined as a standard mapping error by Van Den Eeckhaut et al. (2007).

Frequency-size distribution analysis was used here to quantify the consistency of landslide maps produced by the expert interpreters (Figs. 5.5 and Table 5.9). For the reference data the landslide areas varied with four orders of magnitude $\left(10^{5}\right.$ to $\left.10^{2} \mathrm{~m}^{2}\right)$ while Maps 1 to 4 had a smaller range. The rollover $(\bar{A})$ point indicates the size, below which landslides are missing from the inventory. The reference maps had a rollover point ranging from 400 to $800 \mathrm{~m}^{2}$, while the other inventories showed rollover points between 1000 to $12000 \mathrm{~m}^{2}$. The assessment revealed that Maps 1 to 3 consisted of fewer landslides, generally larger than $10^{4} \mathrm{~m}^{2}$, while Maps 4 to 6 reports a larger number of slope failures. Only the reference maps portrayed slope failures consistently for landslide sizes larger than the rollover point. 


\section{Comparison of ALS-derived landslide inventories containing landslides of varying age \\ Differentiating between historic landslides, and landslides that occurred under different environmental conditions is important in landslide susceptibility mapping (Brabb, 1984). ALS-derived images proved suitable for detailed mapping of landslides, but it remained unclear whether all the mapped landslides have occurred under similar environmental conditions as the actual situation. Dating older landslides in the Cameron Highlands would be an important next step. The mapping error between the historic landslide inventory and the ALS inventories proved to be almost $100 \%$. This suggests that a larger part of the area might be susceptible to landsliding, and that the effect of road cuts and deforestation in the future is difficult to assess. \\ 8.3 Landslide susceptibility mapping based on ALS data}

Several studies have been carried out to model landslide susceptibility in Malaysia (Pradhan, 2010; Pradhan et al., 2010; Pradhan and Lee, 2010a). Predicting areas that are susceptible to landslides requires insight in the process-controlling factors, the geo-environmental conditions, the availability of a historic record and an indication of the accuracy of these data. ALS products were evaluated to deliver these data.

Accuracy of ALS-factors maps for landslide susceptibility mapping This research investigated the possibilities to derive landslide conditioning factor maps for susceptibility analysis from ALS data. Four major categories of causal factors were identified and can potentially be derived from ALS: topographic factors (elevation, slope gradient, slope aspect, and plan curvature), hydrological factors (sediment transport index, topographic wetness index, and distance to drainage network), anthropogenic factors (land-cover and road-cut), and structural geological factors (distance to lineament).

The topographic and hydrologic factor maps (7 maps in total) are relatively easy to produce in a GIS and the DTM from which these maps were generated is accurate ( $0.866 \mathrm{~m}$ vertical accuracy; Chapter 4 ; Table 8.1$)$. The anthropogenic and structural geological factor maps (3 maps in total) are not straightforward to produce and required more efforts. They were generated using an ALS-derived DTM, with $1 \mathrm{~m}$ resolution, with the support of ALSderived surface models (DSM) and canopy models (CHM). Derivative maps such as land cover, roads, and buildings were generated.

Land cover derived from low density ALS data had an average accuracy of $89 \%$ and is more accurate than the published land cover map based on a 
SPOT image. Vegetation characteristics extracted from ALS data are optionally useful information next to the normalized difference vegetation index map (NDVI) widely used in landslide susceptibility studies. Buildings and roads were also extracted from ALS data and independently evaluated for elements-at-risk mapping. Buildings were identified at $81 \%$ accuracy compared to stereoscopic DSM visual analysis. The completeness and correctness was $88.6 \%$ and $90 \%$ respectively. The extracted roads had an increment of $58 \%$ compared to the existing road map (Pradhan and Lee, 2009), with a RMSE of $0.68 \mathrm{~m}$. Furthermore, the ALS-derived images revealed four times more geological lineaments (predominantly covered by vegetation) compared to the published national geological map (Chow et al., 2003). The ALS-derived neotectonic data indicate that some landslides might have been triggered by earthquakes (Chapters 4 and 5).

\section{Additional required data}

The causal factor maps used in landslide susceptibility assessment were generated from a $1 \mathrm{~m}$ resolution DEM. For more complex combinations of conditions between the controlling factor maps and historic landslide distribution, it is relevant to incorporate factor maps related to lithology, weathering, soil types and soil depth. ALS can also be a source to derive these factor maps when combined with field information and geostatistical analysis.

\section{Susceptibility mapping and the effect of historic landslides in the landslide inventory map}

Two landslide inventory maps were used in logistic regression analysis, which resulted in two susceptibility maps. The ALS-based inventory was correctly predicted for 59\%, whereas the historic inventory was $90 \%$ correct. The resulting susceptibility maps (Fig. 6.5, Chapter 6) showed very different patterns. Interestingly, no single landslide recorded in the historical database occurred in the forested area, which is explained by the fact that landslides under forest could not be mapped using aerial photo-interpretation. If a new road would be constructed in areas now indicated with low landslide susceptibility, this would change the initial conditions leading very probably to the initiation of landslides. Despite the advantages of ALS imagery to identify and map landslides beneath forests, the complex characteristics of each landslide and the unknown age make it necessary to apply tuned approaches for susceptibility analysis. The temporal aspects of both the landslide inventories and factors maps play a crucial role in landslide susceptibility prediction.

The choice of the landslide inventory map as dependent variable in the logistic regression strongly affected the outcome. The existing landslide map contains the historical events that occurred in the recent past, such as those 
along the main roads, or the ones that caused fatalities. In contrast, the ALSderived landslide inventory map includes slope failures of both historic and unknown ages. It also contains different landslide types, which may result from specific combinations of causal factors (different slope classes, topographic conditions and land cover classes). This study recommends to produce landslide susceptibility maps using the historic landslide inventory as a basis for statistical analysis, and next use the ALS-based inventory as a separate legend class in the susceptibility map. It is important to account for older landslides and for changing environmental conditions over time.

\subsection{Vegetation as bio-indicators of landslides}

Landslides are one of the contributors to forest disturbances (Frolking et al. 2009). Landslides may affect tree height, density, orientation, inclination, and bending. Forest gaps may differ between stable and unstable areas. In Chapter 7 the use of tree properties as bio-indicators for landslide activity was evaluated. A method was presented to derive these parameters from ALS for the Bois Noir area, in France. The low point density of the ALS data in the Cameron Highlands prohibited the application of the method in that region.

Field-based bio-indicators for slope stability

The properties of 560 individual trees were collected though field measurements in the Bois Noir area. About $60 \%$ was collected on the landslide area and $40 \%$ on the stable areas nearby. The tree species composition is about $75 \%$ (420) Pinus uncinata, 15\% (82) Pinus sylvestris, and $10 \%$ (58) Larix decidua. Trees disturbed by landslides are lower and more inclined, while the forest canopy gaps are larger and the gap frequency is higher for landslide areas as compared to stable areas (Table 7.3). Differences were significant at the $95 \%$ confidence level.

\section{ALS-based bio-indicators for slope stability}

A method was developed using pixel-, object oriented-, and point cloudbased techniques to retrieve tree height, canopy gaps, inclination and

orientation from ALS data. The detection of individual trees and estimation of tree height was done using TreeVaW software. The estimated tree heights had an overall accuracy of $0.80 R^{2}(1.43 \mathrm{~m}$ RMSE) compared to field observations.

An object-oriented image analysis method was used to extract forest canopy gaps, resulted with an overall accuracy of $0.79 R^{2}$ (110.140 $\mathrm{m}^{2}$ RMSE) compared to the field data. Gaulton and Malthus (2010) reported better accuracy (88\%) in a Picea sitchensis plantation in the UK. Vepakomma et al. (2008) obtained an accuracy of $96 \%$ in mature forests in Canada. Both 
studies were carried out in managed forests with a relatively flat terrain and where the canopy gaps are caused by different processes such as forest fires, spruce budworm outbreaks, wind-throw, and tree-falls.

Tree irregularity (inclination and orientation) is retrieved from high density ALS data. The SkelTre-skeletonization method was used to extract the tree inclination and orientation (Chapter 7). The current limitation of the algorithm lies on the quality of delineated single trees. The method provided good results if sufficient laser points represented the tree structure, but results became less accurate when only few points represented the position of the tree. Undulated terrain or high ruggedness further complicates the delineation and characterization of the trees and their position. This study showed that ALS-derived disrupted vegetation characteristics (tree height, forest canopy gaps, tree inclination and orientation) show differences between active landslide and non-landslide zones, indicating the potential to use vegetation as bio-indicator for landslides.

\section{Required point density for bio-indicator mapping with ALS data}

HDALS data were used here to map and characterize bio-indicators induced by landslides in Bois Noir, France. Extraction of tree inclination and orientation requires very high density point clouds, particularly with sufficient hits on the tree stem. The point density of ALS data varies per tree species due to their shape and form, e.g. Pinus uncinata is likely to provide much more points on the tree stem than Larix decidua, which tends to have more data on the tree crown area and branches. The methods used to extract the indicators would require a lower point density, if a canopy height model can be used. An experimental assessment done by Hatami (2012) in Bois Noir suggested that a point density of about 30 points $\mathrm{m}^{2}$ is needed to achieve height accuracy estimation of about $0.73 \mathrm{R}^{2}$ and $1.8 \mathrm{~m}$ RMSE. The success of canopy gap extraction depends on the quantity of points representing the shape of tree crowns. Single tree analysis in the tropics remains very challenging given the complexity and irregularity of tropical vegetation.

\subsection{Research challenges and future research direction}

In conclusion, the emergence of ALS for investigating geomorphic processes and activities has improved our ability to map, monitor and model the topographic terrain signature and the landslide-induced vegetation anomalies. ALS is an important new data source to characterize landslides in complex landscapes. The increased availability of modern ALS systems and advanced point cloud processing software have led the way to improve future landslide maps and subsequently reduce possible landslide risks in a changing environment. Possible future research directions include: 
i. An object-oriented and transferable model for tropical or sub-tropical landscapes could be developed to automate the creation and updating of landslide inventory maps. This might be faster, and easier to reproduce, but the drawback is the development of a rule set that can take the variety of shapes into account.

ii. Dating of the abundant and apparently old landslides in the tropics could give insights in the climatological conditions that caused these events. A dendrogeomorphological study could be used to assess the recurrence of events, the timing, the movement rates, and the magnitude of events.

iii. Understanding the neotectonic features and their activity found in the tropics could provide input for ongoing regional seismotectonic study.

iv. Establish a relationship between the velocity of slow moving landslides and tree deformations.

v. A single tree analysis using SkelTre-skeletonization should be investigated for handling structurally complex tropical trees and their undergrowth.

vi. Spatiotemporal analysis of multi-temporal laser scanning data can be performed for understanding and quantifying surface changes associated with hillslope processes and anthropogenic activity. 


\section{References}

Alexandrowicz, Z., Margielewski, W., 2010. Impact of mass movements on geo- and biodiversity in the Polish Outer (Flysch) Carpathians. Geomorphology 123, 290-304.

Amaranthus, M.P., Rice, R.M., Barr, N.R., Ziemer, R.R., 1985. Logging and forest roads related to increased debris slides in southwestern Oregon. J. For. 83 229-233.

Ardizzone, F., Cardinali, M., Carrara, A., Guzzetti, F., Reichenback, P., 2002. Impact of mapping errors on the reliability of landslide hazard maps. Natural Hazards and Earth System Sciences 2, 3-14.

Ardizzone, F., Cardinali, M., Galli, M., Guzzetti, F., Reichenbach, P., 2007. Identification and mapping of recent rainfall-induced landslides using elevation data collected by airborne Lidar. Natural Hazards Earth System Sciences 7, 637-650.

Arnaud, F., 1906. Documents et notices historiques sur la vallee de Barcelonnette, notice historique sur les torrents de l'Ubaye. Barcelonnette, $1^{\text {st }}$ volume.

Axelsson, P., 2000. DEM generation from laser scanner data using adaptive TIN models. International Archives of Photogrammetry and Remote Sensing 35, 110-117.

Ayalew, L., Yamagishi, H., 2005. The application of GIS-based logistic regression for landslide susceptibility mapping in the Kakuda-Yahiko Mountains, Central Japan. Geomorphology 65, 15-31.

Baatz, M., Schäpe, M., 2000. Multiresolution segmentation - An optimization approach for high quality multi-scale image segmentation. In: Strobl, J., Blaschke, T., Griesebner, G. (Eds.), Angewandte Geographische Informations-Verarbeitung XII. Wichmann Verlag, Karlsruhe, 12-23.

Baghdadi, N., Cavelier, S., Chiles, J.P., Bourgine, B., Toutin, T.H., King, C., Daniels, P., Truffert, C., 2005. Merging of airborne elevation data and Radarsat data to develop a Digital Elevation Model. International Journal of Remote Sensing 26, 141-166.

Begueria, S., 2006. Validation and evaluation of predictive models in hazard assessment and risk management. Natural Hazards 37, 315-329.

Bell, R., Petschko, H., Röhrs, M., Dix, A., 2012. Assessment of landslide age, landslide persistence and human impact using airborne laser scanning digital terrain models. Geografiska Annaler Series A Physical Geography 94(1), 135-156. 
Blackburn, G. A., Milton, E. J., 1996. Filling the gaps: Remote sensing meets woodland ecology. Global Ecology and Biography 5, 175-191.

Blair, J.B., Hofton, M.A., 1999. Modeling laser altimetry return waveforms over complex vegetation using high-resolution elevation data. Geophysical Research Letters 26, 2509-2512.

Borghuis, A.M., Chang, K., Lee, H.Y., 2007. Comparison between automated and manual mapping of typhoon-triggered landslides from SPOT-5 imagery. International Journal of Remote Sensing 28, 1843-1856.

Braam, R.R., Weiss, E.E.T., Burrough, P.A., 1987. Dendrogeomorphological analysis of mass movement a technical note on the research methods. CATENA, 14, 585-589.

Brabb, E.E., 1984. Innovative approaches to landslide hazard and risk mapping. Proc., Fourth International Symposium on Landslides, vol. 1. Canadian Geotechnical Society, Toronto, Canada, 307-324.

Brabb, E.E., 1991. The world landslide problem. Episodes 14 (1), 52-61.

Brabb, E.E., Colgan, J.P., Best, T.C., 2000. Map showing inventory and regional susceptibility for Holocene debris flows and related fast-moving landslides in the conterminous United States. U.S. Geological Survey Miscellaneous Field Studies Map, MF-2329 http://geopubs.wr.usgs.gov/map-mf/mf2329/.

Brabb, E.E., Harrod, B.L. (Eds.), 1989. Landslides: Extent and Economic Significance. A.A. Balkema Publisher, Rotterdam. 385 p.

Bräker, O., 2002. Measuring and data processing in tree-ring research-a methodological introduction. Dendrochronologia 20, 203-216.

Brand, E.W., 1989. Occurrence and significance of landslides in Southeast Asia. In: Brabb and Harrod (Eds), Landslides: extent and economic significance, Balkema, Rotterdam, 303-324.

Brardinoni, F., Slaymaker, O., Hassan, M.A., 2003. Landslide inventory in a rugged forested watershed: a comparison between air-photo and field survey data. Geomorphology 54, 179-196.

Briese, C., 2004. Breakline modelling from airborne laser scanner data. Ph.D. Thesis, Vienna University Technology, Austria.

Broadbent, E.N., Asner, G.P., Pena-Claros, M., Palace, M., Soriano, M., 2008. Spatial partitioning of biomass and diversity in a lowland Bolivian forest: Linking field and remote sensing measurements, For. Ecol. Manage., 255, 2602- 2616, doi:10.1016/j.foreco.2008.01.044.

Burrough, P.A., McDonell, R.A., 1998. Principles of Geographical Information Systems. Oxford University Press, New York, 190 p. 
Bucksch, A., 2011. Revealing the skeleton from imperfect point clouds. PhD Thesis at Delft University of Technology, Dr. Hut, Munich. ISBN 978-386853-877-9.

Bucksch, A., Lindenberg, R., Menenti, M., 2010. Robust skeleton extraction from imperfect point clouds. The Visual Computer 26(10), 1283-1300.

Bucksch, A., Lindenbergh, R., 2008. CAMPINO - a skeletonization method for point cloud processing. ISPRS Journal of Photogrammetry and Remote Sensing 63, 115-127.

Bujang, B.K.H., Faisal, H.A., David, H.B., Harwant, S., Husaini, O., 2008, Landslides in Malaysia. Occurrences, Assessment, Analysis and Remediation, Penerbitan Universiti Putra Malaysia, 406-421.

Cardinali, M., Antonini, G., Reichenbach, P., Guzzetti, F., 2001. Photo geological and landslide inventory map for the Upper Tiber River basin. CNR, Gruppo Nazionale per la Difesa dalle Catastrofi Idrogeologiche, Publication n. 2116, scale 1:100,000.

Cardinali, M., Ardizzone, F., Galli, M., Guzzetti, F., Reichenbach, P., 2000. Landslides triggered by rapid snow melting: the December 1996-January 1997 event in Central Italy. In: Claps, P., Siccardi, F. (Eds.), Proceedings 1st Plinius Conference, Maratea. Bios Publisher, Cosenza, 439-448.

Cardinali, M., Carrara, A., Guzzetti, F., Reichenbach, P., 2002. Landslide hazard map for the Upper Tiber River basin. CNR, Gruppo Nazionale per la Difesa dalle Catastrofi Idrogeologiche, Publication n. 2116, scale $1: 100,000$.

Carrara, A., Cardinali, M., Guzzetti, F., 1992. Uncertainty in assessing landslide hazard and risk. ITC Journal. The Netherlands 2, 172-183.

Carrara, A., Cardinali, M., Guzzetti, F., Reichenbach, P., 1995. GIS technology in mapping landslide hazard. In: Carrara, A., Guzzetti, F. (Eds.), Geographical Information Systems in Assessing Natural Hazards. Kluwer Academic Publisher, Dordrecht, The Netherlands, 135-176 pp.

Carrara, P.E., O'Neill, J.M., 2003. Tree-ring dated landslide movements and their relationship to seismic events in southwestern Montana. Quaternary Research 59, 25-35.

Chen, Y., Shi, P., Den, I., Li, J., 2007. Generation of a top-of-canopy Digital Elevation Model (DEM) in tropical rain forest regions using radargrammetry. International Journal of Remote Sensing 28 (19), 43454349.

Chiba, T., Kaneta, S.I., Suzuki, Y., 2008. Red relief image map: new visualization method for three dimensional data. In: The International 
Archives of the Photogrammetry, Remote Sensing and Spatial Information Sciences vol. XXXVII, Part B2. Beijing, 1071-1076.

Chow, W.S., Zakaria, M., 2003. Geological terrain mapping. JMG unpublished report. JMG.SWP.GS, vol. 16, 1-42 pp.

Chung, C.J., Fabbri, A.G., 1999. Probabilistic prediction models for landslide hazard mapping. Photogrammetric Engineering \& Remote Sensing 65 (12), 1389-1399.

Clark, D.B., 1990. The role of disturbance in the regeneration of neotropical moist forests. In: Bawa, K. S., Hadley, M. (Eds.), Reproductive Ecology of Tropical Forest Plants, Man and the Biosphere Series vol. 7, 291-315 p.

Clark, M.L., Clark, D.B., Roberts, D.A., 2004. Small-footprint LiDAR estimation of sub-canopy elevation and tree height in a tropical rain forest landscape. Remote Sensing Environment 91(1), 68-89.

Corominas, J., Moya, J., 2008. A review of assessing landslide frequency for hazard zoning purposes. Engineering Geology 102, 193-213.

Crozier, M.J., 2010. Deciphering the effect of climate change on landslide activity: A review. Geomorphology 124, 260-267.

Crozier, M.J, 2005. Management frameworks for landslide hazard and risk: Issues and options. In: Glade, T., Anderson, M., Crozier, M.J. (Eds.) Landslide Hazard and Risk, John Wiley and Sons, Chichester, 331-350.

Cruden, D.M., 1991. A simple definition of a landslide. Bulletin of the International Association of Engineering Geology 43, 27-29.

Das, I., Stein, A., Kerle, N., Dadhwal, V.K., 2011. Probabilistic landslide hazard assessment using homogeneous susceptible units (HSU) along a national highway corridor in the northern Himalayas, India. Landslides 8(3), 293-308.

De Ploey, J., Cruz, O., 1979. Landslides in the Serra do Mar, Brazil. Catena 6, 111-122.

De Villiers, M., 2001. Water - the fate of our most precious resource. Mariner Book, Boston (ISBN 0-618-12744-5), 352 p.

Dearman, W.R., 1978. Weathering classification in the characterization of rock: a revision. Bulletin of International Association of Engineering Geologists 18, 23-128.

Douglas, I., 1999. Hydrological investigations of forest disturbance and land cover impacts in South-East Asia: a review. Philosophical Transactions of the Royal Society of London. Series B 354, 1725-1738. 
Douglas, D.H., Peucker, T.K., 1973. Algorithms for the reduction of the number of points required to represent a digitized line or its caricature. The Canadian Cartographer 10, 112-122.

Durgin, P.B., 1977. Landslides and the weathering of granitic rocks. In: Landslides, Geological Society of America, Reviews in Engineering Geology 3, 127-131.

Efthymiadis, D., Jones, P.D., Briffa, K.R., Auer, I., Böhm, R., Schöner, W., Frei, C., Schmidli, J., 2006. Construction of a 10-min-gridded precipitation data set for the Greater Alpine Region for 1800-2003. Journal of Geophysical Research 111, D01105, doi:10.1029/2005JD006120.

EM-DAT., 2011. The CRED International Disaster Database, Natural Disasters Trends. http://www.emdat.be/natural-disasters-trends.

Eysn, L., Pfeifer, N., Ressl, C., Hollaus, M., Grafl, A., Morsdorf, F., 2013. A practical approach for extracting tree models in forest environments based on equirectangular projections of terrestrial laser scans. Remote Sensing 5, 5424-5448.

Fantucci, R., 1999. Dendrogemorphology in landslide analysis. In Casale, R., Margottini, C (Eds.), Floods and Landslides: integrated risk assessment. Berlin: Springer-Verlag.

Fell, R., Corominas, J., Bonnard, C., Cascini, L., Leroi, E., Savage, W.Z., 2008. Guidelines for landslide susceptibility, hazard and risk zoning for land use planning. Eng Geol 102:85-89. doi:10.1016/j.enggeo.2008.03.022.

Fiorucci, F., Cardinali, M., Carlà, R., Rossi, M., Mondini, A.C., Santurri, L., Ardizzone, F., Guzzetti, F., 2011. Seasonal landslides mapping and estimation of landslide mobilization rates using aerial and satellite images. Geomorphology 129 (1-2), 59-70. doi: 10.1016/j.geomorph.2011.01.013.

Flageollet, J.-C., Maquaire, O., Martin, B., Weber, D., 1999. Landslides and climatic conditions in the Barcelonnette and Vars basins (Southern French Alps, France). Geomorphology 30, 65-78.

Fookes, P.G., Dale, S.G., Land, J.M., 1991. Some observations on a comparative aerial photography interpretation of a landslipped area. The Quarterly Journal of Engineering Geology 24, 249-265.

Fox, T.J., Knutson, M.G., Hines, R.K., 2000. Mapping forest canopy gaps using air-photo interpretation and ground surveys. Wildlife Society Bulletin, 882-889. 
Frolking, S., Palace, M.W., Clark, D.B., Chambers, J.Q., Shugart, H.H., 2009. Forest disturbance and recovery: A general review in the context of spaceborne remote sensing on aboveground biomass and canopy structure. Journal of Geophysical Research 114, 27 p.

Galli, M., Ardizzone, F., Cardinali, M., Guzzetti, F., Reichenbach, P., 2008. Comparing landslide inventory maps. Geomorphology 94, 268-289.

Gaulton, R., Malthus, T.J., 2010. LiDAR mapping of canopy gaps in continuous cover forests: A comparison of canopy height model and point cloud based techniques, International Journal of Remote Sensing, 31:5, 1193-1211.

Glade, T., 2001. Landslide hazard assessment and historical landslide data an inseparable couple? In: Glade, T., Albini, P., Frances, F (Eds.), The Use of Historical Data in Natural Hazards Assessment (Advances in Natural and Technological Hazard Research). Kluwer Academic Publications, Dordrecht, The Netherlands, 153-168.

Glenn, N.F., Streutker, D.R., Chadwick, J., Glenn, D.J., Thackray, G.D., Dorsch, S.J., 2006. Analysis of LiDAR-derived topographic information for characterizing and differentiating landslide morphology and activity. Geomorphology 73, 131-148.

Gode, A., 2012. Extraction of forest structural attributes as indicators of landslide-induced disturbance using LiDAR data. M.Sc Thesis. University of Twente Faculty of Geo-Information and Earth Observation ITC, the Netherlands. ITC Dissertation, 57 p.

Gray, D.H., Megahan, W.F., 1981. Forest vegetation removal and slope stability in the Idaho Batholith, USDA Forest Service Research Paper INT271, Ogden, UT, 23 p.

Greenway, D.R., 1987. Vegetation and slope stability. In: Anderson and Richards (eds), Slope Stability, John Wiley \& Sons, 187-231 p.

Guzzetti, F., Cardinali, M., Reichenbach, P., Carrara, A., 2000. Comparing landslide maps: a case study in the Upper Tiber River Basin, Central Italy. Environmental Management 25, 247-263.

Guzzetti, F., Carrara, A., Cardinali, M., Reichenbach, P., 1999. Landslide hazard evaluation: a review of current techniques and their application in a multi-scale study, Central Italy. Geomorphology 31, 181-216.

Guzzetti, F., Mondini, A.C., Cardinali, M., Fiorucci, F., Santangelo, M., Chang, K.-T., 2012. Landslide inventory maps: New tools for an old problem. Earth-Science Reviews 112, 42-66. 
Guzzetti, F., Reichenbach, P., Cardinali, M., Galli, M., Ardizzone, F., 2005. Probabilistic landslide hazard assessment at the basin scale. Geomorphology 72(1-4), 272-299.

Haneberg, W. C., Cole, W. F., Kasali, G., 2009. High resolution lidar-based landslide hazard mapping and modeling, UCSF Parnassus Campus, San Francisco, USA. Bulletin of Engineering Geology and the Environment, 68 (2), 263-276.

Harbury, N.A., Jones, M. E., Audley-Charles, M.G., Metcalfe, I., Mohamed, K.R., 1990. Structural evolution of Mesozoic Peninsular Malaysia. Journal of the Geological Society, 147, 11-26. doi: 10.1144/gsjgs.147.1.0011

Hatami, F., 2012. Carbon estimation of individual trees using high laser density data of airborne lidar: A case study in Bois Noir, France. M.Sc Thesis. University of Twente Faculty of Geo-Information and Earth Observation ITC, the Netherlands. ITC Dissertation, $65 \mathrm{p}$.

Haugerud, R., Harding, D.J., Johnson, S.Y., Harless, J.L., Weaver, C.S., Sherrod, B.L., 2003. High-resolution topography of the Puget Lowland, Washington - a bonanza for earth science. GSA Today 13, 4-10.

Hencher, S.R., Martin, R.P., 1982. The description and classification of weathered rocks in Hong Kong for engineering purposes. Proceedings of 7th South-east Asian Geotechnical Conference. Hong Kong, vol. 1, 125142

Hippolyte, J.C., Dumont, T., 2002. Identification of quaternary thrusts, folds and faults in a low seismicity area: examples in the Southern Alps (France). Terra Nova 12, 156-162.

Hodgson, M.E., Jensen, J.R., Schmidt, L., Schill, S., Davis, B., 2003. An evaluation of LiDAR- and IFSAR-derived digital elevation models in leaf on conditions with USGS Level 1 and Level 2 DEMs. Remote Sensing Environment 84, 295-308.

Hodgson, M.E., Bresnahan, P., 2004. Accuracy of airborne lidar-derived elevation: emperical assessment and error budget. Photogrammetric Engineering \& Remote Sensing 70, 331-339.

Hofton, M.A., Rocchio, L.E., Blair, J.B., Dubayah, R., 2002. Validation of vegetation canopy lidar sub-canopy topography measurements for a dense tropica forest. Journal of Geodynamics 34, 491-502.

Hollaus, M., Wagner, W., Eberhofer, C., Karel, W., 2006. Accuracy of largescale canopy heights derived from LiDAR data under operational constraints in a complex alpine environment. ISPRS Journal of Photogrammetry and Remote Sensing 60, 323-338. 
Horn, B.K.P., 1981. Hill shading and the reflectance map. Proc. IEEE 69(1), 14-47.

Huising, E.J., Gomes Pereira, L.M., 1998. Errors and accuracy estimates of laser data acquired by various laser scanning systems for topographic applications. ISPRS Journal of Photogrammetry and Remote Sensing 53, 245-261.

Husaini, O., Daud, M., Zohadaie, M.B., Maail S., Azizi, A.A., Muniandy, R., 2005, Failure of cut slopes during construction of highways in mountainous area. Pertanika Journal of Science and Technology, 13, pp. 73-83.

Hutchinson, M.F., 1989. A new procedure for gridding elevation and stream line data with automatic removal of spurious pits. Journal of Hydrology $106,211-232$.

Ibsen, M., Brunsden, D., 1996. The nature, use and problems of historical archives for the temporal occurrence of landslides, with specific reference to the south coast of Britain, Ventnor, Isle of Wight. Geomorphology 15, 241-258.

ILWIS., 2012. The ILWIS software. The $52^{\circ}$ North Inititaive for Geospatial Open Source Software GmbH, Germany. www.52north.org.

Isaaks, E.H., Srivastava, R.M., 1989. An Introduction to Applied Geostatistics. Oxford University Press, New York, 561 p.

Jaapar, A.R, 2006. A framework of a national slope safety system for Malaysia. M.Sc dissertation, University of Hong Kong. http://hub.hku.hk/handle/10722/50173.

James, L.A., Watson, D.G., Hansen, W.F., 2007. Using LiDAR data to map gullies and headwater streams under forest canopy: South Carolina, USA. Catena 71, 132-144.

Jones, F.O., 1973. Landslides of Rio de Janeiro and the Serra das Araras Escarpment, Brazil. US Geological Survey Professional Paper 697.

Kasai, M., Ikeda, M., Asahina, T., Fujisawa, K., 2009. LiDAR-derived DEM evaluation of deep-seated landslides in a steep and rocky region of Japan. Geomorphology 113, 57-69.

Kobler, A., Pfeifer, N., Ogrinc, P., Todorovski, L., Oštir, K., Džeroski, S., 2007. Repetitive interpolation: A robust algorithm for DTM generation from Aerial Laser Scanner Data in forested terrain. Remote Sensing of Environment 108, 9-23. 
Korup, O., 2005. Geomorphic imprint of landslides on alpine river systems, southwest New Zealand. Earth Surface Processes and Landforms 30, 783-800.

Koukoulas, S., Blackburn, G. A., 2004. Quantifying the spatial properties of forest canopy gaps using LIDAR imagery and GIS. International Journal of Remote Sensing 25, 3049-3071.

Krahenbuhl, R., 1991. Magmatism, tin mineralization and tectonic development of Main Range, Malaysian Peninsula: consequences for plate tectonic model of Southeast Asia based on Rb-Sr, K-Ar and fission track analysis. Geological Society of Malaysia Bulletin 29, 1-100.

Kraus, K., Mikhail, E.M., 1972. Linear least squares interpolation. Photogrammetric Engineering 38, 1016 - 1029.

Kraus, K., Pfeifer, N., 1998. Determination of terrain models in wooded areas with airborne laser scanner data. ISPRS Journal of Photogrammetry and Remote Sensing 53, 193-203.

Kraus, K., 2007. Photogrammetry, 2nd ed. Walter de Gruyter, Berlin.

Kuriakose, S.L., 2010. Physically based dynamic modelling of the effect of land use changes on shallow landslide initiation in the Western Ghats of Kerala. PhD Thesis. University of Twente Faculty of Geo-Information and Earth Observation ITC, 2010. ITC Dissertation 178, ISBN: 978-90-6164298-5.

Larsen, M.C., Parks, J.E., 1997. How wide is a road? The association of roads and mass-wasting in a forested montane environment. Earth Surface Processes and Landforms 22, 835-848.

Lauknes, T.R., Piyush Shanker, A., Dehls, J.F., Zebker, H.A., Henderson, I.H.C., Larsen, Y., 2010. Detailed rockslide mapping in northern Norway with small baseline and persistent scatterer interferometric SAR time series methods. Remote Sensing of Environment 114, 2097-2109. doi: $10.1016 /$ j.rse.2010.04.015.

Leberl, F., Irschara, A., Pock, T., Meixner, P., Gruber, M., Scholz, S., Wiechert, A., 2010. Point clouds: Lidar versus 3D vision. Photogrammetric Engineering \& Remote Sensing 78(10), 1123-1134.

Ledoux, H., Gold, C.M., 2004. An efficient natural neighbour interpolation algorithm for geoscientific modelling. In: Fisher, P. (Ed.), Development in Spatial Data Handling. 11th Inter. Symposium on Spatial Data Handling. Springer, 97-108.

Lee, D.S., Shan, J., Bethel, J.S., 2003. Class-guided building extraction from IKONOS imagery. Photogrammetric Engineering and Remote Sensing 69 (2), 143-150. 
Lefsky, M.A., Cohen, W.B., Parker, G.G., Harding, D.J., 2002. Lidar remote sensing for ecosystem studies. BioScience 19 (52), 14 p.

Lopez Saez, J., Corona, C., Stoffel, M., Astrade, L., Berger, F., Malet, J.-P., 2011. Dendrogeomorphic reconstruction of past landslide reactivation with seasonal precision: Bois Noir landslide, southern French Alps. Geomorphology, 25 p.

Lowman, N., Rinker., H (Eds.)., 2004. Forest Canopies, 2nd ed., Elsevier, Amsterdam.

Mackey, B.H., Roering, J.J., 2011. Sediment yield, spatial characteristics, and the long-term evolution of active earthflow determined from airborne LiDAR and historical aerial photographs, Eel River, California. Geological Society of America Bulletin 123(7-8), 1560-1576.

Mackey, B.H., Roering, J.J., McKean, J.A., 2009. Long-term kinematics and sediment flux of an active earthflow, Eel River, California. Geology 37, 803-806.

Malamud, B.D., Turcotte, D.L., Guzzetti, F., Reichenbach, P., 2004. Landslide inventories and their statistical properties. Earth Surface Processes and Landforms 29 (6), 687-711.

Marchesini, I., Rossi, M., Santangelo, M., Cardinali, M., Reichenbach, P., Ardizzone, F., Fiorucci, F., Balducci, V., Mondini, A.C, Guzzetti, F., 2012. WPS tools to support geological and geomorphological mapping. OGRS 2012 Symposium Proceedings, 280-287.

Martha, T.R., Kerle, N., Jetten, V., Van Westen, C., Vinod Kumar, K., 2010. Characterising spectral, spatial and morphometric properties of landslides for semi-automatic detection using object-oriented methods. Geomorphology 116, 24-36.

Martha, T., Kerle, N., Van Westen, C.J., Jetten, V., Kumar, K.V., 2011. Segment optimization and data-driven thresholding for knowledge-based landslide detection by object-based image analysis. IEEE Transactions on Geoscience and Remote Sensing 49, 4928-4943.

Martha, T., Kerle, N., Van Westen, C.J., Jetten, V., Kumar, K.V., 2012. Object-oriented analysis of multi-temporal panchromatic images for creation of historical landslide inventories. ISPRS Journal of Photogrammetry and Remote Sensing 67, 105-119.

Marthers, T., Burslem, D., Phillips, R., Mullins, C., 2008. Modelling direct radiation and canopy gap regimes in tropical forests. Biotropica 40(6), 676-685.

Maquaire, O., Malet, J. -P., Remaître, A., Locat, J., Klotz, S., Guillon, J., 2003. Instability conditions of marly hillslopes: towards landsliding or 
gullying? The case of the Barcelonnette Basin, South East France. Eng Geol, 70,109-130.

Mattheck., C., 1993. Design in der Natur. Reihe Ökologie 1: Rombach Wissenschaft.

Mayer, D. G., Butler, D. G., 1993. Statistical validation. Ecological Modelling, $68,21-32$.

McIntosh, P.D., Price, D.M., Eberhardt, R., Slee, A.J., 2009. Late Quaternary erosion events in lowland and mid-altitude Tasmania in relation to climate change and first human arrival. Quaternary Science Reviews 28, 850-872.

McKean, J., Roering, J., 2004. Objective landslide detection and surface morphology mapping using high-resolution airborne laser altimetry. Geomorphology 57, 331-351.

Metcalfe, I., 2000. The Bentong-Raub Suture Zone. Journal of Asian Earth Sciences 18, 691-712.

MMD, 2011. Malaysian Meterological Department. http://www.met.gov.my/

Moore, I.D., Grayson, R.B., Ladson, A.R., 1991. Digital terrain modeling: a review of hydrological, geomorphological, and biological applications. Hydrological Processes 5, 3-30.

Moore, I.D., Wilson, J.P., 1992. Length-slope factors for the Revised Universal Soil Loss Equation: Simplified method of estimation: Jour, Soil and Water Conservation 4(5), 423-428.

Mondini, A.C., Guzzetti, F., Reichenbach, P., Rossi, M., Cardinali, M., Ardizzone, F., 2011. Semi-automatic recognition and mapping of rainfall induced shallow landslides using satellite optical images. Remote Sensing of Environment 115, 1743-1757. doi:10.1016/j.rse.2011.03.006.

Mugnier, C.J., 2009. Grids and datums: Malaysia. Photogrammetric Engineering and Remote Sensing 345-346.

Nadem, F., Kjekstad, O., Peduzzi, P., Herold, C., Jaedicke, C., 2006. Global landslide and avalanche hotspots. Landslides 3, 159-173.

Nefeslioglu, H.A., Duman, T.Y., Durmaz, S., 2008b. Landslide susceptibility mapping for a part of tectonic Kelkit Valley (Eastern Black Sea region of Turkey). Geomorphology 94 (3-4), 401-418.

Nefeslioglu, H.A., Gokceoglu, C., 2011. Probabilistic risk assessment in medium scale for rainfall induced earthflows: Catakli catchment area (Cayeli, Rize, Turkey). Mathematical Problems in Engineering, Article ID 280431. 
Nefeslioglu, H.A., Gokceoglu, C., Sonmez, H., 2008a. An assessment on the use of logistic regression and artificial neural networks with different sampling strategies for the preparation of landslide susceptibility maps. Engineering Geology 97(3-4), 171-191.

Nefeslioglu, H.A., San, B.T., Gokceoglu, C., Duman, T.Y., 2012. An assessment on the use of Terra ASTER L3A data in landslide susceptibility mapping. International Journal of Applied Earth Observation and Geoinformation 14, 40-60.

Nichol, J.E., Shaker, A., Wong, M.S., 2006. Application of high-resolution stereo satellite images to detailed landslide hazard assessment. Geomorphology 76, 68-75.

Oguchi, T., Aokib, T., Matsuta, N., 2003. Identification of an active fault in the Japanese Alps from DEM-based hill shading. Computer and Geosciences 29, 885-891.

ONF, 2011. ONF Forest-Landslides Archives 1895-2010 in Bois Noir, Barcelonnette France.

Parise, M., 2003. Observation of surface features on an active landslide, and implications for understanding its history of movement. Natural Hazards and Earth Sys. Sciences 3, 569-580.

Petersen, M.D., James, D., Stephan, H., Charles, M., Stephan, H, Arthur, D., Frankel, K.R., 2004. Probabilistic seismic hazard analysis for Sumatra, Indonesia and across the Southern Malaysian Peninsula. Tectonophysics, 390(1-4), 141-158.

Petley, D.N., 2011. The landslide blog. http://blogs.agu.org/landslideblog/. Accessed 21 June 2012.

Petley, D.N., 2010. On the impact of urban landslides: In: Culshaw, M., Reeves, H.J., Jefferson, I., Spink, T.W. (Eds.), Engineering geology for tomorrow's cities. Geological Society, London, Engineering Geology Special Publications 22, 83-99.

Petley, D.N., Dunning, S.A., Rosser, N.J., 2005. The analysis of global landslide risk through the creation of a database of worldwide fatalities. In: Hungr, I., Fell, R., Couture, R., Eberhardt, E. (Eds.), Landslide risk management. Balkema, Rotterdam, 367-374.

Petley, D.N., Hearn, G.J., Hart, A., Rosser, N.J., Dunning, S.A., Oven, K., Mitcell, W.A., 2007. Trends in landslide occurrence in Nepal. Natural Hazards 43, 23-44.

Petrie, G., Toth, C. K., 2008. Introduction to laser ranging, profiling, and scanning. In: J. Shan, C. K. Toth (Eds.), Topographic Laser Ranging and 
Scanning: Principles and Processing. Boca Raton: CRC/Taylor \& Francis, 1-27.

Pfeifer, N., Mandlburger, G., 2009. LiDAR data filtering and DTM generation. In: Shan, J., Toth, C.K. (Eds.), Topographic Laser Ranging and Scanning: Principles and Processing. CRC / Taylor \& Francis, 307-333.

Pfeifer, N., Stadler, P., Briese, C., 2001. Derivation of digital terrain models in the SCOP++ environment. OEEPE workshop on airborne laserscanning and interferometric SAR for detailed digital elevation models, Stockholm, Sweden.

Piper, B., 1993. Properties of local coordinates based on dirichlet tessellations. Computing 8, 227-239.

Pirotti, F., Tarolli, P., 2010. Suitability of LiDAR point density and derived landform curvature maps for channel network extraction. Hydrological Processes 24, 1187-1197.

Popescu, S.C., Wynne, R.H., 2004. Seeing the trees in the forest using lidar and multispectral data fusion with local filtering and variable window size for estimating tree height. Photog. Eng. and Rem. Sens. 70(5), 589-604.

Popescu, S.C., Wynne, R.H., Nelson, R.F., 2002. Estimating plot-level tree heights with lidar: local filtering with a canopy-height based variable window size. Computers and Electronics in Agriculture 37, 1-95.

Pradhan, B., 2010. Remote sensing and GIS-based landslide hazard analysis and cross-validation using multivariate logistic regression model on three test areas in Malaysia. Advances in Space Research 45(10), 1244-1256.

Pradhan, B., Akcapinar Sezer, E., Gokceoglu, C., Buchroithner, M.F., 2010. Landslide susceptibility mapping by neuro-fuzzy approach in a landslide prone area (Cameron Highland, Malaysia). IEEE Transactions on Geoscience and Remote Sensing 48(12), 4164-4177.

Pradhan B, Lee S (2010b) Delineation of landslide hazard areas on Penang Island, Malaysia, by using frequency ratio, logistic regression, and artificial neural network models. Environ Earth Sci 60(5):1037-1054

Pradhan, B., Lee, S., 2010a. Regional landslide susceptibility analysis using back-propagation neural network model at Cameron Highlands, Malaysia. Landslides 7(1), 13-30.

Pradhan, B., Youssef, A.M., 2009. Manifestation of remote sensing data and GIS on landslide hazard analysis using spatial-based statistical models. Arabian Journal of Geosciences. doi:10.1007/s12517-009-0089-2. 
Prokesova, R., Kardos, M., Medvedova, A., 2010. Landslide dynamics from high-resolution aerial photographs: A case study from the Western Carpathians, Slovakia. Geomorphology 115, 90-101.

PWD., 2009. National Slope Master Plan 2009-2023. The Public Works Department Malaysia, ISBN 978-983-99552-9-3.

Raj, J.K., 1985. Characterization of the weathering profile developed over a porphyritic biotite granite bedrock in Peninsular Malaysia. Bulletin Int. Assoc. Engineering Geology 32, 121-128.

Regmi, N.R., Giardina, J.R, Vitek, J.D., 2010. Modeling susceptibility to landslides using the weight of evidence approach: Western Colorado, USA. Geomorphology 115, 172-187.

Reitberger, J., Schnorr, C. I., Krzystek, P., Stilla, U., 2009. 3D segmentation of single trees exploiting full waveform LIDAR data. ISPRS Journal of Photogrammetry and Remote Sensing 64, 561-574.

Reutebuch, S.E., McGaughey, R.J., Anderson, H.E., Carson, W.W., 2003. Accuracy of a high-resolution LiDAR terrain model under a conifer forest canopy. Canadian Journal of Remote Sensing 29, 527-535.

Rossi, M., Cardinali, M., Fiorucci, F., Marchesini, I., Mondini, A.C., Santangelo, M., Ghosh, S., Riguer, Del., Lahousse, T., Chang, K.T., Guzzetti, F., 2012. A tool for the estimation of the distribution of landslide area in R. Geophysical Research Abstracts 14, EGU2012-94381.

Rott, H., 2009. Advances in interferometric synthetic aperture radar (InSAR) in earth system science. Progress in Physical Geography 33, 769-791.

Rottensteiner, F., Trinder, J., Clode, S., Kubik, K., 2005. Using the DempsterShafer method for the fusion of LIDAR data and multi-spectral images for building detection. Information Fusion 6(4), 283-300.

Runkle, J.R., 1981. Gap regeneration in some old-growth forests in the eastern United States. Ecology 62, 1041-1051.

Santangelo, M., Cardinali, M., Rossi, M., Mondini, A.C., Guzzetti, F., 2010. Remote landslide mapping using a laser rangefinder binocular and GPS. Natural Hazards and Earth System Sciences 10, 2539-2546. doi: 10.5194/nhess-10-2539-2010.

SafeLand Deliverable 4.1., 2010. Review of techniques for landslide detection, fast characterization, rapid mapping and long-term monitoring. In: Michoud, C., Abellán, A., Derron, M-H., Jaboyedoff, M (Eds). The Deliverable 4.1 of the European project SAFELAND. Available at http://www.safelad-fp7.eu. 
Schulz W.H., 2007. Landslide susceptibility revealed by LIDAR imagery and historical records, Seattle, Washington. Engineering Geology 89, 67-87.

SCOP ++ , 2008. The SCOP++ software manual, IPF, TU Vienna and INPHO Gmbh, Germany.

Sekiguchi, T., Sato., H.P., 2004. Mapping of micro topography using airborne laser scanning. Landslides 3, 195-202.

Shepard, D., 1968. A two-dimensional interpolation function for irregularlyspaced data. Proceedings of the 1968 ACM National Conference, ACM, pp. 517-524.

Shroder., J.F., 1978. Dendrogeomorphological analysis of mass movements on Table Cliff Plateau, Utah. Quaternary Research 9, 168-185.

Sibson, R., 1981. A brief description of natural neighbor interpolation. In: Barnett, V. (Ed.), Interpreting Multivariate Data. Chichester, John Wiley \& Sons, New York, 21-36.

Sidle, R.C., Ochiai, H., 2006. Landslides: processes, prediction, and land use. Water Resources Monograph 18, American Geophysical Union, Washington, DC, $312 \mathrm{p}$.

Sidle, R.C., Ziegler, A.D., Negishi, J.N., Nik, A.R., Siew R, Turkelboom, F., 2006. Erosion processes in steep terrain - Truths, myths, and uncertainties related to forest management in Southest Asia. Forest Ecology and Management 224, 199-225.

Singhroy, V., Molch, K., 2004. Characterizing and monitoring rockslides from SAR techniques. Advances in Space Research 33 (3), 290-295.

Sithole, G., Vosselman, G., 2004. Experimental comparison of filter algorithms for bare-earth extraction from airborne laser scanning points clouds. ISPRS Journal of Photogrammetry and Rem. Sensing 59, 85-101.

Smith, M.J., Clark, C.D., 2005. Methods for the visualization of digital elevation models for landform mapping. Earth Surface Processess and Landforms 30, 885-900.

So, C.L., 1971. Mass movements associated with the rainstorm of June 1966 in Hong Kong. Transactions of the Institute of British Geographers 53, 55-65.

Soeters, R., Van Westen, C.J., 1996. Slope instability recognition, analysis, and zonation. In: Turner AK, Schuster RL (eds) Landslides, Investigation and Mitigation. Transportation Research Board, Special Report 247, Washington D.C., USA, 129-177. 
Sohn, G., Downman, I., 2007. Data fusion of high-resolution satellite imagery and LiDAR data for automatic building extraction. ISPRS Journal of Photogrammetry \& Remote Sensing 62, 43-63.

Stark C.P, Hovius N., 2001. The characterization of landslide size distributions. Geophysical Research Letters 28: 1091-1094.

Stefanini, M.C., 2004. Spatio-temporal analysis of a complex landslide in the Northern Apenines (Italy) by means of dendrochronology. Geomorphology, 63,191-202.

Stoffel, M., 2006. A review of studies dealing with tree rings and rockfall activity: The role of dendogeomorphology in natural hazard research. Natural Hazards, 39, 51-70.

Stoffel, M., Bollschweiler, M., 2008. Tree-ring analysis in natural hazards research - an overview. Nat. Hazrads Earth Systm. Sci., 9, 187-202.

Stumpf, A., Kerle, N., 2011. Object-oriented mapping of landslides using Random Forests. Remote Sensing of Environment 115, 2564-2577.

Szekely, B., Zamolyi, A., Drahanits, E., Briese, C., 2009. Geomorphic expression of neotectonic activity in a low relief area in an Airborne Laser Scanning DTM: A case study of the Little Hungarian Plain (Pannonian Basin). Tectonophysics 474, 353-366.

Tarolli, P., Sofia, G., Dalla Fontana, G., 2010. Geomorphic features extraction from high resolution topography: landslide crowns and bank erosion. Natural Hazards. doi:10.1007/s11069-010-9695-2.

Thiery, Y., Malet, J.-P., Maquaire, O., 2004. Observation on the activity of the Bois Noir landslide. Internal Report, EC-FP5 Alarm Project, Brussels, $10 \mathrm{p}$.

Thiery, Y., Malet, J.-P., Sterlacchini, S., Puissant, A., Maquaire., 2007. Landslide susceptibility assessment by bivariate methods at large scales: Application to a complex mountainous environment. Geomorphology 92, 38-59.

Thomas, M.F., 1983. Contemporary denudation systems and the effects of climatic change in the humid tropics - some problems from Sierra Leone. In: Briggs DJ and Waters RS (Eds), Studies in Quaternary Geomorphology. Geo Books, Norwich, 195-214.

Thomas, M.F., 1994. Geomorphology in the tropics: a study of weathering and denudation in low latitudes, $460 \mathrm{p}$.

Tsai, F., Hwang, J.-H., Chen, L.-C., Lin, T.-H., 2010. Post-disaster assessment of landslides in southern Taiwan after 2009 Typhoon Morakot using remote sensing and spatial analysis. Natural Hazards and Earth System Sciences 10, 2179-2190. doi:10.5194/nhess-10-2179-2010. 
TUV, 2012. The SCOP++ software. Institute of Photogrammetry and Remote Sensing (I.P.F), University of Vienna, Austria and INPHO GmbH, Stuttgart, Germany. http://www.ipf.tuwien.ac.at/products/produktinfo/scop/scop_dtm_sheet. htm.

UN-ESCAP, 2008. Economic and social survey of Asia and the Pacific 2008. United Nations, New York.

Vallet, J., Skaloud, J., 2004. Development and experiences with a fully digital handheld mapping system operated from a helicopter. In: The International Archives of Photogrammetry, Remote Sensing and Spatial Information Sciences vol. XXXV, Part B5. Istanbul, 791-797.

Van Den Eeckhaut, M., Poesen, J., Verstraeten, G., Vanacker, V., Moeyersons, J., Nyssen J., Van Beek, L.P.H., 2005. The effectiveness of hillshade maps and expert knowledge in mapping old deep-seated landslides. Geomorphology 67, 351-363.

Van Den Eeckhaut, M., Poesen, J., Van Loy, K., Poesen, J., Beeckman, H., 2009. Evidence for repeated re-activation of old landslides under forest. Earth Surface Processes and Landforms 34, 352-365.

Van Den Eeckhaut, M., Muys, B., Verstraeten, G., Vanacker, V., Nyssen, J, Moeyersons, J., Van Beek, L.P.H., Vandekerckhove, L., 2007. Use of LIDAR-derived images for mapping old landslides under forest. Earth Surface Processes and Landforms 32, 754-769.

Van Westen, C.J., Castellanos, E., Kuriakose, S.L., 2008. Spatial data for landslide susceptibility, hazard, and vulnerability assessment: An overview. Engineering Geology 102, 112-131.

Van Westen, C.J., Lulie Getahun, F., 2003. Analyzing the evolution of the Tessina landslide using aerial photographs and digital elevation models. Geomorphology 54, 77-89.

Van Westen, C.J., Van Asch, T.W.J., Soeters, R., 2006. Landslide hazard and risk zonation-why is it still so difficult?. Bull Eng Geol Env 65, 167-184.

Varnes, D.J., 1978. Slope movement types and processes. In: Schuster, R.L., Krizek, R.J. (eds). Landslides Analysis and Control. Nat. Acad. Sci., Trans Res Bd., spec rep 176, Washington DC, 11-33.

Vepakomma, U., St-Onge, B., Kneeshaw, D., 2008. Spatially explicit characterization of boreal forest gap dynamics using multi-temporal lidar data. Remote Sensing of Environment, 112(5), 2326-2340.

Vigny, C., Simon, W.J.F., Abu, S., Bamphenyu, R., Satirapod, C., Choosakul, N., Subarya, C., Socquet, A., Omar, K., Abidin, H.Z., Ambrosius, B.A.C., 
2005. Insight into the 2004 Sumatra-Andaman earthquake from GPS measurements in Southeast Asia. Nature 436, 201-206.

Vosselman, G., Klein, R., 2010. Visualisation and structuring of point clouds In: Vosselman, G., Maas, H.G. (Eds.), Airborne and Terrestrial Laser Scanning. Whittles Publishing, ISBN 978-1904445-87-6, 43-79.

Wahba, G., 1990. Splinemodels for observational data. Proceedings of CBMSNSF Regional Conference Series in Applied Mathematics, Soc. Ind. Appl. Maths. Philadelphia, Pennsylvania, $180 \mathrm{p}$.

Wang, C., Glenn, N.F., 2009. Integrating lidar intensity and elevation data for terrain characterization in a forested area. IEEE Geosciences and Remote Sensing Letters 6, 463-466.

Watson, D.F., 1988. Natural neighbour sorting on the n-dimensional sphere. Pattern Recognition 21, 63-67.

Weber, 1994. Research into earth movements in the Barcelonnette. http://eost.u-trasbg.fr/omiv/Publications/Weber 1994 EPOCH.pdf

Wechsler, S.P., Kroll, C.N., 2006. Quantifying DEM uncertainty and its effect on topographic parameters. Photogrammetric Engineering and Remote Sensing 72, 1081-1091.

White, R.A., Dietterick, B.C., Mastin, T., Strohman, R., 2010. Forest roads mapped using LiDAR in steep forested terrain. Remote Sensing 2, 11201141.

Wieczorek, G.F., 1984. Preparing a detailed landslide-inventory map for hazard evaluation and reduction. Bulletin of the Association of Engineering Geologists 21 (3), 337-342.

Wikipedia., 2013. Dendrometry. Wikipedia, the free encyclopedia. Accessed in Nov 2013. http://en.wikipedia.org/wiki/Dendrometry.

Wiles, G.C., Calkin, P.E., Jacoby, G.C., 1996. Tree-ring analysis and Quaternary geology: principles and recent applications. Geomorphology $16,259-272$.

Wills, C.J., 2002. Acquisition of a LIDAR survey of the highway 299 corridor, Humboldt County, California and preliminary analysis of its utility for landslide mapping, summary report. California Geological Survey 16.

Wills, C.J., McCrink, T.P., 2002. Comparing landslide inventories: The map depends on the method. Environmental \& Engineering Geoscience 8(4), 279-293.

Wilson, J.P., Gallant, J.C., 2000. Terrain analysis principles and applications. John Wiley and Sons, Inc., Canada. 
Wyatt-Smith, J., 1995. Manual of Malayan silviculture for inland forest (Malayan forest record 23 vol. 1). Forest Research Institute Malaysia, pp. III-7/1-III-7/58.

Yan, A.S.W., Suratman, S., Liau, A., Hamzah, M., Ramli, M.Y., Ariffin, H., Manap, M.A., Taib, M.B.M., Ali, A., Tjia, H.D., 2006. Report on the geological and seismotectonic information of Malaysia. Department of Minerals and Geosciences (JMG) Malaysia. 49 p.

Yang, X., Chen, L., 2010. Using multi-temporal remote sensor imagery to detect earthquake-triggered landslides. International Journal of Applied Earth Observation and Geoinformation, Geospatial Technologies for Disaster Management 12 (6), 487-495.

Yesilnacar, E., Topal, T., 2005. Landslide susceptibility mapping: a comparison of logistic regression and neural networks methods in a medium scale study, Hendek region (Turkey). Eng. Geology 79, 251-266.

Yilmaz, I., 2009. Landslide susceptibility mapping using frequency ratio, logistic regression, artificial neural networks and their comparison: A case study from Kat landslides (Tokat-Turkey). Computers \& Geosciences 35(6), 1125-1138.

Yokoyama, R., Shirasawa, M., Pike, R.J., 2002. Visualizing topography by openness: a new application of image processing digital elevation models. Photogrammetric Engineering \& Remote Sensing 68, 257-265.

Zhang, 2008. Identification of gaps in mangrove forests with airborne LiDAR. Remote Sensing of Environment 112(5), 2309-2325. 


\section{Summary}

Landslide hazard and risk have increased over the last decades and pose a significant threat to modern society. Despite remarkable efforts of compiling and updating landslide maps at regional, national or global scales, the number of landslide events is often underestimated, especially in forested areas where the vegetation obscures the geomorphic features indicative of landsliding. The primary objective of this study was to investigate the suitability of an active remote sensing technique, airborne laser scanning (ALS), for mapping and classifying landslides in temperate and tropical forest environments. The methods were developed in two study areas: (1) the Bois Noir area in France (Southern French Alps), (2) the Cameron Highlands in Malaysia (tropical rainforest region). The French study area consisted of mixed temperate forest with high density ALS data available, whereas the Cameron Highlands was covered with tropical forests, agricultural terraces, and tea plantations and the ALS data was much less dense.

ALS-derived digital terrain models (DTMs) were assessed using quantitative and qualitative methods for both temperate and tropical areas. An optimal DTM for landslide mapping was produced using hierarchical robust filtering in an iterative way with more stringent settings for each iteration. Vertical terrain accuracy was 0.30 (m RMSE) for the high density ALS (HDALS) data and decreased to 0.89 (m RMSE) for the low density data in the tropics. The error was not evenly distributed across the landscape. In the Cameron Highlands, $64 \%$ of the landslides occur in areas with a terrain slope between 21 and $40^{\circ}$, and showed an overall RMSE of $0.87 \mathrm{~m}$. Interestingly, the filtering output with the lowest error did not lead to the best landslide interpretability for producing landslide maps. A combination of filtering results gives interpreters the best insight in the landslide morphology. Multiscale visual analysis of stereoscopic ALS images unveiled 10 times more landslides compared to the 21 years archived landslide map and resulted in newly found neotectonic features. An important question answered in this study is the choice on the required point density for future landslide mapping. A point density of more than 6 points $\mathrm{m}^{-2}$ proved suitable for a detailed landslide morphological analysis in our case studies.

To understand the uncertainty of tropical landslide inventory maps (LIMs), this study quantifies the positional mismatch and completeness of six LIMs produced by expert image interpreters. The interpretations based on the highest and most diverse input were assumed to represent the truth. The other interpretations and the existing LIM were compared to the reference data. The lowest positional mismatch was $93,85,82 \%$ for forested, agricultural and tea plantation area, respectively. The completeness and consistency of each LIMs and reference maps were evaluated using 
frequency-size distribution analysis. The expert-based analysis of ALS data with low point density should be carried out by dedicated and skilful landslide interpreters, using a series of ALS-derived products that take sufficient time for interpretation. This study provided a first indication on mapping errors and completeness assessment of landslide inventory maps in tropical regions.

In support of a predictive modelling of landslide hazard, this study investigated the suitability of ALS data for creating landslide susceptibility maps (LSMs). Landslide susceptibility mapping was carried out with landslide conditioning factor (LCF) maps based solely on ALS data. Twenty-two LCF maps were created, categorized in topographic-, hydrologic-, anthropogenic-, and geological factors. The LCF maps were subsequently used in a multivariate logistic regression analysis to predict landslide occurrence. One of the LCF maps, land cover, showed an overall classification accuracy of $88.5 \%$. The elements at risk, notably the buildings and roads were independently assessed resulting in $81 \%$ overall classification accuracy.

Two LIMs were used as independent variables in the regression analyses: (1) the existing LIM based on historic data and traditional remote sensing products, and (2) a LIM based on manual interpretation of the ALS data, which also included prehistoric landslides. The landslide susceptibility map (LSM) based on historical was predicted better than the LSM derived from ALS data. The historical LIM contains substantially less landslides with smaller sizes, whereas the ALS-derived LIMs contain many more landslides without information on the relative age. The results showed the choice of the landslide inventory maps as dependent variables in the statistical modelling strongly affected the produced LSMs. It is important to use the quality of the input data (landslide inventory and factor maps) and their temporal variation. Moreover, a higher accuracy indicator of a LSM, e.g. a higher value of the AUC, is not an absolute indicator for the quality of the map. With combination of good historical information, ALS-derived LIM and factor maps data can be an important contribution in landslide susceptibility assessment.

As a key component in the assessment of landslide activity, this study evaluates the possibility of HDALS to characterize disrupted trees. With an average point density of 170 points $\mathrm{m}^{-2}$ across the Bois Noir and Trieves study areas, we evaluated pixel-based, object oriented, and point cloudbased techniques to retrieve vegetation characteristics, such as tree height dissimilarity, forest canopy gaps, inclination and orientation that are associated to growth disturbance. Field validation and ALS-derived data distinctly indicated the signature of tree anomalies in the landslide area compared to the forest on stable ground nearby. The variable window filter algorithm was used to identify 80000 individual trees and to estimate the tree height. The ALS-derived tree heights had an overall accuracy of $0.80 R^{2}$ 
compared to field observations. An object-oriented image analysis coupling to spatial GIS analysis was used to extract the forest canopy gaps induced by landslides, resulting with an overall of $0.79 R^{2}$. Tree inclination and orientation were calculated by skeletonizing the point cloud of a single tree using the SkelTre-skeletonization method. The result depicted a high predictive quality for tree inclination and orientation with an average $\mathrm{R}^{2}$ of 0.77 and 0.83 , respectively.

Statistical tests of ALS-derived disrupted vegetation characteristics proved that there are clear differences between the extracted parameters in landslide and non-landslide zones at the $95 \%$ confidence level. This difference was present in both the field data as well as the HDALS data: landslide trees are lower, more dissimilar in height, and more inclined and dispersed at different orientations. With respect to vegetation anomalies, the drunken tree phenomenon was characterized as a result of tilted and bended trees with peculiarity of tree orientation. ALS-derived vegetation characteristics provide informative clues to landslide activity in a rugged vegetated terrain.

In conclusion, the emergence of ALS for investigating geomorphic processes and activities has improved our ability to map, monitor and model the topographic terrain signature and landslide-induced vegetation anomalies. This study explicitly proved that ALS can be a very important new data source and mapping tool to characterize landslides even in a complex environment. The increased prevalence of modern ALS system and advanced point cloud processing had led the ways to improve future landslide maps and subsequently reduce landslide risk. Given the complexity of the terrain, automating the inventorization will still be challenging in the tropics with extensive anthropogenic activity, and differentiating the vegetative reaction in response to different earth surface processes requires further research. Airborne remote sensing is a critical and supportive tool for better understanding of landslide geomorphology in a changing environment. 


\section{Samenvatting}

De kans op aardverschuivingen en het risico van schade en slachtoffers dat de samenleving daarmee loopt is de laatste tientallen jaren toegenomen en vormt een belangrijke bedrijging. Ondanks de moeite die wordt gedaan voor het karteren van aardverschuivingen op regionale, nationale, of wereldwijde schaal wordt het aantal aardverschuivingen onderschat. Vooral beboste aardverschuivingen worden vaak gemist, omdat de vegetatie de geomorfologische signatuur verdoezelt die inzicht biedt in het onderliggende proces. Het doel van deze studie was om de geschiktheid van laseraltimetrie te onderzoeken voor het karteren en klassificeren van aardverschuivingen in gematigde en tropische gebieden. De methoden zijn ontwikkeld in twee studiegebieden: (1) het Bois Noir gebied in de Alpes de Haute Provence in Frankrijk en (2) de Cameron Highlands in Maleisië. De vegetatie in Bois Noir bestond uit gemengd bos, representatief voor een gematigd alpien klimaat, contrasterend met de tropische vegetatie, landbouw terrassen en theeplantages in de Cameron Highlands. De laseraltimetriedata in Bois Noir bestond uit 170 punten per vierkante meter, en was daarmee honderd keer hoger dan de puntdichtheid van de data in de Cameron Highlands.

De laseraltimetriepuntenwolk is omgezet naar een digitaal terrein model (DTM) dat de hoogte van de bodem beschrijft. Hiervoor zijn verschillende verschillende methoden gebruikt. De kwaliteit van de DTMs is bepaald aan de hand van quantitatieve en kwalitatieve methoden. Een optimaal DTM is gevonden door het iteratief gebruik van hierarchical robust filtering, een filtermethode die is geïmplemteerd in de SCOP++ software. In iedere iteratie werd strenger geselecteerd om uiteindelijk te komen tot het beste terrein model. De vertikale nauwkeurigheid van het DTM was $0.30 \mathrm{~m}$ (RMSE) voor Bois Noir en $0.89 \mathrm{~m}$ (RMSE) voor de Cameron Highlands, maar de fout was niet gelijk verdeeld over het landschap variëerde met de helling van het terrein. In de Cameron Highlands komt 64\% van de aardverschuivingen voor bij een helling tussen de 21 en $40^{\circ}$. De fout in de terreinhoogte was $0.87 \mathrm{~m}$ voor deze hellingsklasse. Wat opviel was dat het terrein model met de kleinste vertikale fout niet de beste mogelijkheid gaf tot visuele interpretatie van het terrein. Een combinatie van de uitkomst van de verschillende iteraties gaf het beste inzicht in de morfologie van de aardverschuivingen in de Cameron Highlands. De visuele interpretatie van de stereoscopische DTMs leidde tot tien keer meer gekarteerde aardverschuivingen in vergelijking met de bestaande kaart die is gebaseerd op een inventarisatie van gebeurtenissen in de afgelopen 21 jaar. Daarnaast kwamen er nieuwe neotectonische landschapselementen aan het licht die tot nu toe onbekend waren. Voor toekomstige campagnes voor het inwinnen van laseraltimetriedata voor morphologische interpretatie raden we een puntdichtheid aan van zes punten per vierkante meter. 
De aardverschuivingskaart (landslide inventory map of LIM) op basis van een handmatige kartering bevat fouten ten gevolge van de arbitraire keuzes die de cartograaf maakt. In deze studie zijn voor de Cameron Highlands de kaarten (LIMs) van zes verschillende kaartenmakers vergeleken met betrekking tot (1) de fout in de overlap tussen de aardverschuivingen en (2) de volledigheid van karteren van alle aardverschuivingen. Aangezien er geen LIM bestond die foutvrij en volledig was, is de referentiekaart gebaseerd op de interpretatie door de twee meest ervaren kaartenmakers die werkten op basis van de beste data en de meeste tijd gespendeerd hebben aan de interpretatie. De vier andere interpretaties en de bestaande LIM zijn vergeleken met de referentiekaart. De laagste fout in de overlap was 93, 85, en $82 \%$ voor respectievelijk bos, landbouw en theeplantages. De volledigheid van deze kaarten is bepaald aan de hand van de relatie tussen de grootte van de aardverschuivingen en het aantal aardverschuivingen met die grootte. De referentiekaart toonde een veel completere inventarisatie dan de andere vier LIMs. Op basis van deze eerste quantitatieve vergelijking van LIMs in tropisch gebied was de conclusie dat een interpretatie alleen betekenisvol gedaan kan worden door ervaren kaartenmakers die genoeg tijd uittrekken voor de kartering en gebruik kunnen maken van een serie afgeleide bestanden van de laseraltimetriedata.

Ter ondersteuning van het voorspellen van de kans op een aardverschuiving is in deze studie gekeken naar geschiktheid van laseraltimetriedata voor het leveren van input voor het maken van een gevoeligheidskaart voor aardverschuivingen (landslide susceptibility map; LSM). De gevoeligheid is bepaald door het toepassen van een multivariate logistische regressie, waarbij de 22 onafhandelijke variabelen zijn geextraheerd uit de laseraltimetriedata. Deze 22 variabelen kunnen worden gegroepeerd in vier klassen: topografie, hydrografie, antropogeen, en geologisch. Landgebruik was een van de klassen en de algemene classificatienauwkeurigheid was $88.5 \%$. Gebouwen en wegen werden geclassificeerd met een algemene nauwkeurigheid van $81 \%$. De andere variabelen zijn niet gevalideerd. De afhankelijke variabele in de logistische regressie was een LIM. Twee regressieanalyses zijn uitgevoerd. Bij de eerste is de bestaande LIM gebruikt als onafhankelijke variabele en bij de tweede is de referentiekaart gebruikt van de handmatige interpretatie van de aardverschuivingen. De laatste bevatte ook de prehistorische aardverschuivingen die sinds lange tijd bebost zijn. De resultaten lieten zien dat de historische LIM beter werd voorspeld dan de LIM op basis van de laseraltimetriedata en dat het voorspelde patroon sterk afhing van de LIM die als afhankelijke variabele werd gebruikt. Een reden van de hogere nauwkeurigheid bij het voorspellen van de bestaande LIM is dat grootte van de aardverschuivingen groter was bij deze kaart en dat het landgebruik een directe relatie heeft met het ontstaan van de aardverschuiving. Voor de prehistorische aardverschuivingen was geen 
datering aanwezig, en er is geen relatie tussen het huidige tropische volwassen bos en de aardverschuivingen. Een hogere nauwkeurigheid in de voorspelling is ook niet de enige indicator voor de kwaliteit van de LSM. De combinatie van goede historische informatie en laseraltimetriedata voor het bepalen van de LIMs en de afgeleidde onafhankelijke variabelen kan een belangrijke bijdrage leveren aan het karteren van de gevoeligheid van het terrein voor aardverschuivingen.

De activiteit is een belangrijke karakteristiek van een aardverschuiving, welke zich bij beboste aardverschuivingen uit in deformatie van de boomstammen. In deze studie evalueerden we de mogelijkheden om laseraltimetriedata met hoge puntdichtheid te gebruiken voor het karteren van boomdeformatie in Bois Noir. Gebruik makend van technieken op basis van rasters, objecten, en puntenwolken is de vegetatie gekarakteriseerd met betrekking tot variatie in boomhoogte, openingen in het bladerdak, inclinatie en orientatie van individuele bomen. Een algoritme op basis van een variabele venstergrootte identificeerde 80000 individuele bomen en voorspelde de boomhoogte met een verklaarde variantie van 0.80 in vergelijking met veld data. Een object-georienteerde analyse van de openingen in het kroondek verklaarde 79 procent van de variatie die we in het veld maten. Boominclinatie en -orientatie zijn berekend aan de hand van een skeletrepresentatie van de puntenwolk per boom met behulp van de SkelTre applicatie. Dit resulteerde in een hoge verklaarde variantie van respectievelijk 0.77 en 0.83 . Zowel uit de veldmetingen, als uit de afgeleide data uit de laseraltimetrie, bleek een significant verschil in vegetatiekarakteristieken tussen beboste aardverschuivingen en de stabiele helling in de buurt met een betrouwbaarheid van 95\%. Bomen op aardverschuivingen waren lager, meer gevariëerd in hoogte, stonden over het algemeen schuiner, en lieten een grotere variatie in oriëntatie zien. Vegetatiekarakteristieken die relevant zijn voor de activiteit van aardverschuivingen kunnen dus uit laseraltimetrie bepaald worden.

Concluderend kunnen we stellen dat laseraltimetrie bijdraagt aan het karteren, monitoren, en modelleren van relevante karakteristieken van zowel de geomorphologie als van de vegetatie in het kader van aardverschuivingen. Deze studie heeft bewezen dat laseraltimetrie een belangrijke databron kan zijn voor het karakteriseren van aardverschuivingen, zelfs in complex terrein. Voor tropisch bos is nog meer onderzoek nodig naar het effect van bewegingen van de grond op de vegetatie, en de automatisering van de complete data-analyse geeft ook een uitdaging voor de toekomst. De toegenomen beschikbaarheid van laseraltimetrie-instrumenten en geavanceerde algoritmes voor de analyse van de puntenwolken kan een bijdrage leveren aan de inventarisatie van aardverschuivingen en de reductie van de schade en slachtoffers als gevolg van aardverschuivingen. 
Laseraltimetrie biedt een belangrijk stuk gereedschap voor beter begrip van aardverschuivingen in een veranderende omgeving. 


\section{List of publications}

\section{ISI J ournal Articles}

Razak, K.A., Santangelo, M., Van Westen, C.J., Straatsma, M.W., de Jong, S. M., 2013. Generating an optimal DTM from airborne laser scanning data for landslide mapping in a tropical forest environment. Geomorphology 190, 112-125.

Razak, K.A., Straatsma, M.W., Van Westen, C.J., Malet, J.P., de Jong, S.M., 2011. Airborne laser scanning of forested landslides characterization: terrain model quality and visualization. Geomorphology 126 (1-2), 186200.

Razak, K.A., Van Westen, C.J., Santangelo, M., Damen, M., Abd Talib, J., Endut, N., Cardinali M., Straatsma, M.W., de Jong, S. M., 2013. Airborne laser scanning derived landslide inventory in the tropics: Map comparison and uncertainty analysis. (Submitted to the Journal of Earth Surface Processes and Landforms).

Razak, K.A., Nefeslioglu, H.A., Van Westen, C.J., Straatsma, M., de Jong, S.M. Landslide susceptibility assessment using airborne laser scanningderived maps in a tropical environment. (Under preparation).

Razak, K.A., Bucksch, A, Straatsma, M, Van Westen, C.J., de Jong, S.M., High density airborne lidar estimation of disrupted trees induced by landslides. (Under preparation).

\section{Conference Proceedings}

Razak, K.A., Bucksch, A., Damen, M., van Westen, C.J., Straatsma, M.W., de Jong, S.M., 2013. Characterizing tree growth anomaly induced by landslides using LIDAR. In: Landslide Science and Practice: Landslide Inventory, Susceptibility and Hazard Zoning, (Eds.) Margottini, C., Canuti, P., Sassa, K. Springer-Verlag Berlin Heidelberg, Germany, 235241.

Razak, K.A., Bucksch, A, Straatsma, M, Van Westen, C.J., Abu Bakar, R., de Jong, S., 2013. High density airborne lidar estimation of disrupted trees induced by landslides. In: Proceedings of the IEEE International Geoscience and Remote Sensing Symposium 21-26 July 2013, Melbourne Australia.

Razak, K.A., Quan Luna, B., 2013. Airborne laser scanning of forested rock extraction; Airborne parameterizations, quality assessment, and rockfall modeling. IAG 2013 International Conference on Geomorphology, Paris, France, 26-31 August 2013.

Gode, A., Razak, K.A., 2013. Characterization of forest canopy gaps caused by landslides using high density airborne laser scanning. International Symposium \& Exhibition on Geoinformation (ISG 2013). Kuala Lumpur, Malaysia 24-25 September 2013. 
Razak, K.A., Bucksch, A., Damen, M., van Westen, C.J., Straatsma, M.W., de Jong, S.M., 2012. Characterizing tree growth anomaly induced by landslides using LIDAR. In: Proceedings of the $2^{\text {nd }}$ World Landslide Forum, Vol. 1, 03-09 October, Rome Italy. Springer-Verlag.

Razak, K.A., van Westen, C.J., Straatsma, M.W., de Jong, S.M., 2011. Mapping of elements at risk for landslides in the tropics using airborne laser scanning. In: FIG working week 2011: bridging the gap between cultures: Technical programme and proceedings, Marrakech, Morocco, 18-22 May 2011. 16 p.

Razak, K.A., Abu Bakar, R., Wah, Q, Y., Wan Mohd Akib, W.A.A., 2011. Geodetic laser scanning technique for characterizing landslides along high-risk road zone: Applications and limitations. In: Proceedings of FIG working week 2011: bridging the gap between cultures, Marrakech, Morocco, 18-22 May 2011. 13 p.

Razak, K. A., Straatsma, M., van Westen, C.J., Malet, J.P and de Jong, S. M., 2010. Use of high resolution Airborne Laser Scanning data for landslide interpretation under mixed forest and tropical rainforest: case study in Barcelonnette, France and Cameron Highlands, Malaysia. In: Geophysical research abstracts 12 EGU2010-7184, European Geosciences Union General Assembly 19-24 April 2010, Austria.

Razak, K. A., Straatsma, M., van Westen, C.J., Malet, J.P., de Jong, S.M., 2010. Airborne laser scanning as an effective tool for disaster mapping over mountainous forested landscapes. In: Geophysical Research Abstracts, 12 (2010) EGU2010-7192, European Geosciences Union General Assembly 19-24 April 2010, Vienna. Austria.

Razak, K.A., Straatsma, M.W., Van Westen, C.J., Malet, J.P., 2009. Mapping complex landslides under forest using small - footprint airborne LIDAR data. In: Map Asia 2009: In: Proceedings of the 8th Annual Asian Conference \& Exhibition on Geospatial Information, Technology and Applications, 18-20 August 2009, Singapore. GIS Development.

Razak, K.A., Straatsma, M.W., Van Westen, C.J., Malet, J.P., 2009. Utilization of airborne LIDAR data for landslide mapping in forested terrain: status and challenges. In: Proceedings of the $10^{\text {th }}$ South East Asian Survey Congress in conjunction with 16th UNGEGN Workshop-16th ABLOS Business Meeting and 4th Indonesian Geoinformation Technology Exhibition, 04-07 Aug 2009, Bali, Indonesia. 10 p. 


\section{Curriculum Vitae}

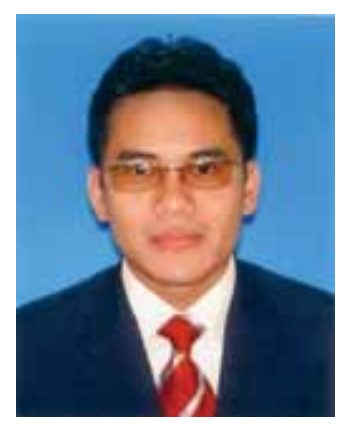

Khamarrul Azahari Razak was born on 07 November 1980 in Kuala Terengganu, Terengganu, Malaysia. He obtained his bachelor degree at the Universiti Teknologi Malaysia and completed his higher education, $\mathrm{MSc}$ in Geomatic Engineering at the Universiti Teknologi Malaysia, Johor Malaysia. During the period of 2004 and 2006, he worked at the Department of Surveying and Mapping Malaysia and National Institute of Land and Survey, Malaysia. He later joined as an academician at the Universiti Teknologi Malaysia, a leading innovation-driven entrepreneurial research university in engineering science and technology located in Kuala Lumpur, the capital city of Malaysia: www.utm.my.

In 2008, Khamarrul Azahari Razak received a PhD scholarship from the Ministry of Higher Education Malaysia and started his PhD research at the International Institute of Geo-Information Science and Earth Observation (ITC), which later it merged with the University of Twente, Enschede, The Netherlands. The PhD research was carried out under the main supervision of Professor Dr. Steven M. De Jong, Faculty of Geosciences, Utrecht University, The Netherlands. He worked on the PhD topic in investigating the suitability of modern topographic laser scanning system for forested landslide mapping in the Southern France Alps (temperate environment) and Cameron Highlands, Malaysia (tropical environment).

Khamarrul Azahari Razak has been involved in different topical workshops and intensive courses that have taken place in different European countries. He has been advisor in several master thesis carried out by ITC-UT students. Currently he is working as a lecturer at the UTM Razak School of Engineering and Advanced Technology, Universiti Teknologi Malaysia Kuala Lumpur and can be contacted as follows:-

\section{KHAMARRUL AZAHARI RAZAK}

UTM Razak School of Engineering and Advanced Technology

Universiti Teknologi Malaysia Kuala Lumpur

54100 Jalan Semarak

Kuala Lumpur, Malaysia

Email : khamarrul@ic.utm.my; khamarrul@gmail.com

Tel (office) : : $+603-22031372$

Tel (mobile) : $\quad+6019-3649495$

Fax : $+603-26934844$ 


\section{Dissertation Lists}

http://www.itc.nl/research/phd/phd/phd graduates.aspx

http://www.igitur.uu.nl/en/default.htm 